\title{
Oligocene stratigraphy across the Eocene and Miocene boundaries in the Valley of Lakes (Mongolia)
}

\author{
Gudrun Daxner-Höck ${ }^{1}$ • Demchig Badamgarav ${ }^{2} \cdot$ Rinchen Barsbold $^{2}$ • \\ Baatarjav Bayarmaa $^{2}$ - Margarita Erbajeva ${ }^{3}$ - Ursula Bettina Göhlich ${ }^{1}$. \\ Mathias Harzhauser $^{1}$ • Eva Höck ${ }^{4}$ • Volker Höck ${ }^{5}$ - Niiden Ichinnorov ${ }^{2}$. \\ Yondon Khand $^{2}$ • Paloma López-Guerrero ${ }^{6}$ - Olivier Maridet $^{7}$ • Thomas Neubauer $^{1}$.

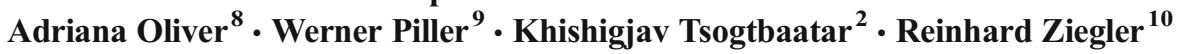

Received: 13 July 2016 /Revised: 13 October 2016 / Accepted: 9 November 2016/Published online: 7 March 2017

(C) The Author(s) 2017. This article is published with open access at Springerlink.com

\begin{abstract}
Cenozoic sediments of the Taatsiin Gol and TaatsiinTsagaan Nuur area are rich in fossils that provide unique evidence of mammal evolution in Mongolia. The strata are intercalated with basalt flows. ${ }^{40} \mathrm{Ar} /{ }^{39} \mathrm{Ar}$ data of the basalts frame the time of sediment deposition and mammal evolution and enable a composite age chronology for the studied area. We
\end{abstract}

This article is a contribution to the special issue "The Valley of Lakes in Mongolia, a key area of Cenozoic mammal evolution and stratigraphy"

Electronic supplementary material The online version of this article (doi:10.1007/s12549-016-0257-9) contains supplementary material, which is available to authorized users.

\section{Gudrun Daxner-Höck}

gudrun.hoeck@nhm-wien.ac.at; gudrun.hoeck@sbg.at

Rinchen Barsbold

paleomas@yahoo.com

Baatarjav Bayarmaa

bayaraa_bio85@yahoo.com

Margarita Erbajeva

erbajeva@gin.bscnet.ru

Ursula Bettina Göhlich

ursula.goehlich@nhm-wien.ac.at

Mathias Harzhauser

mathias.harzhauser@nhm-wien.ac.at

Eva Höck

mofeh@aon.at

Volker Höck

volker.hoeck@sbg.ac.at

Niiden Ichinnorov

iichka@yahoo.com

Yondon Khand

paleomas@yahoo.com investigated 20 geological sections and 6 fossil localities of Oligocene and early Miocene deposits from this region. Seventy fossil beds yielded more than 19,000 mammal fossils. This huge collection encompasses 175 mammal species: 50\% Rodentia, 13\% Eulipotyphla and Didelphomorphia, and 12\% Lagomorpha. The remaining $25 \%$ of species are distributed

Paloma López-Guerrero

palomalopez1981@gmail.com

Olivier Maridet

olivier.maridet@jurassica.ch

Thomas Neubauer

thomas.neubauer@nhm-wien.ac.at

Adriana Oliver

adriana@mncn.csic.es

Werner Piller

werner.piller@uni-graz.at

Khishigjav Tsogtbaatar

tsogtmondin@gmail.com

Reinhard Ziegler

ziegler.smns@naturkundemuseum-bw.de

Natural History Museum Vienna, Burgring 7, 1010 Vienna, Austria

2 Institute of Paleontology and Geology, Mongolian Academy of Sciences, S. Danzan street-3/1, Ulaanbaatar 15160, P.O.B. 46/650, Mongolia

3 Geological Institute, Siberian Branch, Russian Academy of Sciences, Ulan-Ude; Sahianova Str., 6a, 670047 Ulan-Ude, Russia 
among herbivorous and carnivorous large mammals. The representation of lower vertebrates and gastropods is comparatively poor. Several hundred SEM images illustrate the diversity of Marsupialia, Eulipotyphla, and Rodentia dentition and give insight into small mammal evolution in Mongolia during the Oligocene and early Miocene. This dataset, the radiometric ages of basalt I $(\sim 31.5 \mathrm{Ma})$ and basalt II $(\sim 27 \mathrm{Ma})$, and the magnetostratigraphic data provide ages of mammal assemblages and time ranges of the Mongolian biozones: letter zone $\mathrm{A}$ ranges from $\sim 33$ to $\sim 31.5 \mathrm{Ma}$, letter zone B from $\sim 31.5$ to $\sim 28 \mathrm{Ma}$, letter zone $\mathrm{C}$ from $\sim 28$ to $25.6 \mathrm{Ma}$, letter zone $\mathrm{C} 1$ from 25.6 to $24 \mathrm{Ma}$, letter zone C1-D from 24 to $23 \mathrm{Ma}$, and letter zone D from $\sim 23$ to $\sim 21 \mathrm{Ma}$.

Keywords Mongolia $\cdot$ Oligocene $\cdot$ Miocene $\cdot$ Correlation $\cdot$ Stratigraphy $\cdot$ Mammals

\section{Introduction}

The Valley of Lakes is an intermontane depression with a NWSE longitudinal axis. It is bounded by the Khangai Mountains in the north and the Gobi Altai Mountains in the south. Our working area, the Taatsiin Gol region and Taatsiin Tsagaan Nuur region, ranging from $100^{\circ} 55^{\prime}$ to $102^{\circ} 05^{\prime}$ longitude and $45^{\circ}$ $11^{\prime}$ to $45^{\circ} 45^{\prime}$ latitude, is part of the Valley of Lakes (Fig. 1).

This region has been intensively explored during the past two decades. In a collaboration between the Mongolian Academy of Sciences and the Natural History Museum Vienna, fieldwork was conducted during eight field seasons between 1995 and 2012.

The present study focuses on the stratigraphically lower part, the Oligocene and lower Miocene sediment sequences of the Hsanda Gol and Loh Formations. Here, 20 geological sections and 6 fossil sites are described and illustrated for the first time. Along these sections, fossils were collected from 70 fossil horizons. They contain the richest small mammal assemblages ever found in Mongolia and outline Cenozoic mammalian evolution (Daxner-Höck 2000, 2001; Daxner-Höck and Wu 2003;

4 Häusla 35, 8341 Paldau, Austria

5 Department of Geography and Geology, University Salzburg, Hellbrunnerstr. 34, 5020 Salzburg, Austria

6 Departamento de Paleontología, Facultad de Ciencias Geológicas, Universidad Complutense de Madrid, C/ José Antonio Novais, 2, 28040 Madrid, Spain

7 Jurassica Museum, Fontenais 21, 2900 Porrentruy, Switzerland

8 Paleobiology Department, Museo Nacional de Ciencias Naturales - CSIC, C/ José Gutiérrez Abascal, 2, 28006 Madrid, Spain

9 Institute of Earth Sciences, Graz University, Heinrichstraße 26, 8010 Graz, Austria

10 Staatliches Museum für Naturkunde Stuttgart, Rosensteinstraße 1, 70191 Stuttgart, Germany
Erbajeva 2007; Schmidt-Kittler et al. 2007; Ziegler et al. 2007; Erbajeva 2013; Erbajeva and Daxner-Höck 2014; Wessels et al. 2014; Daxner-Höck et al. 2014, 2015; Maridet et al. 2014a, b, 2015; Erbajeva et al. 2017, this issue; López-Guerrero et al. 2017a, b, this issue; Maridet et al. 2017, this issue; Oliver et al. 2017, this issue; Harzhauser et al. 2016). In contrast, the record of large mammals (Vislobokova and Daxner-Höck 2002; Morlo and Nagel 2002, 2006, 2007; Nagel and Morlo 2003; Heissig 2007), lower vertebrates (Böhme 2007), and gastropods (Stworzewicz 2007; Neubauer et al. 2013) is comparatively scarce. It has to be noted that fossils which were collected before from the studied area (by American-Mongolian, SovietMongolian, and Polish-Mongolian expeditions) are not included in the present dataset because their precise stratigraphic position remains questionable. Consequently, descriptions of these fossils were not considered in the present study.

The Cenozoic strata are intercalated with basalt flows, and ${ }^{40} \mathrm{Ar} /{ }^{39} \mathrm{Ar}$ data provide a timeframe for sediment deposition and the included fossils. Thus, basalt ages and Mongolian letter zones yield a composite age chronology for the studied area (Daxner-Höck et al. 1997; Höck et al. 1999; DaxnerHöck et al. 2010; Daxner-Höck and Badamgarav 2007; Harzhauser et al. 2017, this issue). Additional basalt data were provided by Devjatkin et al. (2002). Finally, magnetostratigraphic measurements (Kraatz and Geisler 2010; Sun and Windley 2015) were performed along the Taatsiin West plateau (sections-TGR below basalt I and TGR-C; Figs. 13, 14, and 15) and in Tatal Gol (see Kraatz and Geisler 2010).

\section{Materials and methods}

Fieldwork comprised geological mapping and studying geological sections based on lithology, structures, tectonics, and the fossil content. Basalt samples were dated by the ${ }^{40} \mathrm{Ar} /{ }^{39} \mathrm{Ar}$ method at the University of Vienna. Magnetic susceptibility and Gamma log measurements of sediments were carried out along five key sections, and sediment samples were taken for geochemical analyses and to determine the $\delta^{18} \mathrm{O}$ and $\delta^{13} \mathrm{C}$ patterns (Richoz et al. 2017, this issue). Along the geological sections, more than 100 palaeontological test samples and 60 bulk-samples of one to several tons of sediment were taken for wet screening in the field laboratory at the Taatsiin Gol camp. Sieves with $0.5,2.5$, and $5.0 \mathrm{~mm}$ mesh sizes were used.

In the field camp, the teeth, jaws, and bones were picked out from the dry residual using head lenses and field microscopes. The subsequent process of cleaning, identifying, and arranging the fossils took place at the NHMW (Natural History Museum Vienna). SEM images of small mammal teeth were taken using a Philips XL 20 scanning electron microscope at the Biocenter, University of Vienna. The fossils are stored in the collections of the NHMW and the MPC (Institute of Paleontology and Geology, Academy of Sciences of Mongolia). 
Fig. 1 Location of the working area in the Taatsiin Gol and Taatsiin Tsagaan Nuur region, which is part of the Valley of Lakes in Central Mongolia. "Taatsiin Gol" means River Taatsiin ( $\mathrm{gol}=$ river), but also the area around the river. "Tsagaan Nuur" means White Lake $($ tsagaan $=$ white, nuur $=$ lake $)$

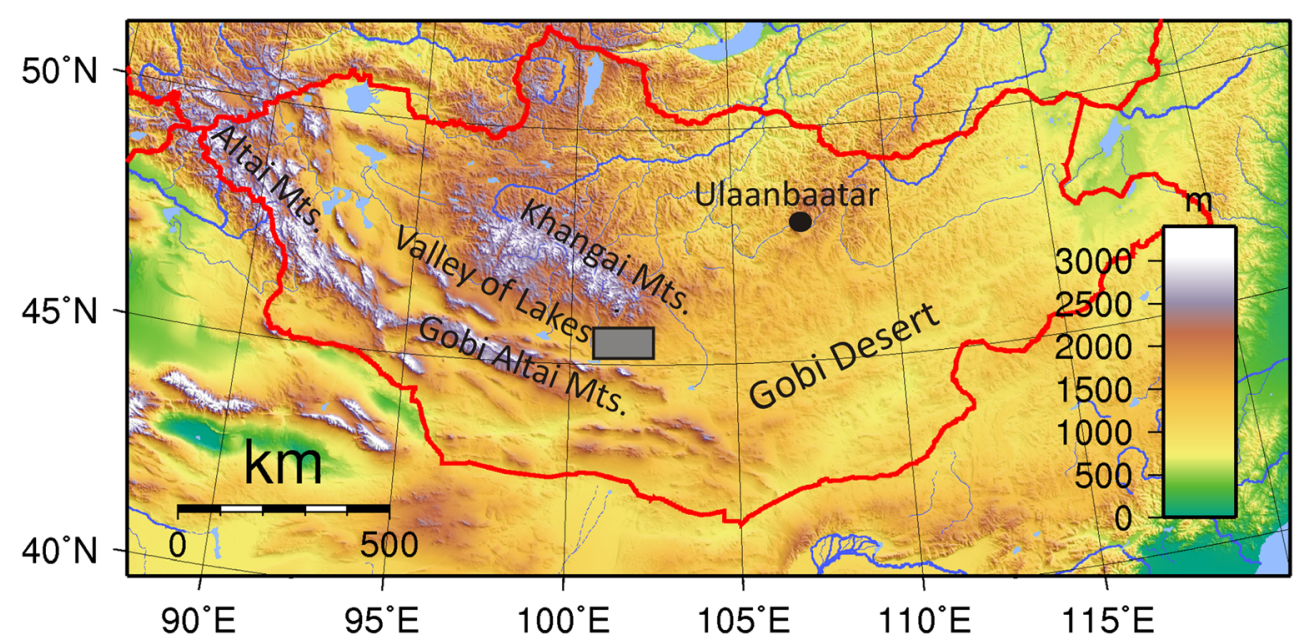

\section{Geological setting and stratigraphy}

The Taatsiin Tsagaan Nuur Basin belongs to the Valley of Lakes, which is one of the Pre-Altai depressions in Mongolia, between the Gobi Altai mountains in the south and the Khangai mountains in the north. Here, above a Precambrian to Permian basement, the basin is filled by continental Jurassic, Cretaceous, and Cenozoic sediments. The basin tectonics is complex and beyond the scope of this study. Note, however, that several fault systems were observed in the course of geological mapping here (Höck et al. 1999). A prominent fault close to the northern margin of the basin, the Del fault, strikes NW-SE to W-E and was mapped from the Dzun Hsir in the east along the southern escarpment of the Uskok range (= Ushgoeg range) to the northwest close to Unzing Churum. As already described by Berkey and
Morris (1927), the movement along the fault is a dip-slip towards the south (southwest) with an offset of at least 20 to $30 \mathrm{~m}$. The fault plane varies from south dipping to vertical. Along the Del fault, sediments of the Tsagan Ovo Fm. and the Hsanda Gol Fm. including basalt I are inclined. In contrast, horizontally bedded sediments of the Loh Fm. on top of the Eocene-Oligocene strata date the Del fault as late Oligocene or earliest Miocene. Two younger fault systems striking NESW and E-W are overlain by the middle Miocene basalt III (Höck et al. 1999). The recent seismic activity south of the Valley of Lakes along the northern rim of the Gobi Altai, i.e. along the Gobi Altai or Ikh Bogd fault, has a sinistral sense of movement but also a dip-slip component towards the N. There, the last major earthquake took place in 1957 with a magnitude 8/9 (Baljinyam et al. 1993; Kurushin et al. 1997; Schlupp 1996). The recent Petro Matad's exploration program

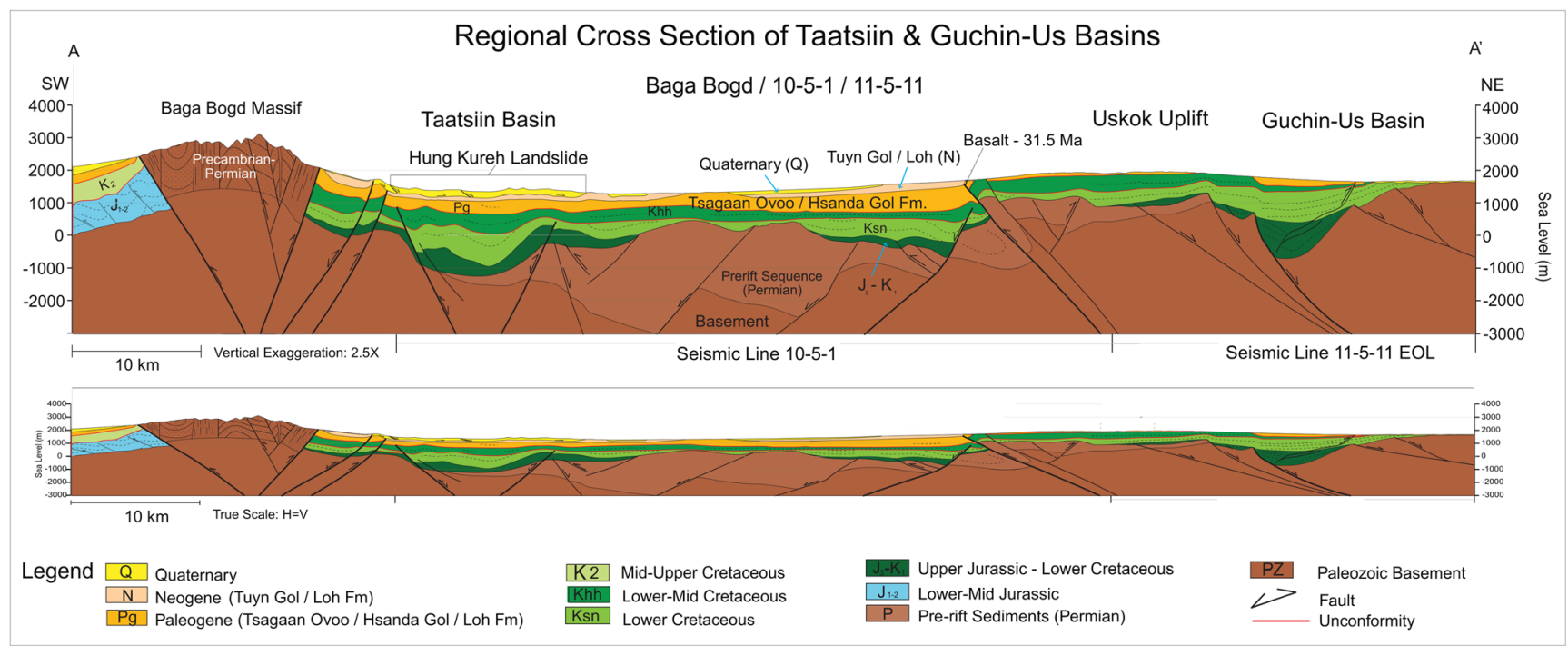

Fig. 2 Unpublished geologic cross-section of the Taatsiin Gol and Guchin-Us basins (Mongolia) that was made available to us for publication by Justin Tully, Petro Matad LLC 
of seismic, gravity, and stratigraphic core drilling demonstrates up to $4 \mathrm{~km}$ of folded and faulted basin fill, Mesozoic to Paleogene episodes of extension forming a half graben, and Neogene to recent episodes of compression (Fig. 2). The latter caused the ongoing uplift of the Gobi Altai range (Bag Bogd Massif).

This area is one of the best places in Mongolia to study Paleogene and Neogene sediment-basalt associations. Four lithological units can be identified: the Tsagan Ovo, Hsanda Gol, Loh, and Tuyn Gol formations (Daxner-Höck et al. 1997; Höck et al. 1999). The rich fossil content allows an update of the letter zones A, B, C, C1, and C1-D (Oligocene) and D (lowermost Miocene). These informal letter zones were defined as Biozones according to the International Stratigraphic Guide (Harzhauser et al. 2017, this issue).

\section{Lithological units}

\section{Tsagan Ovo Fm.}

The basal unit, the Tsagan Ovo Fm., is dominated by alternating grey, green-grey, whitish gravels and partly cross-bedded sand layers. The hanging parts are generally finer clastic and frequently show trough and planar cross-bedding, channel fills, and ripples. Normal graded and inverse graded beds with rip up clasts in decimetre size occur. Normal graded sandy beds can pass into fine-grained ones, which show lamination and root traces. The Tsagan Ovo Fm. was interpreted as a braided fluvial fan with a palaeocurrent direction from $\mathrm{N}$ to S (Höck et al.1999: 92-95) and partly as lake deposits. The time of deposition was late Eocene based on magnetostratigraphic correlation (Kraatz and Geisler 2010; Sun and Windley 2015).

\section{Hsanda Gol Fm.}

In many outcrops of the study area, the Tsagan Ovo Fm. is topped by the Hsanda Gol Fm. The latter consists of the lower Hsanda Gol beds, basalt I, and the upper Hsanda Gol beds. The term Tatal Member was introduced for the Hsanda Gol beds below basalt I and Shand Member for Hsanda Gol beds above basalt I (Dashzeveg 1996). The lower Hsanda Gol beds are of early Oligocene age, including fossils of letter zone A. The upper Hsanda Gol beds, however, range from the early Oligocene (including fossils of letter zone B) to the late Oligocene (including fossils of letter zones $\mathrm{C}$ and $\mathrm{C} 1$ ) or even reach the Oligocene/Miocene transition (evidenced by fossils of letter zone C1-D in section TAT-E/32; Figs. 21 and 22). The sediments are poorly sorted clay and silty clay and are reddish brown, brick red, to dark brown. Rare sand lenses or layers can be imbedded locally, e.g. in the Hsanda Gol region (SHGA/14 and SHG-D/12; Fig. 25). Within these sediments, caliche horizons with different features are present, including compact layers, nodules, caliche grading laterally into clay layers, or occurrences of calichized basalt (Höck et al. 1999: 95-97). The Hsanda Gol beds are well known for their fossil richness. Fossil concentrations were observed in, below, or/ and above caliche layers, and partly articulated skeletons were found in fossil burrows. The caliche layers are interpreted as palaeosol horizons, but the origin of the fine-grained Hsanda Gol sediments is under discussion. The interpretations range from ephemeral lake deposits, and braided fluvial fan sediments of the Tsagan Ovo Fm. that were eroded and transported by wind and/or by ephemeral streams (Höck et al. 1999), to eolian loess transported by westerly winds (Sun and Windley 2015).

\section{Loh Fm.}

Sediments of the Loh Fm. are most widespread in the study area. In many outcrops, the Hsanda Gol beds are covered by sediments of the Loh Fm., and in other places we found Loh sediments immediately on top of the Tsagan Ovo Fm. Loh sediments are predominantly trough cross-bedded, poorly sorted, polymict, matrix-supported gravels and sands of fluvial origin, with structures and colours similar to the Tsagan Ovo Fm. The two formations mainly differ in the gravel spectra: the Loh Fm. contains basalt, carbonate, and carbonate-tuff components due to erosion of basalts (I, II, and III) and Hsanda Gol sediments. Moreover, red to beige silty sand and sandy layers of several metres thickness can alternate with caliche and/or light-coloured sand and gravel layers (Höck et al. 1999: 97-100). These red-rose silts and caliche layers contain mammal fossils of late Oligocene to late Miocene age. The middle Miocene basalt III (13 Ma) is part of the Loh Fm.; it is frequently exposed on top of the plateaus east, north, and northwest of Taatsiin Gol.

\section{Tuyn Gol Fm.}

This formation crops out rarely and is restricted to the plateaus west and east of the Taatsiin Gol. The sediments are poorly sorted, grey-brown gravels of $\sim 9 \mathrm{~cm}$ diametre. Quartz components with $\mathrm{Fe}_{2} \mathrm{O}_{3}$ coatings, along with basalt, siltstone, granite, quartzite, gneiss, rhyolite, sandstone, and pegmatite, dominate the gravel spectrum (Höck et al. 1999: 100).

\section{Basalt ages}

\section{Basalts I}

The basalts have been dated by the ${ }^{40} \mathrm{Ar} /{ }^{39} \mathrm{Ar}$ method, providing a stratigraphic framework in which the biostratigraphic data are fitted. Based on 31 dated basalt samples, three main groups of basalt occurrences were identified by Höck et al. (1999: 108-113; Fig. 18). These are the early Oligocene basalt 
Table $1 \mathbf{a}^{40} \mathrm{Ar} /{ }^{39} \mathrm{Ar}$ data of basalt I-III from the Taatsiin Gol and Taatsiin Tsaagan Nuur region (Valley of Lakes, Mongolia). Basalt I (20 samples), basalt II (14 samples), basalt III (14 samples)

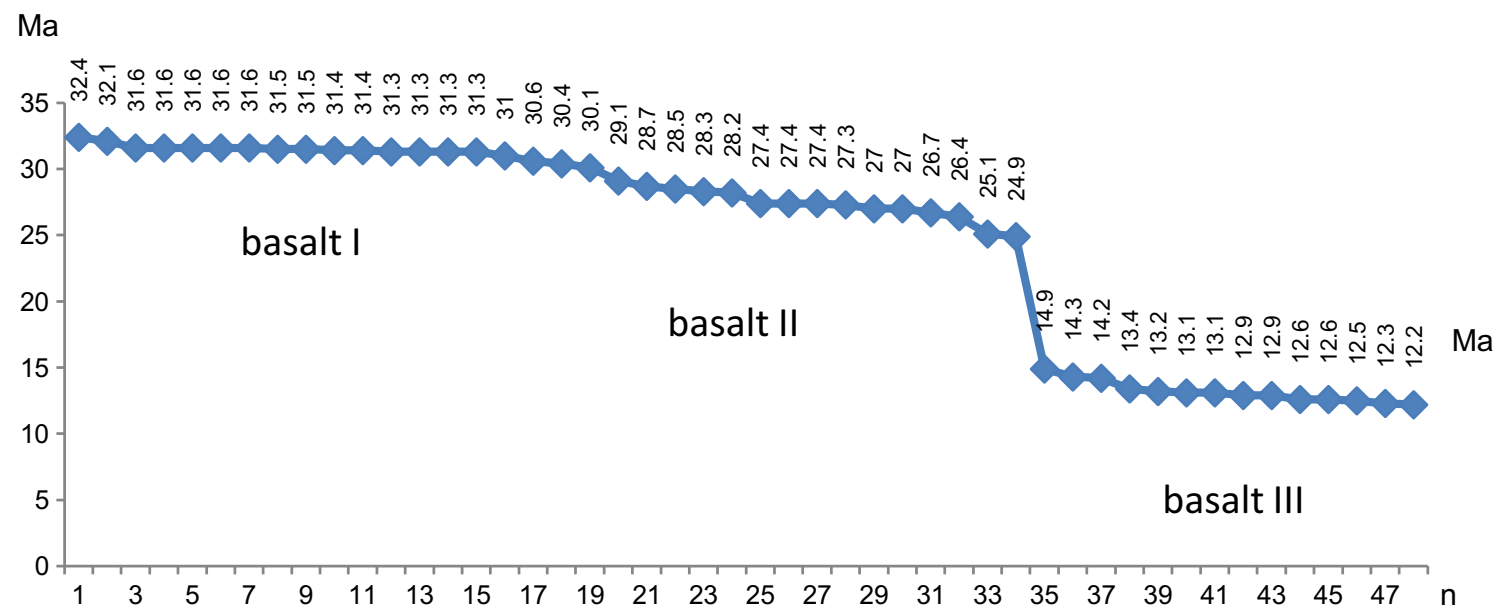

I group around $31.5 \mathrm{Ma}(32.2-30.4 \mathrm{Ma})$, the late Oligocene basalt II group around $28 \mathrm{Ma}(29-27 \mathrm{Ma})$, and the middle Miocene basalt III around $13 \mathrm{Ma}$ (13.2-12.2 Ma). The geochemistry and mineralogy of basalts I-III was described by Höck et al. (1999: 104-108: Table 5, Figs. 12, 13, 14, 15, 16, and 17). Since then, additional basalt ages have become available, showing that the Oligocene basalt events (basalt I and basalt II groups) occurred more or less continuously (32.4-

Table 2 Localization and age dating of basalt samples from the Valley of Lakes are given in columns 1-5: 1 sample codes; 2 coordinates; 3 basalt group I, II, III; $4{ }^{40} \mathrm{Ar} /{ }^{39} \mathrm{Ar}$ age of the basalt sample; 5 localization of the basalt sample/section or fossil locality [section ABOA (Abzag Ovo); section TGL-A (Taatsiin Gol left side of the river);
29.1 and 28.7-24.9 Ma, respectively). The middle Miocene volcanism (basalt III group), however, started after an interval of 10 million years (14.9-12.2 Ma) (Tables 1 and 2).

In contrast, the regional distribution of basalt I and II differs significantly. Basalt I occurrences are concentrated in the southern and central part of the study area. They extend from the western as far as the easternmost investigated regions. The most prominent outcrops are visible at the plateau west of

sections TGR-A, TGR-B, TGR-AB (Taatsiin Gol right side of the river), TGR-ZO/1, 2 (fossil site at Taatsiin Gol right side); section TAR-A (Unzing Churum), DEL (tilted basalt at Del); section TAT-C, TAT (Tatal Gol); section GRAB (Talyn Churum)]

\begin{tabular}{|c|c|c|c|c|c|}
\hline Basalt sample code: & $\mathrm{N}$ & $\mathrm{E}$ & Basalt I-III & Range (Ma) & Section/pal. sample \\
\hline \multicolumn{6}{|c|}{ Western region: Luuny Yas-Luugar Khudag-Abzag Ovo } \\
\hline M132/97 & $45^{\circ} 34^{\prime} 52^{\prime \prime}$ & $101^{\circ} 04^{\prime} 21^{\prime \prime}$ & II & $27.0 \pm 0.9$ & \multirow[t]{11}{*}{ ABO-A top } \\
\hline M109/97 & $45^{\circ} 34^{\prime} 08^{\prime \prime}$ & $101^{\circ} 08^{\prime} 19^{\prime \prime}$ & II & $26.7 \pm 0.7$ & \\
\hline M52/97 & $45^{\circ} 33^{\prime} 16^{\prime \prime}$ & $101^{\circ} 06^{\prime} 35^{\prime \prime}$ & II & $25.1 \pm 0.5$ & \\
\hline M53/97 & $45^{\circ} 32^{\prime} 31^{\prime \prime}$ & $101^{\circ} 06^{\prime} 57^{\prime \prime}$ & II & $24.9 \pm 0.5$ & \\
\hline M44/97 & $45^{\circ} 32^{\prime} 24^{\prime \prime}$ & $101^{\circ} 08^{\prime} 18^{\prime \prime}$ & III & $12.5 \pm 0.5$ & \\
\hline M108/97 & $45^{\circ} 35^{\prime} 45^{\prime \prime}$ & $101^{\circ} 07^{\prime} 54^{\prime \prime}$ & III & $13.4 \pm 0.4$ & \\
\hline M113/97 & $45^{\circ} 37^{\prime} 17^{\prime \prime}$ & $101^{\circ} 02^{\prime} 18^{\prime \prime}$ & III & $12.3 \pm 0.7$ & \\
\hline M116/97 & $45^{\circ} 29^{\prime} 23^{\prime \prime}$ & $101^{\circ} 01^{\prime} 47^{\prime \prime}$ & III & $14.3 \pm 0.4$ & \\
\hline M131/97 & $45^{\circ} 30^{\prime} 48^{\prime \prime}$ & $100^{\circ} 58^{\prime} 22^{\prime \prime}$ & III & $12.6 \pm 0.9$ & \\
\hline M118/97 & $45^{\circ} 27^{\prime} 56^{\prime \prime}$ & $100^{\circ} 57^{\prime} 13^{\prime \prime}$ & III & $14.9 \pm 0.5$ & \\
\hline M1/96 & $45^{\circ} 24^{\prime} 41^{\prime \prime}$ & $101^{\circ} 01^{\prime} 33^{\prime \prime}$ & III & $14.2 \pm 0.2$ & \\
\hline \multicolumn{6}{|c|}{ Taatsiin region: Taatsiin Gol left and right } \\
\hline M142/97 & $45^{\circ} 44^{\prime} 56^{\prime \prime}$ & $101^{\circ} 12^{\prime} 28^{\prime \prime}$ & III & $12.6 \pm 0.3$ & \multirow{5}{*}{$\begin{array}{l}\text { TGL-A top } \\
\text { TGL-A basis }\end{array}$} \\
\hline M143/97 & $45^{\circ} 44^{\prime} 56^{\prime \prime}$ & $101^{\circ} 12^{\prime} 28^{\prime \prime}$ & III & $12.2 \pm 0.7$ & \\
\hline TLA25/95 & $45^{\circ} 27^{\prime} 11^{\prime \prime}$ & $101^{\circ} 16^{\prime} 39^{\prime \prime}$ & III & $13.1 \pm 0.2$ & \\
\hline TLA10/95 & $45^{\circ} 26^{\prime} 59^{\prime \prime}$ & $101^{\circ} 16^{\prime} 23^{\prime \prime}$ & I & $31.6 \pm 0.5$ & \\
\hline M46/96 & $45^{\circ} 27^{\prime} 31^{\prime \prime}$ & $101^{\circ} 12^{\prime} 32^{\prime \prime}$ & I & $32.1 \pm 0.4$ & \\
\hline
\end{tabular}


Table 2 (continued)

\begin{tabular}{|c|c|c|c|c|c|}
\hline Basalt sample code: & $\mathrm{N}$ & $\mathrm{E}$ & Basalt I-III & Range (Ma) & Section/pal. sample \\
\hline M47/96 & $45^{\circ} 27^{\prime} 31^{\prime \prime}$ & $101^{\circ} 12^{\prime} 32^{\prime \prime}$ & I & $30.4 \pm 0.7$ & \\
\hline M68/96 & $45^{\circ} 25^{\prime} 27^{\prime \prime}$ & $101^{\circ} 15^{\prime} 25^{\prime \prime}$ & I & $29.1 \pm 0.9$ & \\
\hline TRB1/95 & $45^{\circ} 25^{\prime} 11^{\prime \prime}$ & $101^{\circ} 15^{\prime} 35^{\prime \prime}$ & I & $30.6 \pm 0.6$ & Near TGR-A, B, AB \\
\hline TRA19/95 & $45^{\circ} 25^{\prime} 11^{\prime \prime}$ & $101^{\circ} 15^{\prime} 35^{\prime \prime}$ & I & $32.4 \pm 1.0$ & Near TGR-A, B, AB \\
\hline M5/96 & $45^{\circ} 24^{\prime} 58^{\prime \prime}$ & $101^{\circ} 15^{\prime} 42^{\prime \prime}$ & I & $31.6 \pm 0.6$ & Near TGR-A, B, AB \\
\hline TRA20/95 & $45^{\circ} 24^{\prime} 54^{\prime \prime}$ & $101^{\circ} 15^{\prime} 44^{\prime \prime}$ & I & $31.0 \pm 0.4$ & Near TGR-A, B, AB \\
\hline M48/96 & $45^{\circ} 24^{\prime} 15^{\prime \prime}$ & $101^{\circ} 15^{\prime} 52^{\prime \prime}$ & I & $31.3 \pm 0.5$ & TGR-ZO-1, 2 \\
\hline \multicolumn{6}{|c|}{ Unzing Churum and Del region } \\
\hline DIV/95 & & & III & $12.9 \pm 0.3$ & \\
\hline $\mathrm{DV} / 95$ & $45^{\circ} 31^{\prime} 17^{\prime \prime}$ & $101^{\circ} 18^{\prime} 12^{\prime \prime}$ & III & $12.9 \pm 0.1$ & TAR-A top \\
\hline M17/96 & $45^{\circ} 31^{\prime} 22^{\prime \prime}$ & $101^{\circ} 18^{\prime} 30^{\prime \prime}$ & III & $13.1 \pm 0.2$ & \\
\hline M18/96 & $45^{\circ} 31^{\prime} 22^{\prime \prime}$ & $101^{\circ} 18^{\prime} 30^{\prime \prime}$ & III & $13.2 \pm 0.3$ & \\
\hline DIII2/95 & $45^{\circ} 31^{\prime} 13^{\prime \prime}$ & $101^{\circ} 18^{\prime} 10^{\prime \prime}$ & II & $28.2 \pm 0.7$ & \\
\hline M56/96 & $45^{\circ} 31^{\prime} 10^{\prime \prime}$ & $101^{\circ} 18^{\prime} 09^{\prime \prime}$ & II & $27.4 \pm 0.4$ & TAR-A basis \\
\hline M4/96 & $45^{\circ} 32^{\prime} 10^{\prime \prime}$ & $101^{\circ} 18^{\prime} 15^{\prime \prime}$ & II & $27.3 \pm 0.5$ & \\
\hline DA2/95 & $45^{\circ} 29^{\prime} 45^{\prime \prime}$ & $101^{\circ} 17^{\prime} 50^{\prime \prime}$ & I & $31.5 \pm 0.4$ & \\
\hline M4/96 & $45^{\circ} 29^{\prime} 39^{\prime \prime}$ & $101^{\circ} 18^{\prime} 14^{\prime \prime}$ & I & $31.6 \pm 0.6$ & \\
\hline M45/96 & $45^{\circ} 27^{\prime} 54^{\prime \prime}$ & $101^{\circ} 20^{\prime} 28^{\prime \prime}$ & I & $31.6 \pm 0.5$ & \\
\hline $\mathrm{DA} / 95$ & $45^{\circ} 27^{\prime} 29^{\prime \prime}$ & $101^{\circ} 21^{\prime} 25^{\prime \prime}$ & I & $31.4 \pm 0.6$ & \\
\hline M32/96 & $45^{\circ} 27^{\prime} 28^{\prime \prime}$ & $101^{\circ} 21^{\prime} 31^{\prime \prime}$ & I & $30.1 \pm 0.7$ & \\
\hline \multicolumn{6}{|l|}{ Tatal Gol region } \\
\hline M5/97 & $45^{\circ} 22^{\prime} 46^{\prime \prime}$ & $101^{\circ} 38^{\prime} 47^{\prime \prime}$ & II & $27.4 \pm 0.7$ & \\
\hline M11/97 & $45^{\circ} 22^{\prime} 46^{\prime \prime}$ & $101^{\circ} 38^{\prime} 47^{\prime \prime}$ & II & $28.5 \pm 0.8$ & \\
\hline M28/97 & $45^{\circ} 20^{\prime} 13^{\prime \prime}$ & $101^{\circ} 38^{\prime} 23^{\prime \prime}$ & II & $26.4 \pm 0.7$ & \\
\hline M30/79 & $45^{\circ} 19^{\prime} 31^{\prime \prime}$ & $101^{\circ} 39^{\prime} 53^{\prime \prime}$ & II & $27.0 \pm 0.6$ & \\
\hline TAT3/95 & $45^{\circ} 18^{\prime} 21^{\prime \prime}$ & $101^{\circ} 38^{\prime} 01^{\prime \prime}$ & I & $31.6 \pm 0.5$ & Close to TAT-C \\
\hline TAT2/95 & $45^{\circ} 18^{\prime} 08^{\prime \prime}$ & $101^{\circ} 37^{\prime} 53^{\prime \prime}$ & I & $31.3 \pm 0.5$ & \\
\hline TAT1/95 & $45^{\circ} 17^{\prime} 50^{\prime \prime}$ & $101^{\circ} 37^{\prime} 46^{\prime \prime}$ & I & $31.4 \pm 0.7$ & \\
\hline M25/96 & $45^{\circ} 23^{\prime} 42^{\prime \prime}$ & $101^{\circ} 34^{\prime} 05^{\prime \prime}$ & I & $31.3 \pm 0.5$ & \\
\hline \multicolumn{6}{|c|}{ Eastern region: Ulan Tolgoi to Talyn Churum } \\
\hline M37/97 & $45^{\circ} 28^{\prime} 56^{\prime \prime}$ & $101^{\circ} 51^{\prime} 19^{\prime \prime}$ & II & $28.3 \pm 0.6$ & \\
\hline M41/97 & $45^{\circ} 28^{\prime} 24^{\prime \prime}$ & $101^{\circ} 52^{\prime} 01^{\prime \prime}$ & II & $27.4 \pm 1.1$ & \\
\hline M17/97 & $45^{\circ} 20^{\prime} 03^{\prime \prime}$ & $101^{\circ} 53^{\prime} 13^{\prime \prime}$ & II & $28.7 \pm 0.7$ & \\
\hline UTO/95 & $45^{\circ} 20^{\prime} 49^{\prime \prime}$ & $101^{\circ} 50^{\prime} 16^{\prime \prime}$ & I & $31.3 \pm 0.5$ & \\
\hline GII/95 & $45^{\circ} 16^{\prime} 53^{\prime \prime}$ & $101^{\circ} 57^{\prime} 30^{\prime \prime}$ & I & $31.5 \pm 0.7$ & GRAB-II top \\
\hline
\end{tabular}

Taatsiin Gol (sections TGR-A, TGR-B, TGR-AB, TGW-A, HL-A; Figs. 8, 14, and 15), the plateau east of Taatsiin Gol (section TGL-A; Fig. 16), along the Del fault (section DEL-B; Fig. 20) where the basalt I and tuff I are tilted, in Tatal Gol (section TAT-C; Fig. 23), and east of Tatal Gol (sections SHG$\mathrm{C}$ and GRAB-II; Figs. 24 and 27). Basalt $\mathrm{I}$ is imbedded in red clay/silty clay of the Hsanda Gol Fm. In N-S direction, all basalt I occurrences are located south of basalt II. Basalt II is exposed in the northern parts of the study area in four main regions, the northwest region (section ABO-A; Fig. 6), the Unzing Churum region (section TAR-A; Figs. 18 and 19), the northern Tatal Gol region, and north of Ulan Tolgoi. Basalt II is bound to strata of the Loh Fm. For localization of sections, see Fig. 3.

Some basalt occurrences with fossil contact are chronostratigraphically important. In the Taatsiin Gol, Del, and Tatal Gol regions, basalt I is intercalated with strata of the Hsanda Gol Fm. Consequently, fossil beds below basalt I are older, and those above basalt I are younger than $\sim 31.5 \mathrm{Ma}$. In the northern regions, for example, basalt II (sample M132/97) of section ABO-A (Fig. 6) is located immediately above fossil bed $\mathrm{ABO}-\mathrm{A} / 3$ and dates the fossils older than $27.9 \pm$ $0.9 \mathrm{Ma}$. In the Unzing Churum region (Figs. 18 and 19), 
basalt II (sample M132/97) is located immediately below fossil bed TAR-A/2 and dates the fossils younger than 27.4 $\pm 0.4 \mathrm{Ma}$ (Tables 1 and 2).

Basalt III is part of the Loh Fm. and forms the top layer of several plateaus, i.e. the plateau to the left side (east) of Taatsiin Gol, the Unzing Churum plateau, and extended plateaus in the northwest region. In the latter, fossil-bearing strata are locally sandwiched between basalt II and basalt III.

\section{Geological sections}

The present study provides a detailed presentation and correlation of the elaborated sections comprising the Oligocene and lowermost Miocene strata. Middle and late Miocene sediment sequences have been excluded from this study because of ongoing investigations in this region.
We describe the sections/localities according to their location from west to east (Fig. 3a to z). A complete overview of all investigated sections/localities, fossil samples, the respective codes, coordinates, and letter zones are given in Table 3. Some assemblage lists (e.g. TGR-C/1+2) are composite. They comprise fossils of two individual samples from subsequent, time-equivalent sediment layers of the same section. All these data are published here for the first time. For some published data of the figured sections, we give references in the figure captions.

\section{Locality Luuny Yas}

Samples: LUS-027, LUS-028, LUS-029 (=LUS-078)

Luuny Yas is the westernmost fossil point of the study area (Fig. 3a), first recognised during geological mapping in 1997.

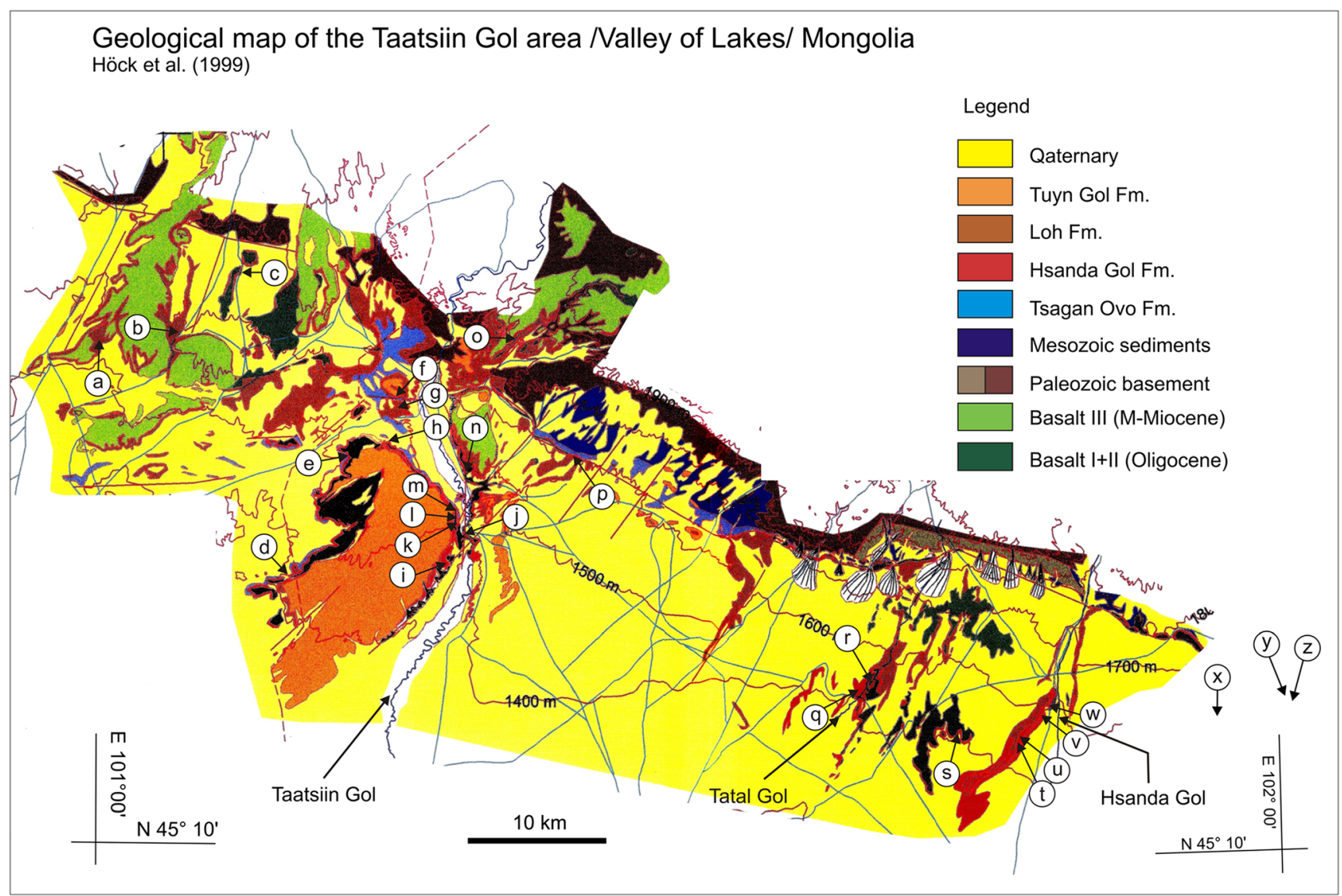

Fig. 3 Geological map of the Taatsiin Gol and Taatsiin Tsagaan Nuur region in the Valley of Lakes (Höck et al. 1999). The letters $a-z$ designate fossil places and investigated sections. $\boldsymbol{a}$ Luuny Yas (LUS), $\boldsymbol{b}$ Luugar Khudag (LOG-A), $\boldsymbol{c}$ Abzag Ovo (ABO-A), $\boldsymbol{d}$ Toglorhoi (TGW), $\boldsymbol{e}$ Khongil (HL), $\boldsymbol{f}$ Huch Teeg (RHN), $g$ Hotuliin Teeg (HTE, HTS, HTSE), $h$ Unkheltseg (UNCH-A), $i$ Taatsiin Gol south (TGR-C), $j$ Tsagan Ovo (TGR-ZO), $k$ Taatsiin Gol right (TGR-B), $l$ Taatsiin Gol right
(TGR-AB), $m$ Taatsiin Gol right (TGR-A), $n$ Taatsiin Gol left (TGL-A), $o$ Unzing Churum (TAR-A), $p$ Del (DEL-B), $q$ Tatal Gol (TAT-D+E), $r$ Tatal Gol (TAT-C), $s$ Hsanda Gol (SHG-C), $t$ Hsanda Gol (SHG-A), $u$ Hsanda Gol (SHG-D), $v$ Loh (LOH-C), $w$ Loh (LOH-B), $x$ Talyn Churum (GRAB-II), $y$ Ikh Argalatyn Nuruu (IKH-A), $z$ Ikh Argalatyn Nuruu (IKH-B) 
Table 3 Overview of the figured sections/fossil sites, fossil samples, the respective codes, coordinates, and letter zones

\begin{tabular}{|c|c|c|c|c|c|}
\hline & Locality & Code section/locality & Code sample & Coordinates & Letter zone \\
\hline Fig. 4 & Luuny Yas & LUS & LUS-027 & $\begin{array}{l}\text { N } 45^{\circ} 32^{\prime} 05.5^{\prime \prime} \\
\text { E } 100^{\circ} 56^{\prime} 49.9^{\prime \prime}\end{array}$ & $\mathrm{D}$ \\
\hline Fig. 4 & Luuny Yas & LUS & LUS-028 & $\begin{array}{l}\text { N } 45^{\circ} 32^{\prime} 06.4^{\prime \prime} \\
\text { E } 100^{\circ} 56^{\prime} 54.5^{\prime \prime}\end{array}$ & $\mathrm{D}$ \\
\hline Fig. 4 & Luuny Yas & LUS & LUS-029 & $\begin{array}{l}\text { N } 45^{\circ} 32^{\prime} 20.9 \\
\text { E } 100^{\circ} 00^{\prime} 51.3^{\prime \prime}\end{array}$ & $\mathrm{D}$ \\
\hline Fig. 5 & Luugar Khudag & LOG-A & LOG-A/1 & $\begin{array}{l}\text { N } 45^{\circ} 32^{\prime} 19.6^{\prime \prime} \\
\text { E } 101^{\circ} 00^{\prime} 51.3^{\prime \prime}\end{array}$ & $\mathrm{D}$ \\
\hline Fig. 6 & Abzag Ovo & ABO-A & $\mathrm{ABO}-\mathrm{A} / 3$ & $\begin{array}{l}\text { N } 45^{\circ} 34^{\prime} 25.4^{\prime \prime} \\
\text { E } 101^{\circ} 03^{\prime} 49.7^{\prime \prime}\end{array}$ & $\mathrm{C}$ \\
\hline Fig. 7 & Toglorhoi & TGW-A & TGW-A/1-2 & & $\mathrm{C}$ \\
\hline Fig. 7 & Toglorhoi & TGW-A & TGW-A/3-4 & & $\mathrm{C} 1$ \\
\hline Fig. 7 & Toglorhoi & TGW-A & TGW-A/5 & $\begin{array}{l}\text { N } 45^{\circ} 22^{\prime} 37.6^{\prime \prime} \\
\text { E } 101^{\circ} 05^{\prime} 49.2^{\prime \prime}\end{array}$ & $\mathrm{C} 1$ \\
\hline Fig. 8 & Khongil & HL-A & HL-A/1-2 & $\begin{array}{l}\text { N } 45^{\circ} 27^{\prime} 40.4^{\prime \prime} \\
\text { E } 101^{\circ} 09^{\prime} 18.5^{\prime \prime}\end{array}$ & A \\
\hline Fig. 9 & Huch Teeg & RHN-A & RHN-A/12 & $\begin{array}{l}\text { N } 45^{\circ} 29^{\prime} 29.9^{\prime \prime} \\
\text { E } 101^{\circ} 12^{\prime} 17.1^{\prime \prime}\end{array}$ & $\mathrm{D}$ \\
\hline Fig. 9 & Huch Teeg & RHN-A & RHN-020 & $\begin{array}{l}\text { N } 45^{\circ} 29^{\prime} 29.8^{\prime \prime} \\
\text { E } 101^{\circ} 12^{\prime} 18.3^{\prime \prime}\end{array}$ & $\mathrm{D}$ \\
\hline Fig. 9 & Huch Teeg & RHN-A & RHN-021; RHN-A/11 & $\begin{array}{l}\text { N } 45^{\circ} 29^{\prime} 30.6^{\prime \prime} \\
\text { E } 101^{\circ} 12^{\prime} 19.1^{\prime \prime}\end{array}$ & C1-D \\
\hline Fig. 9 & Huch Teeg & RHN-A & RHN-019; RHN-A/10 & $\begin{array}{l}\text { N } 45^{\circ} 29^{\prime} 30.5^{\prime \prime} \\
\text { E } 101^{\circ} 12^{\prime} 20.2^{\prime \prime}\end{array}$ & $\mathrm{C} 1$ \\
\hline Fig. 9 & Huch Teeg & RHN-A & RHN-A/7; RHN-A/8-9 & $\begin{array}{l}\text { N } 45^{\circ} 29^{\prime} 36.0^{\prime \prime} \\
\text { E } 101^{\circ} 12^{\prime} 22.2^{\prime \prime}\end{array}$ & $\mathrm{C} 1$ \\
\hline Fig. 9 & Huch Teeg & RHN-A & RHN-023 & $\begin{array}{l}\text { N } 45^{\circ} 29^{\prime} 33.6^{\prime \prime} \\
\text { E } 101^{\circ} 12^{\prime} 30.0^{\prime \prime}\end{array}$ & $\mathrm{C} 1$ \\
\hline $\begin{array}{l}\text { Fig. } 10 \\
\text { Fig. } 11 \mathrm{~d}\end{array}$ & Hotuliin Teeg & HTE & HTE-057 & $\begin{array}{l}\mathrm{N} 45^{\circ} 28^{\prime} 54.2^{\prime \prime} \\
\mathrm{E} 101^{\circ} 12^{\prime} 26.2^{\prime \prime}\end{array}$ & $\mathrm{C} 1$ \\
\hline Fig. $11 \mathrm{c}$ & Hotuliin Teeg & HTE & $\begin{array}{l}\text { HTE-008; HTE-003; HTE-009; } \\
\text { HTE-014-018 }\end{array}$ & $\begin{array}{l}\text { N } 45^{\circ} 29^{\prime} 07.4^{\prime \prime} \\
\text { E } 101^{\circ} 11^{\prime} 58.9^{\prime \prime}\end{array}$ & $\mathrm{D}$ \\
\hline & Hotuliin Teeg & HTE & HTE-007 & $\begin{array}{l}\text { N } 45^{\circ} 29^{\prime} 08.2^{\prime \prime} \\
\text { E } 101^{\circ} 11^{\prime} 49.3^{\prime \prime}\end{array}$ & $\mathrm{D}$ \\
\hline Fig. 11b & Hotuliin Teeg & HTE & HTE-005; HTE-12/6; HTE-12/8 & $\begin{array}{l}\text { N } 45^{\circ} 29^{\prime} 09.7^{\prime \prime} \\
\text { E } 101^{\circ} 11^{\prime} 49.0^{\prime \prime}\end{array}$ & $\begin{array}{l}\mathrm{D} \\
\mathrm{D}\end{array}$ \\
\hline Fig. 11b & Hotuliin Teeg & HTE & HTE-012; HTE-12/7 & $\begin{array}{l}\text { N } 45^{\circ} 29^{\prime} 11.9^{\prime \prime} \\
\text { E } 101^{\circ} 11^{\prime} 49.3^{\prime \prime}\end{array}$ & $\mathrm{D}$ \\
\hline Fig. 11f & Hotuliin Teeg & HTSE & HTSE-009 & $\begin{array}{l}\text { N } 45^{\circ} 28^{\prime} 49.2^{\prime \prime} \\
\text { E } 101^{\circ} 11^{\prime} 55.0^{\prime \prime}\end{array}$ & $\mathrm{C} 1$ \\
\hline Fig. 11f & Hotuliin Teeg & HTSE & HTSE-013 & $\begin{array}{l}\text { N } 45^{\circ} 28^{\prime} 49.9^{\prime \prime} \\
\text { E } 101^{\circ} 11^{\prime} 57.2^{\prime \prime}\end{array}$ & $\mathrm{C} 1$ \\
\hline Fig. 11e & Hotuliin Teeg & HTS & HTS- $056 / 1+2$ & $\begin{array}{l}\text { N } 45^{\circ} 28^{\prime} 53.2^{\prime \prime} \\
\text { E } 101^{\circ} 11^{\prime} 34.9^{\prime \prime}\end{array}$ & C1-D \\
\hline Fig. 11e & Hotuliin Teeg & HTS & HTS- $056 / 3$ & $\begin{array}{l}\text { N } 45^{\circ} 28^{\prime} 54.5^{\prime \prime} \\
\text { E } 101^{\circ} 11^{\prime} 36.3^{\prime \prime}\end{array}$ & C1-D \\
\hline $\begin{array}{l}\text { Fig. } 11 \mathrm{a} \\
\text { Fig. } 12 \mathrm{a}-\mathrm{d}\end{array}$ & Unkheltseg & UNCH-A & UNCH-A/3B+4B & $\begin{array}{l}\text { N } 45^{\circ} 27^{\prime} 40.1^{\prime \prime} \\
\text { E } 101^{\circ} 12^{\prime} 04.4^{\prime \prime}\end{array}$ & B \\
\hline $\begin{array}{l}\text { Fig. 11a } \\
\text { Fig. 12a-d }\end{array}$ & Unkheltseg & UNCH-A & $\mathrm{UNCH}-\mathrm{A} / 3+4$ & $\begin{array}{l}\text { N } 45^{\circ} 27^{\prime} 40.1^{\prime \prime} \\
\text { E } 101^{\circ} 12^{\prime} 04.4^{\prime \prime}\end{array}$ & $\mathrm{D}$ \\
\hline Fig. 13 & Taatsiin Gol (south) & TGR-C & TGR-C/1 & $\begin{array}{l}\text { N } 45^{\circ} 23^{\prime} 10.9^{\prime \prime} \\
\text { E } 101^{\circ} 14^{\prime} 34.9^{\prime \prime}\end{array}$ & $\mathrm{C}$ \\
\hline Fig. 13 & Taatsiin Gol (south) & TGR-C' & TGR-C'/1 & $\begin{array}{l}\text { N } 45^{\circ} 23^{\prime} 12.3^{\prime \prime} \\
\text { E } 101^{\circ} 14^{\prime} 35.4^{\prime \prime}\end{array}$ & $\mathrm{C}$ \\
\hline & Taatsiin Gol (right) & TGR-ZO & TGR-ZO/1+2 & $\mathrm{N} 45^{\circ} 24^{\prime} 13.5^{\prime \prime}$ & ?B \\
\hline
\end{tabular}


Table 3 (continued)

\begin{tabular}{|c|c|c|c|c|c|}
\hline & Locality & Code section/locality & Code sample & Coordinates & Letter zone \\
\hline & & & & E $101^{\circ} 15^{\prime} 53.0^{\prime \prime}$ & \\
\hline \multirow[t]{2}{*}{ Figs. 14 and 15} & Taatsiin Gol (right) & TGR-B' & TGR-B/1 & $\mathrm{N} 45^{\circ} 24^{\prime} 47.3^{\prime \prime}$ & B \\
\hline & & & & E $101^{\circ} 15^{\prime} 23.2^{\prime \prime}$ & \\
\hline \multirow[t]{2}{*}{ Fig. 14} & Taatsiin Gol (right) & TGR-AB & TGR-AB (basis) & $\mathrm{N} 45^{\circ} 25^{\prime} 08.8^{\prime \prime}$ & Eocene \\
\hline & & & & E $101^{\circ} 15^{\prime} 39.2^{\prime \prime}$ & \\
\hline \multirow[t]{2}{*}{ Figs. 14 and 15} & Taatsiin Gol (right) & TGR-AB & TGR-AB/21 & $\mathrm{N} 45^{\circ} 24^{\prime} 41.1^{\prime \prime}$ & B \\
\hline & & & & E $101^{\circ} 15^{\prime} 24.7^{\prime \prime}$ & \\
\hline Fig. 14 & Taatsiin Gol (right) & TGR-AB & TGR-AB/22 & & B \\
\hline \multirow[t]{2}{*}{ Fig. 14} & Taatsiin Gol (right) & TGR-A & TGR-A/13+14 & $\mathrm{N} 45^{\circ} 25^{\prime} 12.5^{\prime \prime}$ & $\mathrm{A}$ \\
\hline & & & & E $101^{\circ} 15^{\prime} 44.3^{\prime \prime}$ & \\
\hline \multirow[t]{2}{*}{ Fig. 16} & Taatsiin Gol (left) & TGL-A & TGL-A/1+2 & N 452 $26^{\prime} 57.4^{\prime \prime}$ & A \\
\hline & & & & E $101^{\circ} 16^{\prime} 20.9^{\prime \prime}$ & \\
\hline Fig. 17 & Taatsiin Gol (left) & TGL-A' & TGL-A/11 & & B \\
\hline \multirow[t]{2}{*}{ Figs. 18-19 } & Unzing Churum & TAR-A & TAR-A/2 & N 453' $31^{\prime} 14.4^{\prime \prime}$ & $\mathrm{C}$ \\
\hline & & & & E $101^{\circ} 18^{\prime} 19.2^{\prime \prime}$ & \\
\hline \multirow[t]{2}{*}{ Fig. 20} & Del & DEL-B & DEL-B/7+8 & $\mathrm{N} 45^{\circ} 27^{\prime} 10.2^{\prime \prime}$ & B \\
\hline & & & & E $101^{\circ} 22^{\prime} 22.3^{\prime \prime}$ & \\
\hline Fig. 20 & Del & DEL-B & DEL-B/12 & & $\mathrm{C} 1$ \\
\hline Figs. 21 and 22 & Tatal Gol & & & & \\
\hline \multirow[t]{2}{*}{ Fig. 22a } & Tatal Gol & TAT & TAT-051/2 & $\mathrm{N} 45^{\circ} 18^{\prime} 08.2^{\prime \prime}$ & $\mathrm{C} 1$ \\
\hline & & & & E $101^{\circ} 37^{\prime} 09.3^{\prime \prime}$ & \\
\hline Fig. 22a & Tatal Gol & TAT & TAT-051/1 & & $\mathrm{C} 1$ \\
\hline \multirow[t]{2}{*}{ Fig. 22a } & Tatal Gol & TAT & TAT-054 & $\mathrm{N} 45^{\circ} 18^{\prime} 07.6^{\prime \prime}$ & B \\
\hline & & & & E $101^{\circ} 37^{\prime} 09.7^{\prime \prime}$ & \\
\hline \multirow[t]{2}{*}{ Fig. 22a } & Tatal Gol & TAT & TAT- $052 / 2$ & $\mathrm{~N} 45^{\circ} 18^{\prime} 09.4^{\prime \prime}$ & C1-D \\
\hline & & & & E $101^{\circ} 37^{\prime} 14.5^{\prime \prime}$ & \\
\hline Fig. 22a & Tatal Gol & TAT & TAT-052/1 & & $\mathrm{C} 1$ \\
\hline \multirow[t]{2}{*}{ Fig. 22a } & Tatal Gol & TAT-E & TAT-E/32 & $\mathrm{N} 45^{\circ} 18^{\prime} 12.6^{\prime \prime}$ & C1-D \\
\hline & & & & E $101^{\circ} 37^{\prime} 15.7^{\prime \prime}$ & \\
\hline Fig. 21a & Tatal Gol & TAT-E & TAT-E/27 & & $\mathrm{C} 1$ \\
\hline Fig. 21a & Tatal Gol & TAT-E & TAT-E/22 & & $\mathrm{C} 1$ \\
\hline \multirow[t]{2}{*}{ Fig. 22b } & Tatal Gol & TAT-E & TAT-044 & $\mathrm{N} 45^{\circ} 18^{\prime} 00.5^{\prime \prime}$ & $\mathrm{C} 1$ \\
\hline & & & & E $101^{\circ} 37^{\prime} 20.6^{\prime \prime}$ & \\
\hline \multirow[t]{2}{*}{ Fig. $22 b$} & Tatal Gol & TAT-E & TAT-043 & $\mathrm{N} 45^{\circ} 17^{\prime} 59.8^{\prime \prime}$ & $\mathrm{C} 1$ \\
\hline & & & & E $101^{\circ} 37^{\prime} 17.1^{\prime \prime}$ & \\
\hline \multirow[t]{2}{*}{ Fig. 22b } & Tatal Gol & TAT-E & TAT-055 & N 4517'59.0" & $\mathrm{C}$ \\
\hline & & & & E $101^{\circ} 37^{\prime} 16.6^{\prime \prime}$ & \\
\hline \multirow[t]{6}{*}{ Fig. 22b } & Tatal Gol & TAT-E & TAT-E/3 & $\mathrm{N} 45^{\circ} 14^{\prime} 58.2^{\prime \prime}$ & B \\
\hline & & & & E $101^{\circ} 37^{\prime} 16.6^{\prime \prime}$ & \\
\hline & Tatal Gol & TAT & TAT-038 & $\mathrm{N} 45^{\circ} 17^{\prime} 56.0^{\prime \prime}$ & B \\
\hline & & & & E $101^{\circ} 37^{\prime} 10.9^{\prime \prime}$ & \\
\hline & Tatal Gol & TAT & TAT-037 & $\mathrm{N} 45^{\circ} 17^{\prime} 54.1^{\prime \prime}$ & A \\
\hline & & & & E $101^{\circ} 37^{\prime} 11.7^{\prime \prime}$ & \\
\hline \multirow[t]{2}{*}{ Fig. 22c } & Tatal Gol & TAT-D & TAT-D/1 & $\mathrm{N} 45^{\circ} 17^{\prime} 52.2^{\prime \prime}$ & A \\
\hline & & & & E $101^{\circ} 37^{\prime} 18.5^{\prime \prime}$ & \\
\hline \multirow[t]{2}{*}{ Fig. 23} & Tatal Gol & TAT-C & TAT-C/1-3 & $\mathrm{N} 45^{\circ} 18^{\prime} 19.5^{\prime \prime}$ & A \\
\hline & & & & E $101^{\circ} 38^{\prime} 00.0^{\prime \prime}$ & \\
\hline Fig. 23 & Tatal Gol & TAT-C & TAT-C/6-7 & & B \\
\hline \multirow[t]{2}{*}{ Fig. 24} & Hsanda Gol & SHG-C & SHG-C/1-2 & N 4515'49.9" & A \\
\hline & & & & E $101^{\circ} 43^{\prime} 04.9^{\prime \prime}$ & \\
\hline Fig. 25 & Hsanda Gol & SHG-A & SHG-A/6-20 & & B \\
\hline Fig. 25 & Hsanda Gol & SHG-AB & SHG-AB/15-20 & & B \\
\hline Fig. 25 & Hsanda Gol & SHG-AB & SHG-top & & $\mathrm{C} 1$ \\
\hline Fig. 25 & Hsanda Gol & SHG-D & SHG-D/12 & $\mathrm{N} 45^{\circ} 16^{\prime} 11.8^{\prime \prime}$ & Sandstone \\
\hline & & & & E $101^{\circ} 45^{\prime} 55.9^{\prime \prime}$ & \\
\hline
\end{tabular}


Table 3 (continued)

\begin{tabular}{|c|c|c|c|c|c|}
\hline & Locality & Code section/locality & Code sample & Coordinates & Letter zone \\
\hline \multirow[t]{2}{*}{ Fig. 25} & Hsanda Gol & SHG-D & SHG-D/12-26 & & $\mathrm{B}$ \\
\hline & Loh & LOH-C & LOH-C/1 & & $\mathrm{C} 1$ \\
\hline \multirow[t]{2}{*}{ Fig. 26} & Loh & LOH-B & LOH-B/3 & $\mathrm{N} 45^{\circ} 17^{\prime} 04.9^{\prime \prime}$ & $\mathrm{C} 1$ \\
\hline & & & & E $101^{\circ} 47^{\prime} 22.7^{\prime \prime}$ & \\
\hline \multirow[t]{2}{*}{ Fig. 27} & Talyn Churum & GRAB & GRAB-II & $\mathrm{N} 45^{\circ} 16^{\prime} 50.4^{\prime \prime}$ & A \\
\hline & & & & E $101^{\circ} 57^{\prime} 28.4^{\prime \prime}$ & \\
\hline \multirow[t]{2}{*}{ Fig. 28} & Ikh Argalatyn Nuruu & IKH-A & IKH-A/1 & $\mathrm{N} 45^{\circ} 17^{\prime} 48.4^{\prime \prime}$ & $\mathrm{B}$ \\
\hline & & & IKH-A/2-4 & E $102^{\circ} 04^{\prime} 57.2^{\prime \prime}$ & \\
\hline \multirow[t]{2}{*}{ Fig. 28} & Ikh Argalatyn Nuruu & IKH-A & IKH-A/5 & $\mathrm{N} 45^{\circ} 17^{\prime} 49.1^{\prime \prime}$ & $\mathrm{C} 1$ \\
\hline & & & & E $102^{\circ} 05^{\prime} 00.7^{\prime \prime}$ & \\
\hline \multirow[t]{2}{*}{ Fig. 29} & Ikh Argalatyn Nuruu & IKH-B & IKH-B/2 & $\mathrm{N} 45^{\circ} 17^{\prime} 32.6^{\prime \prime}$ & $\mathrm{B}$ \\
\hline & & & & E $102^{\circ} 05^{\prime} 34.2^{\prime \prime}$ & \\
\hline Fig. 29 & Ikh Argalatyn Nuruu & IKH-B & IKH-B/5 & & $\mathrm{C} 1$ \\
\hline
\end{tabular}

Later, in the field seasons 2006, 2011, and 2012, fossils were collected from the surface at three locations (LUS027, LUS-028, and LUS-029; Fig. 4). So far, no geological section has been studied in detail. In Luuny Yas, the red-brown sandy silts of the Loh Fm. are topped by basalt
III. At LUS-029, fossil concentrations are visible on top of a caliche layer. From this site, a test sample (sample LUS-078/ 500 kg) was investigated. The lower Miocene and letter zone D are indicated by the small mammals (composite fossil list below).

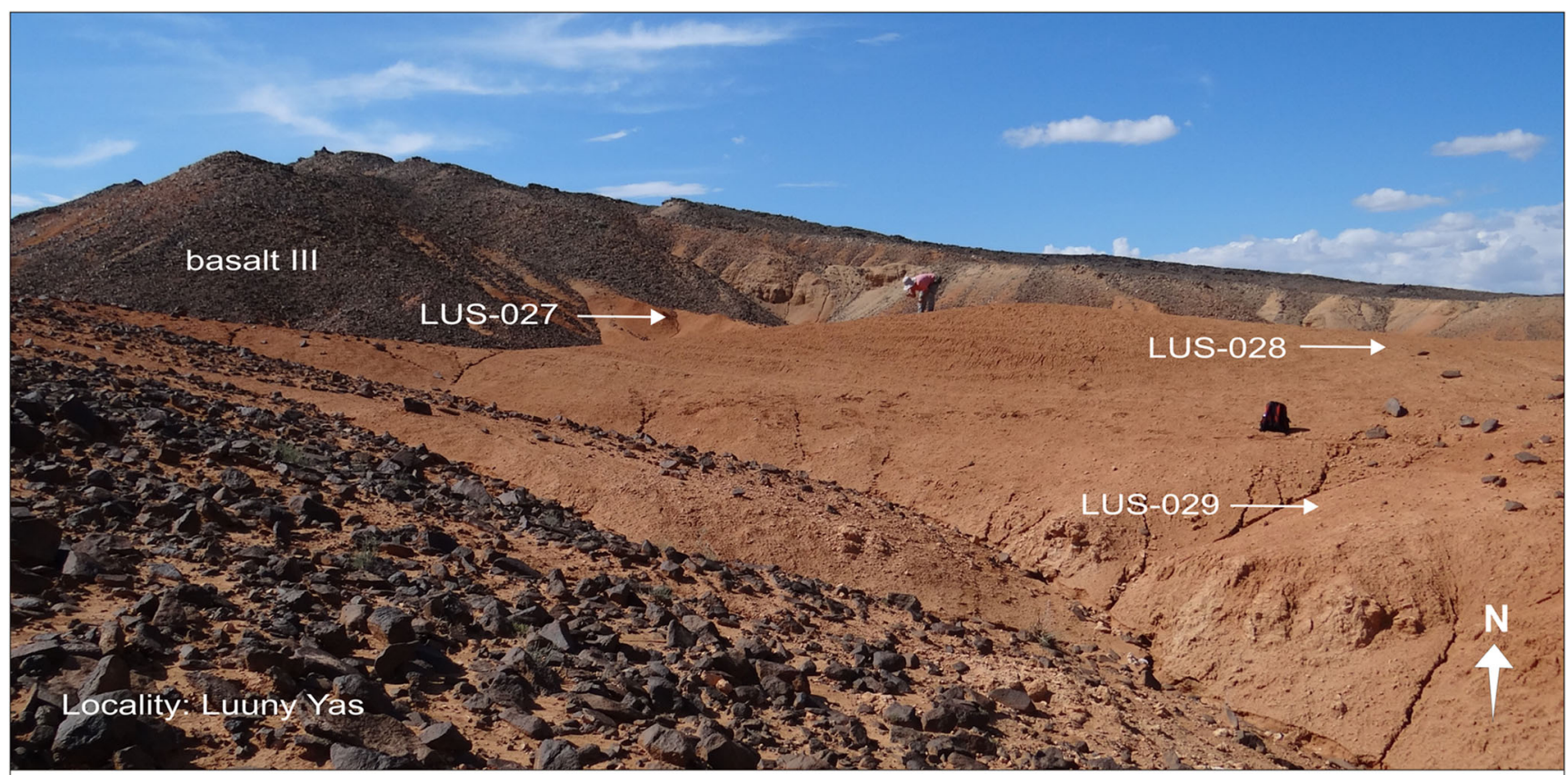

Composite fossil list of samples LUS-027, $-028,-029,-078$ :

Lagomorpha

Sinolagomys ulungurensis Tong, 1989

Sinolagomys gracilis Bohlin, 1943

Sinolagomys sp.

Amphilagus magnus Erbajeva, 2013

Amphilagus orientalis Erbajeva, 2013

Bellatona cf. kazakhstanica Erbajeva, 1988

Amphilagus complicidens nov. spec.
Eulipotyphla Amphechinus aff. taatsiingolensis Ziegler et al., 2007

Rodentia

Asianeomys dangheensis (Wang, 2002)

Plesiosminthus sp.

Tachyoryctoides kokonorensis Li \& Qiu, 1980

Fig. 4 The locality name Luuny Yas means "dragon bone". Arrows mark the fossil points LUS-027, LUS-028, and LUS-029 (= LUS-078) 


\section{Locality Luugar Khudag}

Sample: $L O G-A / 1$

Luugar Khudag is located in the northwestern part of the study area (Fig. 3b). The palaeontological sample LOG-A/1 ( $\sim 500 \mathrm{~kg}$ brick-red sandy silt of the Loh Fm.) was taken close to a well in the dry river bed (Fig. 5). The lower Miocene is indicated by characteristic fossils of letter zone D.

\section{Locality Abzag Ovo}

Section: ABO-A; samples: ABO-A/3,-083

Abzag Ovo and the section ABO-A are located $\sim 30 \mathrm{~km}$ northwest of the Taatsiin Gol (Fig. 3c). At Abzag Ovo, the red silty claystone of the Hsanda Gol Fm. is up to $10 \mathrm{~m}$ thick. It is topped by a $1-5-\mathrm{m}$-thick basalt II, which was dated at $27.0 \pm 0.9 \mathrm{Ma}\left({ }^{40} \mathrm{Ar} /{ }^{39} \mathrm{Ar}\right.$ age $)$. The palaeontological samples ABO-A/3 ( 500 kg sampled 1997) and ABO-083 ( 500 kg sampled 1997 and 2011) were taken 1-2 m below basalt II (Fig. 6). The two samples yield identical fossils. Basalt II and the small mammal assemblage indicate a late Oligocene age and letter zone C. Abzag Ovo is one of the rare assemblages yielding land gastropods.

\section{Locality Toglorhoi}

Section: TGW-A; samples: TGW-A/1-5

The locality Toglorhoi is located in the Khunug Valley, west of the Taatsiin Gol region (Fig. 3d). The section comprises $\sim 7$ m of red-brown sediments of the Hsanda Gol Fm. (Fig. 7). Fossil concentrations are mostly bound to caliche layers and caliche nodules. The colour of the silty clay grades from red-brown (TGW-A/1) to dark red-brown in its higher part (TGW-A/5). Bulk samples of several tons were investigated from all horizons with visible fossil content (TGW-A/1-5). Samples TGW-A/1, TGW-A/2a, and TGW-A/2b yield index fossils of letter zone $\mathrm{C}$. The prevailing fossils of samples TGW-A/3, TGW-A/4, and TGW$\mathrm{A} / 5$ from the higher part of the section are Tsaganomys and the large ctenodactylid Yindirtemys deflexus; the latter is an excellent marker of letter zone C1 (Table 4). The entire sequence is of late Oligocene age.

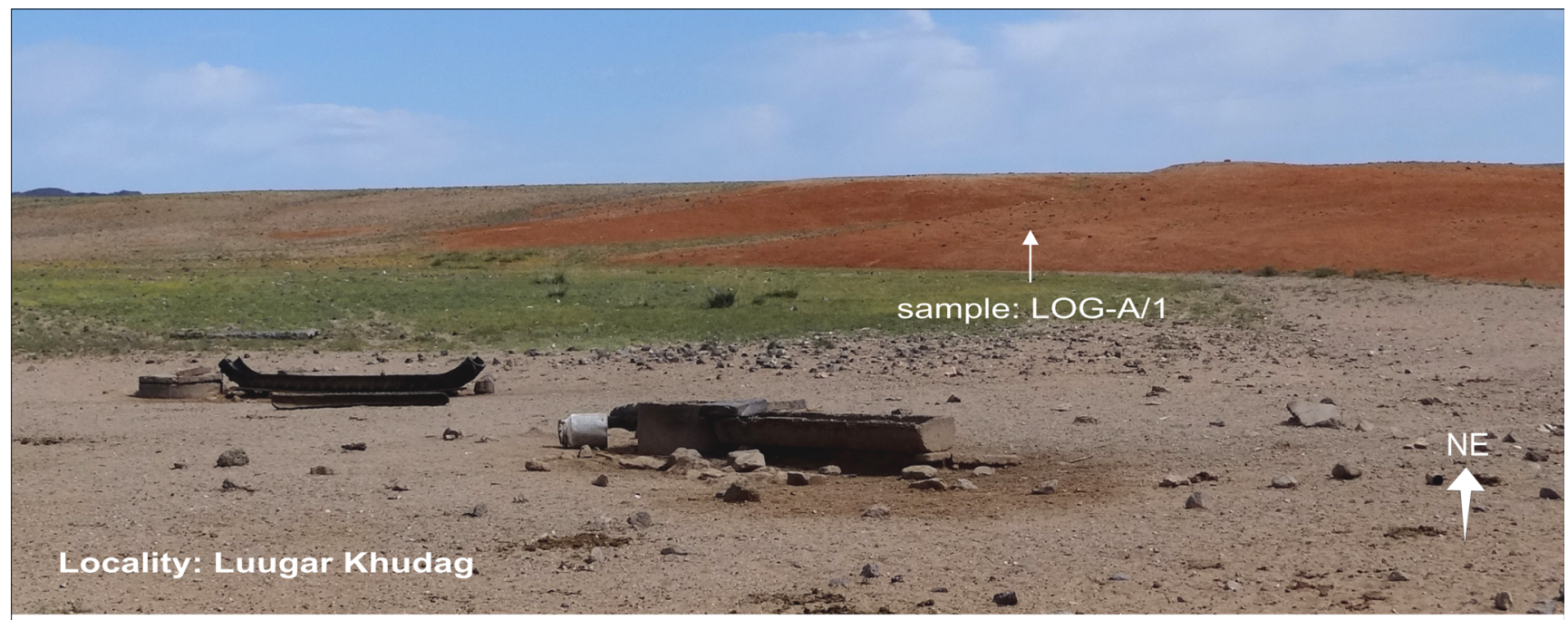

Fossil list of sample LOG-A/1:

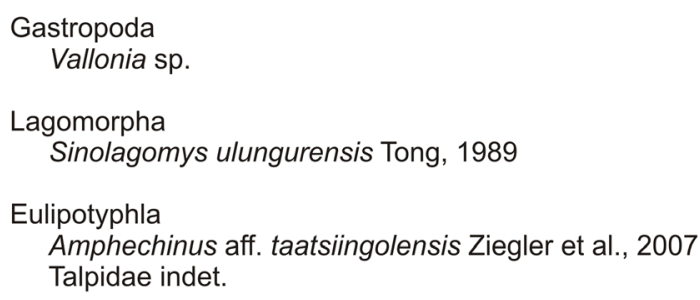

Rodentia

Prodistylomys nov. spec. 2

Plesiosminthus barsboldi Daxner-Höck \& Wu, 2003

Litodonomys lajeensis (Li \& Qiu, 1980)

Ayakozomys sp.

Fig. 5 Sample point LOG-A/1 from the locality Luugar Khudag, Valley of Lakes 


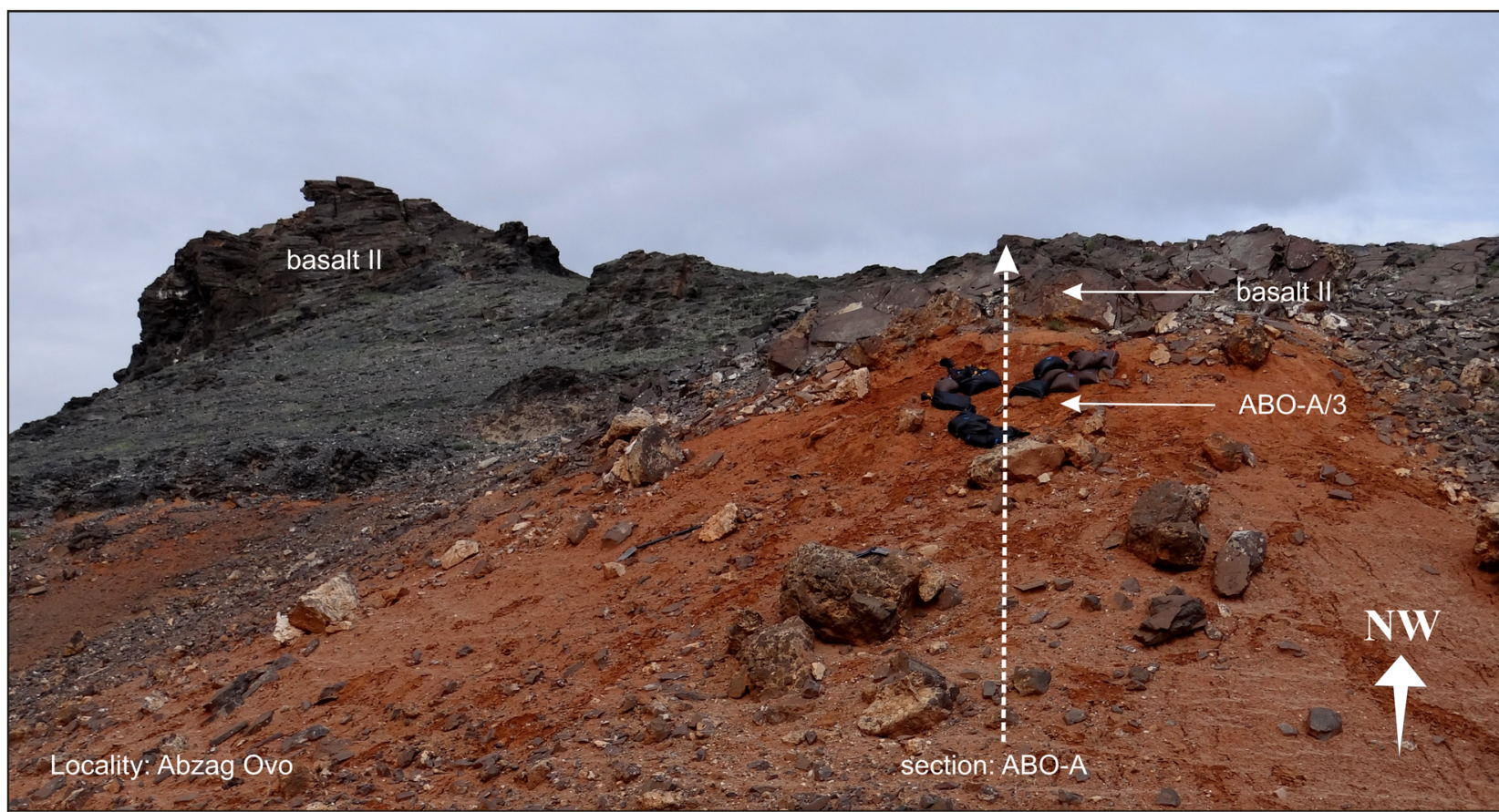

\section{Abzag Ovo Section: ABO-A}

Format. $\mathrm{m}$ layer lithology
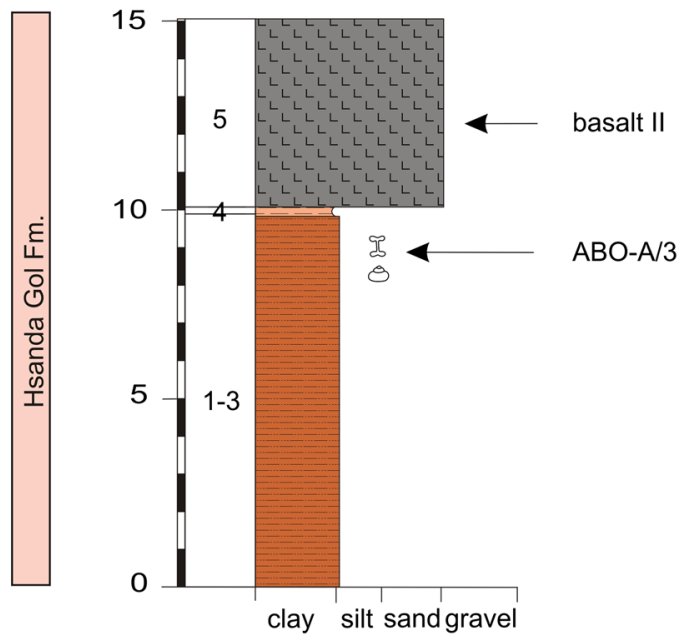

Composite fossil list of samples $A B O-A / 3$ and $A B O-083$ :

Gastropoda

Pupoides steklovi Prysjazhnjuk et al., 1975

Vallonia stworzewiczae Neubauer et al., 2013

Vallonia tumida Stworzewicz, 2007

Vertigo cf. bicolumellata Steklov \& Tsytovich, 1967

Gastrocopta devjatkini Prysjazhnjuk et al., 1975

Gastrocopta cf. mongolica Prysjazhnjuk et al., 1975

Gastrocopta shandgolica Prysjazhnjuk et al., 1975

Gastrocopta tuvaense Steklov, 1967

Lagomorpha

Desmatolagus gobiensis Matthew \& Granger, 1923

Desmatolagus cf. simplex (Argyropulo, 1940)
GPS: ABO-A/1

N $45^{\circ} 34^{\prime} 25.4^{\prime \prime}$

E $101^{\circ} 03^{\prime} 49.7^{\prime \prime}$

\section{Description of section ABO-A:}

layer

5) $100-500 \mathrm{~cm}$

grey basalt II $(27.0+/-0.9 \mathrm{Ma})$.

4) $10 \mathrm{~cm}$ :

rose laminated clay.

1-3) $1000 \mathrm{~cm}$ :

red-brown silty claystone; sample $\mathrm{ABO}-\mathrm{A} / 3$ about $150 \mathrm{~cm}$ below basalt II; mammal fossils indicate letter zone C.

\begin{tabular}{|c|c|c|}
\hline \multicolumn{3}{|l|}{ Legend: } \\
\hline$L_{L}^{L} L^{-}{ }^{-}$basalt & $\theta$ & gastropoda \\
\hline $\begin{array}{l}=\text { clay } \\
=\text { silty clay }\end{array}$ & Th & small mammals \\
\hline
\end{tabular}

Desmatolagus sp.

\section{Eulipotyphla}

Amphechinus taatsiingolensis Ziegler et al., 2007

Rodentia

Yindirtemys shevyrevae Vianey-Liaud et al., 2006

Tatataromys minor longidens Schmidt-Kittler et al., 2007

Heosminthus chimidae Daxner-Höck et al., 2014

Bohlinosminthus parvulus (Bohlin, 1946)

Eocricetodon cf. meridionalis (Wang \& Meng, 1986)

Eucricetodon bagus Gomes Rodrigues et al., 2012

Bagacricetodon tongi Gomes Rodrigues et al., 2012 Cricetidae indet.

Fig. 6 In Abzag Ovo, the samples ABO-A/3 and ABO-083 were taken from red silty claystone $1-2 \mathrm{~m}$ below the late Oligocene basalt II 
Table 4 Fossil list from the locality Toglorhoi (section-TGW-A, samples-TGW-A/1, TGW-A/2a+2b, TGW-A/3+4, TGW-A/5) [the age of the assemblages is late Oligocene (letter zones $\mathrm{C}$ and $\mathrm{C} 1$ )]

\begin{tabular}{llll}
\hline Toglorhoi & TGW-A/1 & TGW-A/2a+b & TGW-A/3+4 \\
Letter zone & C & C & TGW-A/5 \\
\hline
\end{tabular}

Gastropoda

Vallonia sp.

Lagomorpha

Ordolagus cf. teilhardi (Burke, 1941)

Desmatolagus gobiensis Matthew and Granger, 1923

Desmatolagus cf. simplex (Argyropulo, 1940)

Desmatolagus cf. chinensis Erbajeva and Sen, 1998

Desmatolagus cf. orlovi (Gureev, 1960)

Desmatolagus sp.

Bohlinotona cf. pusilla (Teilhard de Chardin, 1926)

Sinolagomys badamae nov. spec. Erbajeva et al. (2017, this issue.)

Sinolagomys kansuensis Bohlin, 1937

Sinolagomys major Bohlin, 1937

Sinolagomys sp.

Eulipotyphla

Zaraalestes minutus (Matthew and Granger, 1924a)

Palaeoscaptor acridens Matthew and Granger, 1924a

Palaeoscaptor gigas (Lopatin, 2002)

Palaeoscaptor tenuis Ziegler et al., 2007

Amphechinus taatsiingolensis Ziegler et al., 2007

Amphechinus minutissimus Ziegler et al., 2007

Amphechinus major Ziegler et al., 2007

Erinaceidae indet.

Talpidae indet.

Crocidosoricidae indet.

Rodentia

Ninamys arboraptus (Shevyreva, 1966)

Proansomys badamae sp. nov. Maridet et al., 2017, this issue

Asianeomys bolligeri (Lopatin, 2000)

Tataromys sigmodon Matthew and Granger, 1923

Tatataromys minor longidens Schmidt-Kittler et al., 2007

Tataromys plicidens Matthew and Granger, 1923

Yindirtemys deflexus (Teilhard de Chardin, 1926)

Cyclomylus intermedius Wang, 2001

Tsaganomyidae indet.

Coelodontomys asiaticus Wang, 2001

Tsaganomys altaicus Matthew and Granger, 1923

Allosminthus minutus (Daxner-Höck, 2001)

Heosminthus sp.

Bohlinosminthus parvulus (Bohlin, 1946)

Parasminthus cf. tangingoli Bohlin, 1946

Eocricetodon meridionalis (Wang and Meng, 1986)

Eucricetodon bagus Gomes Rodrigues et al., 2012

Eucricetodon jilantaiensis Gomes Rodrigues at al., 2012

Cicetidae indet.

Bagacricetodon tongi Gomes Rodrigues et al., 2012

Aralocricetodon schokensis Bendukidze, 1993

$\begin{array}{ccc} & \mathrm{x} & \\ & & \\ & \mathrm{x} & \mathrm{x} \\ & \mathrm{x} & \mathrm{x} \\ & \mathrm{x} & \\ & \mathrm{x} & \mathrm{x} \\ \mathrm{x} & \mathrm{x} & \\ \mathrm{x} & \mathrm{x} & \\ & \mathrm{x} & \mathrm{x}\end{array}$

$\mathrm{X}$

X

$\mathrm{X}$

$\mathrm{X}$

$\mathrm{X}$

X

$\mathrm{X}$

X 
Table 4 (continued)

\begin{tabular}{|c|c|c|c|c|}
\hline $\begin{array}{l}\text { Toglorhoi } \\
\text { Letter zone }\end{array}$ & $\begin{array}{l}\text { TGW-A/1 } \\
\text { C }\end{array}$ & $\begin{array}{l}\text { TGW-A/2a+b } \\
\text { C }\end{array}$ & $\begin{array}{l}\text { TGW-A/3+4 } \\
\text { C1 }\end{array}$ & $\begin{array}{l}\text { TGW-A/5 } \\
\mathrm{C} 1\end{array}$ \\
\hline Argyromys nov. spec. López-Guerrero et al. (in prep) & & $\mathrm{x}$ & & \\
\hline Tachyoryctoides bayarmae Daxner-Höck et al., 2015 & & & $\mathrm{x}$ & \\
\hline Tachyoryctoides radnai Daxner-Höck et al., 2015 & & & $\mathrm{x}$ & \\
\hline \multicolumn{5}{|l|}{ Leptictida } \\
\hline Didymoconidae indet. & & & $\mathrm{x}$ & \\
\hline \multicolumn{5}{|l|}{ Carnivora } \\
\hline Asiavorator altidens Spassov and Lange-Badré, 1995 & & & & $\mathrm{x}$ \\
\hline \multicolumn{5}{|l|}{ Ruminantia } \\
\hline Paragelocus aff. scotti Schlosser, 1902 & $\mathrm{x}$ & & & \\
\hline Bovidae gen. 1 & & $\mathrm{x}$ & & \\
\hline Ruminantia indet. & $\mathrm{x}$ & & & \\
\hline
\end{tabular}

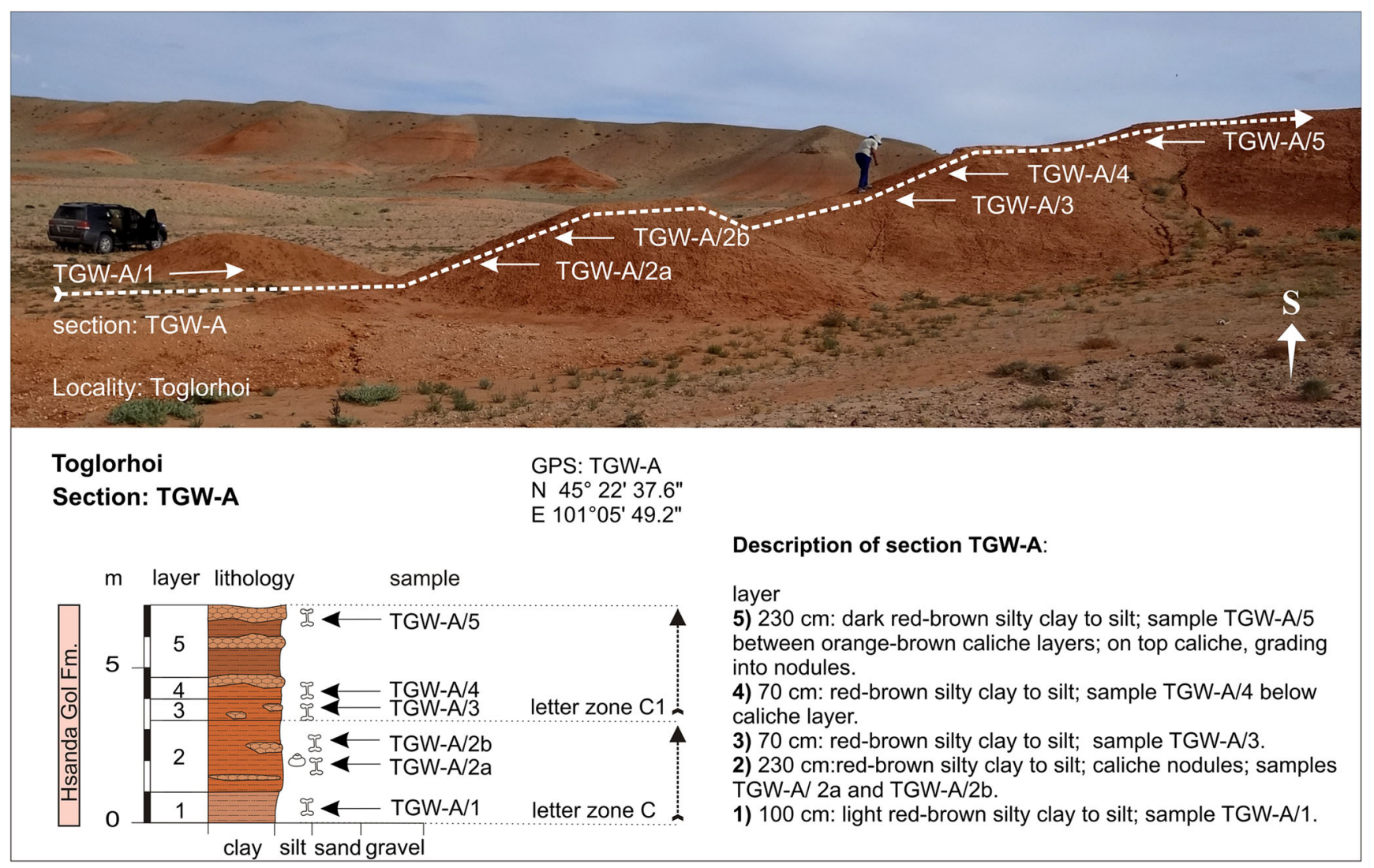

Fig. 7 Section TGW-A from the locality Toglorhoi is located in the Khunug Valley, west of the Taatsiin Gol region 


\section{Locality Khongil}

Samples: HL-A/1 and HL-A/2

Khongil is located at the NW corner of the Taatsiin plateau at the orographic right side of Taatsiin Gol (Fig. 3e). There, several metres of brick-red clay of the Hsanda Gol Fm. are exposed immediately below basalt I. The mammal fauna stems from two test samples HL-A/1 and HL-A/2 (for location, see Fig. 8). The early Oligocene age is indicated by basalt I and by respective fossils.

\section{Locality Huch Teeg}

Section: RHN-A; samples: RHN-A/6-12, RHN-019-023

Huch Teeg is located at the orographic right side of Taatsiin Gol, north of the western Taatsiin plateau (Fig. 3f). The direction of section RHN-A is $\mathrm{N} \rightarrow \mathrm{S}$ (Fig. 9). There, sediments of the Tsagan Ovo and Loh Fms. are exposed; the Hsanda Gol Fm. is missing. The present study does not consider the Tsagan Ovo Fm. from the northernmost part of the section. The fossil-bearing strata of the Loh Fm. (RHN-A/6-10) dip toward south. The southernmost part of the section (samples-RHN-A/11-12) is horizontally bedded and built up of light rose-brown to red-brown sandy silt.

The tilted northern part of the section (samples RHN-A/6-10, RHN-019, and RHN-023 of the Loh $\mathrm{Fm}$.) yields fossils of letter zone $\mathrm{C} 1$, indicating the late Oligocene age. The horizontally bedded southern part (samples RHN-A/11 and RHN-021-22) starts with fossils of letter zone C1-D and ends with fossils of letter zone D (samples RHN-A/12 and RHN-020), indicating an early Miocene age (Table 5). There, concentrations of manganese precipitates and nodule are evident.

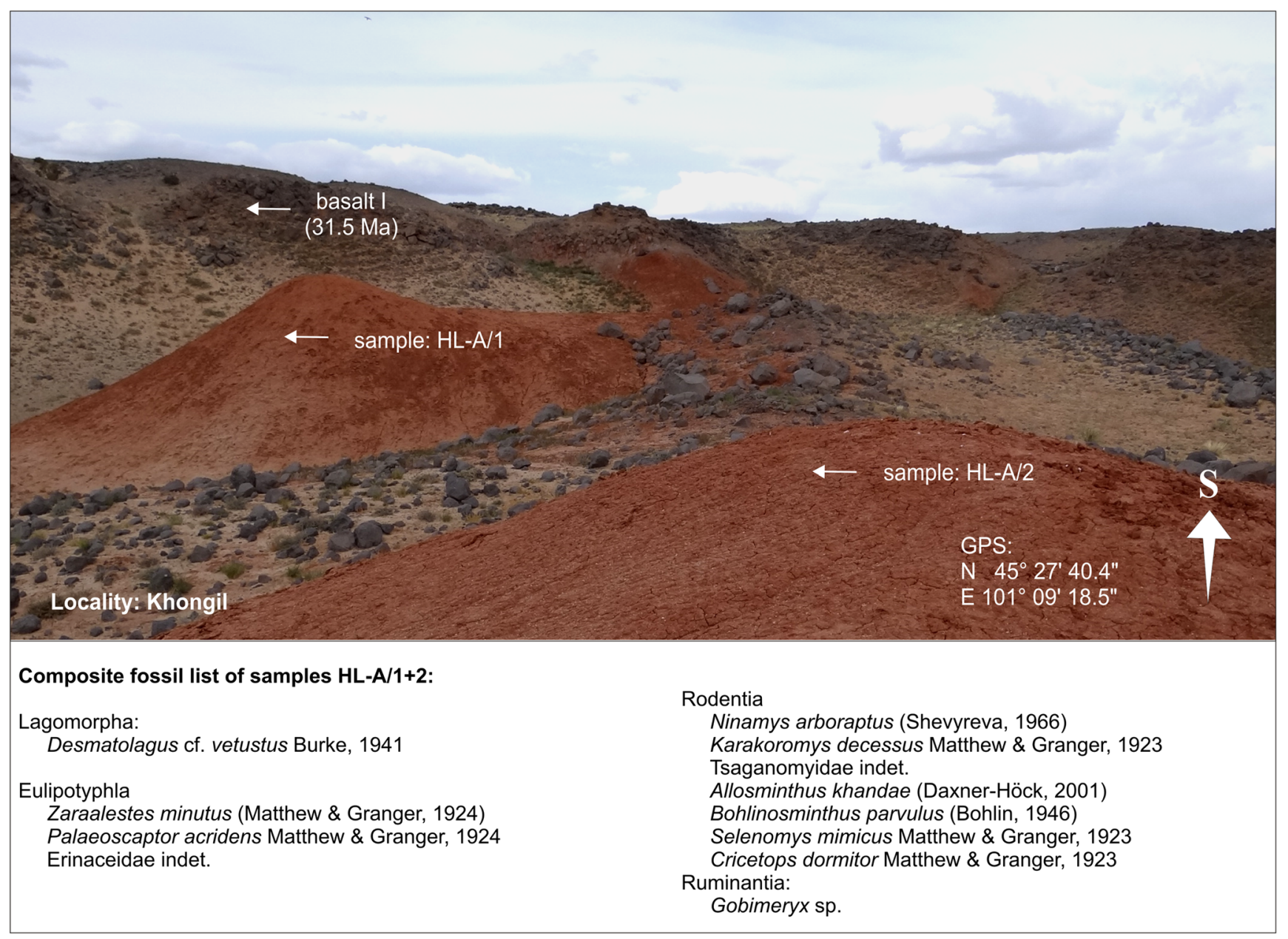

Fig. 8 Khongil is located at the NW corner of the plateau at the orographic right side of Taatsiin Gol. Arrows mark two sample points HL-A/1 and HL-A/ 2 below the early Oligocene basalt I 


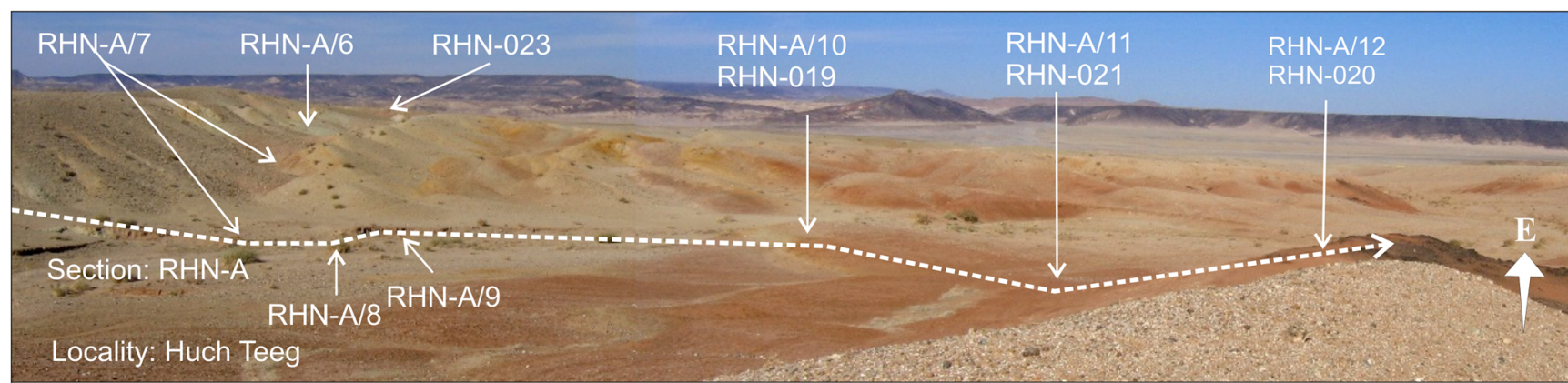

\section{Huch Teeg}

\section{Section: RHN-A}

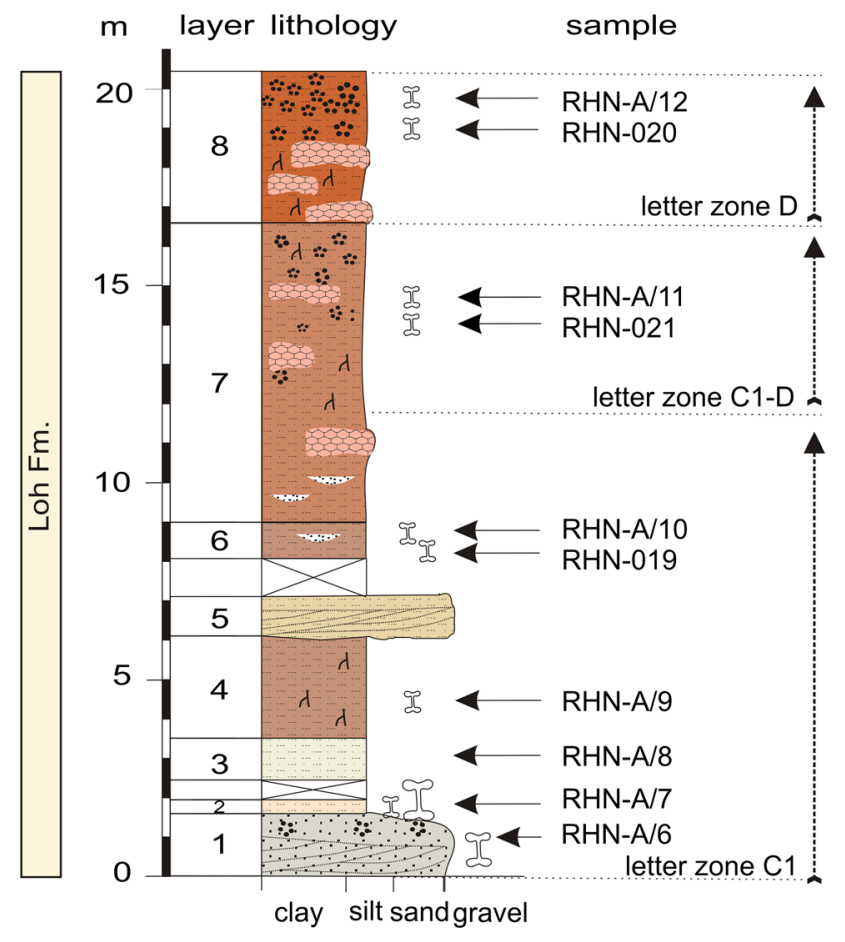

GPS: RHN-A/12

N $45^{\circ} 29^{\prime} 29.9^{\prime \prime}$

E $101^{\circ} 12^{\prime} 17.1^{\prime \prime}$

\section{Description of section RHN-A:}

layer

8) $400 \mathrm{~cm}$ : red-brown sandy silt with abundant manganese precipitates and nodules; samples $\mathrm{RHN}-\mathrm{A} / 12$ and $\mathrm{RHN}-020$.

7) $800 \mathrm{~cm}$ : red-brown sandy silt with manganese nodules, precipitates; samples RHN-A/11 and RHN-021.

6) $100 \mathrm{~cm}$ :light brown sandy silt with sand lenses; samples $\mathrm{RHN}-\mathrm{A} / 10$ and RHN-019.

5) $100 \mathrm{~cm}$ : yellow-green, gravelly cross-bedded sand.

4) $250 \mathrm{~cm}$ : greenish-brown sandy silt; sample RHN-A/9.

3) $110 \mathrm{~cm}$ : yellow sandy silt; sample RHN-A/8 and jaw of Aceratherium.

2) $30 \mathrm{~cm}$ : beige brown sandy silt; sample $R H N-A / 7$ and Elasmotheriini bones.

1) $170 \mathrm{~cm}$ : grey-green gravelly sand; cross-bedded with basalt gravels; manganese precipitates; sample $\mathrm{RHN}-\mathrm{A} / 6$ and bones of Praceratherium and Benaratherium.

\begin{tabular}{|c|c|c|c|c|c|}
\hline \multicolumn{2}{|c|}{ Legend: } & 20 & cross bedding & $n_{*=0}^{n}=$ & manganese \\
\hline$\therefore=$ & sandy silt, silt & $\rightleftarrows$ & sand lense & & \\
\hline$\because \because \because \because$ & fine sand & $y y y$ & rootlets & & small mammals \\
\hline$\therefore \therefore \therefore$ & coarse sand & $\Rightarrow \Rightarrow$ & caliche nodules & 25 & large mammals \\
\hline
\end{tabular}

Fig. 9 Huch Teeg is located at the orographic right side of Taatsiin Gol, north of the western Taatsiin plateau. Description of the section RHN-A modified from Schmid (1999; Abb. A5) and Daxner-Höck et al. (2013, Fig. 20.2) 
Table 5 Fossil list from Huch Teeg (section-RHN-A, samples-RHN-A/6-12, RHN-019-022) [the age of the assemblages is late Oligocene (letter zones C1 and C1-D) to early Miocene (letter zone D)]

\begin{tabular}{|c|c|c|c|c|c|c|c|c|}
\hline Letter zone & $\begin{array}{l}\text { RHN-A/6 } \\
\text { C1 }\end{array}$ & RHN-A/7 & RHN-023 & RHN-A/8 & RHN-A/9 & $\begin{array}{l}\text { RHN-A/10, } \\
\text { RHN-019 } \\
\text { C1 }\end{array}$ & $\begin{array}{l}\text { RHN-A/11, } \\
\text { RHN-021+ } \\
022 \\
\text { C1-D }\end{array}$ & $\begin{array}{l}\text { RHN-A/12, } \\
\text { RHN-020 } \\
\text { D }\end{array}$ \\
\hline \multicolumn{9}{|l|}{ Lagomorpha } \\
\hline $\begin{array}{l}\text { Desmatolagus gobiensis Matthew and } \\
\text { Granger, } 1923\end{array}$ & & $\mathrm{x}$ & & & & & & \\
\hline $\begin{array}{l}\text { Desmatolagus robustus Matthew and } \\
\text { Granger, } 1923\end{array}$ & & & & & $\mathrm{x}$ & & & \\
\hline $\begin{array}{l}\text { Desmatolagus } \text { cf. chinensis } \\
\text { Erbajeva and Sen, } 1998\end{array}$ & & $\mathrm{x}$ & & & & & & \\
\hline $\begin{array}{l}\text { Bohlinotona } \mathrm{cf} \text {. pusilla (Teilhard de } \\
\text { Chardin, 1926) }\end{array}$ & & & & & $\mathrm{x}$ & & & \\
\hline Sinolagomys kansuensis Bohlin, 1937 & & & $\mathrm{x}$ & & $\mathrm{x}$ & $\mathrm{x}$ & $\mathrm{x}$ & $\mathrm{x}$ \\
\hline Sinolagomys major Bohlin, 1937 & & & $\mathrm{x}$ & & & $\mathrm{x}$ & $\mathrm{x}$ & \\
\hline Sinolagomys ulungurensis Tong, 1989 & & & & & & $\mathrm{x}$ & & $\mathrm{x}$ \\
\hline Sinolagomys sp. & & $\mathrm{x}$ & & & $\mathrm{x}$ & $\mathrm{x}$ & $\mathrm{x}$ & \\
\hline Amphilagus magnus Erbajeva, 2013 & & & & & & & $\mathrm{x}$ & $\mathrm{x}$ \\
\hline \multicolumn{9}{|l|}{ Eulipotyphla } \\
\hline $\begin{array}{l}\text { Palaeoscaptor } \text { cf. rectus Matthew and } \\
\text { Granger, 1924a } \\
\text { Palaeoscaptor tenuis Ziegler et al., } 2007\end{array}$ & & $\mathrm{x}$ & $\mathrm{x}$ & & & & & $\mathrm{x}$ \\
\hline $\begin{array}{l}\text { Amphechinus taatsiingolensis Ziegler } \\
\text { et al., } 2007\end{array}$ & & & & & & $\mathrm{x}$ & & $\mathrm{x}$ \\
\hline $\begin{array}{l}\text { Amphechinus minutissimus Ziegler } \\
\text { et al., } 2007\end{array}$ & & $\mathrm{x}$ & & & $\mathrm{x}$ & $\mathrm{x}$ & & \\
\hline Amphechinus major Ziegler et al., 2007 & & $\mathrm{x}$ & $\mathrm{x}$ & & $\mathrm{x}$ & $\mathrm{x}$ & & \\
\hline $\begin{array}{l}\text { Amphechinus aff. taatsiingolensis Ziegler } \\
\text { et al., } 2007\end{array}$ & & & & & & & & $\mathrm{x}$ \\
\hline Tavoonyia altaica Ziegler et al., 2007 & & & & & $\mathrm{x}$ & & & \\
\hline Heterosoricinae indet. & & $\mathrm{x}$ & & & & & & \\
\hline \multicolumn{9}{|l|}{ Rodentia } \\
\hline $\begin{array}{l}\text { Proansomys badamae sp. nov. Maridet } \\
\text { et al. (2017, this issue) }\end{array}$ & & $\mathrm{x}$ & & & & & & \\
\hline Ansomys sp. 1 & & & & & & & & $\mathrm{x}$ \\
\hline $\begin{array}{l}\text { Yindirtemys deflexus (Teilhard de } \\
\text { Chardin, 1926) } \\
\text { Prodistylomys nov. spec. } 2 \text { Oliver et al. (in prep) }\end{array}$ & & $\mathrm{x}$ & $\mathrm{x}$ & & & & & $\mathrm{x}$ \\
\hline $\begin{array}{l}\text { Tsaganomys altaicus } \text { Matthew and } \\
\text { Granger, } 1923\end{array}$ & & $\mathrm{x}$ & & & & & & \\
\hline $\begin{array}{l}\text { Heosminthus borrae Daxner-Höck } \\
\text { et al., } 2014\end{array}$ & & & & & & & & $\mathrm{x}$ \\
\hline $\begin{array}{l}\text { Bohlinosminthus parvulus (Bohlin, } \\
\text { 1946) } \\
\text { Parasminthus debruijni Lopatin, } 1999\end{array}$ & & $\mathrm{x}$ & $\mathrm{x}$ & & $\mathrm{x}$ & & & \\
\hline $\begin{array}{l}\text { Plesiosminthus asiaticus Daxner-Höck and } \\
\text { Wu, } 2003\end{array}$ & & $\mathrm{x}$ & $\mathrm{x}$ & & & & & \\
\hline Plesiosminthus promyarion Schaub, 1930 & & & & & $\mathrm{x}$ & $\mathrm{x}$ & & \\
\hline $\begin{array}{l}\text { Plesiosminthus olzi Daxner-Höck } \\
\text { et al., } 2014\end{array}$ & & & & & & & & $\mathrm{x}$ \\
\hline $\begin{array}{l}\text { Plesiosminthus barsboldi Daxner-Höck and } \\
\mathrm{Wu}, 2003\end{array}$ & & & & & & & & $\mathrm{x}$ \\
\hline Litodonomys lajeensis (Li and Qiu, 1980) & & & & & & & & $\mathrm{x}$ \\
\hline $\begin{array}{l}\text { Heterosminthus firmus Zazhigin and } \\
\text { Lopatin, } 2000\end{array}$ & & $\mathrm{x}$ & & & $\mathrm{x}$ & $\mathrm{x}$ & & $\mathrm{x}$ \\
\hline & & & $\mathrm{x}$ & & & & $\mathrm{x}$ & \\
\hline
\end{tabular}


Table 5 (continued)

\begin{tabular}{|c|c|c|c|c|c|c|c|c|}
\hline Huch Teeg & RHN-A/6 & RHN-A/7 & RHN-023 & RHN-A/8 & RHN-A/9 & $\begin{array}{l}\text { RHN-A/10, } \\
\text { RHN-019 }\end{array}$ & $\begin{array}{l}\text { RHN-A/11, } \\
\text { RHN-021+ } \\
022\end{array}$ & $\begin{array}{l}\text { RHN-A/12, } \\
\text { RHN-020 }\end{array}$ \\
\hline Letter zone & $\mathrm{C} 1$ & $\mathrm{C} 1$ & $\mathrm{C} 1$ & $\mathrm{C} 1$ & $\mathrm{C} 1$ & $\mathrm{C} 1$ & C1-D & $\mathrm{D}$ \\
\hline $\begin{array}{l}\text { Heterosminthus cf. lanzhouensis } \\
\text { Wang and Qiu, } 2000\end{array}$ & \multicolumn{8}{|c|}{ Heterosminthus cf. lanzhouensis } \\
\hline $\begin{array}{l}\text { Primus sp. } \\
\text { Tachyoryctoides sp. }\end{array}$ & & & & & & & $\mathrm{x}$ & $\mathrm{X}$ \\
\hline \multicolumn{9}{|l|}{ Leptictida } \\
\hline $\begin{array}{l}\text { Didymoconus berkey Matthew and } \\
\text { Granger, } 1924 \mathrm{~b} \\
\text { Didymoconidae indet. }\end{array}$ & & $\mathrm{x}$ & $\mathrm{x}$ & & & & & \\
\hline \multicolumn{9}{|l|}{ Perissodactyla } \\
\hline Paraceratherium sp. & $\mathrm{x}$ & & & & & & & \\
\hline cf. Benaratherium sp. & $\mathrm{x}$ & & & & & & & \\
\hline $\begin{array}{l}\text { Aceratherium (Alicornops) } \\
\text { cf. pauliacense } \\
\text { (Richard, 1937) } \\
\text { Elasmotheriini indet. }\end{array}$ & & $\mathrm{x}$ & & $\mathrm{x}$ & & & & \\
\hline Rhinocerotidae indet. & & & & & & & & $\mathrm{x}$ \\
\hline \multicolumn{9}{|l|}{ Ruminantia } \\
\hline Ruminantia indet. & & & & & $\mathrm{x}$ & $\mathrm{x}$ & & \\
\hline
\end{tabular}

\section{Locality Hotuliin Teeg}

Sections HTE; samples: HTE-003-018 (Fig. 11b, c), HTE-057 (Figs. 10 and 11d); HTSE-009, HTSE-013 (Fig. 11f); HTS-056/1-3 (Fig. 11e)

The Hotuliin Teeg section (HTE) and additional fossil points (HTSE and HTS) are located north of the western Taatsiin plateau (Fig. 3g). The area is flat and comprises no more than $23 \mathrm{~m}$ of sediment. The section HTE (Figs. 10 and 11a) was studied along of a dry creek. In the lower part, several layers of strongly weathered basalt alternate with silty-sandy claystone. On top of this first sequence (Fig. 11d, g), the late Oligocene is indicated by fossils of letter zone $\mathrm{C} 1$.

Upsection, alternating beds of calichized basalt and silty clay continue. The colour changes into light brown. The claystone ultimately grades into thick white chalky caliche, which is topped by badly sorted coarse sand and gravels (Fig. 11c). The boundary horizon between the caliche and gravely sand shows significant fossil concentrations (samples HTE-014-018 from the south bank of the dry creek, Figs. 10 and 11c). Upsection, similar fossil traps were found between sand-silt layers/lenses and caliche beds. The fossils indicate letter zone $\mathrm{D}$ and the lower Miocene. The top layer of the HTE-section is built up by $2-3 \mathrm{~m}$ of beige sand and gravel, which yield fossil bones of the rhinos cf. Hoploaceratherium gobiense and cf. Caementodon sp. (Fig. 11b; Table 6).

Five samples from a neighbouring dry creek yield fossils of letter zone $\mathrm{C} 1$ and letter zone C1-D. These are the samples HTSE-009 and HTSE-013 (Fig. 11f) south-east, and the samples HTS-056/1-3 (Fig. 11e) south of the Hotuliin Teeg creek. Sample HTSE-009 consists of red clay above a white-green caliche layer. On top, basalt pebbles are exposed. Sample HTSE-013 was collected between rose and white caliche layers. Both samples yield fossils of letter zone C1 (Table 7), indicating the late Oligocene. Following the dry river westward leads to the fossil points HTS-056/1+2 and HTS-056/3, which yield fossils of letter zone C1-D and indicate the uppermost Oligocene. 


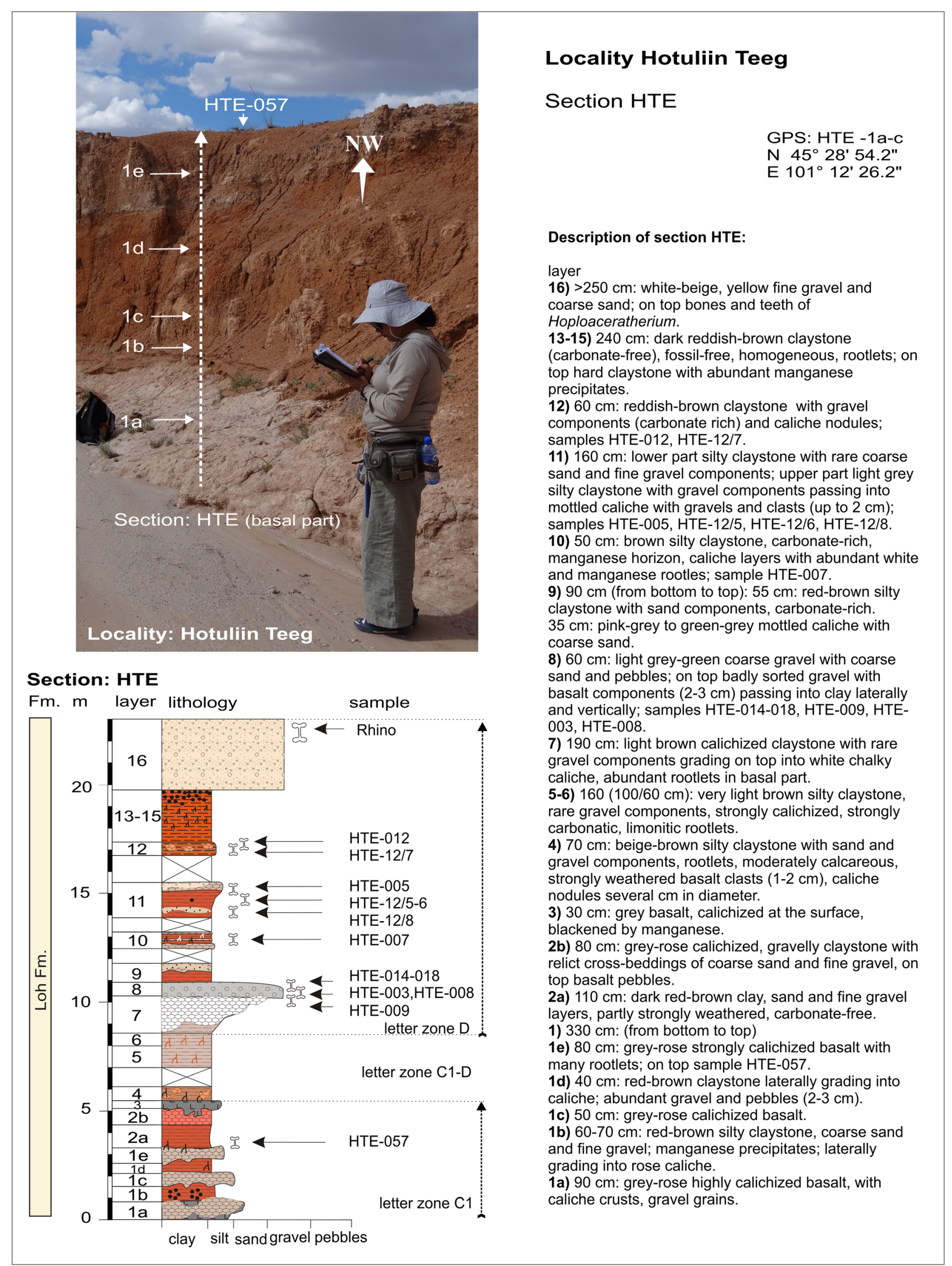

Fig. 10 The Hotuliin Teeg section is located west of the Taatsiin Gol, in a wide NW-SE striking valley north of the main Taatsiin plateau (western plateau). The picture shows the lowermost, the late Oligocene part of the section 
Table 6 Fossils from Hotuliin Teeg (section-HTE, samples-HTE-003-012) [the age of the assemblages is early Miocene (letter zone D)]

Hotuliin Teeg (section HTE)

Letter zone
HTE-009

D

HTE-008+003

D
HTE-014+018
HTE-005+007

$\mathrm{D}$
HTE*

$\mathrm{D}$

HTE-012

Lagomorpha

Desmatolagus gobiensis Matthew and Granger, 1923

Desmatolagus sp.

Sinolagomys kansuensis Bohlin, 1937

Sinolagomys major Bohlin, 1937

Sinolagomys ulungurensis Tong, 1989

Sinolagomys gracilis Bohlin, 1942

Amphilagus magnus Erbajeva, 2013

Amphilagus orientalis Erbajeva, 2013

Bellatona cf. kazakhstanica Erbajeva, 1988

Eulipotyphla

Palaeoscaptor acridens Matthew and Granger, 1924a

Palaeoscaptor cf. rectus Matthew and Granger, 1924a

Palaeoscaptor tenuis Ziegler et al., 2007

Amphechinus taatsiingolensis Ziegler et al., 2007

Amphechinus minutissimus Ziegler et al., 2007

Amphechinus aff. taatsiingolensis Ziegler et al., 2007

Exallerix sp.

Heterosoricinae indet.

Crocidosoricinae indet.

Talpidae indet.

Rodentia

Plesiosciurus aff. sinensis Qiu and Liu, 1986

Kherem shandgoliensis Minjin, 2004

Eutamias sp.

Asianeomys dangheensis (Wang, 2002)

Yindirtemys suni Li \& Qiu, 1980

Prodistylomys sp.

Prodistylomys nov. spec. 1 Oliver et al.

(in prep)

Heosminthus borrae Daxner-Höck et al., 2014

Bohlinosminthus parvulus (Bohlin, 1946)

Plesiosminthus sp.

Plesiosminthus olzi Daxner-Höck et al., 2014

Litodonomys huangheensis Wang \& Qiu, 2000

Litodonomys lajeensis (Li \& Qiu, 1980)

Heterosminthus firmus Zazhigin and Lopatin, 2000

Heterosminthus aff. nanus Zazhigin and Lopatin, 2000

Tachyoryctoides kokonorensis Li and Qiu, 1980

Tachyoryctoides engesseri Wang and Qiu, 2012

Ayakozomys sp.

Carnivora

Carnivora indet.

Perissodactyla

cf. Hoploaceratherium gobiense (Beliajeva, 1960)

cf. Caementodon sp.

Rhinocerotidae indet.

Ruminantia

Ruminantia indet.

$\begin{array}{llll} & & & \\ x & x & x & x \\ x & x & x & x \\ x & x & x & x \\ x & x & & \end{array}$

$\mathrm{x}$

$\mathrm{x}$

$\mathrm{x}$

$\mathrm{x}$

$\mathrm{x} \quad \mathrm{x}$

$\mathrm{x}$

$\mathrm{x}$

$\mathrm{x} \quad \mathrm{x}$

$\mathrm{x} \quad \mathrm{x}$

$\mathrm{x}$

$\mathrm{x}$

$\mathrm{x}$

$\mathrm{x}$

$\mathrm{x}$

$\mathrm{x}$

$\mathrm{x}$

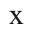

$\mathrm{x}$

$\mathrm{X}$

$\mathrm{X}$

$\mathrm{x}$

$\mathrm{x}$

$\mathrm{X}$

$\mathrm{x}$

$\mathrm{x}$

$\mathrm{x}$

$\mathrm{x}$

$\mathrm{x}$

$\mathrm{x}$

$\mathrm{x}$

$\mathrm{x}$

$\mathrm{x}$

$\mathrm{x}$

$\mathrm{x}$

$\mathrm{x}$

$\mathrm{x}$

$\mathrm{x}$

$\mathrm{x}$

$\mathrm{x}$

$\mathrm{x}$

$\mathrm{x}$

$\mathrm{x}$

$\mathrm{X}$

x $x$

$\mathrm{x}$

$\mathrm{x}$

$\mathrm{x}$

x

$\mathrm{x}$

$\mathrm{X}$

$\mathrm{X}$

$\mathrm{X}$

$\mathrm{X}$

$\mathrm{X}$

X

X

X $\quad \mathrm{X}$

$\mathrm{X}$

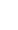

$x$




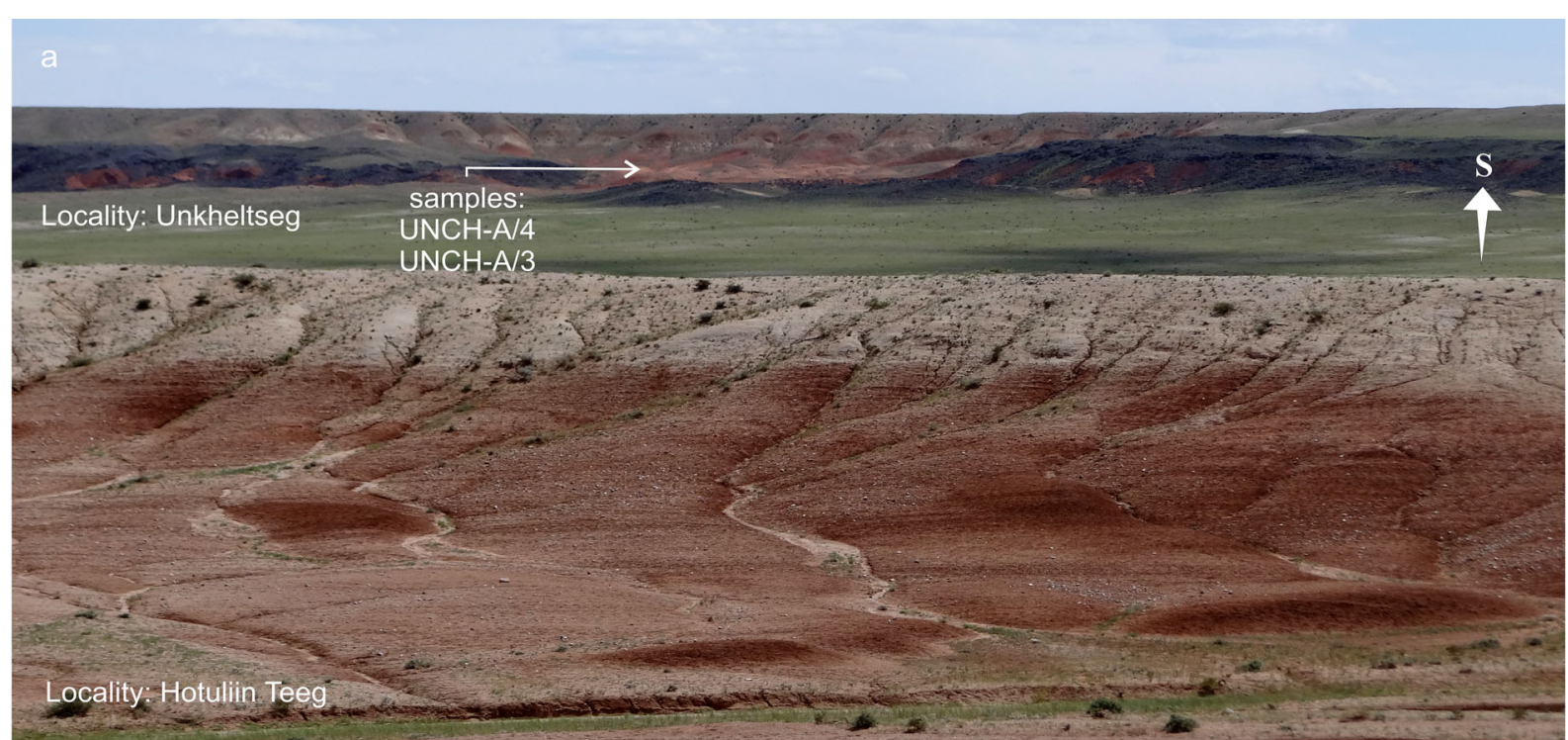

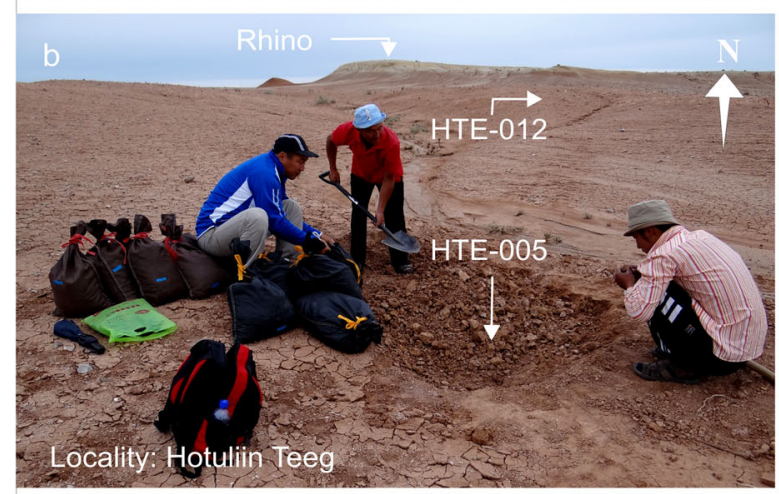
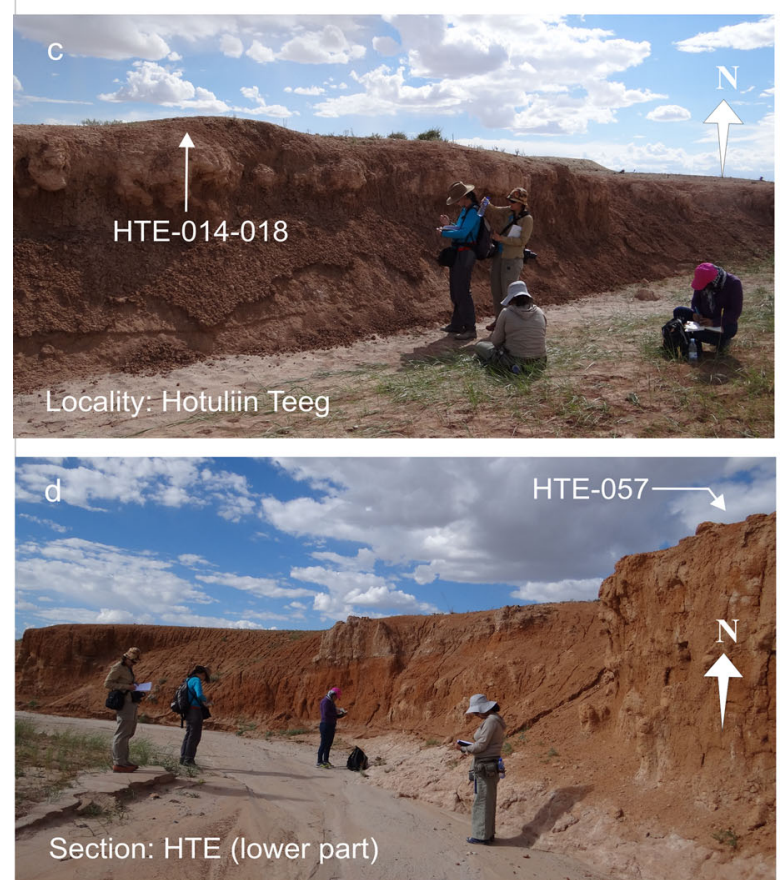

Fig. 11 Localities Hotuliin Teeg and Unkheltseg north of the western Taatsiin plateau. a View in southern direction from Hotuliin Teeg to Unkheltseg at the north rim of the plateau. b Sample place HTE-005 (= HTE-12/5) at the upper part of the HTE-section. c Sample point HTE014-018 in the middle part of the HTE-section. $\mathbf{d}$ Lower part of the HTE-
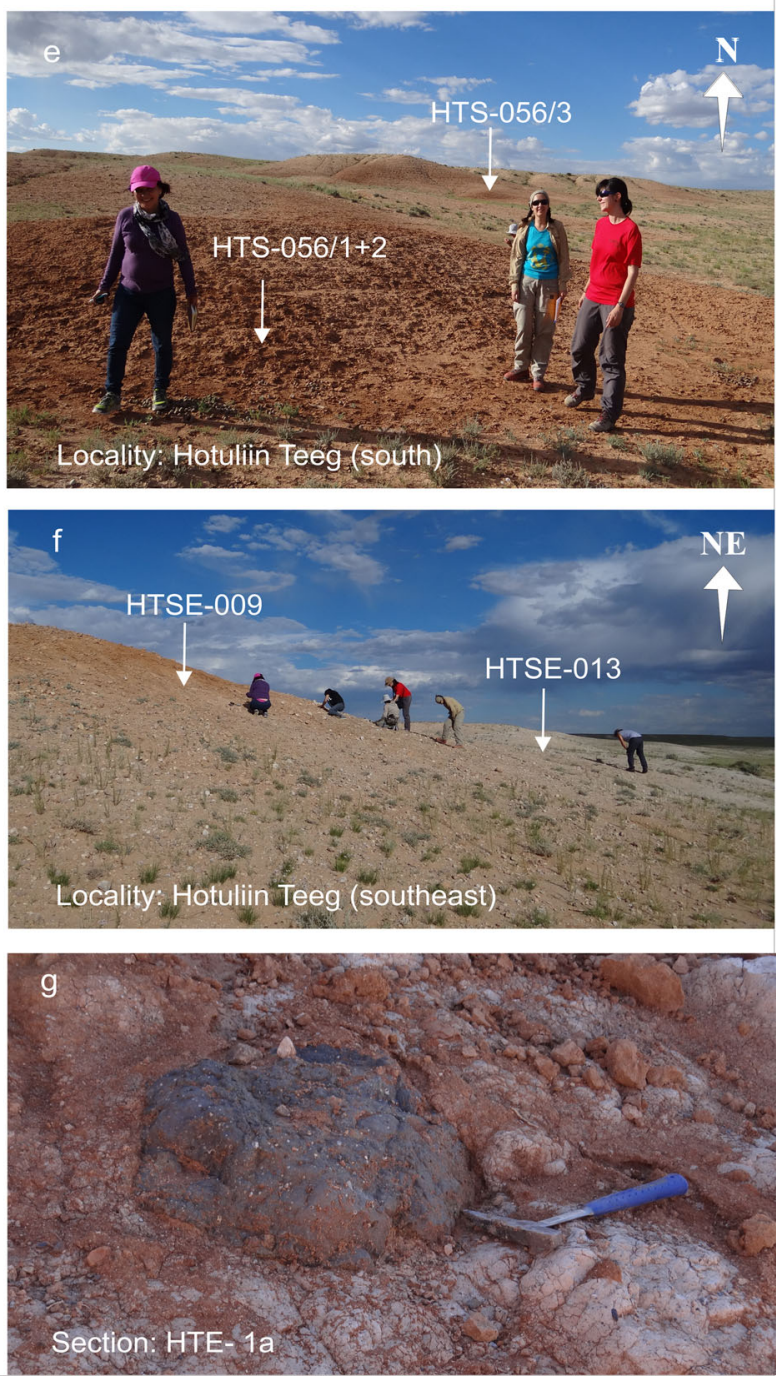

section, showing red silty claystone alternating with calichized basalt, on top sample HTE-057. e HTS-056/1+2 and HTS-056/3. f HTSE-009 and HTSE-013. g Calichized basalt from the lowermost layer of the HTE section 
Table 7 Fossils from Hotuliin Teeg (samples-HTE-057, HTSE-009, HTSE-013, HTS056/1-3) [the age of the assemblages is late Oligocene (letter zones C1 and C1-D)]

\begin{tabular}{|c|c|c|c|}
\hline $\begin{array}{l}\text { Hotuliin Teeg (HTE-057, HTS, HTSE) } \\
\text { Letter zone }\end{array}$ & $\begin{array}{l}\text { HTE-057 } \\
\text { C1 }\end{array}$ & $\begin{array}{l}\text { HTSE-009+013 } \\
\text { C1 }\end{array}$ & $\begin{array}{l}\text { HTS-056/1-3 } \\
\text { C1-D }\end{array}$ \\
\hline \multicolumn{4}{|l|}{ Gastropoda } \\
\hline Pupoides steklovi Prysjazhnjuk et al., 1975 & & & $\mathrm{x}$ \\
\hline Vallonia stworzewiczae Neubauer et al., 2013 & & & $\mathrm{x}$ \\
\hline Vallonia tumida Stworzewicz, 2007 & & & $\mathrm{x}$ \\
\hline Gastrocopta devjatkini Prysjazhnjuk et al., 1975 & & & $\mathrm{x}$ \\
\hline Gastrocopta tuvaense Steklov, 1967 & & & $\mathrm{x}$ \\
\hline \multicolumn{4}{|l|}{ Lagomorpha } \\
\hline Desmatolagus sp. & & $\mathrm{x}$ & \\
\hline Sinolagomys kansuensis Bohlin, 1937 & & $\mathrm{x}$ & $\mathrm{x}$ \\
\hline Sinolagomys major Bohlin, 1937 & & $\mathrm{x}$ & \\
\hline Sinolagomys sp. & $\mathrm{x}$ & & $\mathrm{x}$ \\
\hline Sinolagomys ulungurensis Tong, 1989 & & $\mathrm{x}$ & $\mathrm{x}$ \\
\hline Amphilagus magnus Erbajeva, 2013 & & $\mathrm{x}$ & $\mathrm{x}$ \\
\hline \multicolumn{4}{|l|}{ Eulipotyphla } \\
\hline Palaeoscaptor acridens Matthew \& Granger, 1924a & $\mathrm{x}$ & & \\
\hline Palaeoscaptor cf. rectus Matthew \& Granger, 1924a & & & $\mathrm{x}$ \\
\hline Palaeoscaptor tenuis Ziegler et al., 2007 & & $\mathrm{x}$ & $\mathrm{x}$ \\
\hline Erinaceidae indet. & $\mathrm{x}$ & & $\mathrm{x}$ \\
\hline Amphechinus taatsiingolensis Ziegler et al., 2007 & & $\mathrm{x}$ & $\mathrm{x}$ \\
\hline Amphechinus minutissimus Ziegler et al., 2007 & $\mathrm{x}$ & & $\mathrm{x}$ \\
\hline Amphechinus major Ziegler et al., 2007 & $\mathrm{x}$ & $\mathrm{x}$ & $\mathrm{x}$ \\
\hline Taatsiinia hoeckorum Ziegler et al., 2007 & & & $\mathrm{x}$ \\
\hline \multicolumn{4}{|l|}{ Rodentia } \\
\hline Tataromys sigmodon Matthew \& Granger, 1923 & & $\mathrm{x}$ & \\
\hline Yindirtemys deflexus (Teilhard de Chardin, 1926) & $\mathrm{x}$ & $\mathrm{x}$ & \\
\hline Yindirtemys suni Li \& Qiu, 1980 & & & $\mathrm{x}$ \\
\hline Tsaganomys altaicus Matthew \& Granger, 1923 & & $\mathrm{x}$ & $\mathrm{x}$ \\
\hline Bohlinosminthus parvulus (Bohlin, 1946) & $\mathrm{x}$ & & $\mathrm{x}$ \\
\hline Plesiosminthus promyarion Schaub, 1930 & & & $\mathrm{x}$ \\
\hline Litodonomys lajeensis (Li \& Qiu, 1980) & & & $\mathrm{x}$ \\
\hline Heterosminthus firmus Zazhigin \& Lopatin, 2000 & & & $\mathrm{x}$ \\
\hline Heterosminthus cf. lanzhouensis Wang \& Qiu, 2000 & & & $\mathrm{x}$ \\
\hline Tachyoryctoides obrutschewi Bohlin, 1937 & $\mathrm{x}$ & & \\
\hline Tachyoryctoides tatalgolicus Dashzeveg, 1971 & & $\mathrm{x}$ & \\
\hline \multicolumn{4}{|l|}{ Creodonta } \\
\hline Hyaenodontidae indet. & & $\mathrm{x}$ & \\
\hline \multicolumn{4}{|l|}{ Leptictida } \\
\hline Didymoconidae indet. & & $\mathrm{x}$ & \\
\hline \multicolumn{4}{|l|}{ Perissodactyla } \\
\hline Rhinocerotidae indet. & & & $\mathrm{x}$ \\
\hline \multicolumn{4}{|l|}{ Ruminantia } \\
\hline Ruminantia indet. & & $\mathrm{x}$ & \\
\hline
\end{tabular}

\section{Locality Unkheltseg}

\section{Samples: UNCH-A/3 and UNCH-A/4}

Unkheltseg is located at the northern rim of the Taatsiin plateau, west of the Taatsiin Gol (Fig. 3h). In this area, basalt I is interrupted, and the brick-red clay of the Hsanda Gol Fm. is immediately overlain by a thin layer of rose silty sand and gravels of the Loh Fm. mixed with abundant caliche nodules and reworked basalt (section UNCH-A; Fig. 12b, c). Here, the Loh Fm. yields fossils of letter zone D; the Hsanda Gol clay 

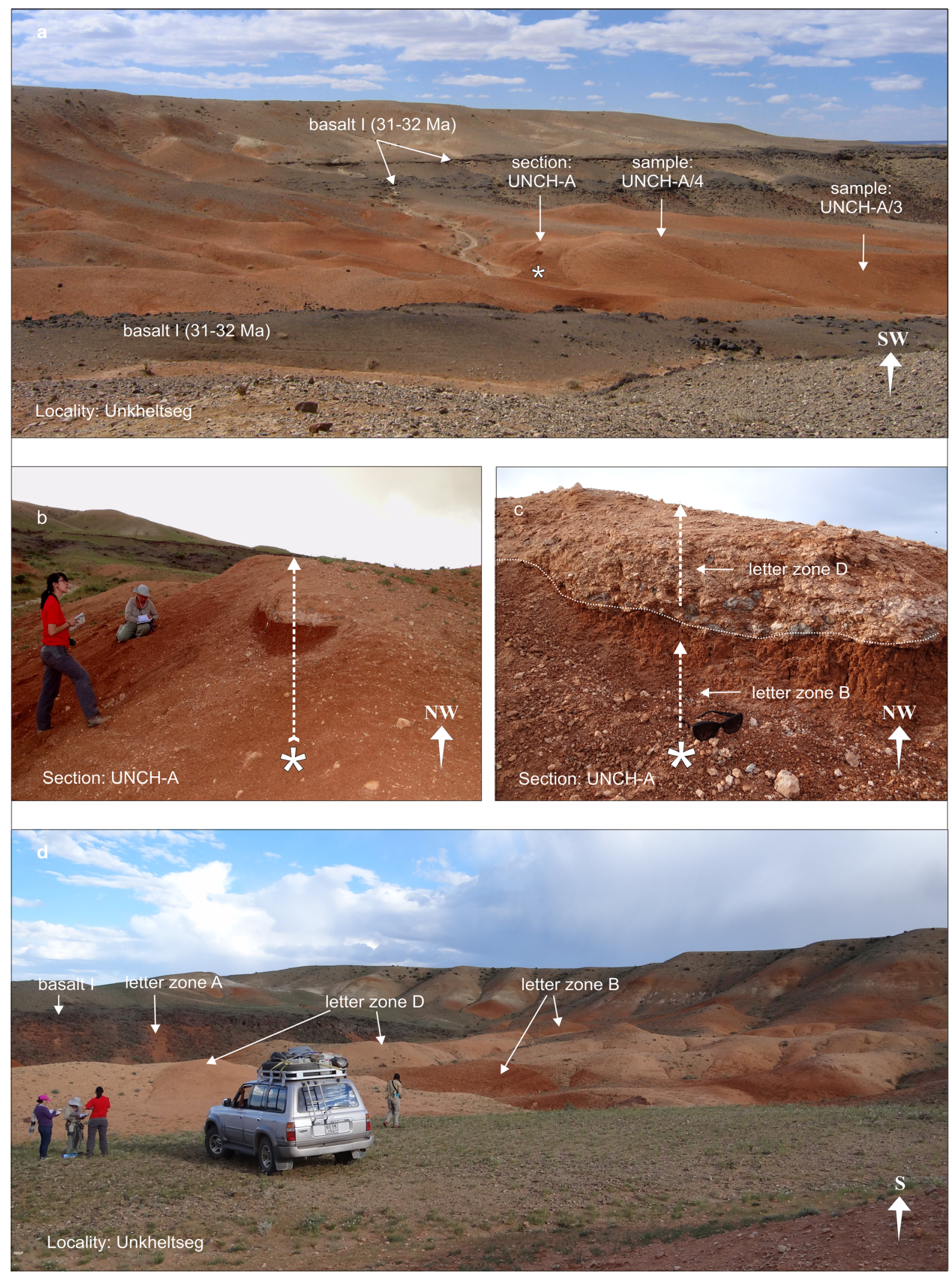

Fig. 12 Locality Unkheltseg showing the sample points UNCH-A/3 and UNCH-A/4. a View from Unkheltseg toward southwest. Localization of section UNCH-A and samples UNCH-A/3 and UNCH-A/4. b, c Section UNCH-A: The contact zone between the Hsanda Gol Fm. with fossils of letter zone B and the Loh Fm. with fossils of letter zone D is marked. d View toward the north rim of the Taatsiin Plateau. The brickred colour indicates the Hsanda Gol Fm. with fossils of letter zones A and $\mathrm{B}$; the rose silt indicates the Loh Fm. with fossils of letter zone D 
Table 8 Fossils from the locality Unkheltseg (samples- $\mathrm{UNCH}$ $\mathrm{A} / 3 \mathrm{~B}+4 \mathrm{~B}$ and $\mathrm{UNCH}-\mathrm{A} / 3+4)$ [the ages of the assemblages are early Oligocene (letter zone B) and early Miocene (letter zone D)]
Unkheltseg (UNCH-A/3B+4B)

Letter zone B

Gastropoda

Strobilops sp.

Lagomorpha

Desmatolagus gobiensis Matthew and Granger, 1923

Desmatolagus cf. simplex (Argyropulo, 1940)

Desmatolagus sp.

Eulipotyphla

Zaraalestes minutus (Matthew and Granger, 1924a)

Palaeoscaptor acridens Matthew and Granger, 1924a

Palaeoscaptor tenuis Ziegler et al., 2007

Gobisorex kingae Sulimski, 1970

Crocidosoricinae indet.

Rodentia

Ninamys kazimierzi Vianey-Liaud et al., 2013

Ninamys arboraptus (Shevyreva, 1966)

Huangomys frequens Schmidt-Kittler et al., 2007

Ardynomys sp.

Anomoemys lohiculus (Matthew and Granger, 1923)

Tsaganomyidae indet.

Coelodontomys asiaticus Wang, 2001

Tsaganomys altaicus Matthew and Granger, 1923

Heosminthus chimidae Daxner-Höck et al., 2014

Heosminthus sp.

Heosminthus borrae Daxner-Höck et al., 2014

Onjosminthus baindi Daxner-Höck et al., 2014

Shamosminthus sodovis Daxner-Höck, 2001

Cricetops dormitor Matthew and Granger, 1923

Witenia sp.

Eocricetodon meridionalis (Wang and Meng, 1986)

Eucricetodon asiaticus Matthew and Granger, 1923

Eucricetodon bagus Gomes Rodrigues et al., 2012

Carnivora

Shandgolictis elegans Hunt, 1998

Nimravus mongoliensis (Gromova, 1959)

Leptictida

Didymoconus berkey Matthew \& Granger, 1924b

Ruminantia

Pseudomeryx sp.

Paragelocus aff. scotti Schlosser, 1902
Unkheltseg (UNCH-A/3+4)

Letter zone D

Lagomorpha

Sinolagomys major Bohlin, 1937

Sinolagomys ulungurensis Tong, 1989

Sinolagomys sp.

Amphilagus magnus Erbajeva, 2013

Amphilagus orientalis Erbajeva, 2013

Amphilagus plicadentis Erbajeva, 2013

Bellatona cf. kazakhstanica Erbajeva, 1988

Bellatona yanghuensis Zhou, 1988

Alloptox cf. minor Li, 1978

Eulipotyphla

Palaeoscaptor acridens Matthew and Granger, 1924a

Amphechinus aff. taatsiingolensis Ziegler et al., 2007

Exallerix sp.

Crocidosoricinae indet.

Rodentia

Plesiosciurus aff. sinensis Qiu and Liu, 1986

Kherem shandgoliensis Minjin, 2004

Pteromyini indet.

Eutamias sp.

Asianeomys dangheensis (Wang, 2002)

Yindirtemys suni Li and Qiu, 1980

Prodistylomys nov. spec. 3 Oliver et al. (in prep)

Plesiosminthus barsboldi Daxner-Höck and Wu, 2003

Litodonomys huangheensis Wang and Qiu, 2000

Litodonomys lajeensis (Li and Qiu, 1980)

Heterosminthus firmus Zazhigin and Lopatin, 2000

Heterosminthus aff. nanus Zazhigin and Lopatin, 2000

Tachyoryctoides kokonorensis Li and Qiu, 1980

Democricetodon sui Maridet et al. 2011

Perissodactyla

cf. Hoploaceratherium gobiense (Beliajeva, 1960)

cf. Caementodon sp.

Ruminantia

Ruminantia indet. yields fossils of letter zone $\mathrm{B}$. When we investigated the first bulk samples UNCH-A/3 and UNCH-A/4, years ago, the formation boundary of section UNCH-A was not visible; thus, fossils of letter zone B and D were mixed in both samples. Later, the fossils could easily be separated into two parts, one of letter zone B and the second of letter zone D (Table 8). 


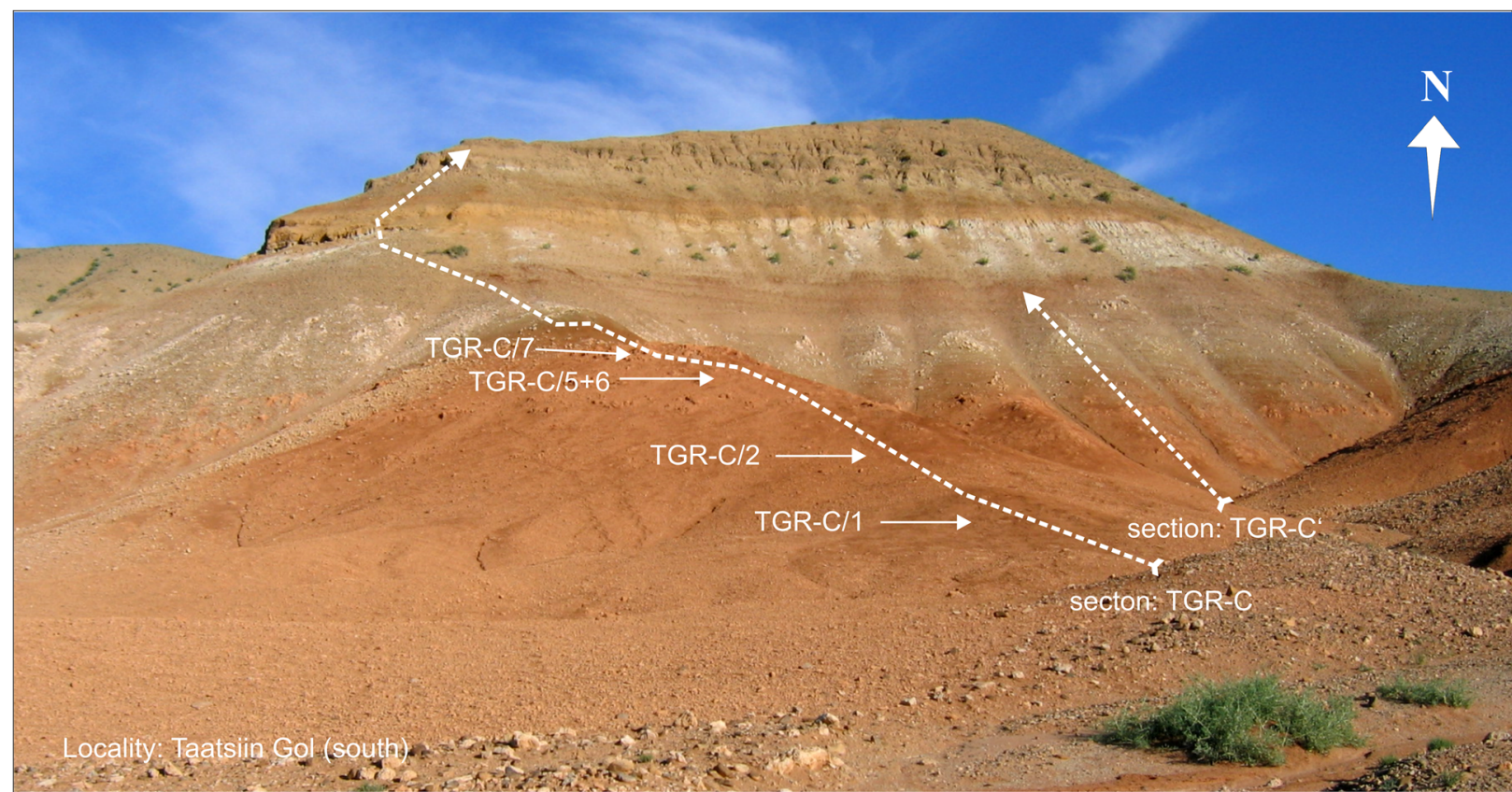

\section{Taatsiin Gol}

\section{Sections: TGR-C and TGR-C،}

Form. $m$ layer lithology

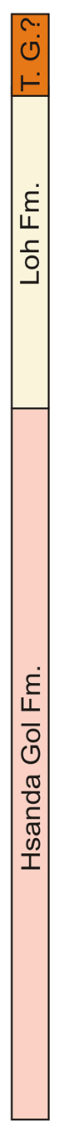

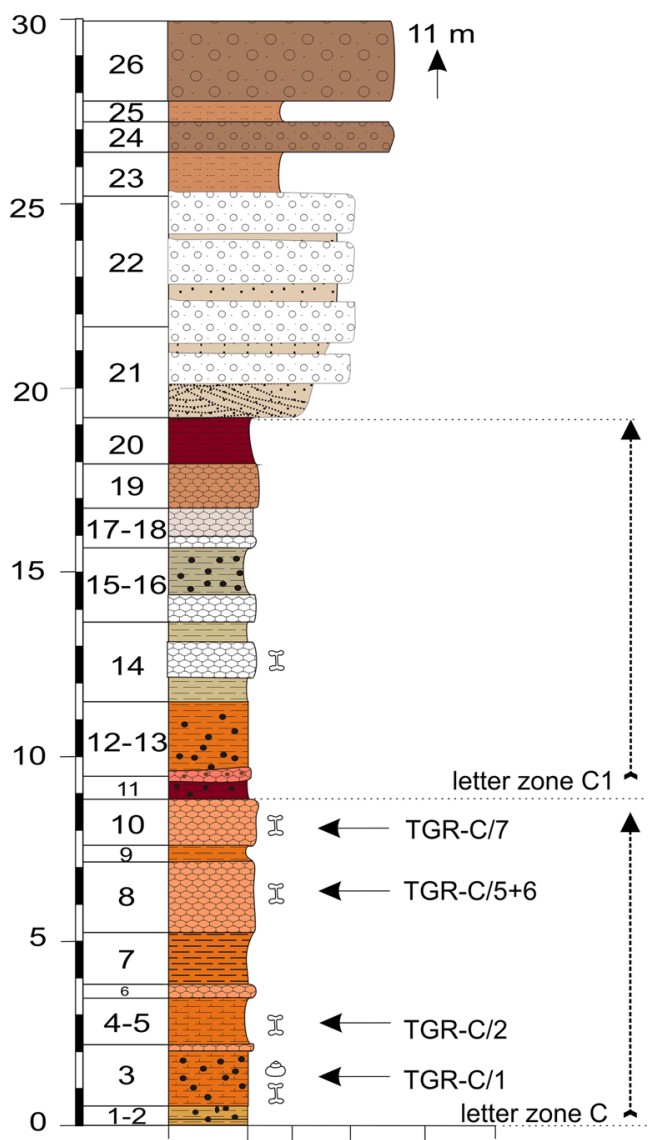

clay silt sand gravel pebbles

\section{Description of sections TGR-C and TGR-C':}

layer

26) $1100 \mathrm{~cm}$ : brown gravel $(60 \mathrm{~cm})$, upsection pebbles.

25) $60 \mathrm{~cm}$ : brown sandy silt.

24) $90 \mathrm{~cm}$ : brown gravel.

23) $125 \mathrm{~cm}$ : red-brown sandy silt.

22) $350 \mathrm{~cm}$ : ochre-brown massive sand; gravel lenses.

21) $260 \mathrm{~cm}$ : white-green coarse sand of the Loh Fm.; cross-bedded; channel, graded upwards; gravel beds.

20) $125 \mathrm{~cm}$ : dark red-brown claystone; few manganese precipitates, uppermost layer greenish below Loh Fm.

19) $130 \mathrm{~cm}$ : orange-brown mottled caliche; rootlets.

17-18) $100 \mathrm{~cm}$ : whitish-grey caliche, fissure fillings of red clay; basal chalky-white mottled caliche, grains $(1-5 \mathrm{~cm})$.

15-16) $200 \mathrm{~cm}$ : greyish-green clay with manganese nodules; carbonate-free; basal white chalky caliche.

14) $210 \mathrm{~cm}$ : olive-green claystone with manganese precipitates,

4 carbonate-free; in middle part chalky caliche;

bones are black.

12-13) $215 \mathrm{~cm}$ : reddish-brown claystone, abundant manganese precipitates and nodules; caliche nodules; basal $12 \mathrm{~cm}$ hard pinkish caliche.

11) $55 \mathrm{~cm}$ : dark reddish-brown claystone with manganese precipitates, few manganese nodules (up to $5 \mathrm{~mm}$ ).

10) $135 \mathrm{~cm}$ : orange-red mottled caliche; laterally grading into red claystone; bioturbations;sample TGR-C/7.

9) $40 \mathrm{~cm}$ : reddish-brown claystone; manganese precipitates; laterally caliche nodules, carbonatic.

8) $190 \mathrm{~cm}$ : rose to brick-red mottled caliche; clasts of $\mathrm{mm}$ size; TGR-C/5-6.

7) $145 \mathrm{~cm}$ : light reddish-brown carbonatic claystone with clay clasts; manganese precipitates.

6) $22 \mathrm{~cm}$ : mottled caliche with rootlets

4-5) $130 \mathrm{~cm}$ : reddish-brown calichized claystone with clay clasts (up to $2 \mathrm{~cm}$ ); passing into caliche; carbonatic; rare manganese precipitates; sample TGR-C/2.

3) $180 \mathrm{~cm}$ : reddish-brown carbonaceous claystone with pinkish caliche nodules; manganese nodules; sample

TGR-C/1; on top, $12 \mathrm{~cm}$ light grey caliche with reddish-brown clay clasts (up to $1 \mathrm{~mm}$ ).

1-2) $60 \mathrm{~cm}$ : ochre-reddish clay with red patches; abundant manganese nodules.

Fig. 13 The sections TGR-C and TGR-C' are located at the southeast rim of the Taatsiin plateau (western plateau) and are exposed toward south. The lower part shows the Hsanda Gol Fm., the upper part is built up by units of the Loh and Tuyn Gol Fms. and ?Pleistocene gravels 
Table 9 Fossils from the locality Tatsiin Gol south (composite samples-TGR-C/1+2 and TGR-C/5-7) [the age of the assemblages is late Oligocene (letter zone C)]

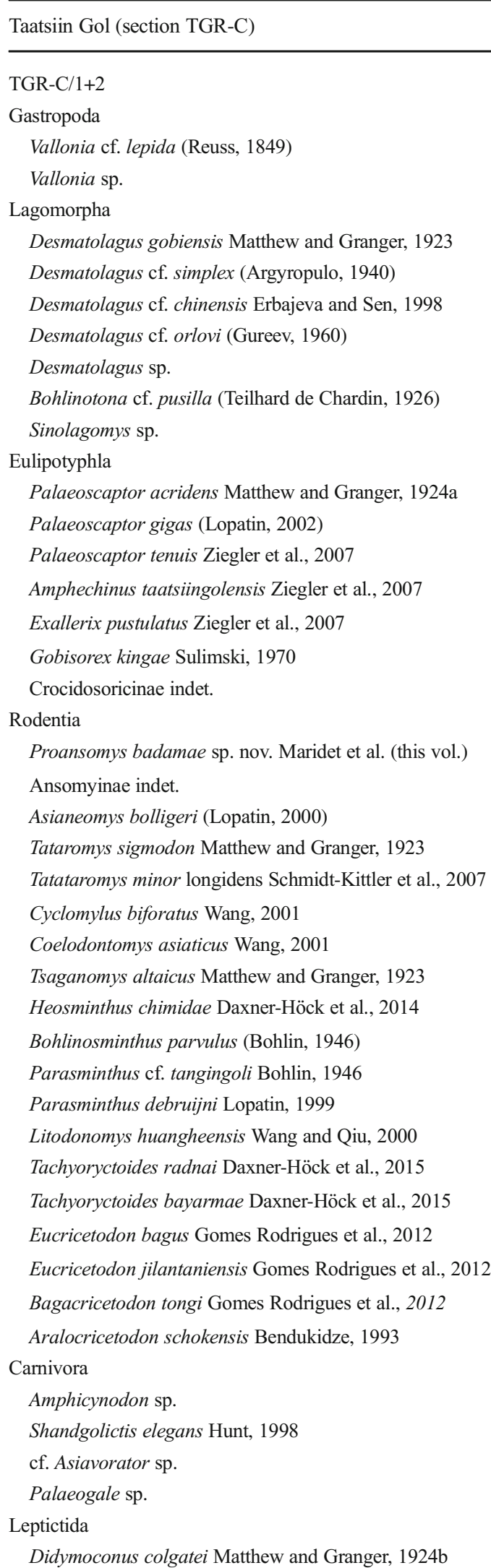

Table 9 (continued)

Taatsiin Gol (section TGR-C)

Ruminantia

Dremotherium cf. guthi Jehenne, 1987

Ruminantia indet.

TGR-C/5-7

Gastropoda

Vallonia cf. lepida (Reuss, 1849)

Lagomorpha

Desmatolagus cf.chinensis Erbajeva and Sen, 1998

Eulipotyphla

Amphechinus taatsiingolensis Ziegler et al., 2007

Rodentia

Proansomys badamae sp. nov. Maridet et al. (2017, this issue)

Cyclomylus intermedius Wang, 2001

Heosminthus borrae Daxner-Höck et al., 2014

Bohlinosminthus parvulus (Bohlin, 1946)

Eocricetodon cf. meridionalis (Wang and Meng, 1986)

Tachyoryctoides radnai Daxner-Höck et al., 2015

\section{Locality Taatsiin Gol (south of the western plateau)}

Sections: TGR-C and TGR-C'; samples: TGR-C/1, TGR-C/2, TGR-C/5+6, TGR-C/7 (Fig. 3i, Fig. 13)

The lower part of the sections consists of red-brown claystone alternating with red-rose caliche layers (layersTGR-C/1-10). It is overlain by $55 \mathrm{~cm}$ of dark brown claystone, a thin layer of orange-pink caliche, and red claystone (sediment layers-TGR-C/11-13). The dark brown claystone and orange-pink caliche (TGR-C/11) mark the boundary between letter zones $\mathrm{C}$ and $\mathrm{C} 1$. The samples TGR-C/1+2 are very fossil-rich, which indicate letter zone C (Table 9). Upsection, olive-green claystone layers alternate with white chalky caliche and grade into red-brown caliche (layers-TGR-C/14-19 with poor fossil content).

The boundary between the Hsanda Gol and Loh Fms. is marked by a second dark red-brown to chocolate-brown clay (sediment layer-TGR-C/20). The uppermost part of the section is dominated by light-coloured sand and gravel layers of the Loh Fm.; on top, gravels of the Tuyn Gol Fm. and/or Pleistocene gravels (TGR-C/21-26) are exposed.

According to magnetostratigraphic investigations (Sun and Windley 2015), the red clay-caliche sequences (layers-TGR-C/1-13) correspond with the palaeomagnetic polarity Chrons C9n-C8n.1n, with an age range of 27.4- 


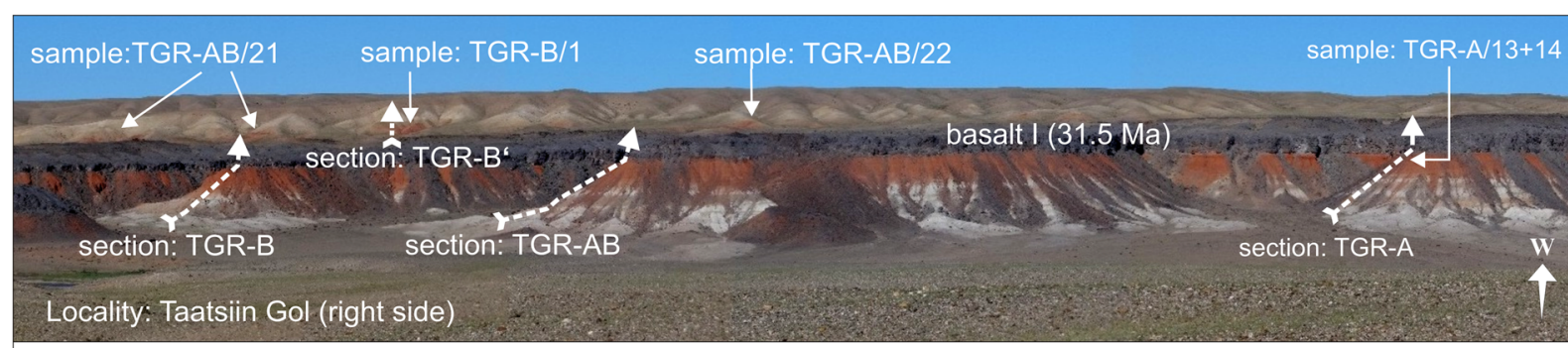

Taatsiin Gol

Section: TGR-AB

TGR-AB (basis)

Formation

$m \quad$ layer lithology

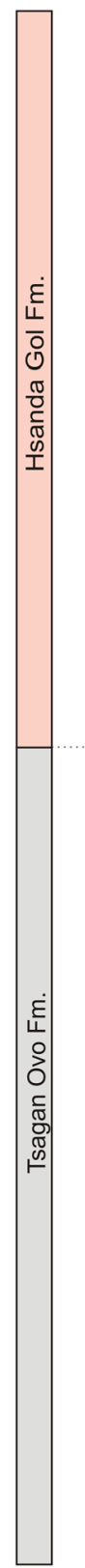

40

36

25

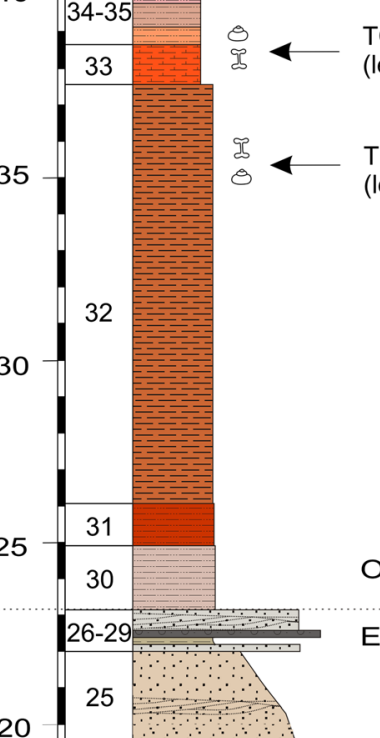

20

15

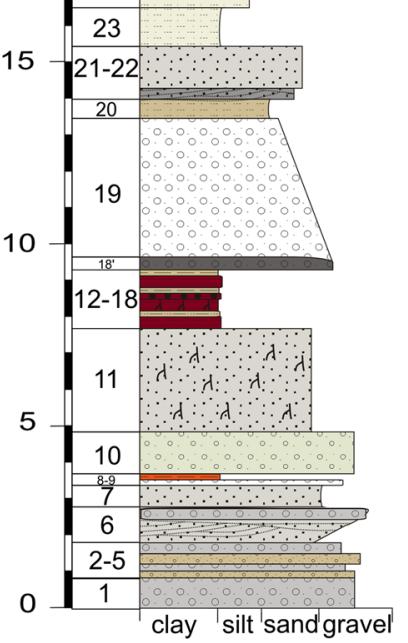

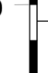

24

$-1$

4

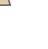

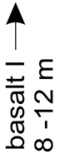

TGR-A/14

(letter zone A)

TGR-A/13

(letter zone A)

Oligocene

\section{Eocene}

21) $21-25 \mathrm{~cm}$ : coarse
matrix; cross-bedded.

20) $65 \mathrm{~cm}$ : green-grey silty sand with gravel layers.

19) $380 \mathrm{~cm}$ : grey-green gravel, fining upward, clay clasts.

18 ') $20-30 \mathrm{~cm}$ : dark grey to black gravel with green clay clasts.

18) $18 \mathrm{~cm}$ : light green clay.

17) $13 \mathrm{~cm}$ : dark brown silty clay.

16) $16 \mathrm{~cm}$ : green to grey clay; flaser bedding.

15) $22 \mathrm{~cm}$ : dark brown silty clay with manganese.

14) $37 \mathrm{~cm}$ : dark brown-grey silty clay; root remains.

13) $15 \mathrm{~cm}$ : grey-green silty clay with pinkish clusters.

12) $20 \mathrm{~cm}$ : dark brown clay; manganese-bearing.

11) $300 \mathrm{~cm}$ : green-grey-brick red-spotted coarse sand; root remains.

10) $125 \mathrm{~cm}$ : light green to whitish medium gravel,

rounded.

9) $13 \mathrm{~cm}$ : rust clay; gravel lenses.

8) $15 \mathrm{~cm}$ : medium gravel with green clay clasts.

7) $45 \mathrm{~cm}$ : medium sand to gravel; fining upward.

6) $90 \mathrm{~cm}$ : coarse sand, cross-bedded; fine gravel layers;

at top a $15-\mathrm{cm}$-thick gravel lens.

2-5) $77 \mathrm{~cm}$ : olive-green to grey coarse sand and gravel, partly with high clay content.

1) $85 \mathrm{~cm}$ : grey gravel, badly sorted, with fine sand matrix (Tsagan Ovo Fm.).

Fig. 14 The eastern rim of Taatsiin plateau exposes the sections TGR-B+B', TGR-AB, TGR-A, and basalt I ( 31.5 Ma) along of the orographic right side of Taatsiin Gol. From bottom to top, the sections display strata of the Tsagan Ovo, Hsanda Gol, Loh, and Tuyn Gol Fms 


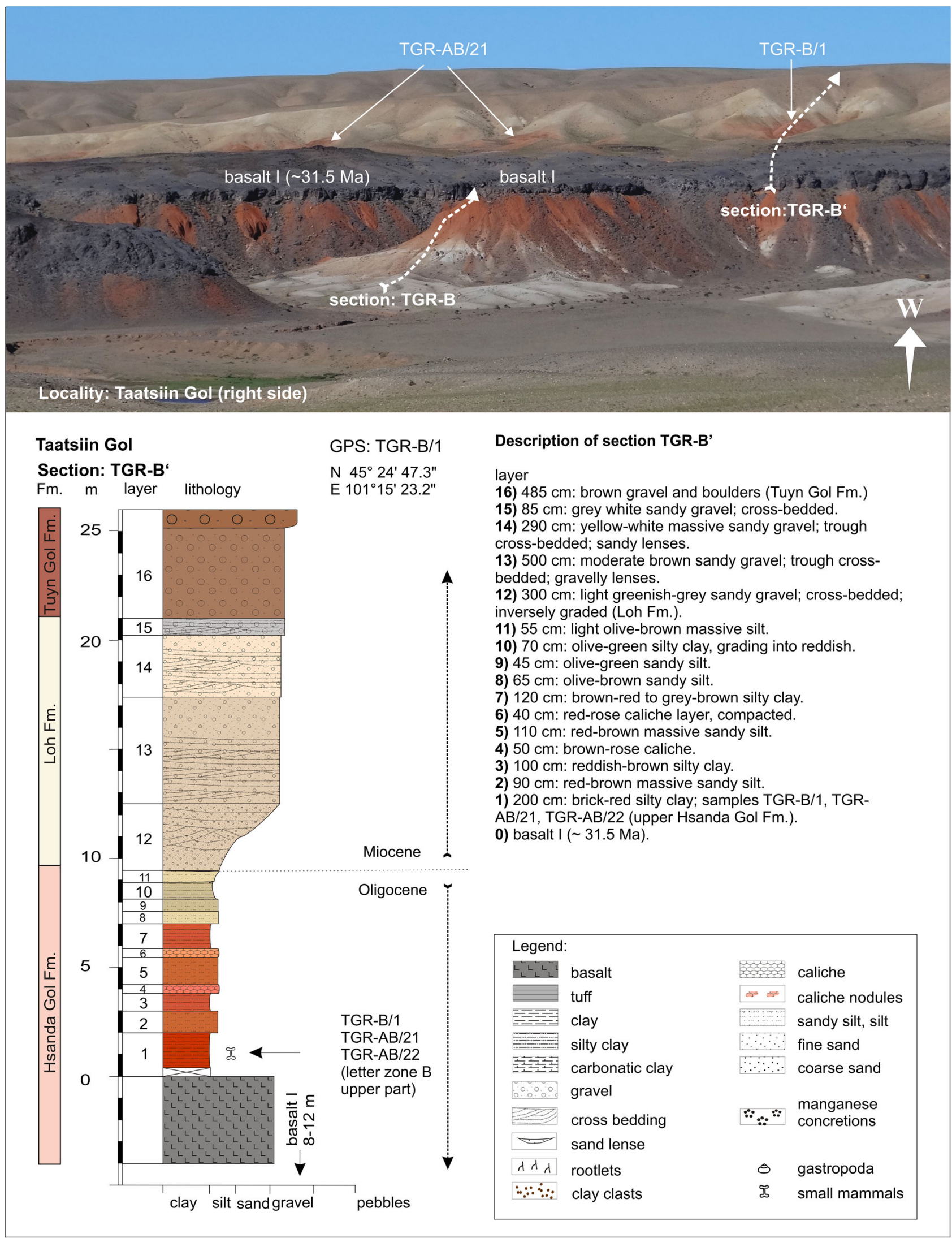

Fig. 15 The section TGR-B and $\mathrm{B}^{\prime}$ is shown in detail. It displays the lightcoloured sediments of the Tsagan Ovo Fm., the lower red beds of the Hsanda Gol Fm., which are overlain by basalt I. Above basalt I, the upper Hsanda

Gol Fm. is locally visible as red exposures (TGR-AB/21, TGR-B/1). On top, sequences of the Loh and Tuyn Gol Fms. in light brownish colours. Description of section TGR-B modified from Schmid (1999, Abb. A1) 
Table 10 Fossils from Taatsiin Gol right side (sections-TGR-A and TGR-B, samples-TGR-A/13+14, TGR-ZO/1+2, TGR-B/1, TGR-AB/21, TGR-AB/22) [the age of the assemblages is early Oligocene (letter zones A and B)]

\begin{tabular}{lllll}
\hline Taatsiin Gol (right side) & TGR-A/13+14 & TGR-ZO/1+2 & TGR-B/1 & TGR-AB/21 \\
Biozone & A & B & B & B -AB/22 \\
& & & B \\
\hline
\end{tabular}

\section{Gastropoda}

Pupoides steklovi Prysjazhnjuk et al., $1975 \quad \mathrm{x}$

Vallonia cf. lepida (Reuss, 1849) x

Vallonia stworzewiczae Neubauer et al., $2013 \quad \mathrm{x}$

Vallonia tumida Stworzewicz, $2007 \quad \mathrm{x}$

Gastrocopta devjatkini Prysjazhnjuk et al., $1975 \quad$ x

Gastrocopta cf. mongolica Prysjazhnjuk et al., 1975 x

Gastrocopta shandgolica Prysjazhnjuk, 1975 x

Reptilia

Tinosaurus sp.

Lacerta sp. 1

Lacerta sp. $2+3$

Scincomorpha indet.

Squamata indet.

Mammalia

Lagomorpha

Desmatolagus youngi (Gureev, 1960)

Desmatolagus gobiensis Matthew and Granger, 1923

Desmatolagus robustus Matthew and Granger, 1923

Desmatolagus cf. chinensis Erbajeva and Sen, 1998

Desmatolagus cf. orlovi (Gureev, 1960)

Desmatolagus sp.

Marsupialia

Asiadelphis zaissanensis Gabunia et al., 1990

Eulipotyphla

Zaraalestes minutus (Matthew and Granger, 1924a)

Zaraalestes sp.

Palaeoscaptor acridens Matthew and Granger, 1924a

Palaeoscaptor tenuis Ziegler et al., 2007

Gobisorex kingae Sulimski, 1970

Taatsiinia hoeckorum Ziegler et al., 2007

Crocidosoricidae indet.

Heterosoricinae indet.

Talpidae indet.

Rodentia

Promeniscomys cf. sinensis Wang 1987

Ninamys kazimierzi Vianey-Liaud et al., 2013

$\mathrm{x}$

$\mathrm{x}$

$\mathrm{x}$

Ninamys arboraptus (Shevyreva, 1966)

Eomys aff. orientalis Wang and Emry, 1991

Eomys sp.

Karakoromys decessus Matthew and Granger, 1923

Huangomys frequens Schmidt-Kittler et al. 2007

Yindirtemys shevyrevae Vianey-Liaud et al., 2006

Tataromys sigmodon Matthew and Granger, 1923

Anomoemys lohiculus (Matthew and Granger, 1923)

Tsaganomyidae indet.

Cyclomylus lohensis Matthew and Granger, 1923

$\mathrm{x}$

$\mathrm{X}$

$\mathrm{x}$

$\begin{array}{ll}\mathrm{x} & \mathrm{x} \\ & \mathrm{x} \\ \mathrm{x} & \mathrm{x} \\ & \mathrm{x}\end{array}$

$x$
$x$
$x$
$x$
$x$
$x$
$x$
$x$

the

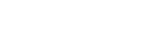

$x$

$\begin{array}{llll} & \mathrm{x} & \mathrm{x} & \mathrm{x} \\ \mathrm{x} & \mathrm{x} & \mathrm{x} & \mathrm{x} \\ \mathrm{x} & \mathrm{x} & \mathrm{x} & \mathrm{x} \\ \mathrm{x} & & \mathrm{x} & \mathrm{x} \\ & \mathrm{x} & & \mathrm{x} \\ & \mathrm{x} & & \mathrm{x} \\ & & \mathrm{x} & \\ & & \mathrm{x} & \end{array}$

$\mathrm{X}$

$\mathrm{x} \quad \mathrm{x}$

$\mathrm{x} \quad \mathrm{x}$

$\mathrm{x} \quad \mathrm{x}$

$\mathrm{x}$

$\begin{array}{lll}\mathrm{x} & \mathrm{x}\end{array}$

x $\quad \mathrm{x}$

$\mathrm{X}$
$\mathrm{X}$$$
\mathrm{x}
$$$$
x
$$
$x$ $\mathrm{x}$ $\mathrm{x}$ $\mathrm{x}$ $\mathrm{X}$ $\mathrm{x}$ $\mathrm{X}$ $\mathrm{X}$ 
Table 10 (continued)

Taatsiin Gol (right side)

Biozone
TGR-A/13+14 TGR-ZO/1+

A B
$\mathrm{B}$

$\begin{array}{lll}\text { TGR-B/1 } & \text { TGR-AB/21 } & \text { TGR-AB/22 } \\ \text { B } & \text { B } & \text { B }\end{array}$

B B B

Cyclomylus intermedius Wang, 2001

Coelodontomys asiaticus Wang, 2001

Tsaganomys altaicus Matthew and Granger, 1923

Allosminthus khandae (Daxner-Höck, 2001)

Allosminthus minutus (Daxner-Höck, 2001)

Heosminthus chimidae Daxner-Höck et al., 2014

Heosminthus sp.

Heosminthus borrae Daxner-Höck et al., 2014

Onjosminthus baindi Daxner-Höck et al., 2014

Shamosminthus sodovis Daxner-Höck, 2001

Ulaancricetodon badamae Daxner-Höck, 2000

Selenomys mimicus Matthew and Granger, 1923

Cricetops dormitor Matthew and Granger, 1923

Eocricetodon meridionalis (Wang and Meng, 1986)

Eucricetodon caducus (Shevyreva, 1967)

Eucricetodon asiaticus Matthew and Granger, 1923

Eucricetodon occasionalis Lopatin, 1996

Eucricetodon jilantaiensis Gomes Rodrigues et al., 2012

Paracricetodon sp.

Carnivora

Amphicticeps shackelfordi Matthew and Granger, 1924b

Palaeogale sp.

Carnivora indet.

Leptictida

cf. Ergilictis sp.

Ruminantia

Praetragulus gobiae (Matthew and Granger, 1925b)

Miomeryx sp.

Gobimeryx sp.

Pseudogelocus mongolicus Vislobokova and Daxner-Höck, 2002

Pseudomeryx sp.

Eumeryx sp.

\begin{tabular}{|c|c|c|c|}
\hline & & \multicolumn{2}{|l|}{$\mathrm{X}$} \\
\hline & & $\mathrm{X}$ & $\mathrm{X}$ \\
\hline \multicolumn{4}{|c|}{$\mathrm{X}$} \\
\hline & & $\mathrm{X}$ & $\mathrm{X}$ \\
\hline $\mathrm{X}$ & & $\mathrm{X}$ & $\mathrm{X}$ \\
\hline \multirow[t]{3}{*}{$\mathrm{x}$} & & $\mathrm{x}$ & \\
\hline & & $\mathrm{X}$ & $\mathrm{X}$ \\
\hline & & $\mathrm{X}$ & $\mathrm{X}$ \\
\hline \multirow[t]{2}{*}{$\mathrm{X}$} & & $\mathrm{X}$ & $\mathrm{X}$ \\
\hline & & $\mathrm{X}$ & $\mathrm{X}$ \\
\hline \multicolumn{4}{|c|}{$\mathrm{X}$} \\
\hline $\mathrm{X}$ & & $\mathrm{X}$ & $\mathrm{X}$ \\
\hline $\mathrm{X}$ & $\mathrm{x}$ & $\mathrm{X}$ & \\
\hline$X$ & $\mathrm{X}$ & $\mathrm{X}$ & $\mathrm{X}$ \\
\hline $\mathrm{X}$ & & $\mathrm{X}$ & $\mathrm{X}$ \\
\hline
\end{tabular}

$\mathrm{x}$

$\mathrm{x}$

$\mathrm{X}$

$\mathrm{X}$

$\mathrm{X}$

$\mathrm{X}$

$\mathrm{X}$

$\mathrm{X}$

$\mathrm{X}$

$\mathrm{X}$

$\mathrm{X}$

$\mathrm{X}$

X $\mathrm{X}$

$\mathrm{X}$

$\mathrm{X}$

X $\quad \mathrm{x}$

$\mathrm{X}$

$\mathrm{X}$

X $\quad x$

25.2 Ma. The whitish clay and caliche sequence up to the chocolate brown clay (layers-TGR-C/14-20) below the sand-gravel sequence of the Loh Fm. correspond with Chrons C7Ar-C7n.2n (age 25.2-24.2 Ma). Our section TGR-C was described as section B by Sun and Windley (2015). The correlation of Mongolian letter zones and magnetostratigraphic data is discussed below. The data from section TGR-C confirm the hitherto estimated age range of 28-25.6 Ma of letter zone C (Daxner-Höck et al. 2015).

\section{Locality Taatsiin Gol (right side of the river Taatsiin; western plateau)}

Sections: TGR-B, TGR-B', TGR-AB, TGR-A; samples: $T G R-B / 1, T G R-A B / 22, T G R-A B / 21, T G R-A / 13+14$, $T G R-Z O / 1$, and $T G R-Z O / 2$

Along of the east rim of the Taatsiin plateau (orographic right side of the river Taatsiin), the sections TGR-A, 
TGR-B, and TGR-AB are exposed (Fig. $3 \mathrm{k}-\mathrm{m}$ ). There, four lithological units are visible: the Tsagan Ovo, Hsanda Gol, Loh, and Tuyn Gol Fms. In its lower part, the sections cover fluvio-lacustrine deposits of the Tsagan Ovo Fm. Upsection, and the brick-red clay of Hsanda Gol Fm. is topped by basalt I of early Oligocene age $\left({ }^{40} \mathrm{Ar} /{ }^{39} \mathrm{Ar}\right.$ age, 31.5 Ma). The fossil beds (TGR-A/13+14), located immediately below basalt I, comprise key fossils of letter zone A. Above basalt I, $7 \mathrm{~m}$ of upper Hsanda Gol beds follow. The samples TGR-B/1, TGR-AB/21, and TGR-AB/22 from above basalt I yield fossils of letter zone B. Upsection, light-coloured sand and gravels of the Loh Fm. follow; on top, brown gavels and boulders of the Tuyn Gol Fm. are exposed (Figs. 14 and 15 and Höck et al. 1999; Fig. 6a).

Samples TGR-ZO/1 and TGR-ZO/2 were taken from red beds between two individual lava flows of basalt I at the east rim of the Taatsiin plateau (Fig. 3j). The mammal assemblages and basalt I indicate an early Oligocene age (Table 10).

Magnetostratigraphic investigations of the Tsagan Ovo Fm. and Hsanda Gol Fm., including basalt I, have been performed along a comparable section, which was named section A by Sun and Windley (2015). The strata above basalt I, containing the upper Hsanda Gol beds and the Loh Fm., were not considered in the magnetostratigraphic investigations.

From bottom to top, the sequences of the Tsagan Ovo Fm. correspond with Chrons C15r-C13r (>35-34 Ma/late
Eocene). Thus, the boundary between the Tsagan Ovo Fm. and Hsanda Gol Fms. corresponds with the EoceneOligocene boundary. The lower Hsanda Gol strata and basalt I correspond with the palaeomagnetic polarity Chrons C13r-C12r, with an age range of 34-31.2 Ma (Kraatz and Geisler 2010; Sun and Windley 2015), which is an early Oligocene age. These data agree with the ${ }^{40} \mathrm{Ar} /{ }^{39} \mathrm{Ar}$ ages measured from several samples of basalt I in the Taatsiin Gol region (Tables 1 and 2).

\section{Locality Taatsiin Gol (left side of the river; eastern plateau)}

Sections: TGL-A+A'; samples: TGL-A/1+2, TGL-A/11

Section TGL-A from the orographic left side of Taatsiin Gol (Fig. 3n) comprises the lower Hsanda Gol beds with fossils of letter zone A (samples TGL-A/1+2) and basalt I (31.6 Ma; Fig. 16). Above basalt I, section TGL-A' displays the upper Hsanda Gol beds with fossils of letter zone B (sample TGL-A/11; Fig. 17) and a $25-\mathrm{m}-$ thick sequence of the Loh Fm. The middle Miocene basalt III (13.1 Ma) forms the top of the plateau. Samples below basalt I $(\mathrm{TGL}-\mathrm{A} / 1+2)$ yield small mammal fossils and land gastropods (Table 11). The early Oligocene age and letter zone A are indicated by basalt I and the included fossils. 


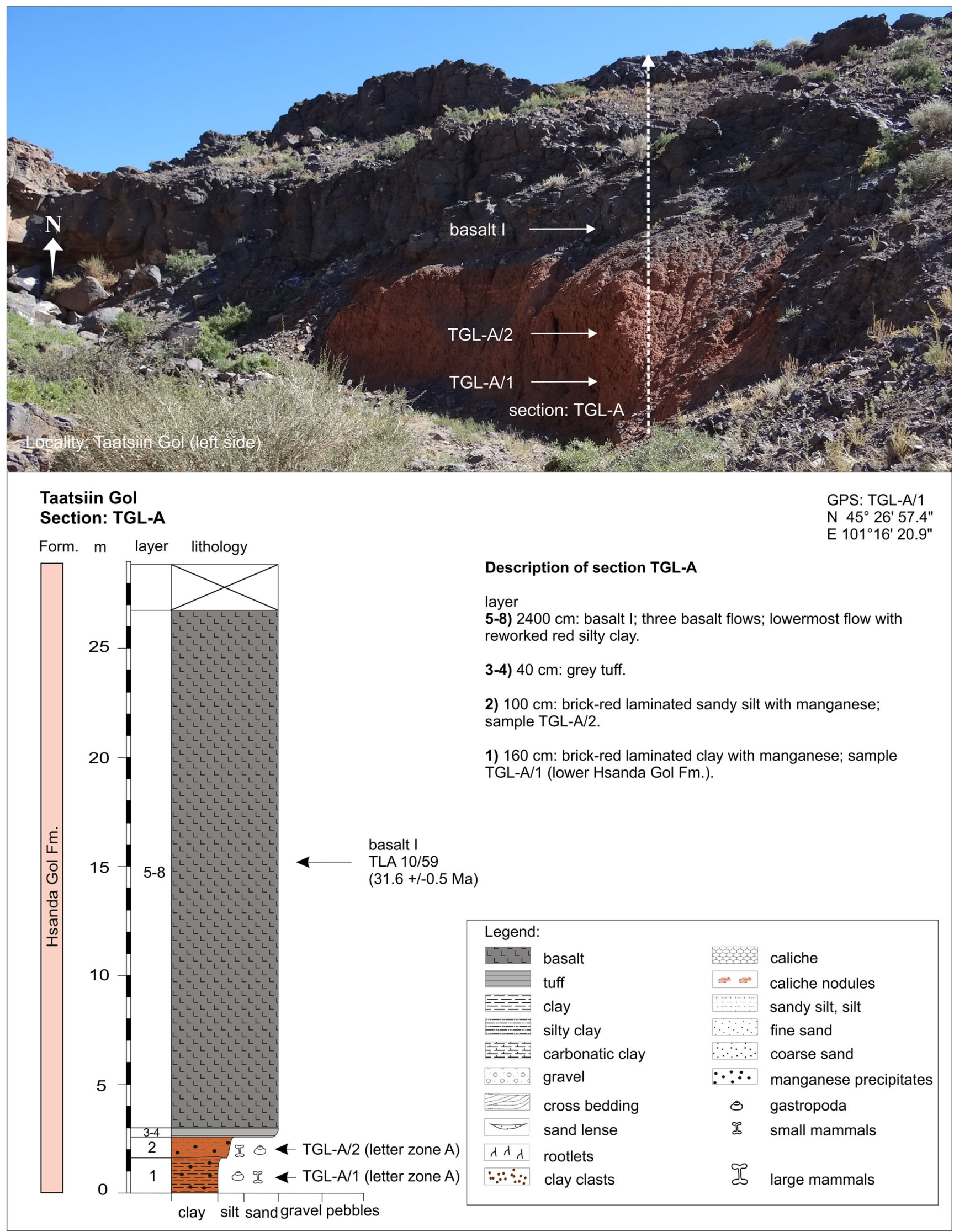

Fig. 16 Section TGL-A is located at the orographic left side of Taatsiin Gol (eastern plateau). The lower part of section TGL-A comprises the lower Hsanda Gol beds and basalt I (31.6 \pm 0.5 Ma). Description of section TGL-A after Daxner-Höck et al. (1997; Fig. 2) 


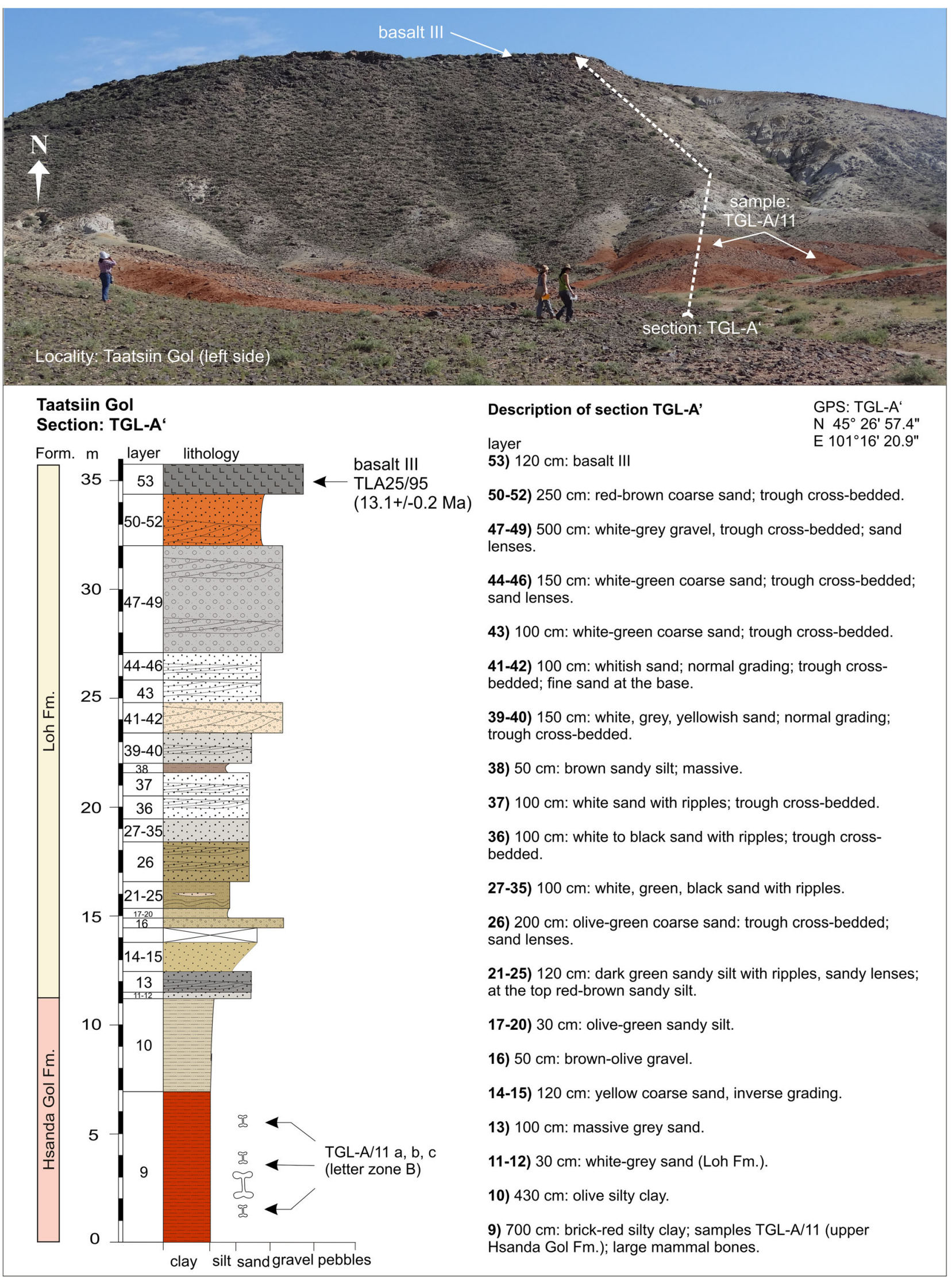

Fig. 17 Above the Oligocene basalt I, the upper Hsanda Gol beds (sample TGL-A/11) are located below light-coloured sand and gravel beds of the Loh Fm. On top, the middle Miocene basalt III (13.1 \pm 0.2 Ma). Description of section TGL-A after Daxner-Höck et al. (1997; Fig. 2) 
Table 11 Fossils from Taatsiin Gol left side (section-TGL-A, samples-TGL-A/1+2, TGL-A/ 11) [the age of the assemblages is early Oligocene (letter zones A and B)]

\begin{tabular}{|c|c|c|}
\hline $\begin{array}{l}\text { Taatsiin Gol (left side) } \\
\text { Letter zone }\end{array}$ & $\begin{array}{l}\text { TGL-A/1+2 } \\
\text { A }\end{array}$ & $\begin{array}{l}\text { TGL-A/11 } \\
\text { B }\end{array}$ \\
\hline \multicolumn{3}{|l|}{ Gastropoda } \\
\hline \multicolumn{3}{|l|}{ Pupoides steklovi Prysjazhnjuk et al., 1975} \\
\hline \multicolumn{3}{|l|}{ Vallonia stworzewiczae Neubauer et al., 2013} \\
\hline \multicolumn{3}{|l|}{ Vallonia tumida Stworzewicz, 2007} \\
\hline \multicolumn{3}{|l|}{ Reptilia } \\
\hline Lacerta 1. & $\mathrm{x}$ & $\mathrm{x}$ \\
\hline Squamata indet. & $\mathrm{x}$ & \\
\hline \multicolumn{3}{|l|}{ Mammalia } \\
\hline \multicolumn{3}{|l|}{ Lagomorpha } \\
\hline Desmatolagus gobiensis Matthew and Granger, 1923 & $\mathrm{x}$ & $\mathrm{x}$ \\
\hline Desmatolagus cf. vetustus Burke, 1941 & $\mathrm{x}$ & \\
\hline Desmatolagus sp. & & $\mathrm{x}$ \\
\hline \multicolumn{3}{|l|}{ Eulipotyphla } \\
\hline Zaraalestes minutus (Matthew and Granger, 1924a) & $\mathrm{x}$ & $\mathrm{x}$ \\
\hline Palaeoscaptor acridens Matthew and Granger, 1924a & $\mathrm{x}$ & $\mathrm{x}$ \\
\hline Palaeoscaptor tenuis Ziegler et al., 2007 & $\mathrm{x}$ & $\mathrm{x}$ \\
\hline Mongolopala tathue Ziegler et al., 2007 & $\mathrm{x}$ & \\
\hline \multicolumn{3}{|l|}{ Rodentia } \\
\hline Ninamys kazimierzi Vianey-Liaud et al., 2013 & $\mathrm{x}$ & $\mathrm{x}$ \\
\hline Ninamys arboraptus (Shevyreva, 1966 & & $\mathrm{x}$ \\
\hline Karakoromys decessus Matthew and Granger, 1923 & $\mathrm{x}$ & \\
\hline Ardynomys sp. & $\mathrm{x}$ & \\
\hline Anomoemys lohiculus (Matthew and Granger, 1923) & & $\mathrm{x}$ \\
\hline Tsaganomyidae indet. & $\mathrm{x}$ & \\
\hline Cyclomylus lohensis Matthew and Granger, 1923 & & $\mathrm{x}$ \\
\hline Cyclomylus intermedius Wang, 2001 & & $\mathrm{x}$ \\
\hline Tsaganomys altaicus Matthew and Granger, 1923 & & $\mathrm{x}$ \\
\hline Heosminthus chimidae Daxner-Höck et al., 2014 & $\mathrm{x}$ & $\mathrm{x}$ \\
\hline Shamosminthus sodovis Daxner-Höck, 2001 & $\mathrm{x}$ & $\mathrm{x}$ \\
\hline Selenomys mimicus Matthew and Granger, 1923 & & $\mathrm{x}$ \\
\hline Cricetops dormitor Matthew and Granger, 1923 & & $\mathrm{x}$ \\
\hline Ulaancricetodon badamae Daxner-Höck, 2000 & $\mathrm{x}$ & $\mathrm{x}$ \\
\hline Eucricetodon caducus (Shevyreva, 1967) & $\mathrm{x}$ & $\mathrm{x}$ \\
\hline Eucricetodon asiaticus Matthew and Granger, 1923 & $\mathrm{x}$ & $\mathrm{x}$ \\
\hline \multicolumn{3}{|l|}{ Creodonta } \\
\hline Hyaenodontidae indet. & & $\mathrm{x}$ \\
\hline \multicolumn{3}{|l|}{ Carnivora } \\
\hline Asiavorator altidens Spassov and Lange-Badré, 1995 & & $\mathrm{x}$ \\
\hline \multicolumn{3}{|l|}{ Ruminantia } \\
\hline Pseudogelocus mongolicus Vislobokova and Daxner-Höck, 2002 & & $\mathrm{x}$ \\
\hline Ruminantia indet. & & $\mathrm{x}$ \\
\hline
\end{tabular}

\section{Locality Unzing Churum}

Section: TAR-A; sample: TAR-A/2

Unzing Churum is located north-east of Taatsiin Gol (Fig. 3o). The lower part of section TAR-A consists of light-coloured fluvial sand and gravel deposits, which are overlain by basalt II. The ${ }^{40} \mathrm{Ar} /{ }^{39} \mathrm{Ar}$ age of basalt II is $27.4 \pm 0.4 \mathrm{Ma}$ (Höck et al. 1999 and Tables 1 and 2). Above basalt II, $8 \mathrm{~m}$ of brick-red sandy silt follow. Sample TAR-A/2 from the white-orange-red silty clay yields fossils of letter zone C (Figs. 18 and 19). 


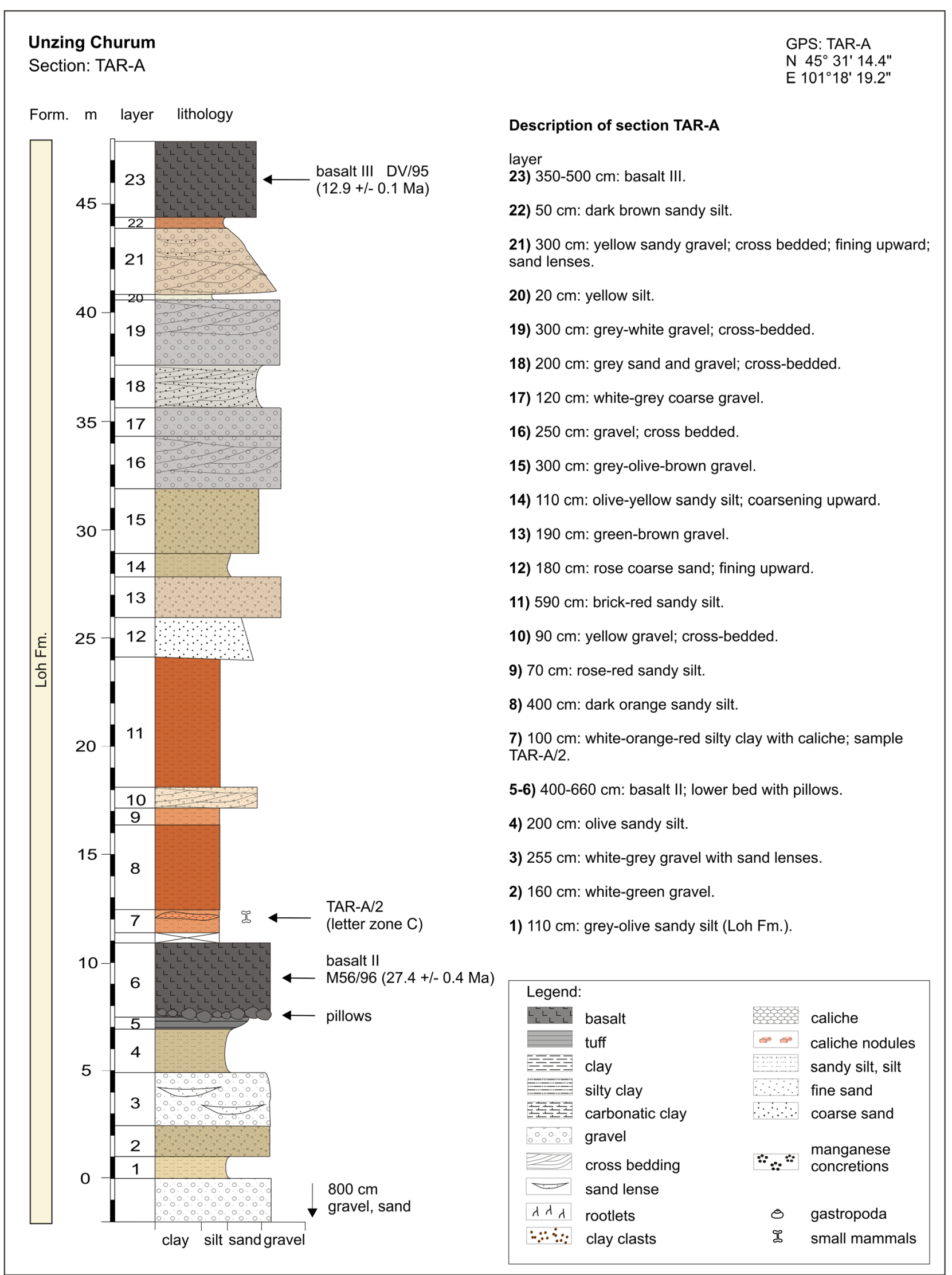

Fig. 18 Section TAR-A is located north-east of Taatsiin Gol. The section comprises sequences of the Loh Fm. including two basalt layers, basalt II and basalt III. Description of section TAR-A modified from Schmid (1999; Abb. A4) 


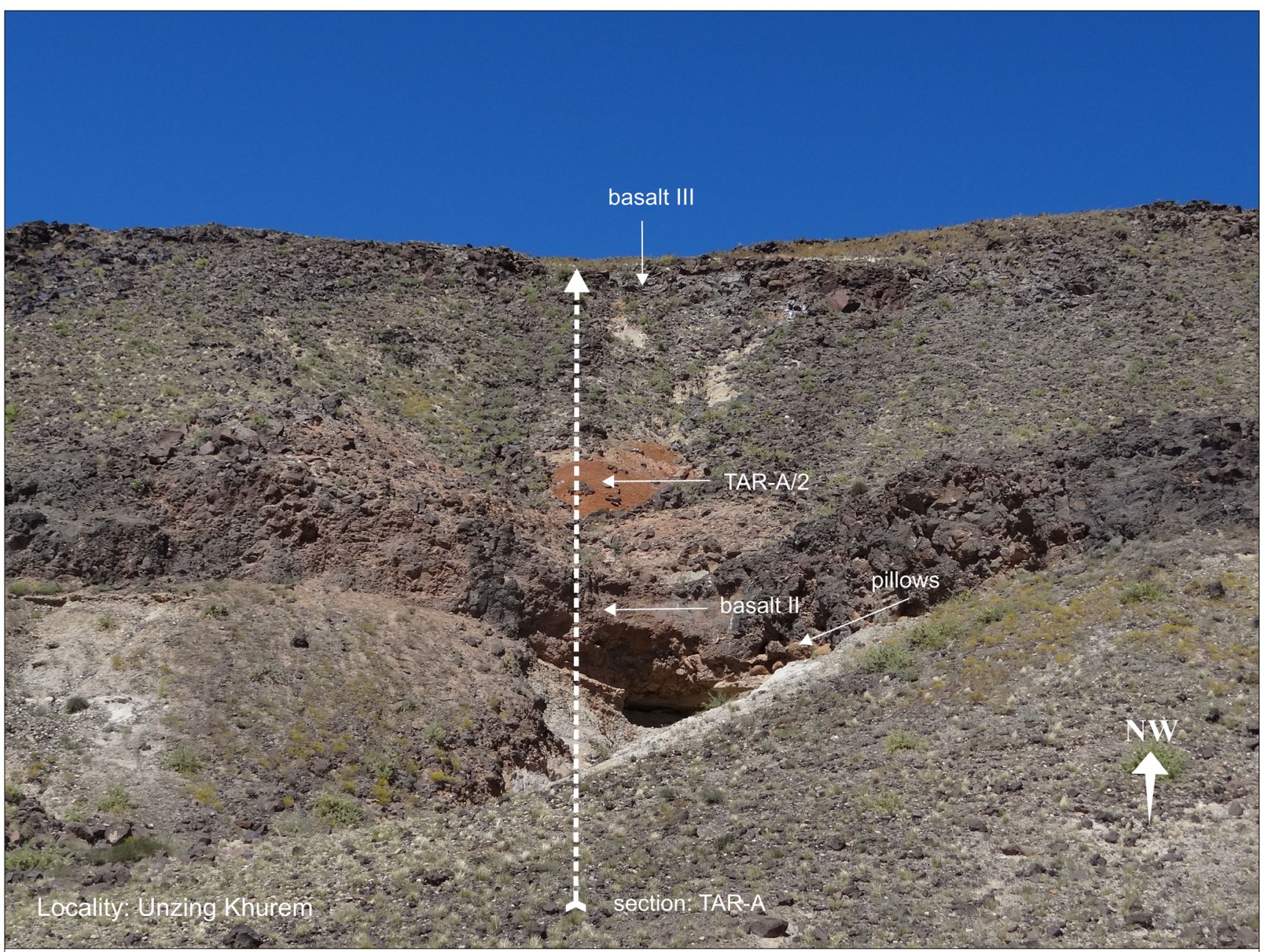

\section{Unzing Churum}

\section{Fossil list of sample TAR-A/2:}

Lagomorpha

Desmatolagus gobiensis Matthew \& Granger, 1923

Desmatolagus cf. shargaltensis Bohlin, 1937

Desmatolagus cf. orlovi (Gureev, 1960)

Bohlinotona cf. pusilla (Teilhard de Chardin, 1926)

Eulipotyphla

Palaeoscaptor acridens Matthew \& Granger, 1924

Palaeoscaptor gigas (Lopatin, 2002)

Amphechinus taatsiingolensis Ziegler et al., 2007
Rodentia

Tataromys sigmodon Matthew \& Granger, 1923

Tataromys minor longidens Schmidt-Kittler et al., 2007

Yindirtemys aff. ulantatalensis (Huang, 1985)

Tsaganomyidae indet.

Heosminthus chimidae Daxner-Höck et al., 2014

Bohlinosminthus parvulus (Bohlin, 1946)

Parasminthus cf. tangingoli Bohlin, 1946

Parasminthus cf. asiaecentralis Bohlin, 1946

Plesiosminthus sp.

Eucricetodon bagus Gomes Rodrigues et al., 2012

Eucricetodon jilantaiensis Gomes Rodrigues et al., 2012

Aralocricetodon schokensis Bendukidze, 1993

Fig. 19 Section TAR-A from the locality Unzing Churum. Sample TAR-A/2 on top of basalt II yields fossils of letter zone C 
Upsection, fluvial deposits follow. These include sand and silt layers and partly cross-bedded gravels. The section is topped by the middle Miocene basalt III, dated at $12.9 \pm 0.1 \mathrm{Ma}$.

For palaeoenvironmental considerations, it is worth to note that pillow structures were formed locally where basalt II flowed into a shallow pond or lake (Höck et al. 1999; Fig. 10b).

\section{Locality Del}

Section: Del-B; samples: DEL-B/2, DEL-B/7+8, DEL-B/12

The locality Del is located in the northern part of the Taatsiin Tsaagan Nuur basin (Fig. 3p). The direction of section DEL-B is $\mathrm{N} \rightarrow \mathrm{S}$. From north to south, strata of the Tsagan Ovo, Hsanda Gol, and Loh Fms. are affected by the Del fault and are tilted towards south. The
Hsanda Gol beds are divided by a tuff layer several metres in thickness (tuff I; Fig. 20). The lower Hsanda Gol beds yield very rare fossils of letter zone A (sample DEL-B/2). Above tuff I, several caliche layers are imbedded in the upper Hsanda Gol beds. The abundant fossils from these caliche layers (samples DEL-B/7 and DEL-B/8) indicate letter zone $\mathrm{B}$ and the early Oligocene. The following grey-brown silt of the Loh Fm. lacks fossils. Upsection, sample DEL-B/12 from a red silt layer yields fossils of letter zone $\mathrm{C} 1$ (Yindirtemys deflexus), pointing to the late Oligocene (Table 12).

Fig. 20 The Del section is located at the Del fault, close to the boundary between Mesozoic and Paleogene strata in the northern part of the Taatsiin Tsagaan Nuur basin. From the left to the right side of the picture, the Tsagan Ovo Fm. (in whitish-grey colours), the lower Hsanda Gol beds (red-brown), tuff I (grey), and the upper Hsanda Gol beds (grey-brown to red) are visible 


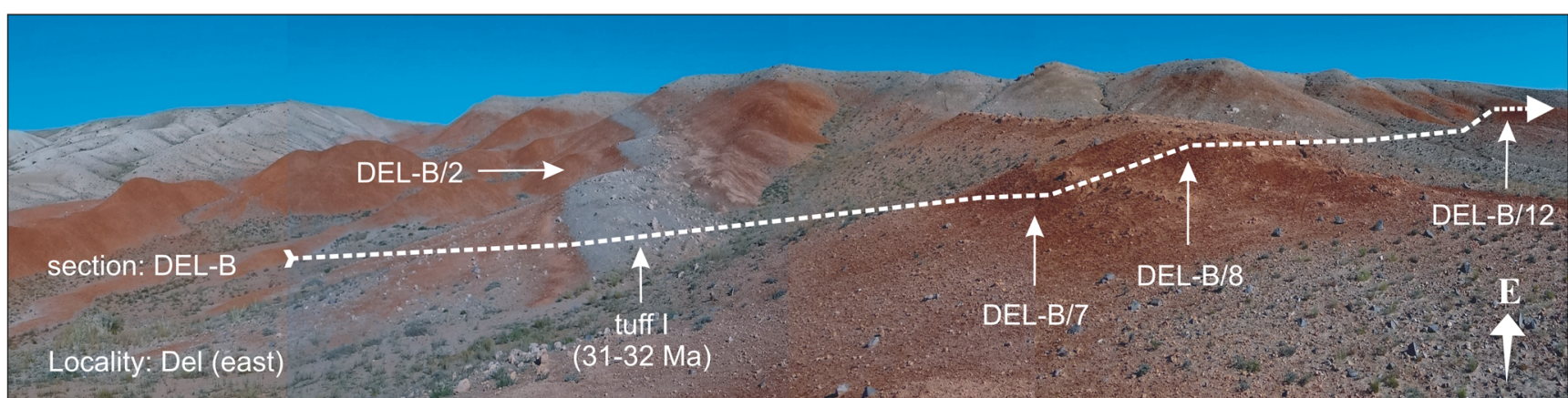

\section{Locality: Del}

GPS: DEL-B/7

\section{Section: DEL-B}
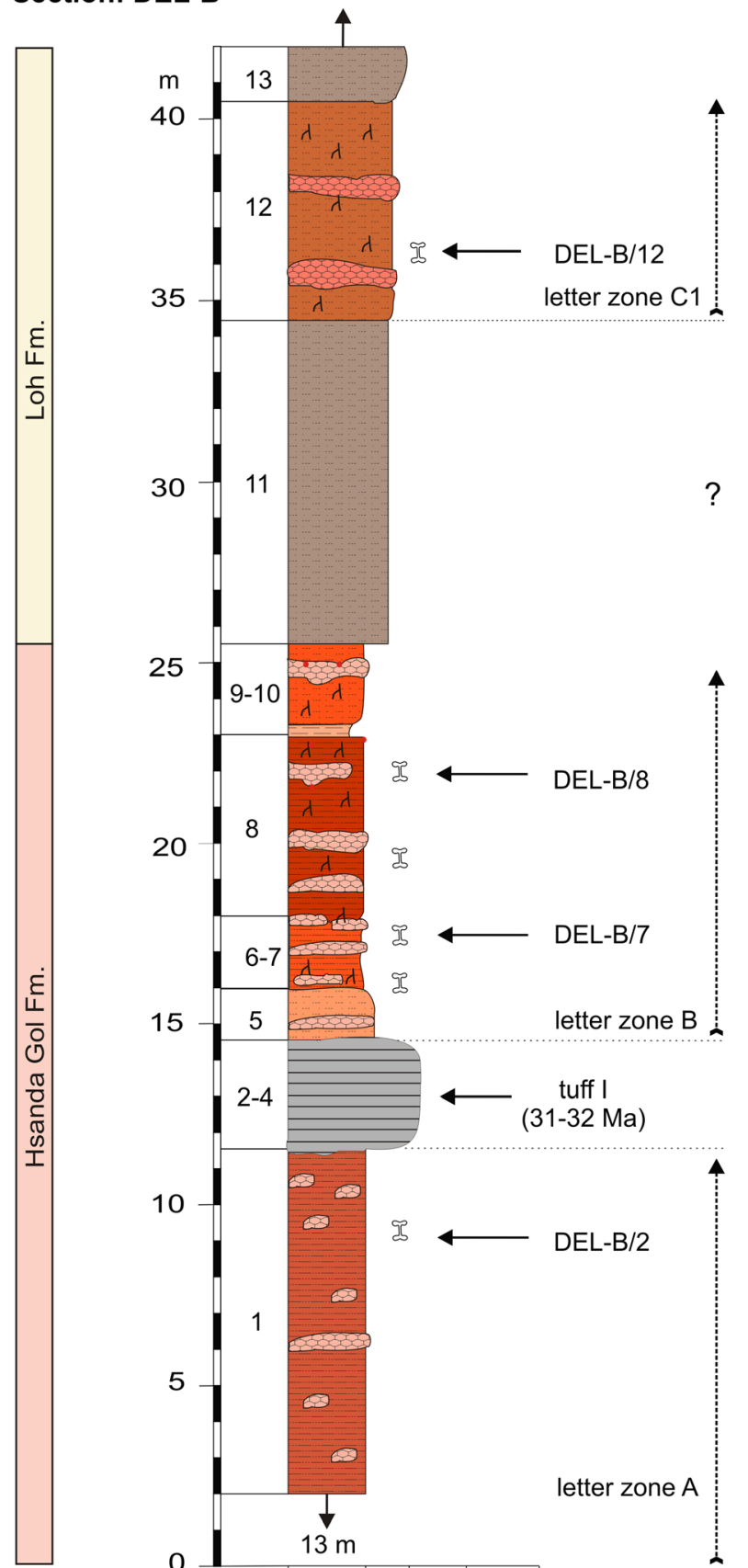

\section{Description of section DEL-B}

layer

13) $400 \mathrm{~cm}$ : grey sandy silt.

12) $600 \mathrm{~cm}$ : red carbonaceous silt; sample $D E L-B / 12$.

11) 900 cm: grey carbonaceous silt (Loh Fm.).

9-10) $250 \mathrm{~cm}$ : brownish-red silt; basal $20 \mathrm{~cm}$ rose claystone.

8) $500 \mathrm{~cm}$ : brown-red carbonaceous silt with caliche layers; sample DEL-B/8.

6-7) $240 \mathrm{~cm}$ : brown-red silty claystone with caliche layers; rich fossil content; sample DEL-B/7.

5) $150 \mathrm{~cm}$ : rose carbonaceous silt (upper Hsanda Gol Fm.).

2-4) $110 \mathrm{~cm}$ : grey-green tuff I.

1) $2500 \mathrm{~cm}$ : red silty claystone (lower Hsanda Gol Fm.)

\begin{tabular}{|c|c|c|c|}
\hline \multicolumn{4}{|c|}{ Legend: } \\
\hline$L_{L}^{-} L_{L}^{-} L_{L}$ & basalt & 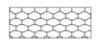 & caliche \\
\hline & tuff & $\infty \infty$ & caliche nodules \\
\hline$E=$ & clay & 50 & carbonaceous silt \\
\hline$=\ldots$ & silty clay & $\therefore \therefore \therefore]$ & fine sand \\
\hline $\begin{array}{l}5=1 \\
y+1\end{array}$ & carbonatic clay & $\therefore \therefore \therefore$ & coarse sand \\
\hline 000.00 & gravel & & manganese \\
\hline$\sum=$ & cross bedding & $\because \because \because$ & concretions \\
\hline 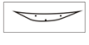 & sand lense & & \\
\hline$y A y$ & rootlets & $\theta$ & gastropoda \\
\hline$\therefore \because \therefore:$ & clay clasts & IS & small mammals \\
\hline
\end{tabular}

letter zone $\mathrm{A}$

0

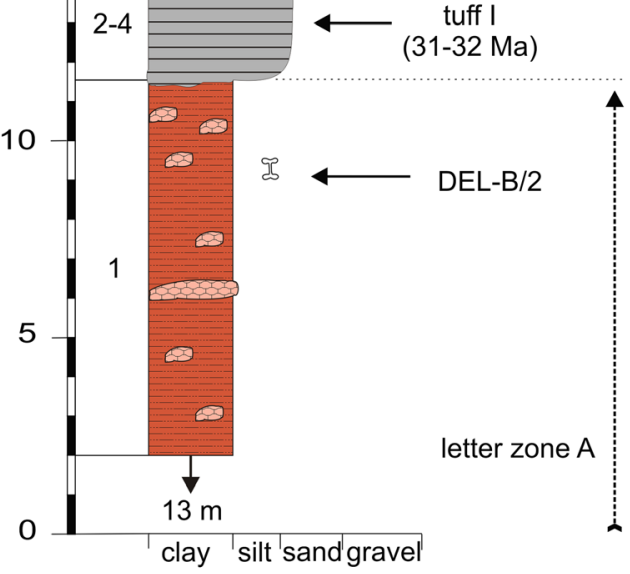


Table 12 Fossils from the locality Del (section-DEL-B, samples-DEL-B/7+8 and DEL-B/12) [the age of assemblages DEL-B/7+8 is early Oligocene (letter zone B) and of assemblage DEL-B/12 is late Oligocene (letter zone C1)]

\begin{tabular}{|c|c|}
\hline DEL-B/7+8 & DEL-B/12 \\
\hline Lagomorpha & Lagomorpha \\
\hline Ordolagus cf. teilhardi (Burke, 1941 & Ordolagus cf. teilhardi (Burke, 1941) \\
\hline Desmatolagus youngi (Gureev, 1960) & Desmatolagus cf. simplex (Argyropulo, 1940) \\
\hline Desmatolagus gobiensis Matthew and Granger, 1923 & Desmatolagus cf. chinensis Erbajeva and Sen, 1998 \\
\hline Desmatolagus robustus Matthew and Granger, 1923 & Bohlinotona cf. pusilla (Teilhard de Chardin, 1926) \\
\hline Desmatolagus cf. simplex (Argyropulo, 1940) & Sinolagomys kansuensis Bohlin, 1937 \\
\hline Desmatolagus cf. orlovi (Gureev, 1960) & Eulipotyphla \\
\hline Desmatolagus sp. & Palaeoscaptor acridens Matthew and Granger, 1924a \\
\hline Eulipotyphla & Palaeoscaptor cf. rectus Matthew and Granger, 1924a \\
\hline Zaraalestes minutus (Matthew and Granger, 1924a) & Amphechinus minutissimus Ziegler et al., 2007 \\
\hline Zaraalestes sp. & Amphechinus major Ziegler et al., 2007 \\
\hline Palaeoscaptor acridens Matthew and Granger, 1924a & Crocidosoricinae indet. \\
\hline Gobisorex kingae Sulimski, 1970 & Rodentia \\
\hline Rodentia & Asianeomys dangheensis (Wang, 2002) \\
\hline Ninamys kazimierzi Vianey-Liaud et al., 2013 & Tatataromys minor longidens Schmidt-Kittler et al., 2007 \\
\hline Anomoemys lohiculus (Matthew and Granger, 1923) & Tataromys plicidens Matthew and Granger, 1923 \\
\hline Cyclomylus lohensis Matthew and Granger, 1923 & Yindirtemys deflexus (Teilhard de Chardin, 1926) \\
\hline Cyclomylus intermedius Wang, 2001 & Tsaganomys altaicus Matthew and Granger, 1923 \\
\hline Tsaganomyidae indet. & Bohlinosminthus parvulus (Bohlin, 1946) \\
\hline Tsaganomys altaicus Matthew and Granger, 1923 & Parasminthus cf. tangingoli Bohlin, 1946 \\
\hline Heosminthus chimidae Daxner-Höck et al., 2014 & Parasminthus debruijni Lopatin, 1999 \\
\hline Heosminthus sp. & Parasminthus cf. asiaecentralis Bohlin, 1946 \\
\hline Shamosminthus sodovis Daxner-Höck, 2001 & Eucricetodon bagus Gomes Rodrigues et al., 2012 \\
\hline Ulaancricetodon badamae Daxner-Höck, 2000 & Bagacricetodon tongi Gomes Rodrigues et al., 2012 \\
\hline Cricetops dormitor Matthew and Granger, 1923 & Aralocricetodon schokensis Bendukidze, 1993 \\
\hline Eocricetodon meridionalis (Wang and Meng, 1986) & Creodonta \\
\hline Eucricetodon caducus (Shevyreva, 1967) & Hyaenodontidae indet. \\
\hline Ruminantia & Carnivora \\
\hline \multirow[t]{4}{*}{ Ruminantia indet. } & Amphicticeps shackelfordi Matthew and Granger, 1924b \\
\hline & Ruminantia \\
\hline & Bovidae gen. 2 \\
\hline & Palaeohypsodontus sp. \\
\hline
\end{tabular}

\section{Locality Tatal Gol}

For localization, see Fig. 3q, r. In Tatal Gol, two sections were studied, the composite section TAT-D+E (Figs. 21 and 22, Tables 13 and 14) and section TAT-C (Fig. 23, Table 16).

Section TAT-D+E (Fig. 21) is located west of the dry creek, called Tatal Gol. The section is composed of three parts: the lower part TAT-D/1-4 (Fig. 22c), the middle part TAT-E/1-20 (Fig. 22b), and the upper part at the "North Ridge" is TAT-E/ 21-32 (Fig. 22a). In section TAT-C (Fig. 23, Table 16), which is located east of the Tatal creek, the Hsanda Gol Fm. displays the lower Hsanda Gol beds, tuff and basalt I, and the upper Hsanda Gol beds.
Section TAT-D+E; samples: TAT-D/1, TAT-E/3, TAT-E/22, TAT-E/27, TAT-E/32; TAT-037, TAT-038-, TAT-054, TAT-055, TAT-043, TAT-044, TAT-051/1-2, TAT-052/1-2

In this section, the Hsanda Gol Fm. comprises fossils of letter zones $\mathrm{A}, \mathrm{B}, \mathrm{C}, \mathrm{C} 1$, and $\mathrm{C} 1-\mathrm{D}$, showing that the Hsanda Gol Fm. ranges from the early Oligocene to the Oligocene/Miocene transition. Although basalt I is missing in the western part of Tatal Gol, the lower and upper Hsanda Gol beds are easily recognisable by the included fossils.

The lower (= southern) part, section TAT-D, is composed of brick-red silty claystone, which yields 


$\begin{array}{ll}\text { Locality: Tatal Gol } & \text { GPS:TAT-E/ top } \\ & \text { N } 45^{\circ} 18^{\prime} 12.6^{\prime \prime} \\ \text { E } 101^{\circ} 37^{\prime} 15.7^{\prime \prime}\end{array}$

Composite section: TAT-D and TAT-E

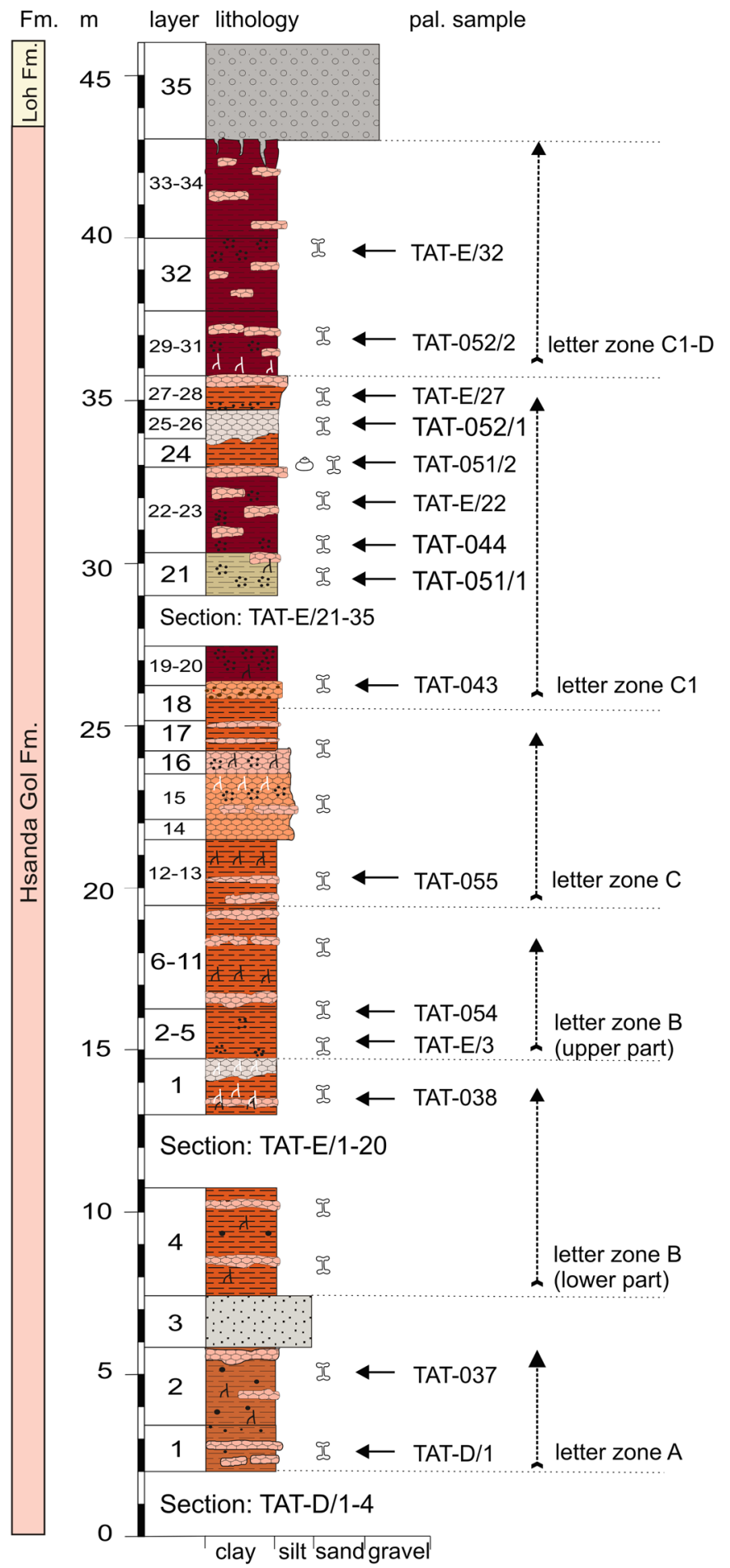

\section{Description of section TAT-E}

Section: TAT-E/1-35

layer

35) gravels of the Loh Fm.

33-34) < $340 \mathrm{~cm}$ : red-brown to greyish-brown claystone with caliche nodules. Towards top strongly weathered with recent fissures with sand infill.

32) $210 \mathrm{~cm}$ : dark red-brown claystone, strongly weathered; with mottled caliche nodules; abundant orange and dark reddish clasts; towards top dominant clay and manganese nodules $(<1 \mathrm{~mm})$. Sample: TAT-E/32.

29-31) $200 \mathrm{~cm}$ : dark red-brown claystone with manganese nodules; caliche nodules in upper part; strongly weathered in upper part; correlated sample: TAT-052/2 (North Ridge). 27-28) $100 \mathrm{~cm}$ : red-brown mottled caliche transitional into caliche layer on top $(20 \mathrm{~cm})$. Sample: TAT-E/27; correlated samples: TAT-1/1, TAT-052/1.

25-26) $85 \mathrm{~cm}$ : red-brown claystone with caliche nodules in lower part $(55 \mathrm{~cm})$ and numerous manganese nodules; grey-pink mottled caliche in upper part $(30 \mathrm{~cm})$; correlated sample from caliche layer: TAT-052/1 (North Ridge).

24) $85 \mathrm{~cm}$ : red-brown claystone; manganese nodules rare. 22-23) $300 \mathrm{~cm}$ : dark red-brown claystone alternating with mottled caliche; numerous manganese nodules in the lower part, rare towards top; manganese precipitates common. On top, $20 \mathrm{~cm}$ light reddish caliche with very small clasts $(<2 \mathrm{~mm})$. Sample TAT-E/22; correlated samples: TAT-044, TAT-050 and TAT-051/2 (North Ridge). 21) $90 \mathrm{~cm}$ : ochre claystone with greenish patches (not carbonatic); manganese nodules up to $150 \mathrm{~mm}$ in diameter, average $2-5 \mathrm{~mm}$ tiny clay clasts; layer clearly visible in the field as grey layer; correlated samples: TAT051/1 (North Ridge; Fig. 21a).

19-20) $120 \mathrm{~cm}$ : brick-red clay with manganese concretions (up to $1 \mathrm{~cm}$ ) increasing in abundance upwards; greenishgrey clasts; upwards violet-reddish-brown claystone.

18) $100 \mathrm{~cm}$ : dark red-brown claystone, on top orange caliche; sample TAT-043.

17) $90 \mathrm{~cm}$ : red-brown silty claystone alternating with caliche.

16) $80 \mathrm{~cm}$ : rose caliche with clay clasts (up to $5 \mathrm{~mm}$ ); manganese precipitates, rootlets.

14-15) $250 \mathrm{~cm}$ : red-brown caliche with clay clasts; abundant manganese precipitates in upper part, white rootlets.

12-13) $200 \mathrm{~cm}$ : red-brown carbonatic claystone; sample TAT-055.

6-11) $310 \mathrm{~cm}$ : red-brown claystone; basally with rose caliche layers; upwards silt with clay clasts; on top caliche with clay clasts (up to $5 \mathrm{~mm}$ ).

2-5) $184 \mathrm{~cm}$ : red-brown claystone; carbonatic with rare manganese precipitates, clay clasts $(2-4 \mathrm{~mm})$; sample TAT-E/3.

1) $160 \mathrm{~cm}$ : red-brown calichized claystone; abundant whitish rootlets and manganese precipitates.

\section{Section: TAT-D/1-4}

layer

4) $330 \mathrm{~cm}$ : red-brown silty clay with manganese precipitates; sandy-silty layers; clay clasts; laterally correlated sample:TAT-038 from upper Hsanda Gol Fm. 3) $162 \mathrm{~cm}$ : grey coarse sand with dark cover, sorted, rounded.

2) $238 \mathrm{~cm}$ : brick-red calichized silty claystone; caliche nodules; laterally correlated: sample TAT- 037 .

1) $150 \mathrm{~cm}$ : brick-red claystone with silty-sandy layers; manganese-rich; toward top rich caliche nodules $(1-5 \mathrm{~cm})$; sample TAT-D/1 from lower Hsanda Gol Fm.

Fig. 21 The Tatal Gol section at the west side of the Tatal creek is composed of three parts, the lower part TAT-D/1-4, the middle part TAT-E/1-20, and the upper part TAT-E/21-35 at the "North Ridge." From south to north, the section comprises the complete sequence of Oligocene sediments 

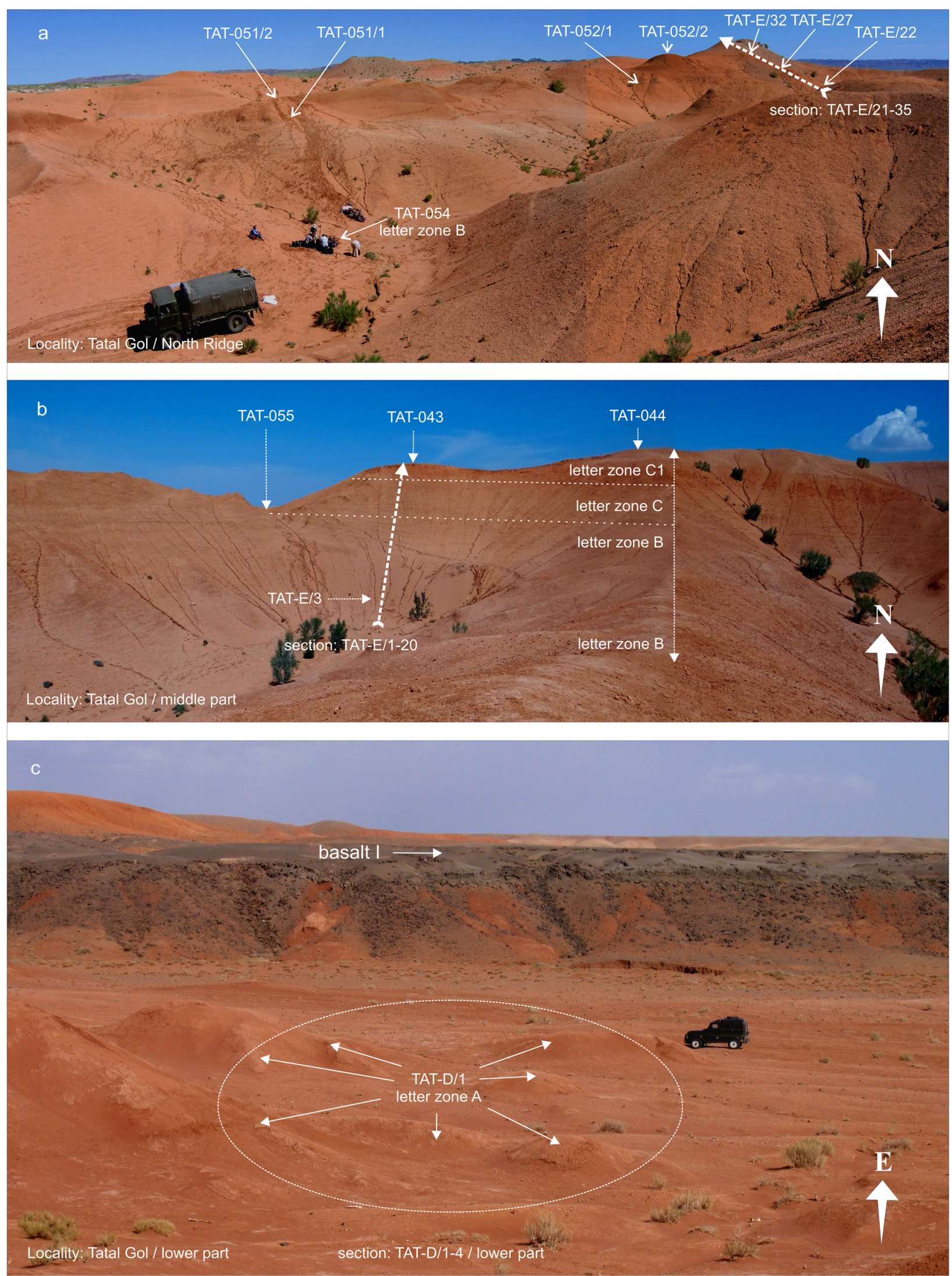

Fig. 22 Locality Tatal Gol. a Tatal Gol North Ridge shows sample points TAT-051/1-2, TAT-052/1-2, TAT-054, and the upper part of section TATE/21-35. b Tatal section Gol middle part shows section TAT-E/1-20 and fossil points TAT-055, TAT-043, TAT-044, and TAT-E/3. c Tatal Gol lower part showing the flat area from where several bulk samples TAT$\mathrm{D} / 1$ were screen washed 
Table 13 Fossils from the locality Tatal Gol (section-TAT-D, sample-TAT-D/1) [the age of assemblage is early Oligocene (letter zone A)]

\section{Tatal Gol: TAT-D/1}

Lagomorpha

Ordolagus cf. teilhardi (Burke, 1941)

Desmatolagus cf. vetustus Burke, 1941

Desmatolagus youngi (Gureev, 1960)

Desmatolagus gobiensis Matthew and Granger, 1923

Desmatolagus cf. chinensis Erbajeva and Sen, 1998

Desmatolagus cf. orlovi (Gureev, 1960)

Desmatolagus sp.

Marsupialia

Asiadelphis tjutkovae Emry et al., 1995

Eulipotyphla

Zaraalestes minutus (Matthew and Granger, 1924a)

Palaeoscaptor acridens Matthew and Granger, 1924a

Palaeoscaptor cf. rectus Matthew and Granger, 1924a

Palaeoscaptor tenuis Ziegler et al., 2007

Erinaceidae indet.

Gobisorex kingae Sulimski, 1970

cf. Asiapternodus mackennai Lopatin, 2003

Mongolopala tathue Ziegler et al., 2007

Talpidae indet.

Rodentia

Ninamys kazimierzi Vianey-Liaud et al., 2013

Prosciurus ? mongoliensis Wang and Dashzeveg, 2005

Prosciurus? nov. spec.

Promeniscomys cf. sinensis Wang, 1987a

Karakoromys decessus Matthew and Granger, 1923

Ardynomys sp.

Cyclomylus lohensis Matthew and Granger, 1923

Cyclomylus biforatus Wang, 2001

Cyclomylus intermedius Wang, 2001

Coelodontomys asiaticus Wang, 2001

Tsaganomys altaicus Matthew and Granger, 1923

Allosminthus khandae (Daxner-Höck, 2001)

Heosminthus chimidae Daxner-Höck et al., 2014

Heosminthus sp.

Shamosminthus sodovis Daxner-Höck, 2001

Ulaancricetodon badamae Daxner-Höck, 2000

Selenomys mimicus Matthew and Granger, 1923

Cricetops dormitor Matthew and Granger, 1923

Cricetops minor Wang, 1987b

Eocricetodon meridionalis (Wang and Meng, 1986)

Eucrucetodon caducus (Shevyreva, 1967)

Eucricetodon asiaticus Matthew and Granger, 1923

Creodonta

Hyaenodon cf. incertus Dashzeveg, 1985

Carnivora

Amphicynodon teilhardi (Matthew and Granger, 1924b)
Table 13 (continued)

Tatal Gol: TAT-D/1

aff. Amphicynodon sp.

Amphicticeps shackelfordi Matthew and Granger, 1924b

Leptictida

Didymoconus colgatei Matthew and Granger, 1924b

Artiodactyla

Lophiomeryx angarae Matthew and Granger, 1925b

Lophiomeryx sp.

Praetragulus gobiae (Matthew and Granger, 1925b)

Miomeryx sp.

Gobimeryx dubius Trofimov, 1957

Pseudomeryx gobiensis Trofimov, 1957

Pseudomeryx sp.

Pseudogelocus mongolicus Vislobokova and Daxner-Höck, 2002

Ruminantia indet

abundant caliche concretions and a mammal assemblage that is very rich in fossils of letter zone A (sample TAT$\mathrm{D} / 1$; Table 13). A layer of coarse grey sand follows, which is topped by the brick-red clay of the Hsanda Gol Fm., yielding fossils of letter zone B. In the middle part (TAT-E/1-11), the upper Hsanda Gol Fm. comprises fossils of letter zone B (sample TAT-E/3; Table 14). Upsection, fossils of letter zone C (sample TAT-055; Table 14) were recovered from a reddish carbonatic claystone below a 3-m-thick red-rose caliche. On top, the colour of caliche changes to orange-red with dark brown clay clast inclusions. The fossils from the orange caliche and the overlying brick-red to dark-brown clay indicate letter zone $\mathrm{C} 1$. These fossil assemblages of letter zone $\mathrm{C} 1$ are characteristic of the higher part of the section (samples TAT-043 to TAT-E/27; Table 14) and of sample points laterally of the main section. Finally, fossils of letter zone C1-D were found in the dark brown clay layers close to the top of the section at the North Ridge (samples TAT-052/2 and TAT-E/32) (Figs. 21 and 22, Table 14), which are easily recognisable by the included fossils. 
Table 14 Fossils from the locality Tatal Gol (section-TAT-E/1-32 and samples - Fig. 21a, b) [the ages of the assemblages are early Oligocene (letter zones A and B) to late Oligocene (letter zones C, C1, and C1-D)]

\begin{tabular}{|c|c|c|c|c|c|c|c|c|c|}
\hline $\begin{array}{l}\text { Tatal Gol Section: TAT-E } \\
\text { Letter zone }\end{array}$ & $\begin{array}{l}\text { TAT-037 } \\
\text { A }\end{array}$ & $\begin{array}{l}\text { TAT-E/3 } \\
\text { B }\end{array}$ & $\begin{array}{l}\text { TAT-055 } \\
\text { C }\end{array}$ & $\begin{array}{l}\text { TAT-043 } \\
\text { C1 }\end{array}$ & $\begin{array}{l}\text { TAT-044 } \\
\text { C1 }\end{array}$ & $\begin{array}{l}\text { TAT- } 051 / 2 \\
\text { C1 }\end{array}$ & $\begin{array}{l}\text { TAT-E/22 } \\
\text { C1 }\end{array}$ & $\begin{array}{l}\text { TAT-E/27 } \\
\text { C1 }\end{array}$ & $\begin{array}{l}\text { TAT-E } / 32 \\
\text { C1-D }\end{array}$ \\
\hline \multicolumn{10}{|l|}{ Gastropoda } \\
\hline \multicolumn{10}{|l|}{ Vallonia sp. } \\
\hline \multicolumn{10}{|l|}{ Lagomorpha } \\
\hline Desmatolagus gobiensis Matthew and & & & $\mathrm{x}$ & & $\mathrm{x}$ & & & & \\
\hline \multicolumn{10}{|l|}{ Granger, 1923} \\
\hline $\begin{array}{l}\text { Desmatolagus cf. simplex (Argyropulo, } \\
1940\end{array}$ & $\mathrm{x}$ & & $\mathrm{x}$ & & $\mathrm{x}$ & $\mathrm{x}$ & & & \\
\hline $\begin{array}{l}\text { Desmatolagus cf. chinensis Erbajeva and } \\
\text { Sen, } 1998\end{array}$ & $\mathrm{x}$ & & & & & & & & \\
\hline Desmatolagus sp. & $\mathrm{x}$ & $\mathrm{x}$ & & $\mathrm{x}$ & $\mathrm{x}$ & & & $\mathrm{x}$ & \\
\hline $\begin{array}{l}\text { Bohlinotona cf. pusilla (Teilhard de } \\
\text { Chardin, 1926) }\end{array}$ & \multicolumn{8}{|c|}{ Chardin, 1926) } & \\
\hline Sinolagomys kansuensis Bohlin, 1937 & & & & $\mathrm{x}$ & $\mathrm{x}$ & $\mathrm{x}$ & $\mathrm{x}$ & $\mathrm{x}$ & $\mathrm{x}$ \\
\hline Sinolagomys major Bohlin, 1937 & & & & & $\mathrm{x}$ & $\mathrm{x}$ & $\mathrm{x}$ & $\mathrm{x}$ & $\mathrm{x}$ \\
\hline Sinolagomys ulungurensis Tong, 1989 & & & & & & & & & $\mathrm{x}$ \\
\hline \multicolumn{10}{|l|}{ Eulipotyphla } \\
\hline $\begin{array}{l}\text { Zaraalestes minutus (Matthew and } \\
\text { Granger, 1924a) }\end{array}$ & $\mathrm{x}$ & $\mathrm{x}$ & $\mathrm{x}$ & & & $\mathrm{x}$ & & & \\
\hline $\begin{array}{l}\text { Palaeoscaptor acridens Matthew and } \\
\text { Granger, } 1924 \mathrm{a}\end{array}$ & $\mathrm{x}$ & $\mathrm{x}$ & $\mathrm{x}$ & $\mathrm{x}$ & & & & & \\
\hline $\begin{array}{l}\text { Palaeoscaptor cf. rectus Matthew and } \\
\text { Granger, } 1924 \mathrm{a}\end{array}$ & & & $\mathrm{x}$ & $\mathrm{x}$ & & $\mathrm{x}$ & & & \\
\hline Palaeoscaptor tenuis Ziegler et al., 2007 & & $\mathrm{x}$ & $\mathrm{x}$ & & & & & & \\
\hline Palaeoscaptor gigas (Lopatin, 2002) & & & & & & $\mathrm{x}$ & & $\mathrm{x}$ & \\
\hline $\begin{array}{l}\text { Amphechinus taatsiingolensis Ziegler } \\
\text { et al., } 2007\end{array}$ & & & $\mathrm{x}$ & $\mathrm{x}$ & & $\mathrm{x}$ & & & $\mathrm{x}$ \\
\hline $\begin{array}{l}\text { Amphechinus minutissimus Ziegler } \\
\text { et al., } 2007\end{array}$ & & & & $\mathrm{x}$ & & $\mathrm{x}$ & $\mathrm{x}$ & $\mathrm{x}$ & \\
\hline Amphechinus major Ziegler et al., 2007 & & & & $\mathrm{x}$ & & $\mathrm{x}$ & $\mathrm{x}$ & $\mathrm{x}$ & $\mathrm{x}$ \\
\hline Erinaceidae indet. & $\mathrm{x}$ & $\mathrm{x}$ & $\mathrm{x}$ & & & $\mathrm{x}$ & & & \\
\hline Gobisorex kingae Sulimski, 1970 & $\mathrm{x}$ & & $\mathrm{x}$ & & & & & & \\
\hline \multicolumn{10}{|l|}{ Rodentia } \\
\hline Promeniscomys sinensis Wang 1987 & & $\mathrm{x}$ & & & & & & & \\
\hline Asianeomys dangheensis (Wang, 2002) & & & & & & & & & $\mathrm{x}$ \\
\hline \multicolumn{9}{|l|}{ Karakoromys decessus Matthew and } & \\
\hline $\begin{array}{l}\text { Yindirtemys shevyrevae Vianey-Liaud } \\
\text { et al., } 2006\end{array}$ & $\mathrm{x}$ & & & & & & & & \\
\hline $\begin{array}{l}\text { Tataromys sigmodon Matthew and } \\
\text { Granger, } 1923\end{array}$ & & & $\mathrm{x}$ & & & & & & \\
\hline $\begin{array}{l}\text { Tatataromys minor longidens Schmidt-Kittler } \\
\text { et al., } 2007\end{array}$ & & & $\mathrm{x}$ & & & & & & \\
\hline $\begin{array}{l}\text { Tataromys plicidens Matthew and } \\
\text { Granger, } 1923\end{array}$ & & & $\mathrm{x}$ & & & & & & \\
\hline
\end{tabular}


Table 14 (continued)

\begin{tabular}{|c|c|c|c|c|c|c|c|c|c|}
\hline $\begin{array}{l}\text { Tatal Gol Section: TAT-E } \\
\text { Letter zone }\end{array}$ & $\begin{array}{l}\text { TAT- } 037 \\
\text { A }\end{array}$ & $\begin{array}{l}\text { TAT-E/3 } \\
\text { B }\end{array}$ & $\begin{array}{l}\text { TAT- }-055 \\
\text { C }\end{array}$ & $\begin{array}{l}\text { TAT- } 043 \\
\text { C1 }\end{array}$ & $\begin{array}{l}\text { TAT-044 } \\
\text { C1 }\end{array}$ & $\begin{array}{l}\text { TAT- } 051 / 2 \\
\text { C1 }\end{array}$ & $\begin{array}{l}\text { TAT-E/22 } \\
\text { C1 }\end{array}$ & $\begin{array}{l}\text { TAT-E/27 } \\
\text { C1 }\end{array}$ & $\begin{array}{l}\text { TAT-E/32 } \\
\text { C1-D }\end{array}$ \\
\hline Yindirtemys deflexus (Teilhard de & & & & $\mathrm{x}$ & $\mathrm{x}$ & $\mathrm{x}$ & $\mathrm{x}$ & $\mathrm{x}$ & \\
\hline Chardin, 1926) & & & & & & & & & \\
\hline Yindirtemys birgeri Bendukidze, 1993 & & & & & & $\mathrm{x}$ & & & \\
\hline Yindirtemys suni $\mathrm{Li}$ and Qiu, 1980 & & & & & & & & & $\mathrm{x}$ \\
\hline Ardynomys sp. & $\mathrm{x}$ & & & & & & & & \\
\hline Cyclomylus intermedius Wang, 2001 & $\mathrm{x}$ & & & & & & & & \\
\hline Tsaganomys altaicus Matthew and & & & $\mathrm{x}$ & $\mathrm{x}$ & $\mathrm{x}$ & $\mathrm{x}$ & & & \\
\hline Granger, 1923 & & & & & & & & & \\
\hline Allosminthus minutus (Daxner-Höck, 2001) & & & $\mathrm{x}$ & & & & & & \\
\hline $\begin{array}{l}\text { Heosminthus chimidae Daxner-Höck } \\
\text { et al., } 2014\end{array}$ & $\mathrm{x}$ & $\mathrm{x}$ & $\mathrm{x}$ & $\mathrm{x}$ & & & $\mathrm{x}$ & & \\
\hline $\begin{array}{l}\text { Heosminthus borrae Daxner-Höck } \\
\text { et al., } 2014\end{array}$ & & & $\mathrm{x}$ & & & & & $\mathrm{x}$ & $\mathrm{x}$ \\
\hline Heosminthus sp. & & & $\mathrm{x}$ & $\mathrm{x}$ & & & & & \\
\hline $\begin{array}{l}\text { Onjosminthus baindi Daxner-Höck } \\
\text { et al., } 2014\end{array}$ & $\mathrm{x}$ & & & & & & & & \\
\hline Shamosminthus sodovis Daxner-Höck, 2001 & & $\mathrm{x}$ & $\mathrm{x}$ & & & & & & \\
\hline Shamosminthus tongi Huang, 1992 & & & $\mathrm{x}$ & & & & & & \\
\hline Bohlinosminthus parvulus (Bohlin, 1946) & & & & $\mathrm{x}$ & & $\mathrm{x}$ & $\mathrm{x}$ & $\mathrm{x}$ & $\mathrm{x}$ \\
\hline Parasminthus cf. tangingoli Bohlin, 1946 & & & & $\mathrm{x}$ & & & & & \\
\hline Parasminthus debruijni Lopatin, 1999 & & & & & & & & $\mathrm{x}$ & \\
\hline Litodonomys huangheensis Wang and Qiu, 2000 & & & & & & & & & $\mathrm{x}$ \\
\hline Litodonomys lajeensis (Li and Qiu, 1980) & & & & & $\mathrm{x}$ & $\mathrm{x}$ & $\mathrm{x}$ & $\mathrm{x}$ & $\mathrm{x}$ \\
\hline Litodonomys lajeensis (Li and Qiu, 1980) & & & & & & & $\mathrm{x}$ & $\mathrm{x}$ & $\mathrm{x}$ \\
\hline Selenomys mimicus Matthew and Granger, 1923 & $\mathrm{x}$ & & & & & & & & \\
\hline Cricetops dormitor Matthew and Granger, 1923 & $\mathrm{x}$ & & & & & & & & \\
\hline $\begin{array}{l}\text { Eocricetodon meridionalis } \\
\text { (Wang and Meng, 1986) }\end{array}$ & $\mathrm{x}$ & & & & & & & $\mathrm{x}$ & \\
\hline Eucricetodon caducus (Shevyreva, 1967) & $\mathrm{x}$ & $\mathrm{x}$ & & & & & & & \\
\hline $\begin{array}{l}\text { Eucricetodon asiaticus Mathew and } \\
\text { Granger, } 1923\end{array}$ & & $\mathrm{x}$ & & & & & & & \\
\hline $\begin{array}{l}\text { Eucricetodon bagus Gomes Rodrigues } \\
\text { et al., } 2012\end{array}$ & & $\mathrm{x}$ & & & & & & $\mathrm{x}$ & \\
\hline Tachyoryctoides radnai Daxner-Höck et al., 2015 & & & $\mathrm{x}$ & & & & & & \\
\hline Tachyoryctoides obrutschewi Bohlin, 1937 & & & & & & $\mathrm{x}$ & & & \\
\hline Tachyoryctoides tatalgolicus Dashzeveg, 1971 & & & & $\mathrm{x}$ & & & $\mathrm{x}$ & & \\
\hline Tachyoryctoides sp. & & & & $\mathrm{x}$ & $\mathrm{x}$ & & & & $x$ \\
\hline
\end{tabular}


Section: TAT-C; samples: TAT-C/1-3, TAT-C/6-7

From bottom to top, the section displays lower Hsanda Gol beds below basalt and tuff I (samples-TAT-C/1-3) and upper Hsanda Gol beds (samples-TAT-C/6-7) above basalt I (Fig. 23; Table 15).

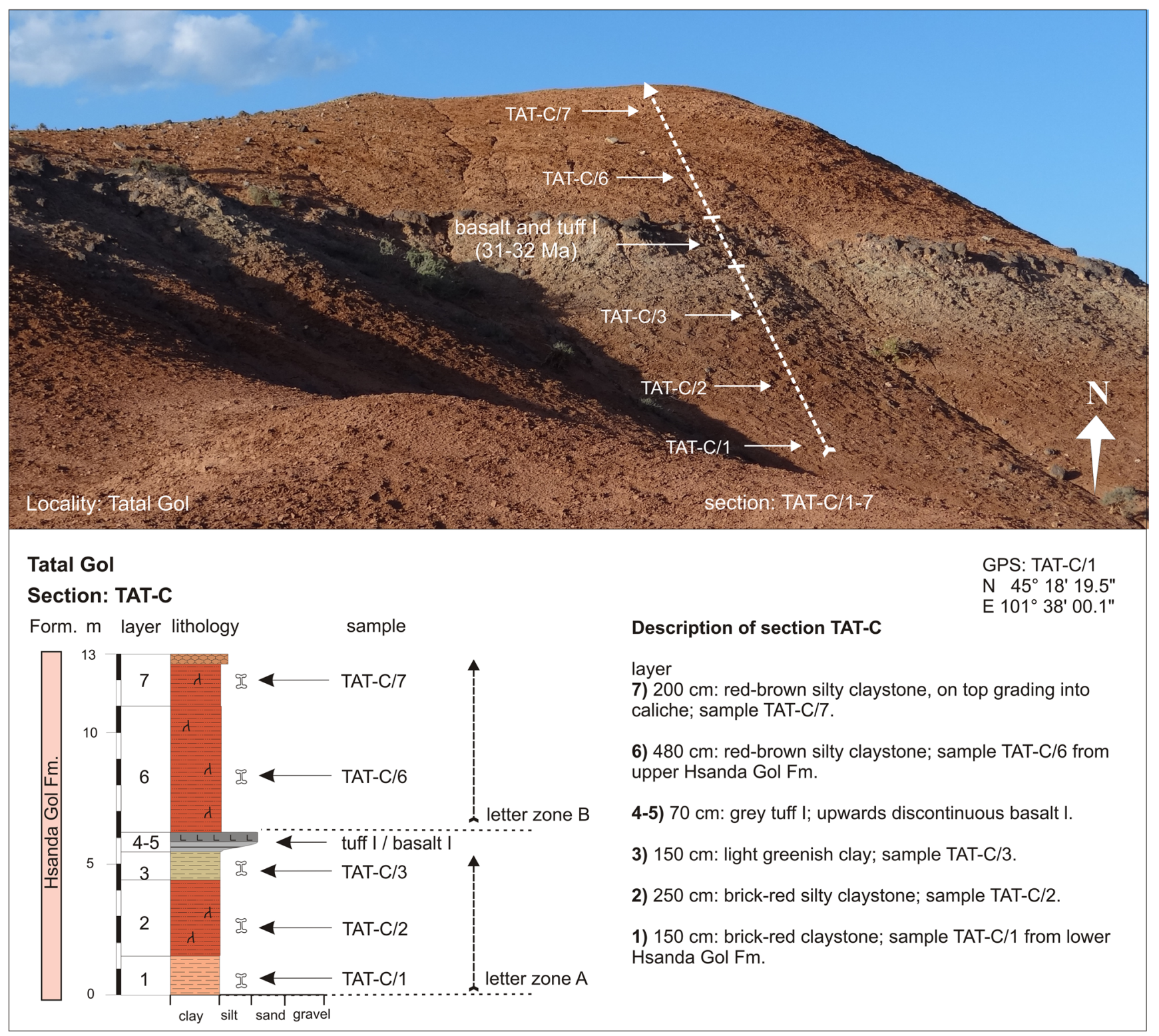

Fig. 23 Section TAT-C is located east side of the Tatal creek in the north-eastern part of the locality 
Table 15 Fossil list from section TAT-C in Tatal Gol (the samples TAT-C/1-3 below basalt I yield fossils of letter zone $\mathrm{A}$, the fossils from samples TAT-C/6-7 above basalt I indicate letter zone B)
Tatal Gol

TAT-C/1-3

TAT-C/6-7

Section: TAT-C

Letter zone

Lagomorpha

Desmatolagus youngi (Gureev, 1960)

Desmatolagus gobiensis Matthew and Granger, 1923 Eulipotyphla

Zaraalestes minutus (Matthew and Granger, 1924a)

Palaeoscaptor acridens Matthew and Granger, 1924a

Palaeoscaptor tenuis Ziegler et al., 2007

Erinaceidae indet.

Crocidosoricinae indet.

Rodentia

Ninamys kazimierzi Vianey-Liaud et al., 2013

Ninamys arboraptus (Shevyreva, 1966)

Eomys cf. orientalis Wang and Emry, 1991

Huangomys frequens Schmidt-Kittler et al., 2007

Cyclomylus lohensis Matthew and Granger, 1923

Cyclomylus intermedius Wang, 2001

Coelodontomys asiaticus Wang, 2001

Tsaganomys altaicus Matthew and Granger, 1923

Allosminthus minutus (Daxner-Höck, 2001)

Heosminthus chimidae Daxner-Höck et al., 2014

Heosminthus borrae Daxner-Höck et al., 2014

Shamosminthus sodovis Daxner-Höck, 2001

Bohlinosminthus parvulus (Bohlin, 1946)

Ulaancricetodon badamae Daxner-Höck, 2000

Eocricetodon meridionalis (Wang and Meng, 1986)

Eucricetodon caducus (Shevyreva, 1967)

Eucricetodon asiaticus Matthew and Granger, 1923

Cricetidae s.l. indet.

Creodonta

Hyaenodon pervagus Matthew and Granger, 1924b

Carnivora

cf. Asiavorator sp.

Ruminantia

Eumeryx culminis Matthew and Granger, 1924a

Ruminantia indet.
A

B

\section{$\mathrm{x}$}

$\mathrm{x}$

$\mathrm{x}$

$\mathrm{x}$

$\mathrm{X}$

$\mathrm{x}$

$\mathrm{x}$

$\mathrm{x}$

$\mathrm{x}$

$\mathrm{x}$

$\mathrm{x}$

$\mathrm{x}$

$\mathrm{x}$

$\mathrm{x}$

x

$\mathrm{x}$

$\mathrm{x}$

$\mathrm{x}$

$\mathrm{x}$

$\mathrm{x}$

$\mathrm{x}$

$\mathrm{x}$

$\mathrm{x}$

$\mathrm{x}$

$\mathrm{x}$

$\mathrm{x}$

$\mathrm{x}$

$\mathrm{x}$

$\mathrm{x}$

$\mathrm{x}$

$\mathrm{x}$

$\mathrm{x}$

$\mathrm{x}$

$\mathrm{x}$

$\mathrm{x}$
$x$ 


\section{Locality Hsanda Gol}

From the Hsanda Gol area, we investigated three sections: SHG-C (Fig. 3s), SHG-A, and SHG-D (Figs. 3t and u).

A basalt plateau of $\sim 50 \mathrm{~km}^{2}$ extension is exposed between the Tatal Gol and Hsand Gol regions, and section SHG-C (Fig. 24) is located in its south-eastern corner. East of the basalt plateau, a SW $\rightarrow \mathrm{NE}$ striking ridge consists of sequences of the Hsanda Gol Fm. The sections SHG-A and SHG-D are located at the southern part of this ridge. Following the ridge in NW direction, the Hsanda Gol Fm. is topped by strata of the
Loh Fm. A small dry creek, the "Hsanda Gol," east of the ridge is giving name to the entire region and to the Hsanda Gol Fm.

\section{Section: $S H G-C$; samples: $S H G-C / 1-2$}

Below basalt I (31-32 Ma), $10 \mathrm{~m}$ of red-brown silty claystone yields fossils of letter zone A (samples-SHG$\mathrm{C} / 1$ and SHG-C/2). The early Oligocene age is indicated by basalt I and by the fossils.

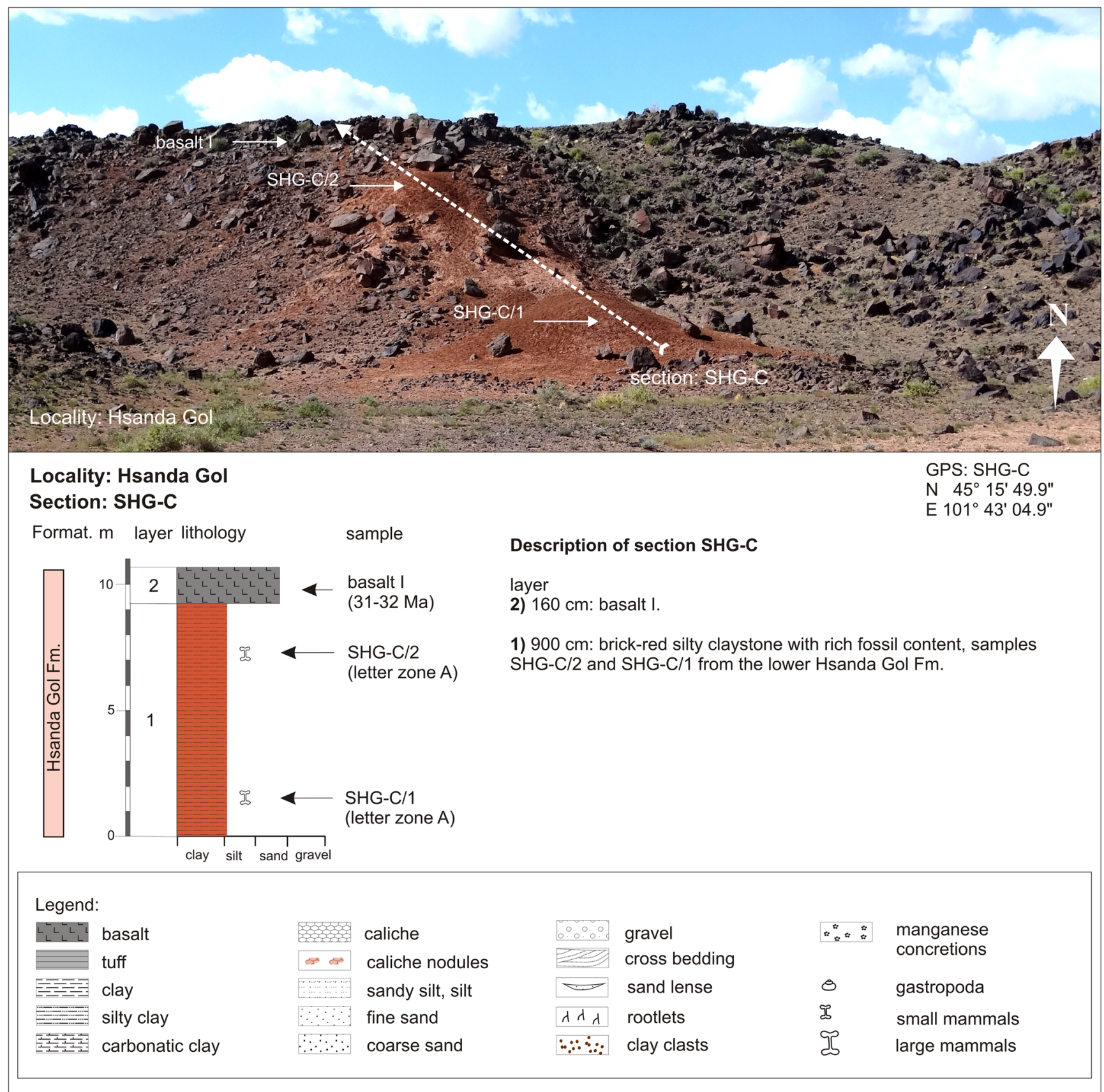

Fig. 24 The Hsanda Gol section SHG-C is located below basalt I of a widespread basalt flow between the Tatal Gol and Hsanda Gol localities 
Sections: SHG-A and SHG-D; samples: $S H G-A / 1$, SHG-A/9-10, SHG-A/12, SHG-A/15, SHG-A/17-20; $S H G-A B / 12, S H G-A B / 15-20, S H G-A B / t o p$

The Hsanda Gol sections SHG-A, SHG-D, and the SHG-AB samples have no contact to any basalt; however, letter zone B is indicated by the rich fossil content (Fig. 25; Tables 15 and 16 and Table 17). Here, the upper Hsanda Gol beds are composed of 35-40 m red-brown claystone alternating with caliche. This sequence is divided by $3 \mathrm{~m}$ of sandstone and gravels (layers-SHG-A/13+14 and SHG-D/12). A significant orange caliche layer (SHG-D/28-31) above dark brown clay-stone (SHG-D/27) terminates the lower Oligocene strata. On top of this sequence, fossils of letter zone $\mathrm{C} 1$ indicate the upper Oligocene. 


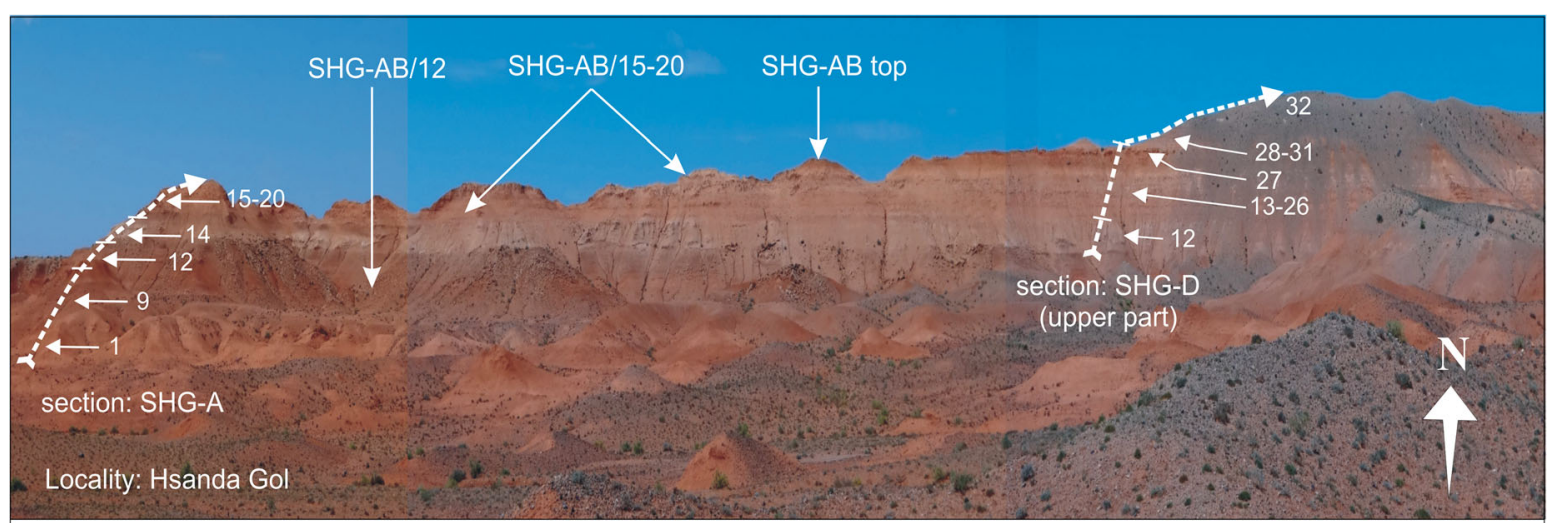

\section{Locality: Hsanda Gol}

\section{Section: SHG-A} Fm. $m$ sed. lithology samples

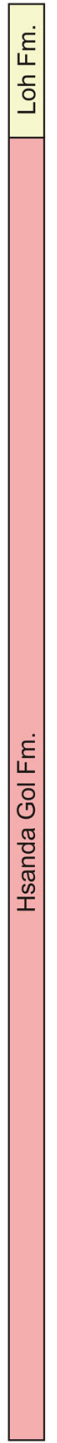

0 $2-4$ 2

1

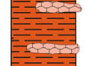

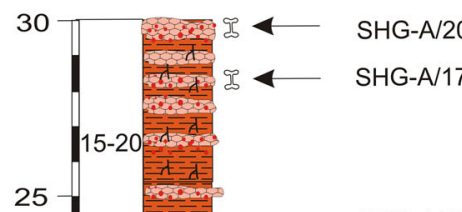

SHG-A/15
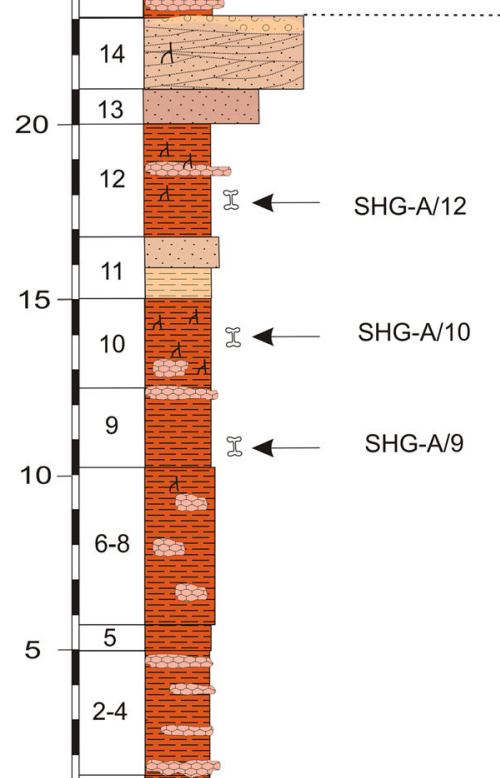

SHG-A/1 samples: SHG-AB

letter zones

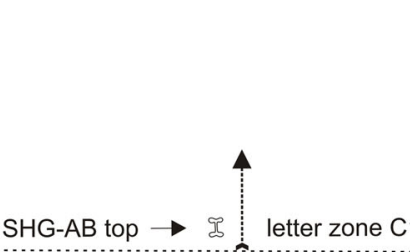

GPS: SHG-A

N $45^{\circ} 16^{\prime} 01^{\prime \prime}$ (upper part)

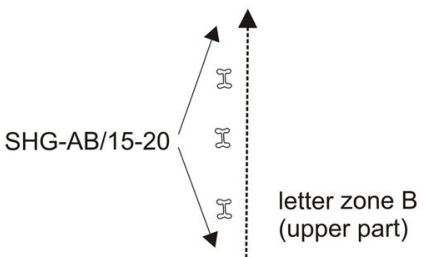

$\mathrm{m}$

Section: SHG-D

sed.

layer lithology

35
32
32

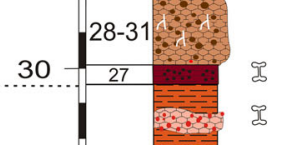

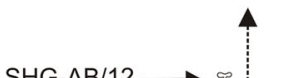

15

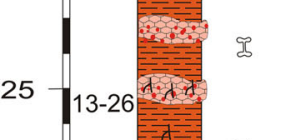

20
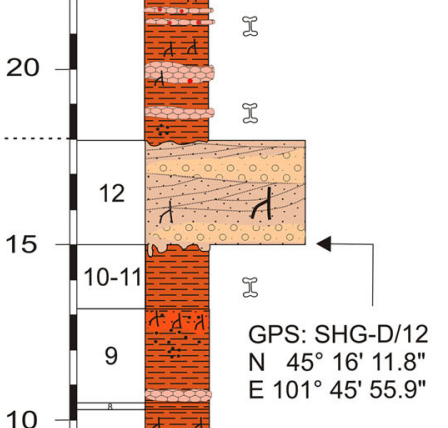

10

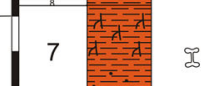

5-6

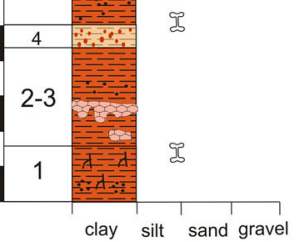

E $101^{\circ} 45^{\prime} 45^{\prime \prime}$

letter zone B (lower part)

Fig. 25 Sections SHG-A and SHG-D are located at the south-western part of the $\mathrm{S} \rightarrow$ NE striking ridge connecting the Hsanda Gol and Loh localities. The southern part of the ridge is dominated by sediments of the Hsanda Gol Fm 
Table 16 Description of sections SHG-A and SHG-D from the Hsanda Gol region

\section{Description of section SHG-A}

Layer

(16-20) $450 \mathrm{~cm}$ : light red-brown claystone alternates with white-rose caliche layers and mottled caliche; caliche with red clay clasts, rootlets. Samples SHG-A/17, SHG-A/18, SHG-A/20

(15) $240 \mathrm{~cm}$ : light red-brown claystone with brown clasts, rich fossil content; sample SHG-A/15

(14) $200 \mathrm{~cm}$ : light grey-ochre fine sand and medium gravel with silt layers, well bedded, cross-bedded

(13) $100 \mathrm{~cm}$ : beige to orange silt and sandy beds overlying the red claystone. Red-brown claystone with rich fossil content; sample SHG-A/12

(11) $180 \mathrm{~cm}$ : orange-brown claystone with silt lenses; upper part silty sand

(10) $320 \mathrm{~cm}$ : red-brown clay; sample SHG-A/10

(9) $230 \mathrm{~cm}$ : red-brown clay; sample SHG-A/9

(6-8) $450 \mathrm{~cm}$ : red-brown calichized claystone with interbedded soft clay layers

(5) $70 \mathrm{~cm}$ : red-brown silty claystone

(2-4) $350 \mathrm{~cm}$ : red-brown claystone alternates with caliche and soft clay layers; poor fossil content

(1) $150 \mathrm{~cm}$ : red-brown silty clay, sample SHG-A/1 from the upper Hsanda Gol Fm.

Description of section SHG-D

Layer

(32) $\rightarrow$ gravels of the Loh Fm.

(28-31) $200 \mathrm{~cm}$ : orange caliche with dark brown clay clasts $(5-50 \mathrm{~mm}$ ) alternating with reddish-brown, silty, calichized claystone. Basal layer with high carbonate content; few rootlets

(27) $50 \mathrm{~cm}$ : dark red-brown silty claystone with rare gravel components, small bones, concretions, manganese-rich caliche layers, and knolls

(13-26) $1150 \mathrm{~cm}$ : light red-brown claystone alternates with white-rose caliche layers and mottled caliche; caliche with red clay clasts; rich fossil content. Basal part reddish-ochre silty clay with clasts, rootlets, low manganese content

(12) $300 \mathrm{~cm}$ : light grey-ochre fine sand and medium gravel with silt layers; cross bedding; ripple-bedded; uppermost part fine sand with clay layers, upper surface irregular

(10-11) $180 \mathrm{~cm}$ : brick-red claystone; moderate manganese content; fine gravel bound to bioturbation; clay more weathered towards overlying sandy beds; ochre clay in basal part; fossil rich

(9) $280 \mathrm{~cm}$ : light brown silty clay with limonitic patches; $60 \mathrm{~cm}$ above base changing to dark red clay; high manganese content; in upper parts fine sandy contents; caliche at the base

(8) $25 \mathrm{~cm}$ : homogeneous, brick-red claystone

(7) $250 \mathrm{~cm}$ : light red-brown claystone with sand lenses; abundant rootlets; manganese bound to rootlets, limonitic colouration; carbonate-free; lateral concretions

(5-6) $185 \mathrm{~cm}$ : red-brown claystone with manganese; caliche in its middle part; fossil rich

(4) $70 \mathrm{~cm}$ : ochre-brown clay with fine gravel clasts and sand lenses; on top grading into caliche

(2-3) $280 \mathrm{~cm}$ : red-brown silty claystone with manganese precipitates; upwards becoming browner; upwards caliche lenses and nodules

(1) $155 \mathrm{~cm}$ : red-brown claystone of the lower Hsanda Gol Fm.; claystone with manganese precipitates; carbonate free 
Table 17 Fossils from the Hsanda Gol locality (sections SHG-C, SHG-A, and SHG-AB-samples yield fossils of the letter zones A, B, and C1)

\begin{tabular}{|c|c|c|c|c|c|c|}
\hline Hsanda Gol & $\mathrm{SHG}-\mathrm{C} / 1+2$ & SHG-A/1-9 & SHG-A/15-20 & $\mathrm{SHG}-\mathrm{AB} / 12+13$ & SHG-AB/17-20 & SHG-AB/top. \\
\hline Letter zone & A & B & $\mathrm{B}$ & $\mathrm{B}$ & $\mathrm{B}$ & $\mathrm{C} 1$ \\
\hline
\end{tabular}

Amphibia

Anura indet.

Reptilia

Tinosaurus sp.

Lacertidae indet.

Calamagras sp.

Melanosaurini indet.

Mammalia

Marsupialia

Asiadelphis zaissanensis Gabunia et al., 1990

Lagomorpha

Ordolagus cf. teilhardi (Burke, 1941)

Desmatolagus youngi (Gureev, 1960)

Desmatolagus gobiensis Matthew and Granger, 1923

Desmatolagus cf. simplex (Argyropulo, 1940)

Desmatolagus cf. chinensis Erbajeva and Sen, 1998

Desmatolagus cf. orlovi (Gureev, 1960)

Desmatolagus sp.

Sinolagomys kansuensis Bohlin, 1937

Eulipotyphla

Zaraalestes minutus (Matthew and Granger, 1924a)

Palaeoscaptor acridens Matthew and Granger, 1924a

Palaeoscaptor tenuis Ziegler et al., 2007

Gobisorex kingae Sulimski, 1970

Taatsiinia hoeckorum Ziegler et al., 2007

Crocidosoricinae indet.

Heterosoricinae indet

Mongolopala tathue Ziegler et al., 2007

Talpidae indet.

Rodentia

Ninamys arboraptus (Shevyreva, 1966)

Eomys aff. orientalis Wang and Emry, 1991

Karakoromys decessus Matthew and Granger, 1923

Yindirtemys shevyrevae Vianey-Liaud et al., 2006

Tataromys sigmodon Matthew and Granger, 1923

Tataromys plicidens Matthew and Granger, 1923

Ardynomys sp.

Cyclomylus intermedius Wang, 2001

Cyclomylus lohensis Matthew and Granger, 1923

Coelodontomys asiaticus Wang, 2001

Tsaganomyidae indet.

Tsaganomys altaicus Matthew and Granger, 1923

Allosminthus khandae (Daxner-Höck, 2001)

Allosminthus minutus (Daxner-Höck, 2001)

Heosminthus chimidae Daxner-Höck et al., 2014

Heosminthus sp.

Onjosminthus baindi Daxner-Höck et al., 2014

Shamosminthus sp.

Bohlinosminthus parvulus (Bohlin, 1946)

Ulaancricetodon badamae Daxner-Höck, 2000

Selenomys mimicus Matthew and Granger, 1923

Cricetops dormitor Matthew and Granger, 1923

Eocricetodon meridionalis (Wang and Meng, 1986)

Eucricetodon caducus (Shevyreva, 1967)

Eucricetodon asiaticus Matthew and Granger, 1923

Tachyoryctoides obrutschewi Bohlin, 1937

Creodonta

Hyaenodon cf. mongoliensis (Dashzeveg, 1964)

Hyaenodon pervagus Matthew and Granger, 1924b

Hyaenodon eminus Matthew and Granger, 1925a

Hyaenodontidae indet. 
Table 17 (continued)

\begin{tabular}{|c|c|c|c|c|c|c|}
\hline $\begin{array}{l}\text { Hsanda Gol } \\
\text { Letter zone }\end{array}$ & $\begin{array}{l}\text { SHG-C/1+2 } \\
\text { A }\end{array}$ & $\begin{array}{l}\text { SHG-A/1-9 } \\
\text { B }\end{array}$ & $\begin{array}{l}\text { SHG-A/15-20 } \\
\text { B }\end{array}$ & $\begin{array}{l}\text { SHG-AB/12+13 } \\
\text { B }\end{array}$ & $\begin{array}{l}\text { SHG-AB/17-20 } \\
\text { B }\end{array}$ & $\begin{array}{l}\text { SHG-AB/top. } \\
\text { C1 }\end{array}$ \\
\hline \multicolumn{7}{|l|}{ Carnivora } \\
\hline Amphicynodon teilhardi (Matthew and Granger, 1924b) & & & & & $\mathrm{x}$ & \\
\hline Amphicynodon sp. & & & & & $\mathrm{x}$ & \\
\hline Shandgolictis elegans Hunt, 1998 & & & & $\mathrm{x}$ & $\mathrm{x}$ & \\
\hline Nimravus mongoliensis (Gromova, 1959) & & & & $\mathrm{x}$ & $\mathrm{x}$ & \\
\hline Palaeogale sp. & & & & $\mathrm{x}$ & & \\
\hline Carnivora indet. & & & & $\mathrm{x}$ & & \\
\hline \multicolumn{7}{|l|}{ Leptictida } \\
\hline Didymoconus colgatei Matthew and Granger, 1924b & & & & $\mathrm{x}$ & & \\
\hline \multicolumn{7}{|l|}{ Artiodactyla } \\
\hline Gobimeryx sp. & & & & & $\mathrm{x}$ & \\
\hline Eumeryx sp. & & & & $\mathrm{x}$ & $\mathrm{x}$ & \\
\hline
\end{tabular}

\section{Locality Loh}

Sections: $\mathrm{LOH}-\mathrm{C}$ and $\mathrm{LOH}-\mathrm{B}$; samples: $\mathrm{LOH}-\mathrm{C} / 1, \mathrm{LOH}-\mathrm{B} / 3$

The sections $\mathrm{LOH}-\mathrm{C}$ and $\mathrm{LOH}-\mathrm{B}$ (Fig. $3 \mathrm{v}$ and $\mathrm{w}$ ) are located in the middle and north-eastern part of the $\mathrm{SW} \rightarrow \mathrm{NE}$ striking ridge, between the Hsanda Gol and Loh regions. From bottom to top, the sections display strata of the Hsanda Gol and Loh Fms. (Fig. 26). Above the orange caliche layer, characteristic fossils of letter zone $\mathrm{C} 1$ were found ( $\mathrm{LOH}-\mathrm{C} /$ 1 and $\mathrm{LOH}-\mathrm{B} / 3$ ). Upsection, light-coloured sand of the Loh Fm. alternates with red silty clay. 


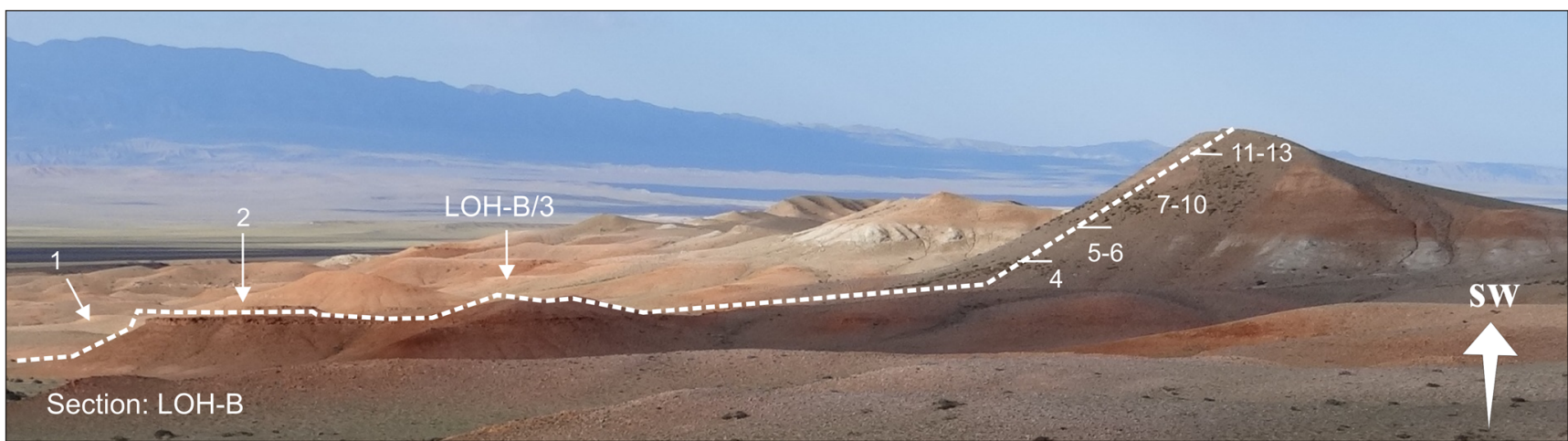

\section{Locality: Loh}

Section: LOH-B

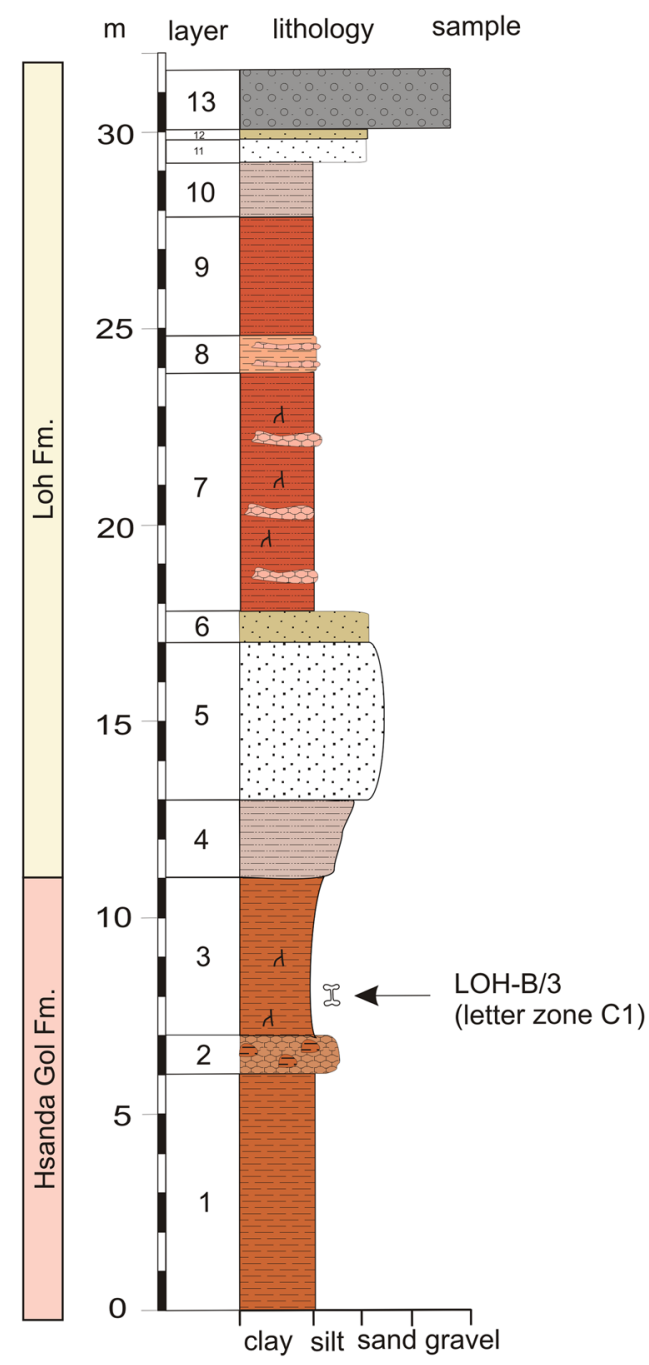

GPS:

N $45^{\circ} 17^{\prime} 04.9^{\prime \prime}$

E $101^{\circ} 47^{\prime} 22.7^{\prime \prime}$

\section{Description of section LOH-B}

layer

13) $150 \mathrm{~cm}$ : grey-green gravel.

12) $20 \mathrm{~cm}$ : olive sand.

11) $50 \mathrm{~cm}$ : white sand.

10) $150 \mathrm{~cm}$ : grey-brown silty clay.

9) $300 \mathrm{~cm}$ : red-brown silty claystone.

8) $100 \mathrm{~cm}$ : rose claystone with caliche layers.

7) $600 \mathrm{~cm}$ : red-brown silty claystone with rootlets and caliche layers.

6) $90 \mathrm{~cm}$ : olive-beige sand.

5) $400 \mathrm{~cm}$ : white sand $400 \mathrm{~cm}$.

4) $200 \mathrm{~cm}$ : grey-beige silty claystone (Loh Fm.).

3) $400 \mathrm{~cm}$ : red-brown claystone; sample LOH-B/3.

2) $100 \mathrm{~cm}$ : orange-red caliche with dark-brown clay clasts.

1) $600 \mathrm{~cm}$ : red-brown claystone (upper Hsanda Gol Fm.).

\begin{tabular}{|c|c|c|}
\hline $\begin{array}{l}\text { Fossils of sections: } \\
\text { Loh - C and LOH - B }\end{array}$ & $\begin{array}{l}\bar{X} \\
\frac{1}{1} \\
0\end{array}$ & $\begin{array}{l}m \\
\stackrel{m}{0} \\
\underline{1} \\
\underline{0}\end{array}$ \\
\hline letter zone & C1 & C1 \\
\hline Lagomorpha & & \\
\hline Desmatolagus cf. chinensis Erbajeva \& Sen, 1998 & $\mathrm{x}$ & \\
\hline Desmatolagus sp. & $\mathrm{x}$ & \\
\hline Bohlinotona cf. pusilla (Teilhard de Chardin, 1926) & & $\mathrm{x}$ \\
\hline Sinolagomys kansuensis Bohlin, 1937 & $\mathrm{x}$ & \\
\hline Sinolagomys major Bohlin, 1937 & & $\mathrm{x}$ \\
\hline Eulipotyphla & & \\
\hline $\begin{array}{l}\text { Palaeoscaptor cf. rectus Matthew \& Granger, } \\
1924\end{array}$ & $\mathrm{x}$ & \\
\hline Amphechinus minutissimus Ziegler et al., 2007 & $\mathrm{x}$ & \\
\hline Amphechinus major Ziegler et al., 2007 & $\mathrm{x}$ & $\mathrm{x}$ \\
\hline Rodentia & & \\
\hline Kherem shandgoliensis Minjin, 2004 & $\mathrm{x}$ & \\
\hline Yindirtemys deflexus (Teilhard de Chardin, 1926) & $x$ & $x$ \\
\hline Bohlinosminthus parvulus (Bohlin, 1946) & $\mathrm{x}$ & \\
\hline Plesiosminthus sp. & $\mathrm{x}$ & \\
\hline Litodonomys huangheensis Wang \& Qiu, 2000 & $\mathrm{x}$ & \\
\hline Heterosminthus firmus Zazhigin \& Lopatin, 2000 & $\mathrm{x}$ & \\
\hline Leptictida & & \\
\hline
\end{tabular}

Fig. 26 Section LOH-B and fossil list of sections LOH-B and LOH-C 


\section{Locality Talyn Churum}

\section{Sample: GRAB-II}

Talyn Churum is one of the eastern fossil points (Fig. $3 \mathrm{x}$ ). The short section displays about $10 \mathrm{~m}$ of red-brown silty claystone of the Hsanda Gol Fm. below basalt I (31-32 Ma) (Fig. 27). The early Oligocene age of the included fauna (letter zone A) is indicated by basalt $\mathrm{I}$.

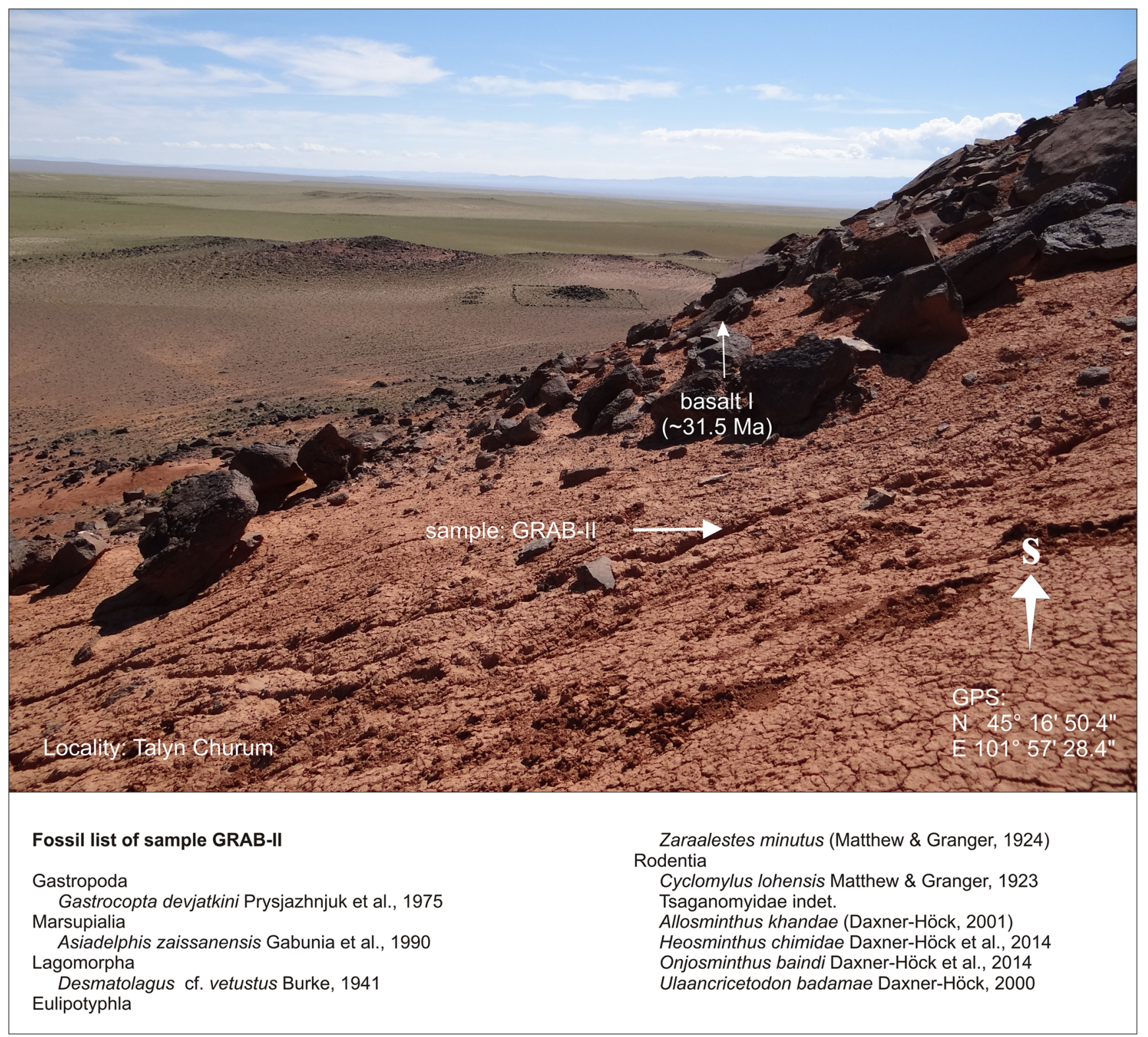

Fig. 27 Talyn Churum is located in the eastern part of the studied area, southeast of the volcano Dzun Hsir. The sample GRAB-II was excavated below basalt I. Graves of the Bronze Age are visible in the background 


\section{Locality Ikh Argalatyn Nuruu}

Sections: IKH-A and IKH-B; samples: IKH-A/1-5, IKH-B/2, $I K H-B / 5$

From Ikh Argalatyn Nuruu, two sections were investigated, section IKH-A (Fig. 3y) and section IKH-B
(Fig. 3z). The two sections are located in the easternmost part of the study area. Section IKH-A exposes red silty clay layers alternating with caliche of the upper Hsanda Gol Fm. Samples IKH-A/1-4 yield fossils of letter zone B. The top layer of orange caliche (yielding $Y$. deflexus) marks the lower boundary of letter zone $\mathrm{C} 1$ (Fig. 28,29; Table 18).

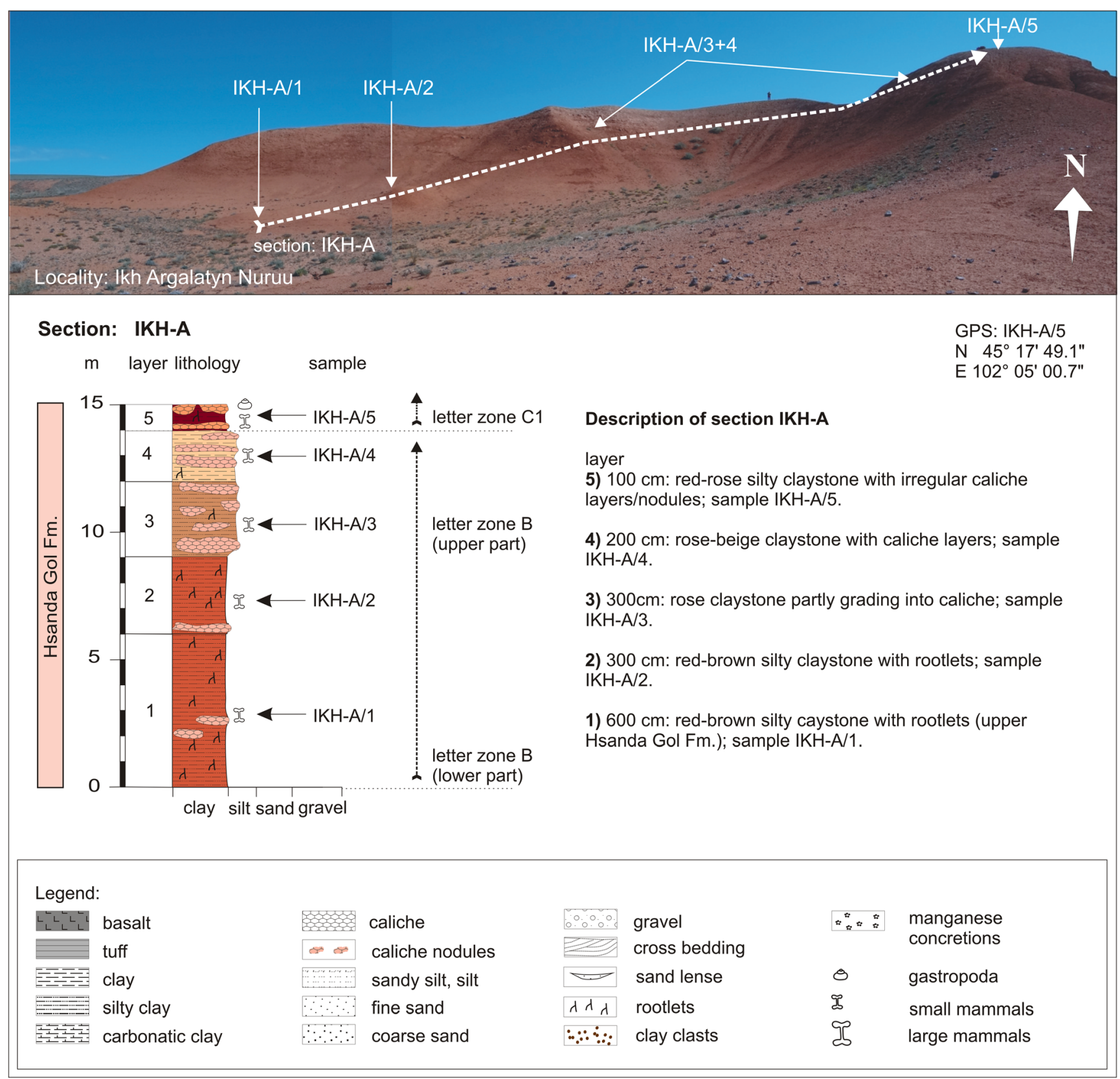

Fig. 28 Ikh Argalatyn Nuruu is located in the eastern part of the studied area. Section IKH-A comprises sequences of the upper Hsanda Gol Fm. ranging from the early to the late Oligocene 


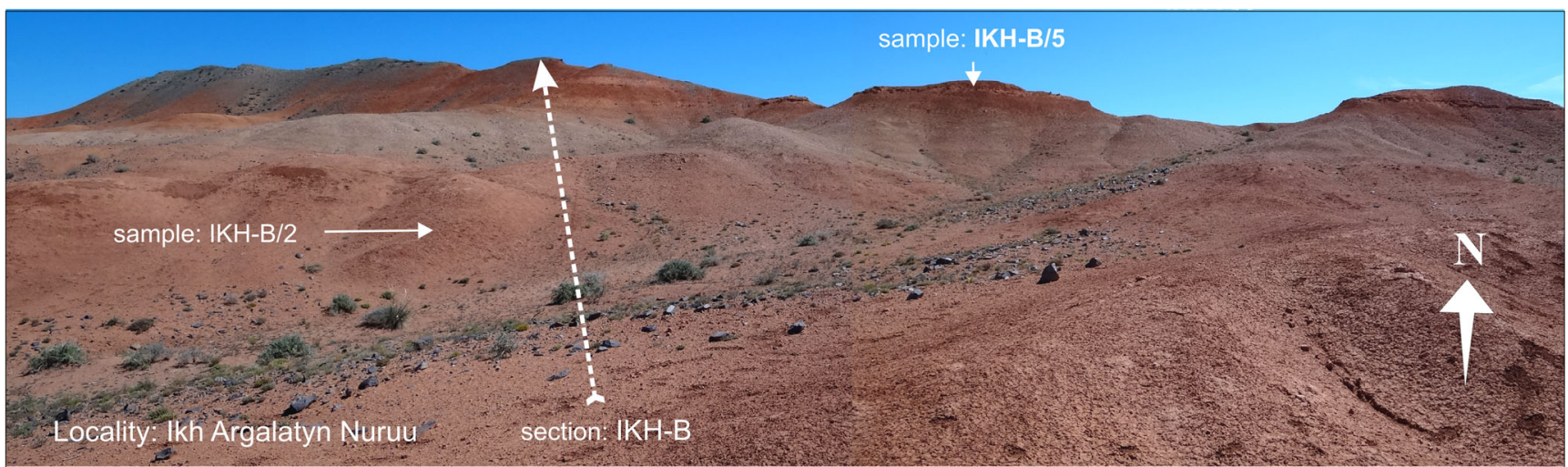

Section: IKH-B

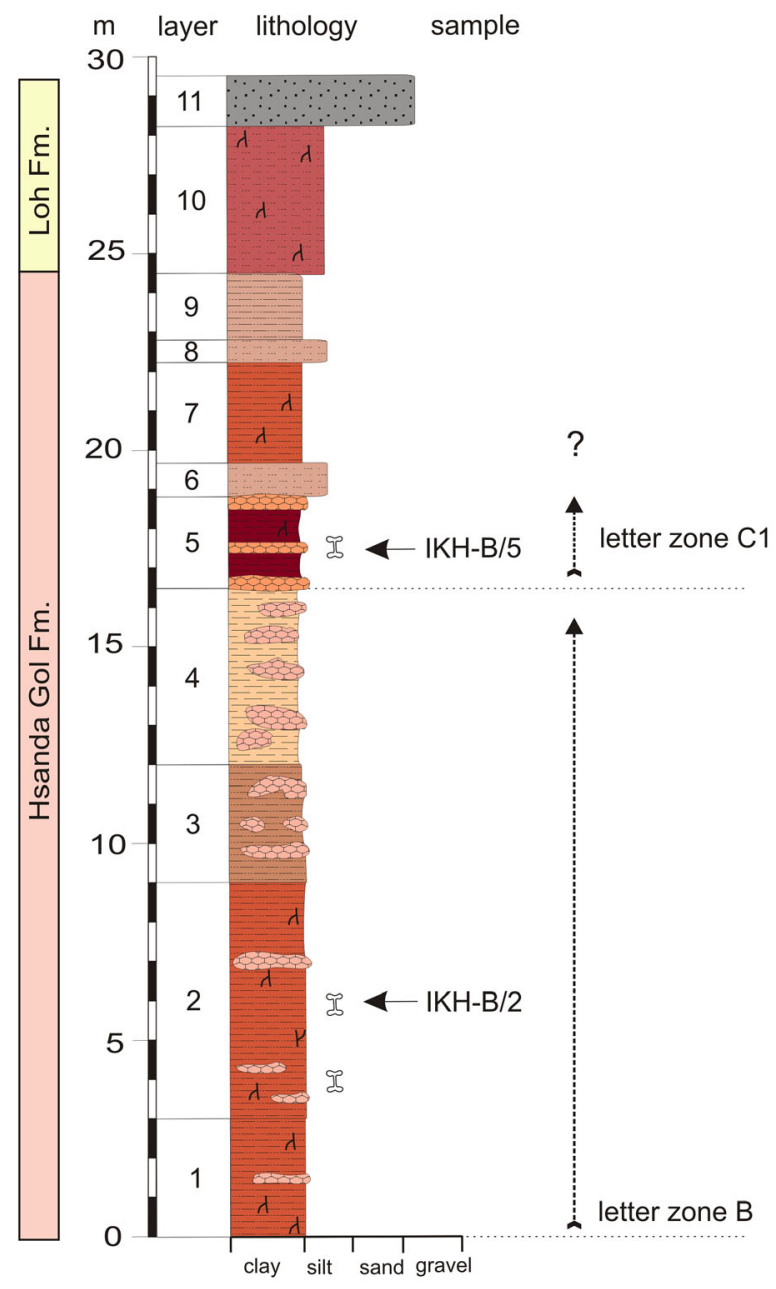

GPS: IKH-B/2

N $45^{\circ} 17^{\prime} 32.6^{\prime \prime}$

E $102^{\circ} 05^{\prime} 34.2^{\prime \prime}$

\section{Description of section IKH-B}

layer

11) $80 \mathrm{~cm}$ : grey-green gravel.

10) $370 \mathrm{~cm}$ : red-brown sandy silt with rootlets (Loh Fm.).

9) $190 \mathrm{~cm}$ : rose silty claystone.

8) $100 \mathrm{~cm}$ : rose silt.

7) $260 \mathrm{~cm}$ : red-brown silty claystone with rootlets.

6) $90 \mathrm{~cm}$ : olive-beige silt.

5) $210 \mathrm{~cm}$ : red claystone with caliche; sample IKH-B/5.

4) $450 \mathrm{~cm}$ : rose-white-beige claystone with caliche layers.

3) $300 \mathrm{~cm}$ : rose-red-brown silty claystone with caliche layers/nodules.

2) $600 \mathrm{~cm}$ : brown-red silty claystone with rootlets; sample $\mathrm{IKH}-\mathrm{B} / 2$.

1) $300 \mathrm{~cm}$ : red-brown silty claystone with rootlets (upper Hsanda Gol. Fm.).

Fig. 29 Section IKH-B is located in the easternmost part of the study area. The section comprises sequences of the Hsanda Gol and Loh Fms 
Table 18 Fossils from the locality Ikh Argalatyn Nuruu [fossils of section IKH-A (samples IKH-A/1-4) indicate the letter zone B (early Oligocene), fossils from samples IKH-A/5 and $\mathrm{IKH}-\mathrm{B} / 5$ indicate letter zone C1 (late Oligocene)]

\begin{tabular}{llll}
\hline Ikh Argalatyn Nuruu & IKH-A/1- & IKH-A/ & IKH-B/ \\
& 4 & 5 & 5 \\
Letter zone & B & C1 & C1 \\
\hline
\end{tabular}

Gastropoda

Vallonia sp.

Reptilia

Acrodonta indet. $\quad x$

Lacerta sp. 1

Mammalia

Lagomorpha

Ordolagus cf. teilhardi (Burke, 1941) x

Desmatolagus youngi (Gureev, 1960) x

Desmatolagus gobiensis Matthew and Granger, $1923 \quad \mathrm{x}$

Desmatolagus robustus Matthew and Granger, 1923 x

Desmatolagus cf. chinensis Erbajeva and Sen, 1998 x

Desmatolagus sp.

Sinolagomys major Bohlin, 1937

Sinolagomys sp.

Eulipotyphla

Zaraalestes minutus (Matthew and Granger, 1924a)

Palaeoscaptor acridens Matthew and Granger, 1924a

Palaeoscaptor cf. rectus Matthew and Granger, 1924a

Amphechinus major Ziegler et al., 2007

Gobisorex kingae Sulimski, 1970

Rodentia

Promeniscomys cf. sinensis Wang 1987

Ninamys kazimierzi Vianey-Liaud et al., 2013

Ninamys arboraptus (Shevyreva, 1966)

Yindirtemys deflexus (Teilhard de Chardin, 1926)

Ardynomys sp.

Cyclomylus intermedius Wang, 2001

Cyclomylus lohensis Matthew and Granger, 1923

Coelodontomys asiaticus Wang, 2001

Tsaganomyidae indet.

Tsaganomys altaicus Matthew and Granger, 1923

Allosminthus minutus (Daxner-Höck, 2001)

Heosminthus chimidae Daxner-Höck et al., 2014

Heosminthus sp.

Onjosminthus baindi Daxner-Höck et al., 2014

Shamosminthus sodovis Daxner-Höck, 2001

Bohlinosminthus parvulus (Bohlin, 1946)

Ulaancricetodon badamae Daxner-Höck, 2000

Cricetops dormitor Matthew and Granger, 1923

Eocricetodon cf. meridionalis (Wang and Meng, 1986)

Eucricetodon caducus (Shevyreva, 1967)

Eucricetodon asiaticus Matthew and Granger, 1923

Eucricetodon cf. occasionalis Lopatin, 1996

Eucricetodon bagus Gomes Rodrigues et al., 2012

Eucricetodon sp.

Cricetidae indet.

Aralocricetodon cf. schokensis Bendukidze, 1993

Tachyoryctoides obrutschewi Bohlin, 1937 $\mathrm{x}$

$\mathrm{x}$

$\mathrm{X}$ 
Table 18 (continued)

\begin{tabular}{|c|c|c|c|}
\hline $\begin{array}{l}\text { Ikh Argalatyn Nuruu } \\
\text { Letter zone }\end{array}$ & $\begin{array}{l}\text { IKH-A/1- } \\
4 \\
\text { B }\end{array}$ & $\begin{array}{l}\text { IKH-A/ } \\
5 \\
\mathrm{C} 1\end{array}$ & $\begin{array}{l}\text { IKH-B/ } \\
5 \\
\mathrm{C} 1\end{array}$ \\
\hline \multicolumn{4}{|l|}{ Creodonta } \\
\hline Hyaenodon cf. incertus Dashzeveg, 1985 & $\mathrm{x}$ & & \\
\hline Hyaenodon pervagus Matthew and Granger, 1924b & $\mathrm{x}$ & & \\
\hline cf. Hyaenodon gigas Dashzeveg, 1985 & $\mathrm{x}$ & & \\
\hline \multicolumn{4}{|l|}{ Carnivora } \\
\hline Amphicynodon teilhardi (Matthew and Granger, 1924b) & $\mathrm{x}$ & & \\
\hline aff. Amphicynodon sp. & $\mathrm{x}$ & & \\
\hline Nimravus mongoliensis (Gromova, 1959) & $\mathrm{x}$ & & \\
\hline Palaeogale sectoria sp. & $\mathrm{x}$ & & \\
\hline \multicolumn{4}{|l|}{ Ruminantia } \\
\hline $\begin{array}{l}\text { Pseudogelocus mongolicus Vislobokova and Daxner-Höck, } \\
2002\end{array}$ & $\mathrm{x}$ & & \\
\hline Prodremotherium sp. & $\mathrm{x}$ & & \\
\hline Eumeryx sp. & $\mathrm{x}$ & & \\
\hline Amphitragulus sp. & & & $\mathrm{x}$ \\
\hline Gobiocerus sp. & & & $\mathrm{x}$ \\
\hline
\end{tabular}

Correlation of geological sections from the Valley of Lakes

Today, the combination of biostratigraphic and lithologic data from the Taatsiin Gol and Taatsiin Tsagaan Nuur regions, the ${ }^{40} \mathrm{Ar} /{ }^{39} \mathrm{Ar}$ ages of basalts (Tables 1 and 2), and magnetostratigraphic data (Sun and Windley 2015) allows correlation of sections and fossil horizons with the Geomagnetic Polarity Time Scale (GPTS) (Gradstein et al. 2012). This provides a composite age chronology for the entire sequence as demonstrated for selected key sections (Fig. 30). 


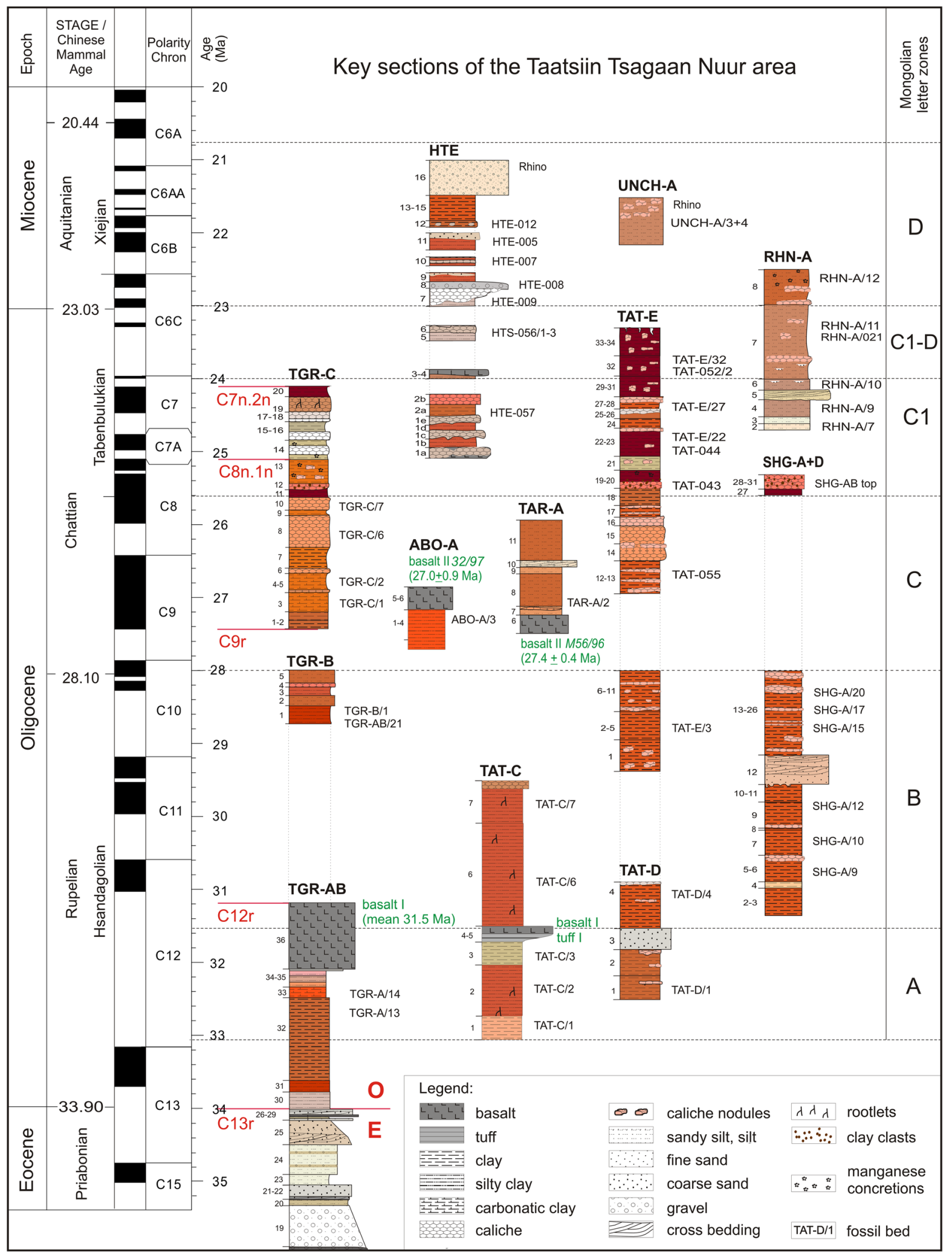

Fig. 30 Chronostratigraphic and geochronologic correlation of key sections from the Valley of Lakes. The stratigraphic chart includes the Geologic Time Scale and the GPTS (Gradstein et al. 2012; Ogg et al. 2004); the Chinese Mammal Ages Hsandagolian, Tabenbulukian, and Xiejian (Meng and McKenna 1998; Meng et al. 2008); ${ }^{40} \mathrm{Ar} /{ }^{39} \mathrm{Ar}$ ages of basalt I and II (Table 1a and b) and Höck et al. (1999; Fig. 18); magnetostratigraphic data (Kraatz and Geisler 2010; Sun and Windley 2015); key sections from the Taatsiin Gol and Taatsiin Tsagaan Nuur region; and the Mongolian letter zones A, B, C, C1, C1-D, and D. Left side of the sections, the sediment layers are numbered. The position of palaeontological samples/fossil layers is shown right side of the sections (e.g. TGR-A/13) 
Late Priabonian to early Rupelian (Hsandagolian/letter zone A)

As outlined above, the lower part of section TGR-AB (Figs. 14 and 30) comprises fluvio-lacustrine deposits of the Tsagan Ovo Fm. followed by brick-red clay of the Hsanda Gol Fm. (lower Hsanda Gol beds), which is topped by basalt I $\left({ }^{40} \mathrm{Ar} /{ }^{39} \mathrm{Ar}\right.$ age $\left.\sim 31.5 \mathrm{Ma}\right)$. The fossils of samples TGR-A/ $13+14$ below basalt I (Table 11) evidence letter zone A and the early Hsandagolian Mammal age, respectively. These data allow correlation of magnetostratigraphic measurements along of the TGR section with the GPTS, showing that the lower Hsanda Gol beds and basalt I are to be correlated with Chrons C12r-C13r (section A in Sun and Windley 2015; Fig. 3) and the early Rupelian, respectively. The age range of the lower Hsanda Gol beds is $\sim 34-31.5 \mathrm{Ma}$. The age range of the Tsagan Ovo sequence is $>35$ to $\sim 34$ Ma (late Piabonian). The Eocene and Oligocene boundary (EOB; Figs. 14 and 30) is located between the Tsagan Ovo and the Hsanda Gol Fms. at 34 Ma (Kraatz and Geisler 2010; Sun and Windley 2015).

Sediment sequences of the early Rupelian (below basalt I or tuff I) are evidenced in the regions Taatsiin Gol (sections TGR-A, TGR-AB, TGR-B, HL-A, TGL-A), Del (section DEL-B), Tatal Gol (sections TAT-D and TAT-C), Hsanda Gol (section SHG-C), and Talyn Churum (GRAB-II) (see Figs. 30 and 31).

\section{Late Rupelian (Hsandagolian/letter zone B)}

From the upper Hsanda Gol beds with fossils of letter zone B, no magnetostratigraphic data are available. The lower boundary is basalt or tuff I ( 31.5 Ma); the upper boundary is built by Hsanda Gol sequences, which include fossils of letter zone $\mathrm{C}$, and which are located below basalt II ( 27 Ma).

This lower part of upper Hsanda Gol beds is not only characterised by abundant fossils of letter zone B but also by increased number and thickness of caliche layers, alternating with brick-red clay/silty clay. In the Hsanda Gol region, the sequence is interrupted by a 2-3-m-thick sandstone layer (Fig. 25).

Sediment sequences of the late Rupelian are evidenced in the regions: Taatsiin Gol (sections TGR-AB, TGR-B, TGL-A), Unkheltseg (section UNCH-A), Del (section DEL-B), Tatal Gol (sections TAT-D, TAT-E, and TAT-C), Hsanda Gol (section SHG-A, SHG-AB, SHG-D), and Ikh Argalatyn Nuruu (sections IKH-A and IKH-B) (see Figs. 30 and 31).

Early Chattian (Hsandagolian/letter zone C) to late Chattian (Tabenbulukian/letter zones $\mathrm{C} 1$ and C1-D)

In the Chattian, some sections consist of sediments of the Hsanda Gol Fm. (sections TGR-C, TGW-A, TAT-E) and others of the Loh Fm. (sections TAR-A, RHN-A). Thus, both formations occur in Chattian strata. Three sections are of special importance for correlation. The sections ABO-A (Fig. 6) and TAR-A (Figs. 18 and 19) provide biostratigraphic data and radiometric ages of basalt II. Magnetostratigraphic measurements of section TGR-C (Fig. 13) allow correlation with the GPTS. In section ABO-A, fossils of letter zone $\mathrm{C}$ (sample ABO-A/3) were recovered below basalt II $(27.0 \pm 0.9 \mathrm{Ma})$; in section TAR-A, fossils of letter zone C (sample TAR-A/2) occur above basalt II (27.4 $\pm 0.4 \mathrm{Ma}$ ) (Höck et al. 1999; Daxner-Höck et al. 2010). These geochronologic data are in agreement with section TGR-C. There, the upper Hsanda Gol beds contain rich mammal assemblages of letter zone $C$, and fossils of letter zone $\mathrm{C} 1$ were sporadically found from the uppermost part of the Hsanda Gol Fm. Magnetostratigraphic measurements from section TGR-C allow correlation of the Hsanda Gol beds with Chrons C9n-C7n.2n (total range 27.4-24.2 Ma). The boundary between the reddish-brown and olive-green claystone (TGR-C/13/14) was correlated with Chron C8n.1n at 25.2 Ma (Sun and Windley 2015; Fig. 3); it is $3 \mathrm{~m}$ above the dark-brown claystone (TGR-C/ 11) marking the boundary between letter zones $\mathrm{C}$ and $\mathrm{C} 1$ at 25.6 Ma. Thus, in section TGR-C, letter zone $\mathrm{C}$ ranges from 27.4 to $25.6 \mathrm{Ma}$, and the range of letter zone $\mathrm{C} 1$ is 25.6 to 24.2 Ma (Fig. 30).

In the locality Tatal Gol, a composite section (section TAT-D+E) displays the sequence ranging from the early Rupelian to the late Chattian. The sequence evidences the early Rupelian (sample TAT-D/1 with fossils of letter zone A), followed by the late Rupelian (sample TAT-E/3 with fossils of letter zone B), the early Chattian (sample TAT-055 with fossils of letter zone C), and the late Chattian/Tabenbulukian (samples_-TAT-043, TAT-044, TAT-E/22, TAT-E/27, TAT-052/1 with fossils of letter zone $\mathrm{C} 1$ ); finally, the sequence is topped by darkbrown clay at the North Ridge (samples TAT-E/32 and TAT-052/2 with fossils of letter zone C1-D; Figs. 21 and 22; Figs. 30 and 31).

In the Taatsiin Gol and Taatsiin Tsagaan Nuur region, characteristic Tabenbulukian fossils cannot be found earlier than 25.6 Ma (Chron C8n.2n). These fossils, Yindirtemys deflexus, Sinolagomys kansuensis, Bohlinosminthus parvulus, and Amphechinus major, mark the beginning of letter zone $\mathrm{C} 1$. Consequently, we follow Meng and McKenna (1998) and (Meng et al. 2008) and draw the Hsandagolian/ Tabenbulukian boundary at 25.6 Ma (Figs. 30 and 31). We do not agree with Kraatz and Geisler (2010, Fig. 3) to shift the lower boundary of the Tabenbulukian Mammal age down to Chron C11r at 30.6 Ma. This opinion of Kraatz and Geisler (2010) contradicts our fossil data (elaborated above and illustrated in Figs. 32, 33, 34, 35, 36, 37, 38, 39, 40, 41, 42, 43, 44, $45,46,47,48,49,50,51,52,53,54,55,56,57,58,59,60,61$, 
and 62), and also contradicts the radiometric ages of basalt II (Höck et all 1999; and Tables 1 and 2) and the magnetostratigraphic correlation of section TGR-C (Sun and Windley 2015).

Sediment sequences of the early Chattian are evidenced in the regions Taatsiin Gol (section TGR-C), Toglorhoi (section TGW-A), Abzag Ovo (section ABOA), Unzing Churum (section TAR-A), and Tatal Gol (section TAT-E).

Sediments of the late Chattian/Tabenbulukian are evidenced in the regions Hotuliin Teeg (section HTE and localities HTSE and HTS), Huch Teeg (section RHNA), Toglorhoi (section TGW-A), Del (section DEL-B), Tatal Gol (section TAT-E), Hsanda Gol (section SHG$\mathrm{AB}$ ), Loh (sections LOH-B, LOH-C), and Ikh Argalatyn Nuruu (sections IKH-A, IKH-B).

\section{Auitanian (Xiejian/letter zone D)}

In the lower part of section HTE (Figs. 10 and 11), strata of the Loh Fm. contain fossils of letter zone C1. The main part of this section is built up by silt and silty claystone and caliche of the Loh Fm. Here, the fossil concentrations are mostly bound to sandy, gravely layers/lenses filling the relief of massive caliche (e.g. fossil layer HTE-007), or to thin layers of caliche nodules (fossil layers HTE-8). The fossils indicate letter zone $\mathrm{D}$ and allow correlation with the Xiejian mammal age and the lowermost Miocene.

Sediments of the Aquitanian/Xiejian are evidenced in the regions Hotuliin Teeg (section HTE), Unkheltseg (section UNCH-A), Huch Teeg (section RHN-A), Luuny Yas (locality LUS), and Luugar Khudag (section LOG-A).

\section{Chronostratigraphic correlation of Mongolian letter zones and calculation of their age ranges}

The initial characterisation of Mongolian letter zones was based on preliminarily determined rodents. It included integrated rodent lists, the first/last records, the most abundant/ characteristic taxa, the lithostratigraphic position, and the relation to one of the basalt events (Daxner-Höck et al. 1997; Höck et al. 1999). Later, new taxonomic and field data enabled several updates of the original informal biozones (Daxner-Höck and Badamgarav 2007: 14, Tables 3 and 4; Daxner-Höck et al. 2010: 352, Tables 2, 3, 4, 5, and 6; Daxner-Höck et al. 2014: 204-205; DaxnerHöck et al. 2015: 188-190). After finalising the taxonomy of almost all mammal groups, the huge dataset allowed to formalize the informal letter zones as biozones according to the International Stratigraphic Guide. Consequently, the letter zones A, B, C, C1, C1-D, and D, covering the Oligocene and lowermost part of the Miocene, were defined as Taxon Range Zones and Abundance Zones (Harzhauser et al. 2017, this issue). Moreover, the biostratigraphic, lithostratigraphic, radiometric, and magnetostratigraphic data from the study area enable correlations with the GPTS and help estimate the time ranges of the Mongolian biozones. All species and the respective stratigraphic ranges are listed in Table 19.

\section{Letter zone A}

The lower Hsanda Gol Fm. correlates with Chron C12 r and the upper part of C13 (Kraatz and Geisler 2010; Sun and Windley 2015) and ranges from the Eocene/Oligocene boundary (EOB) at $\sim 34 \mathrm{Ma}$ to basalt I at $\sim 31.5 \mathrm{Ma}$. Key fossils of letter zone A (Harzhauser et al. 2017, this issue) were recovered from the upper part of the lower Hsanda Gol beds, which correlate with Chron C12r.

Samples: TGR-A/13+14; TGL-A/1+2; HL-A/1+2; TAT-C/13; TAT-D/1; TAT-037; SHG-C/1+2; GRAB-II. The range is $\sim 33$ to $\sim 31.5 \mathrm{Ma}$ (early Oligocene/early Rupelian/early Hsandagolian) (Fig. 31).

\section{Letter zone B}

Fossils of letter zone B are present in upper Hsanda Gol beds above basalt I ( 31.5 Ma). The upper boundary is built by sequences of the Hsanda Gol and Loh Fms., which include fossils of letter zone $C$.

Samples: TGR-B/1; TGR-AB/21, TGR-AB/22; TGL-A/11; UNCH-A/3+4B; DEL-B/7+8; TAT-054; TAT-E/3; TAT-038; TATC/6+7; SHG-A/6, SHG-A/9, SHG-A/12-15; SHG-A/15-20; SHG$\mathrm{AB} / 12$; SHG-AB/17-20; IKH-A/1-4; IKH-B/2. The range is 31.5 to $\sim 28 \mathrm{Ma}$ (early Oligocene/late Rupelian/late Hsandagolian).

\section{Letter zone C}

Fossils of letter zone $\mathrm{C}$ are present in sediments of the upper Hsanda Gol Fm. and/or lower Loh Fm., which correlate with Chron C9n-C8n.2n (section TGR-C; Sun and Windley 2015) and with radiometric ages of basalt II (27-28 Ma) from sections ABO-A and TAR-A.

Samples: TGR-C/1+2; TGR-C/5-7; ABO-A/3; ABO-083; TAR-A/2; TGW-A/1; TGW-A/2a+b; TAT-055.

The range is $\sim 28$ to $25.6 \mathrm{Ma}$ (late Oligocene/early Chattian/ latest Hsandagolian).

Letter Zone C1

Hsanda Gol or Loh sediments with fossils of letter zone C1 are correlated with Chrons C8n.2n-C7n.2n (section TGR-C, 


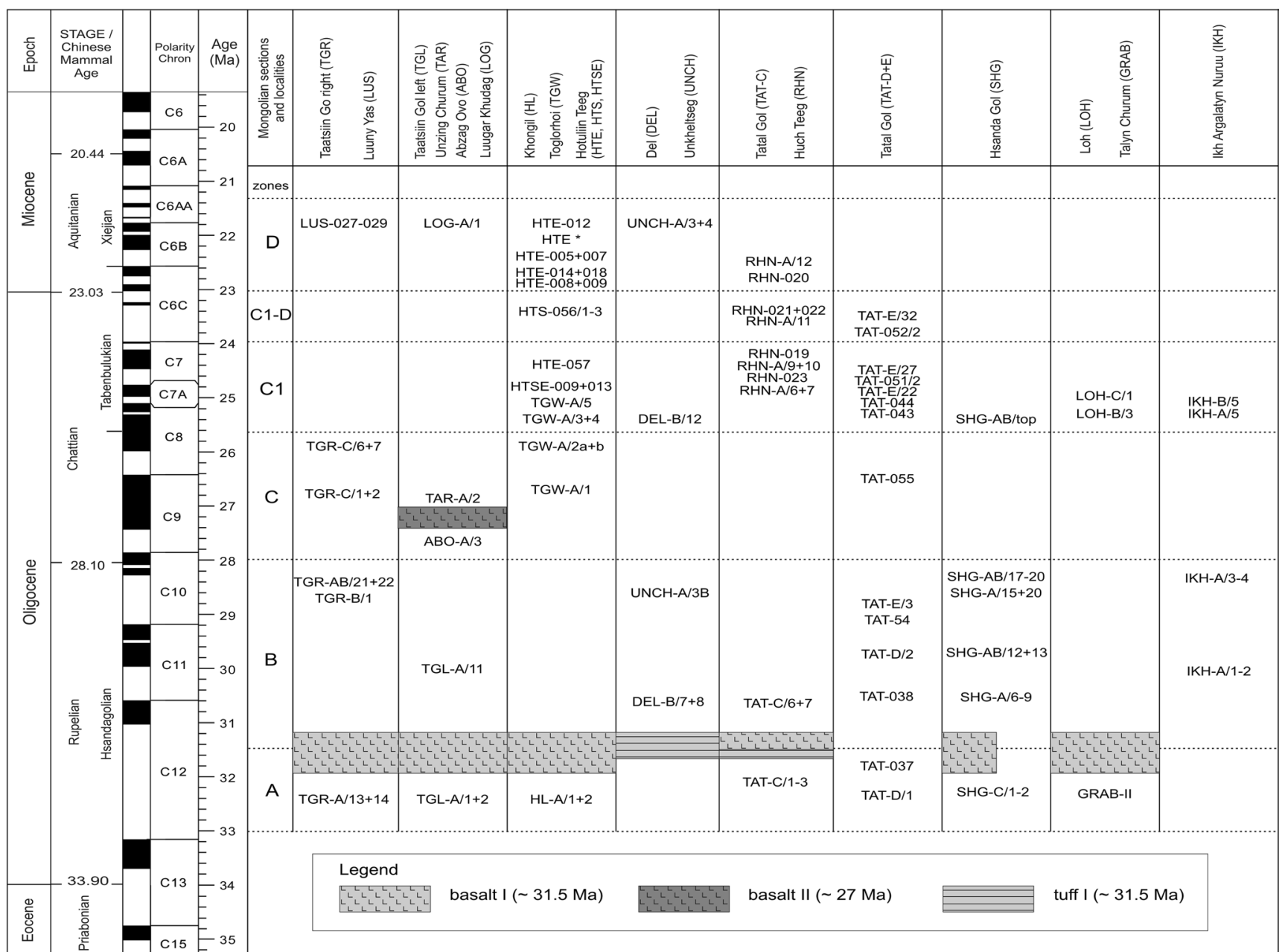

Fig. 31 Chronostratigraphic correlation and calculation of geochronologic ages of mammal assemblages from the Valley of Lakes in Mongolia. The correlation chart includes the Geologic Time Scale and the Geomagnetic Polarity Time Scale (GPTS) (Gradstein et al 2012; Ogg et al. 2004); the Chinese Mammal Ages Hsandagolian, Tabenbulukian, and Xiejian;
${ }^{40} \mathrm{Ar} /{ }^{39} \mathrm{Ar}$ ages of basalt I and II (Höck et al 1999); the Mongolian letter zones A, B, C, C1, C1-D, and D; geological sections and fossil localities from the Taatsiin Gol and Taatsiin Tsagaan Nuur region (Valley of Lakes); and the respective mammal assemblages (acronyms)

Samples: HTS-056/1-3; RHN-021+022; RHN-A/11; TAT-E/32; TAT-052/2.

The estimated range of letter zone C1-D is 24 to $\sim 23 \mathrm{Ma}$ (late Oligocene/late Chattian/Tabenbulukian).

Letter zone D

The lower Loh Fm. with fossils of letter zone D is demonstrated as being early Miocene by the occurrence of Democricetodon sui Maridet et al. 2011, which has its first appearance (FAD) at $22.6 \mathrm{Ma}$ (top of Chron $\mathrm{C} 6 \mathrm{Cn} .1 \mathrm{n}$ ) in the type locality S-II site XJ99005 of the Tieersihabahe section, Junggar Basin, China (Meng et al. 2006, 2008, 2013).

Samples: LUS-027-029; LOG-A/1; HTE-008; HTE-009; HTE-014-018; HTE-005; HTE-007; HTE-12/6; HTE-012/8; 
HTE*; HTE-012; HTE-12/7; UNCH-A/3+4; RHN-A/12; RHN-020.

The estimated range is $\sim 23$ to $\sim 21 \mathrm{Ma}$ (early Miocene/ Aquitanian/Xiejian).

\section{Fossil record and dental morphology of Marsupialia, Eulipotyphla, and Rodentia from the Oligocene and early Miocene of the studied area}

Here, we introduce into the fossil record of the Oligocene and lowermost Miocene (Table 19); younger assemblages are not considered in this issue. The fossils were collected from 70 fossil horizons of 20 geological sections and 6 fossil points in the Valley of Lakes. The recovered fossils encompass Gastropoda (Stworzewicz 2007; Neubauer et al. 2013), Anura and Squamata (Böhme 2007), Creodonta, Carnivora and Leptictida (Morlo and Nagel 2002, 2007; Nagel and Morlo 2003), Perissodactyla (Heissig 2007), and Ruminantia (Vislobokova and Daxner-Höck 2002). The prevailing part of fossils - about $98 \%$ of more than 19,000 fossils - represents small mammals, of which 135 species-level taxa were counted. This small mammal dominance, however, results from wet screening of large samples.

Among small mammals, the order Rodentia dominates in genus, species, and specimen numbers, followed by Lagomorpa and Eulipotyphla and Marsupialia. Rodentia encompass the families Aplodontidae, Sciuridae, Eomyidae, Ctenodactylidae, Cylindrodontidae, Tsaganomyidae, Dipodidae, Cricetidae s. 1., and Tachyoryctoididae. Together, they comprise 85 species-level taxa. Lagomorpha are represented by the families Leporidae, Palaeolagidae, and Ochotonidae, altogether with 23 species-level taxa. Eulipotyphla are represented by the families Erinaceidae, Soricidae, and Talpidae, together 25 species-level taxa. Additionally, two Marsupialia species of the family Didelphidae occur.

In this chapter, the richest small mammal collection ever found in Mongolia is illustrated by SEM images (Figs. 32, 33, 34, 35, 36, 37, 38, 39, 40, 41, 42, 43, 44, 45, 46, 47, 48, 49, 50, $51,52,53,54,55,56,57,58,59,60,61$, and 62). We give an overview of the diversity; show the manifold dental structures of marsupials, eulipotyphlans, and rodents; and provide a first impression of species, which are named in fossil lists or serve as index fossils for biostratigraphy. Fossils which indicate Taxon Range Zones and Abundance Subzones (Harzhauser et al. 2017, this issue) are written in bold letters (see list of figured species, below). Fossil descriptions are not included in this chapter; for more detailed information, we refer on the original descriptions and included references. Other fossil groups, such as gastropods, lower vertebrates, large mammals, lagomorphs, and the large-sized rodents Tsaganomyidae, are not figured in this paper. The figured teeth (SEM images) of marsupials, eulipotyphlans, and rodents are roughly arranged in systematic order. The figure captions include the taxon name, collection and inventory number, the locality, section, fossil layer, the age of the sample, respective letter zone, and the author who identified or described the fossils. For better comparison, all right-side fossils are mirrored (they are figured as if they were from the left side), and these numbers are underlined (e.g. Fig. 32b = right M1 of Asiadelphis zaissanensis). A scale bar shows the magnification of fossils.

The figured species are

Order Marsupialia

Family Didelphidae:

Asiadelphis zaissanensis (Fig. 32a-f)

Asiadelphis tjutkovae (Fig. 32g)

Order Eulipotyphla

Family Erinaceidae:

Exallerix pustulatus (Fig. 32h-j)

Zaraalestes minutus (Fig. 33a-1)

Zaraalestes sp. (Fig. 33m-p)

Amphechinus taatsiingolensis (Fig. 34a-n)

Amphechinus minutissimus (Fig. 35a-i)

Amphechinus major (Fig. 35j-q)

Palaeoscaptor gigas (Fig. 36a-b)

Palaeoscaptor tenuis (Fig. $3 \overline{6} \mathrm{c}-\bar{n}$

Palaeoscaptor acridens (Fig. 37a-g)

Palaeoscaptor cf. rectus (Fig. $3 \overline{7 h}-\underline{n}$ )

Family Soricidae:

Gobisorex kingae (Fig. 38a-i)

Taatsiinia hoeckorum (Fig. 39a-f)

Tavoonyia altaica (Fig. 39/g-n)

Family Talpidae:

Mongolopala tathue (Fig. 40a-f)

Order Rodentia

Family Aplodontidae:

Ninamys kazimierzi (Fig. 41a-e)

Ninamys arboraptus (Fig. 41f-h)

Prosciurus ? mongoliensis (Fig. i-k)

Promeniscomys cf. sinensis (Fig. 411-r)

Proansomys badamae sp. nov. (Fig. 42a-h)

Family Sciuridae:

Kherem shandgoliensis (Fig. 42i-j)

Pteromyini indet. (Fig. 42k-m)

Plesiosciurus aff. sinensis (Fig. 42n-p)

Family Cylindrodontidae:

Anomoemys lohiculus (Fig. 43a-f)

Ardynomys sp. (Fig. 43g-1) 
Family Ctenodactylidae:

Tataromys minor longidens (Fig. 44a-j)

Tataromys sigmodon (Fig. 44k-s)

Tataromys plicidens (Fig. 44t-zz)

Karakoromys decessus (Fig. $4 \overline{5 \mathrm{a}}-\mathrm{i}$ )

Huangomys frequens (Fig. $45 \mathrm{j}^{-} \mathrm{-}$ )

Yindirtemys birgeri (Fig. 46a-d)

Yindirtemys deflexus (Fig. 46e-k)

Yindirtemys suni (Fig. 46/1-q)

Yindirtemys shevyrevae (Fig. 47a-h)

Yindirtemys aff. ulantatalensis (Fig. 47i-j)

Prodistylomys nov. spec. 1 (in prep.) (Fig. 47k)

Prodistylomys nov. spec. 2 (in prep.) (Fig. 471-o)

Family Eomyidae:

Eomys aff. orientalis (Fig. 48a-c)

Eomys cf. orientalis (Fig. 48 $\overline{\mathrm{d}}$ )

cf. Asianeomys bolligeri (Fig. 48e-j)

Asianeomys dangheensis (Fig. $48 \mathrm{k}-\mathrm{s}$ )

Family Dipodidae:

Heosminthus chimidae (Fig. 49a-g)

Heosminthus borrae (Fig. 49h-q)

Plesiosminthus asiaticus (Fig. 50a-c)

Plesiosminthus promyarion (Fig. $50 \overline{\mathrm{d}}-\mathrm{h}$ )

Plesiosminthus barsboldi (Fig. 50i-k)

Plesiosminthus olzi (Fig. 501-s)

Onjosminthus baindi (Fig. 51a-g)

Bohlinosminthus parvulus (Fig. 51h-p)

Parasminthus debruijni (Fig. 52a-d)

Parasminthus cf. tangingoli (Fig. 52e-j])

Parasminthus cf. asiaecentralis (Fig. $52 \mathrm{k}-1$ )

Litodonomys huangheensis (Fig. 53a-d)

Litodonomys jajeensis (Fig. 53e-h)
Allosmintus khandae (Fig. 54a-e)

Allosminthus minutus (Fig. 54f-k-

Shamosminthus sodovis (Fig. 541-p)

Shamosminthus tongi (Fig. 54q)

Heterosminthus aff. nanaus (Fig. 54r-s)

Heterosminthus firmus)

Heterosminthus cf. lanzhouensis (Fig. 54y-zz)

Family Cricetidae s.1.:

Cricetops dormitor (Fig. 55a-e)

Cricetops minor (Fig. 55f)

Selenomys mimicus (Fig. $55 \underline{\mathrm{g}}-\mathrm{h}$ )

Eucricetodon asiaticus (Fig. 5 $\overline{6} \mathrm{a}-\mathrm{f}$ )

Eucricetodon caducus (Fig. 56g-1)

Ulaancricetodon badamae (Fig. 56m-p)

Eucricetodon bagus (Fig. 57a-f)

Eucricetodon jilantaiensis (Fig. $57 \mathrm{~g}-\mathrm{j}$ )

Eucricetodon cf. occasionalis (Fig. 57k-n)

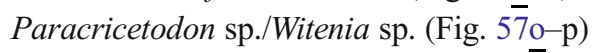

Eocricetodon meridionalis (Fig. 58a-d)

Bagacricetodon tongi (Fig. 58e- $\mathrm{h}$ )

Democricetodon sui (Fig. 58i-1)

Aralocricetodon shokensis (Fig. 59a-f)

Argyromys nov. spec. (Fig. 59g-j)

Family Tachyoryctoididae

Tachyoryctoids bayarmae (Fig. 60a-d)

Tachyoryctoides radnai (Fig. 60--f)

Ayakozomys sp.(Fig. 60g-h)

Tachyoryctoides obrutschewi (Fig. 61a-d)

Tachyoryctoides tatalgolicus (Fig. 61e-- $\mathrm{h}$ )

Tachyoryctoides kokonorensis (Fig. $\overline{6} 2 \mathrm{a}-\mathrm{e}$ )

Tachyoryctoides engesseri (Fig. 62f-h) 


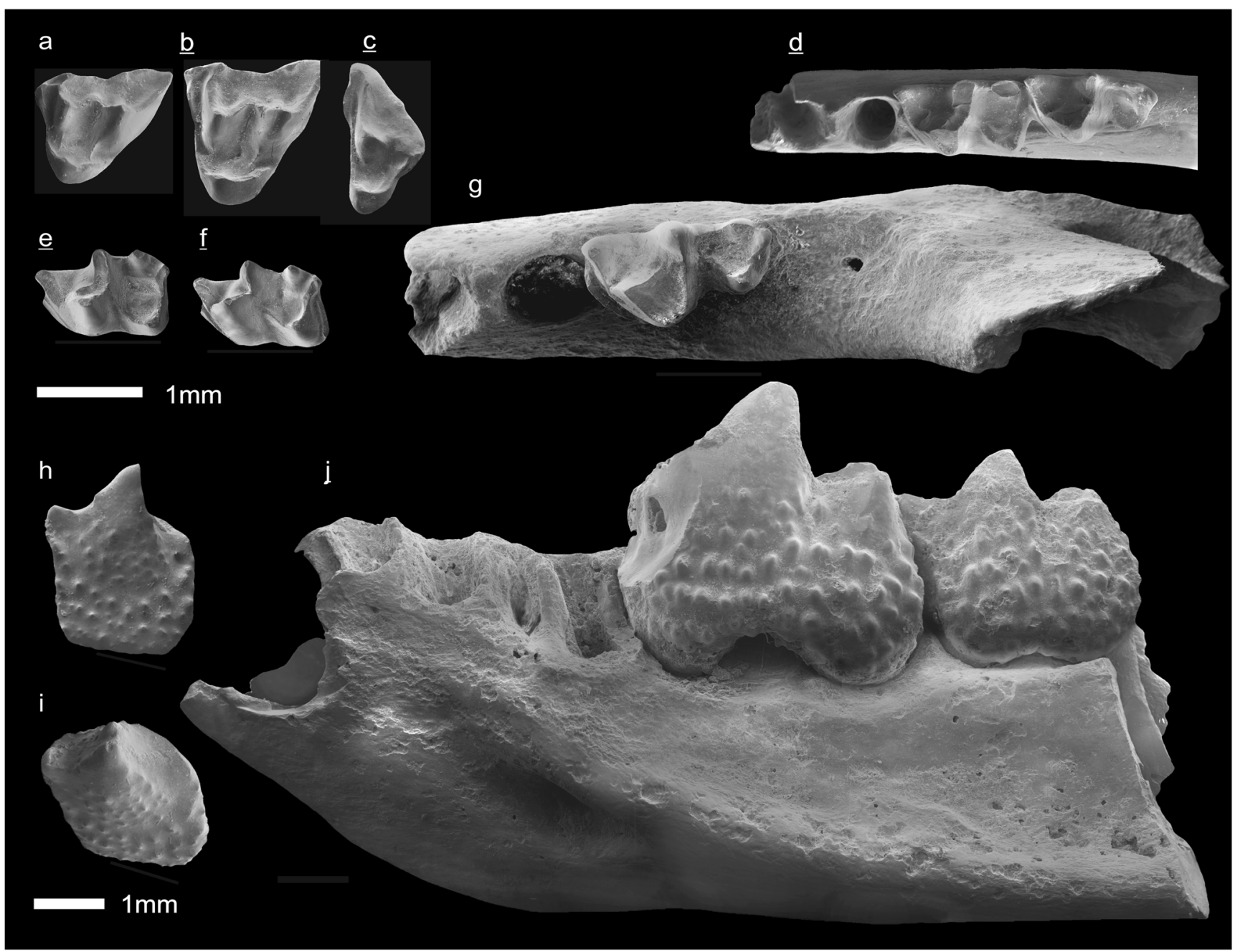

Fig. 32 Family Didelphidae Asiadelphis zaissanensis Gabunia, Shevyreva and Gabunia, 1990 from Taatsiin Gol (TGR-B/1, TGR$\mathrm{AB} / 21, \mathrm{TGR}-\mathrm{AB} / 22$ ) and Hsanda Gol (SHG-A/15+20), Valley of Lakes, Mongolia. Early Oligocene, letter zone B. Ziegler et al. (2007). a Left D3 (NHMW 2006/0115/0001), TGR-AB/21. b Right M1 (NHMW 2006/0116/0002), TGR-AB/22. c Right M4 (NHMW 2006/0117/0001), TGR-B/1. d Right m3-4 (NHM̄W 2006/0116/0001), TGR-AB/22. e Right m1 (NHMW 2006/0118/0001), SHG-A/15+20. f Right m2/3 (NHMW 2006/0116/0002), TGR-AB/22 Asiadelphis tjutkovae Emry,
Lucas, Szalay and Tleuberdina, 1995 from Tatal Gol (TAT-D/ 1 = Hü1), Valley of Lakes, Mongolia. Early Oligocene, letter zone A. Ziegler et al. (2007). g Left mand. m4 (NHMW 2006/0119/0001) Family Erinaceidae Exallerix pustulatus Ziegler, Dahlmann and Storch, 2007 from Taatsiin Gol (TGR-C/1), Valley of Lakes, Mongolia. Late Oligocene, letter zone C. All figured specimens are the holotype $(\mathrm{H})$ and paratypes. Ziegler et al. (2007). h Left p4, labial view (NHMW 2006/0192/0002). i Left p4, occlusal view (NHMW 2006/0192/0002). j right mand. m1-2 (NHMW 2006/0192/0001), H 


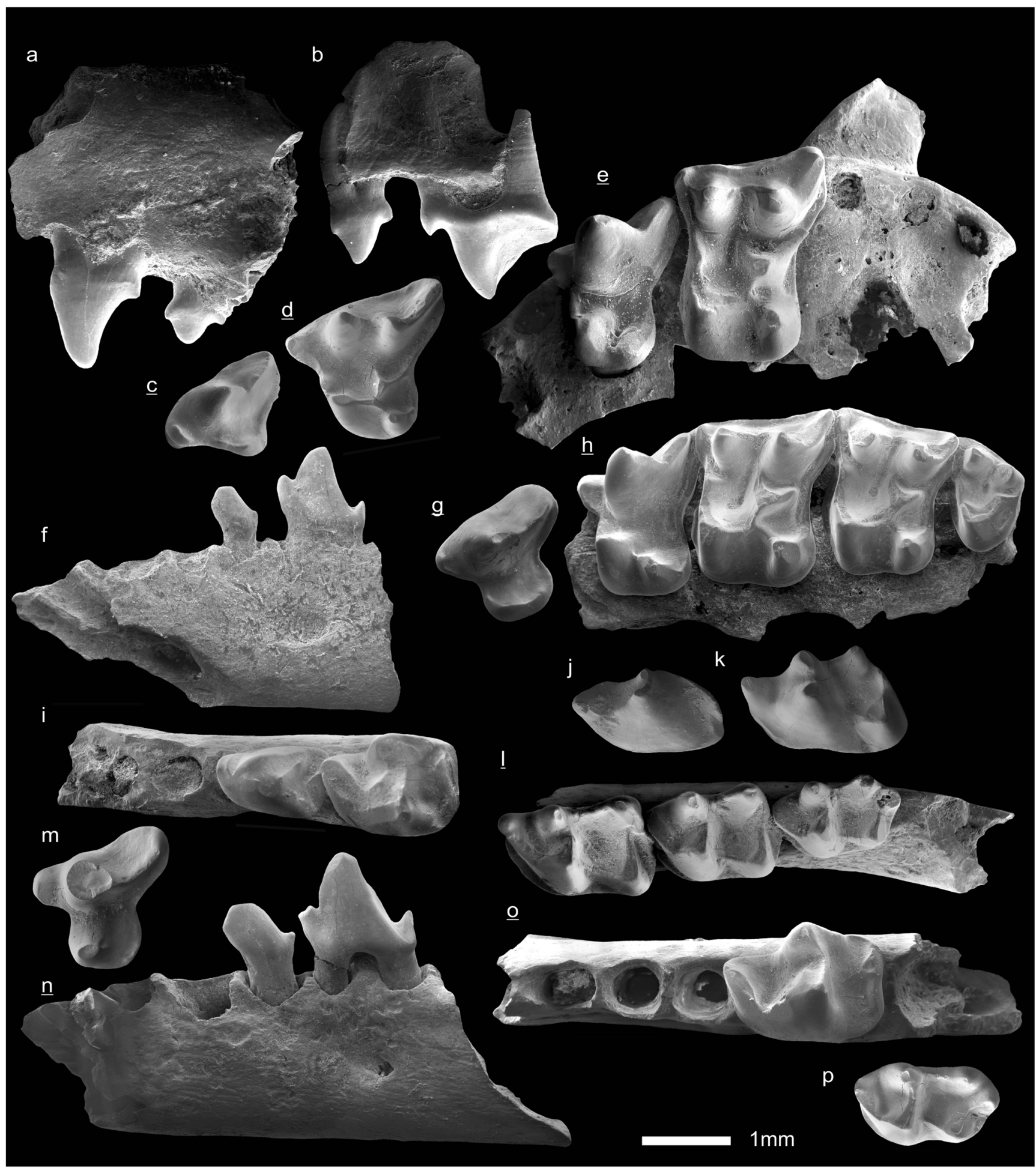

Fig. 33 Family Erinaceidae. Zaraalestes minutus (Matthew and Granger, 1924) from Tatal Gol (TAT-D/1; letter zone A) and Taatsiin Gol (TGR-B/1, TGR-AB/22; letter zone B), Valley of Lakes, Mongolia. Early Oligocene. Ziegler et al. (2007). a Left max. C2-P2 (NHMW 2006/0174/0006), TGR-AB/22. b Left max. P2-3 (NHMW 2006/0174/ 0002), TGR-AB/22. c Right D3 (NHMW 2006/0174/0003), TGR-AB/ 22. d Right D4 (NHM̄̄W 2006/0175/0001), TGR-B/1. e Right max. P4M1 (N)HMW 2006/0174/0007), TGR-AB/22. f Left mand. p 2-3 (NHMW 2006/0121/0001), TAT-D/1. g Right P3 (NHMW 2006/0174/0005),

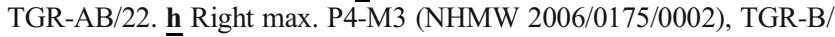

1. i Left mand. p3-4 (NHMW 2006/0121/0002), TAT-D/1. j Left d3 (NHMW 2006/0174/0001), TGR-AB/22. k Left d4 (NHMW 2006/0174/0001), TGR-AB/22. I Right mand. m1-3 (NHMW 2006/0121/0003), TAT-D/1 Zaraalestes sp. from Taatsiin Gol (TGR$\mathrm{AB} / 21$ ) and Del (DEL-B/7) Valley of Lakes, Mongolia. Early Oligocene, letter zone B. Ziegler et al. (2007). m Left P3 (NHMW 2006/0190/0002), TGR-AB/21. n Right mand. p2-3 (NHMW 2006/0190/0002), TGR-AB/21. o Right mand. p4 (NHMW 2006/0191/ 0001), DEL-B/7. p Left m3 (NHMW 2006/0190/0003), TGR-AB/21 


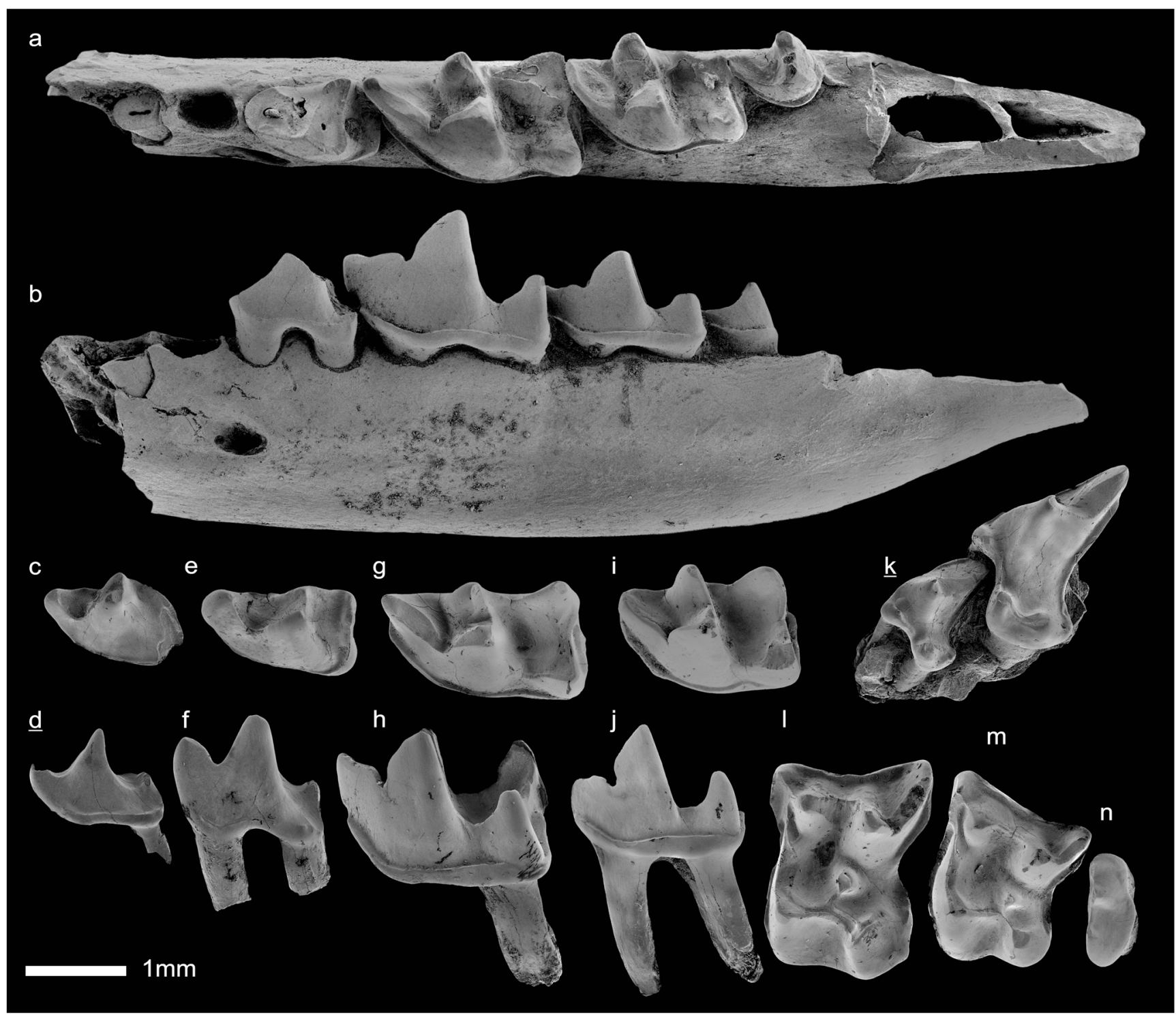

Fig. 34 Family Erinaceidae. Amphechinus taatsiingolensis Ziegler, Dahlmann and Storch, 2007 from Toglorhoi / Khunug Valley (TGWA/2), Valley of Lakes, Mongolia. Late Oligocene, Biozone C. All figured specimens are the holotype $(\mathrm{H})$ and paratypes. Ziegler et al. (2007). a Left mand. p4-m3, occlusal view (NHMW 2005/0152/0001), H. b Left mand. p4-m3, labial view (NHMW 2005/0152/0001), H. c Left d4, occlusal view (NHMW 2005/0152/0002). d Right d4, labial view (NHMW
2005/0152/0003). e Left p4, occlusal view (NHMW 2005/0152/0005). f Left p4, labial view (NHMW 2005/0152/0004). g Left m1, occlusal view (NHMW 2005/0152/0006). h Left m1, labial view (NHMW 2005/0152/0007). i Left m2, occlusal view (NHMW 2005/0152/0008). j Left m2, labial view (NHMW 2005/0152/0009). k Right max. P4-M1 (NHMW 2005/0152/0013). I Left M1(NHMW 2005/0152/0014). m Left M2 (NHMW 2005/0152/0016). n Left M3 (NHMW 2005/0152/0017) 


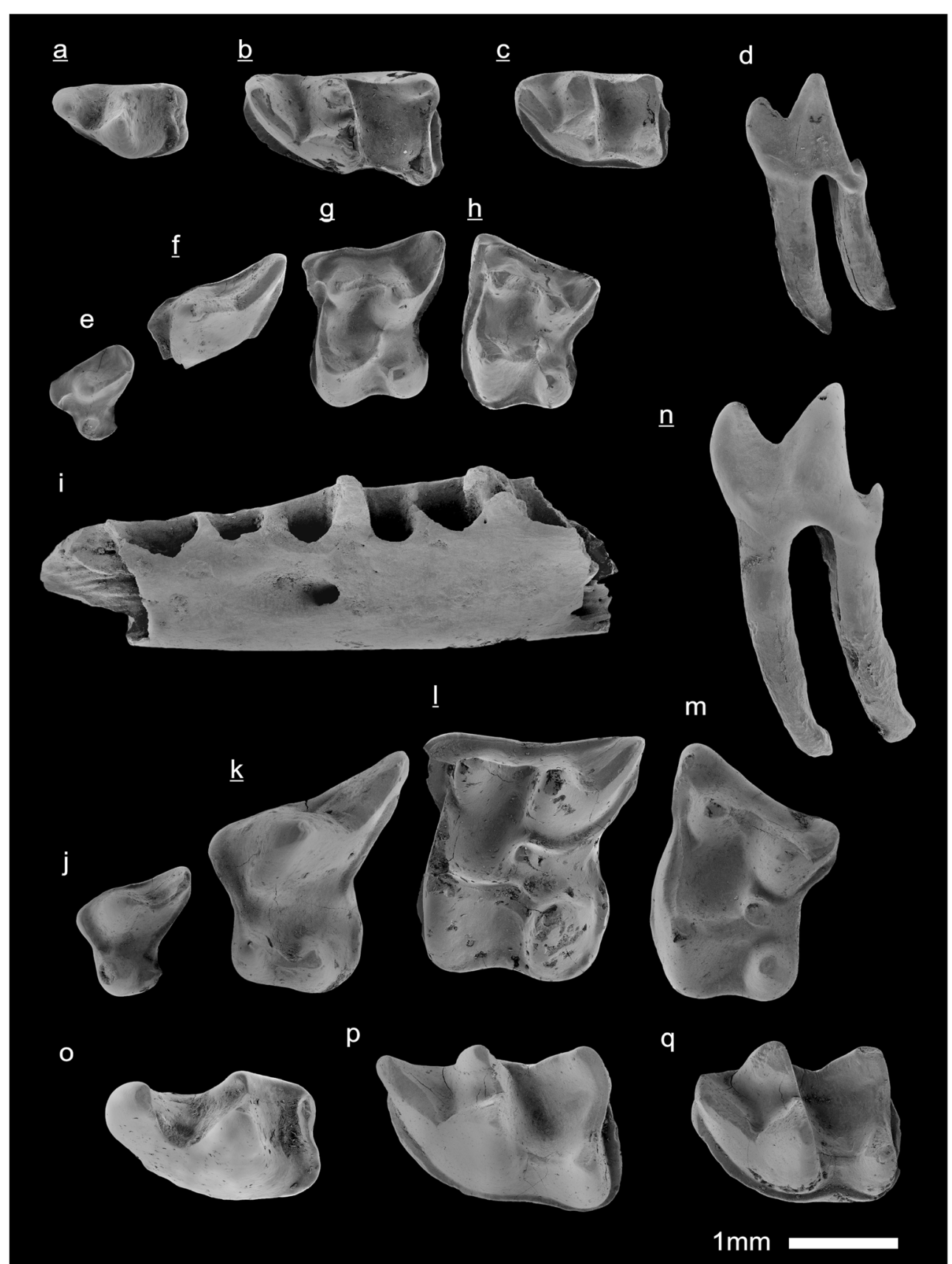

Fig. 35 Family Erinaceidae. Amphechinus minutissimus Ziegler, Dahlmann and Storch, 2007 from Del (DEL-B/12), Valley of Lakes, Mongolia. Late Oligocene, letter zone $\mathrm{C} 1$. All figured specimens are the holotype $(\mathrm{H})$ and paratypes. Ziegler et al. (2007). a Right p4 (NHMW 2005/0196/0002). b Right m1 (NHMW 2005/0196//0003). c Right m2 (NHMW 2005/0199/0003). d Left p4, labial view (NHMW $2005 / 0196 /$ 0001). e Left P3 (NHMW 2005/0196/0004). f Right P4-fragm. (NHMW 2005/0199/0005). g Right M1 (NHMW 2005/0199/0001), H. h Left M2 (NHMW 2005/0196/0005). i Left mand. (NHMW 2005/0199/0002).
Amphechinus major Ziegler, Dahlmann and Storch, 2007 from Del (DEL-B/12), Valley of Lakes, Mongolia. Late Oligocene, Letter zone C1. All figured specimens are paratypes. Ziegler et al. (2007). j Left P3 (NHMW 2005/0198/0008). k Right P4 (NHMW 2005/0198/0003). I Right M1 (NHMW 2005/0183/0001). m Left M2 (NHMW 2005/01987 0010). n Right p4, labial view (NHMW 2005/0198/0004). o Left p4, occlusā view (NHMW 2005/0198/0002). p Left m1 (NHMW 2005/0198/0005). q Left m2 (NHMW 2005/0198/0006) 


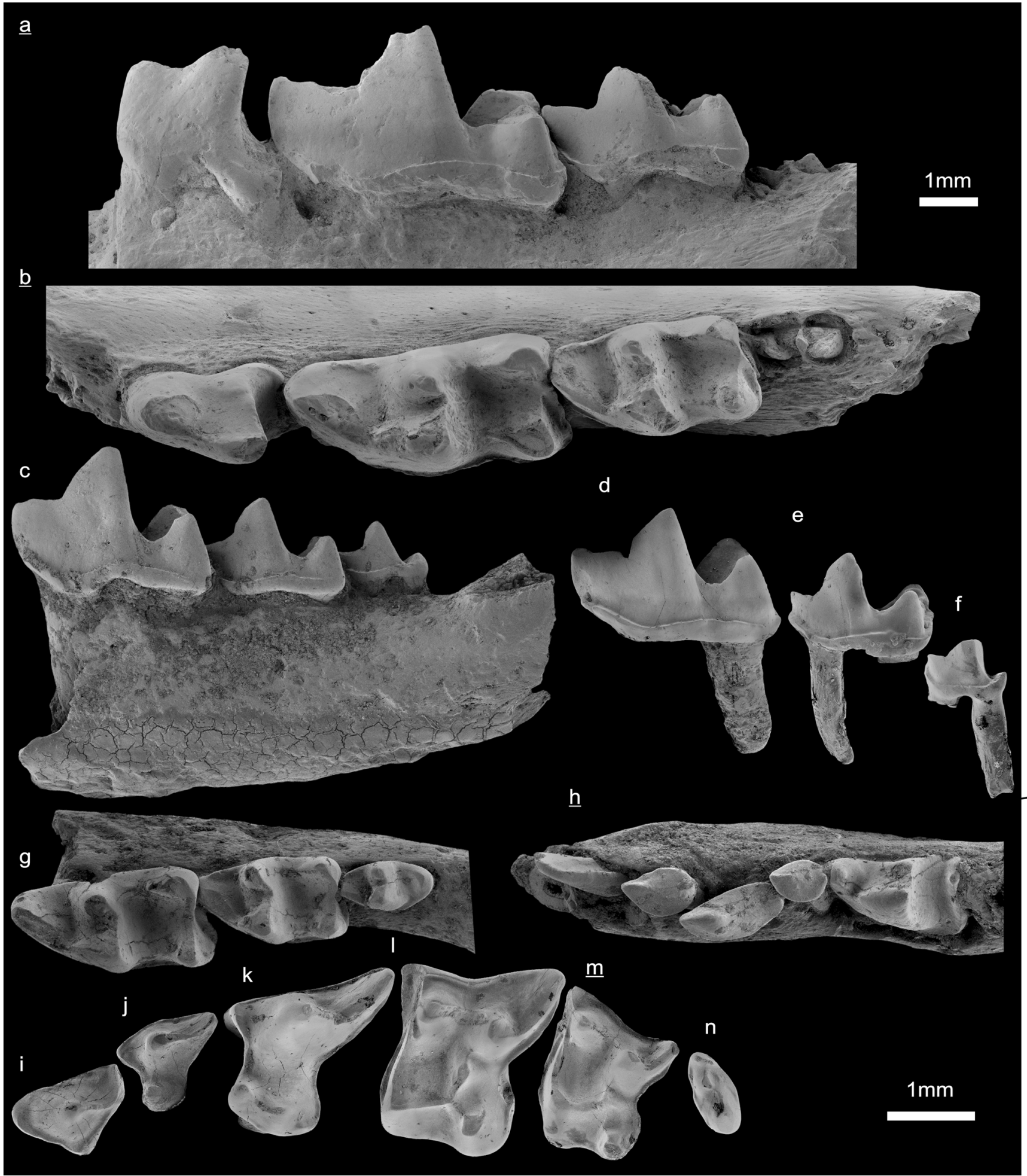

Fig. 36 Family Erinaceidae. Palaeoscaptor gigas (Lopatin, 2002) from Taatsiin Gol (TGR-C/1+2) Valley of Lakes, Mongolia. Late Oligocene, letter zone C. Ziegler et al. (2007). a Right mand. p4-m2, labial view (NHMW 2005/0128/0001). b Right mand. p4-m2, occlusal view (NHMW 2005/0128/0001) Palaeoscaptor tenuis Ziegler, Dahlmann and Storch, 2007 from Tatal Gol (TAT-D/1; letter zone A), Hsanda Gol (SHG-AB/1720; letter zone B), and Unkheltseg (UNCH-A/3B; letter zone B), Valley of Lakes, Mongolia. Early Oligocene. $\mathrm{H}=$ holotype. Ziegler et al. (2007). c Right mand. m1-3, labial view (NHMW 2005/0103/0001), TAT-D/1, H. d
Left m1 (NHMW 2005/0114/0003), SHG-AB/17-20. e Left m2 (NHMW 2005/0114/0004), SHG-AB/17-20. f Right m3 (NHMW 2005/0114/0005), SHG-AB/17-20. g Right mand. m1-3, occlusal view (NHMW 2005/0103/ 0001), TAT-D/1, H. h Right mand. i3, c, p2, i2, p4 (NHMW 2005/0103/ 0002), TAT-D/1. i Left D2 (NHMW 2005/0114/0006), SHG-AB/17-20. j Left P3 (NHMW 2005/0114/0007), SHG-AB/17-20. k Left P4 (NHMW 2005/0114/0008), SHG-AB/17-20. I Left M1 (NHMW 2005/0114/0009), SHG-AB/17-20. m Right M2 (NHMW 2005/0114/0010), SHG-AB/17-20. n Left M3 (NHMW 2005/0114/0012), SHG-AB/17-20 


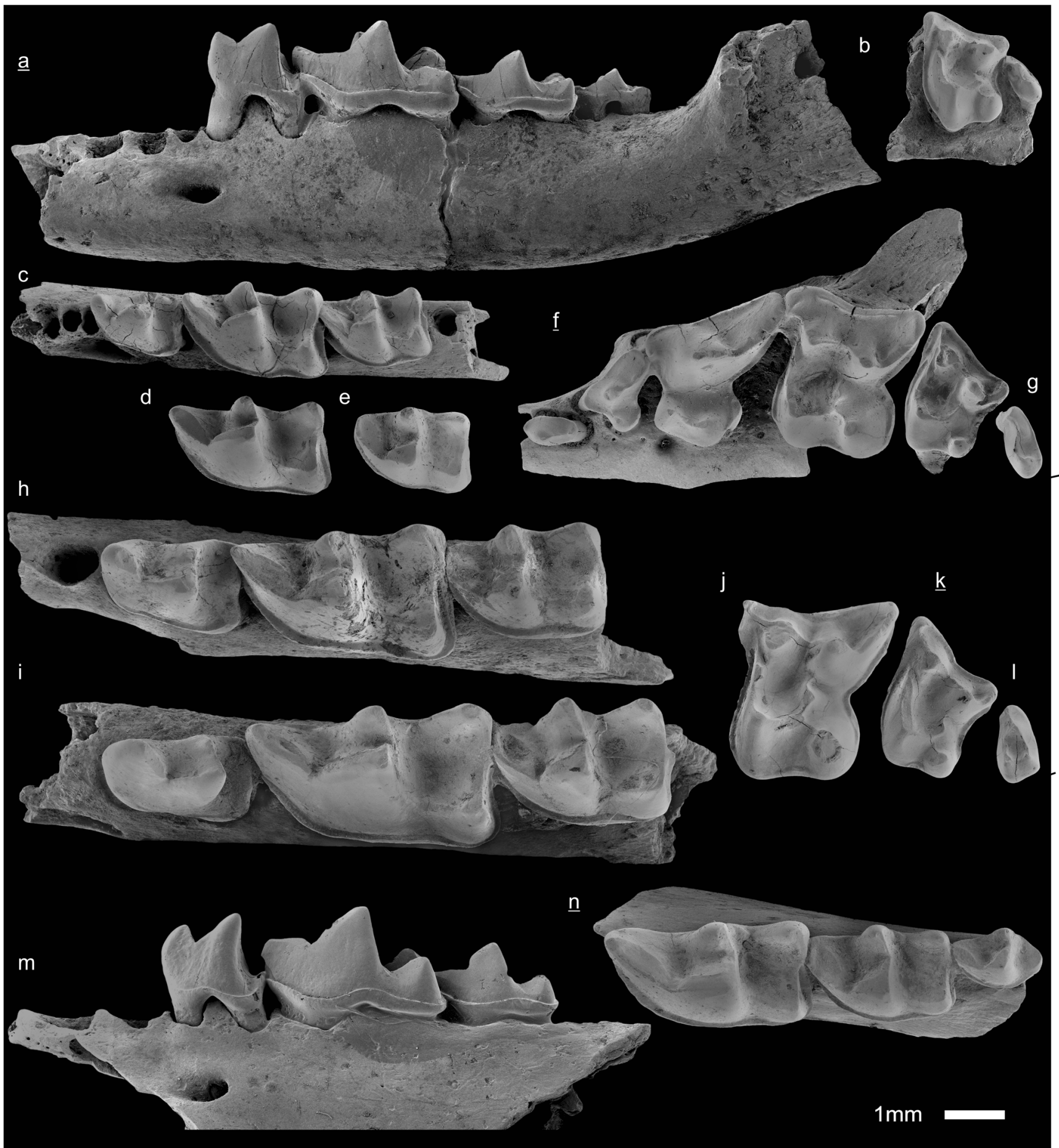

Fig. 37 Family Erinaceidae. Palaeoscaptor acridens (Matthew and Granger, 1924) from Tatal Gol (TAT-D/1; letter zone A), Khongil (HL-A/1+2; letter zone A) and Taatsiin Gol (TGR-AB/ 21, TGR-AB/22; letter zone B), Valley of Lakes, Mongolia. Early Oligocene. Ziegler et al. (2007). a Right mand. p4-m3 (NHMW 2005/0104/0001), TAT-D/1. b- Left max. M2-3 (NHMW 2005/0133/0006), TGR-AB/22. c Left mand. p4-m2 (NHMW 2005/0094/0001), HL-A/1+2. d Left m1 (NHMW 2005/0133/ 0002), TGR-AB/22. e Left m2 (NHMW 2005/0133/0003), TGRAB/22. f Right max. P2-M2 (NHMW 2005/0133/0005), TGR-AB/ 22. g Left M3 (NHMW 2005/ 0136/0002), TGR-AB/21. Palaeoscaptor cf. rectus Matthew and Granger, 1924 from
Hsanda Gol (SHG-AB/17-20; Biozone B), Ikh Argalatyn Nuruu (IKH-B/5; letter zone C1), Tatal Gol (TAT-C/7; letter zone B), Taatsiin Gol (TGR-C/1+2; letter zone C), and Toglorhoi (TGW$\mathrm{A} / 2 \mathrm{a}$ and TGW-A/2b; Biozone C), Valley of Lakes, Mongolia. Early Oligocene and late Oligocene. Ziegler et al. (2007). h Left mand. p4-m2 (NHMW 2005/0115/0001), SHG-AB/17-20. i Left mand. p4-m2 (NHMW 2005/0195/0001), IKH-B/5. j Left M1 (NHMW 2005/0123/0001), TAT-C/7. k Right M2 (NHMW 2005/0160/0001), TGW-A/2b. I Left M $\overline{3}$ (NHMW 2005/0123/ 0001), TAT-C/7. m Left mand. p4-m2, labial view (NHMW 2005/0154/0001), TGW-A/2a. n Right mand. m1-3 (NHMW 2005/0129/0001), TGR-C/1+2 


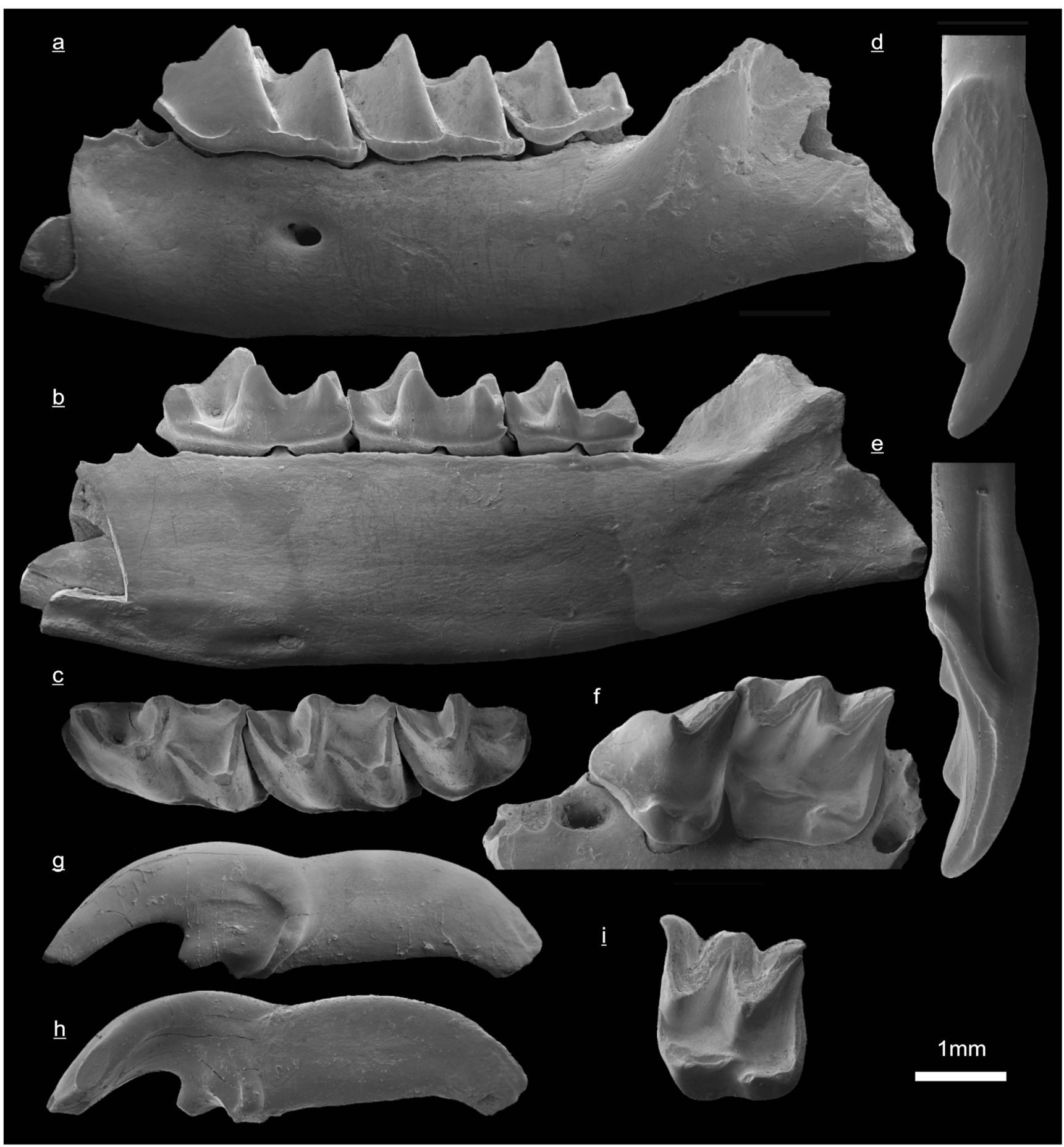

Fig. 38 Family Soricidae. Gobisorex kingae Sulimski, 1970 from Taatsiin Gol (TGR-B/1, TGR-AB/22), Ikh Argalatyn Nuruu (IKH-A/2), Hsanda Gol (SHG-AB/17-20), and Unkheltseg (UNCH-A/3B), Valley of Lakes, Mongolia. Early Oligocene, letter zone B. Ziegler et al. (2007). a Right mand. m1-3, labial view (NHMW 2006/0027/0001), TGR-B/1. $\overline{\mathbf{b}}$ Right mand. m1-3, lingual view (NHMW 2006/0027/0001), TGR-B/1. Right mand. m1-3, occlusal view (NHMW 2006/0027/0001), TGR-B/1. d Right inc. inf., labial view (NHMW 2006/0023/0001), IKH-A/2. e $\bar{R}$ ight inc. inf., lingual view (NHMW 2006/0023/0001), IKH-A/2. f Left max. P4-M1 (NHMW 2006/0025/0001), SHG-AB/17-20. g Right Inc. sup., labial view (NHMW 2006/0030/0001), UNCH-A/3B. h Right Inc. sup., lingual view (NHMW 2006/0030/0001), UNCH-A/3B. $\mathbf{i}$ Right M2 (NHMW 2006/0026/0001), TGR-AB/22 


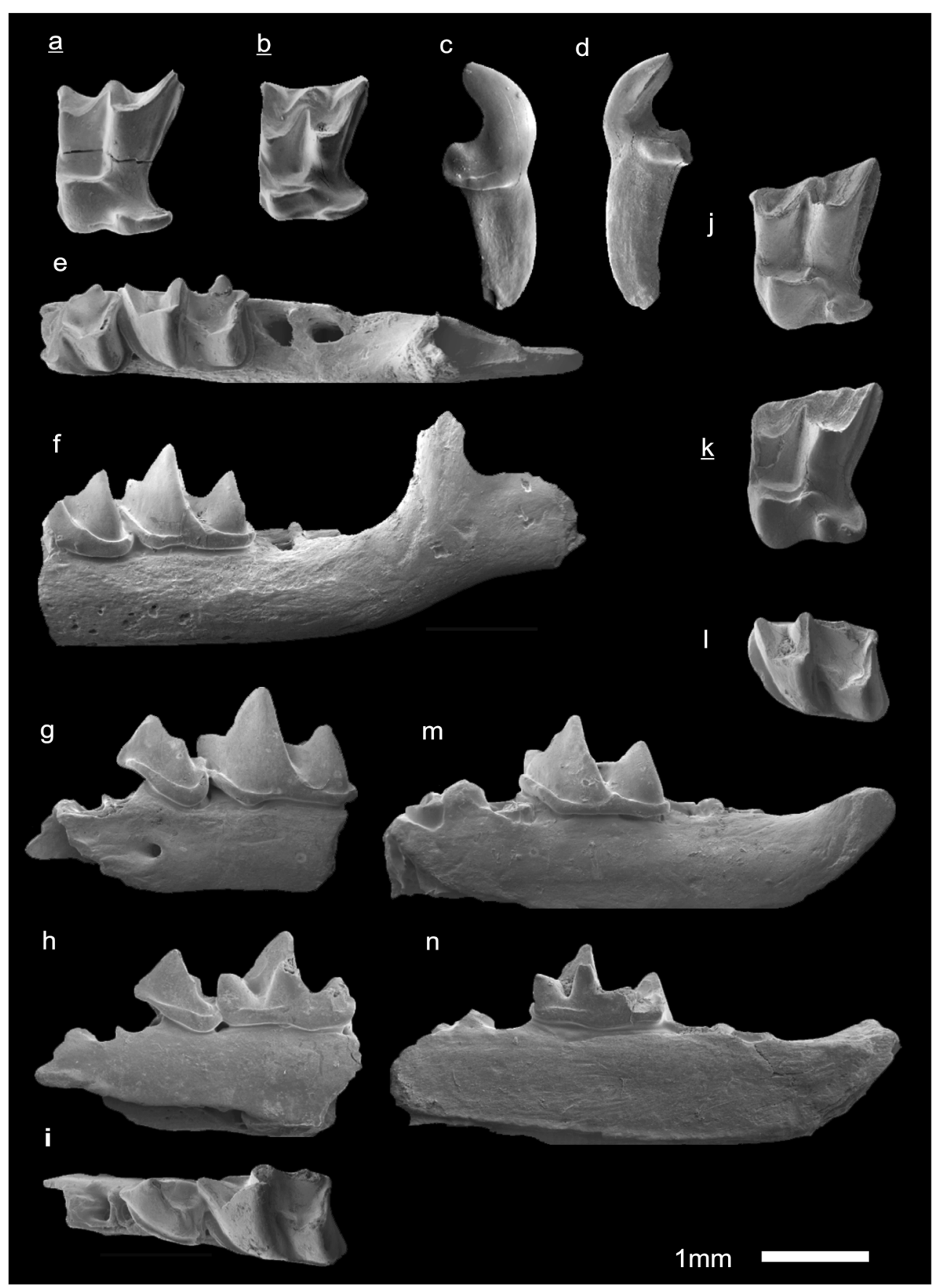

Fig. 39 Family Soricidae. Taatsiinia hoeckorum Ziegler, Dahlmann and Storch, 2007 from Taatsiin Gol (TGR-B/1), Valley of Lakes, Mongolia. Early Oligocene, letter zone B. All figured specimens are the holotype $(\mathrm{H})$ and paratypes. Ziegler et al. (2007). a Right M1 (NHMW 2006 0036/0001), H. b Right M2 (NHMW 2006/0036/0003). c Left I sup, labial view (NHM̄W 2006/0036/0002). d Left I sup, lingual view (NHMW 2006/0036/0002). e Left mand. m1-2, occlusal view (NHMW 2006/0036/0004). f Left mand. m1-2, labial view (NHMW 2006/0036/ 0004). Tavoonyia altaica Ziegler, Dahlmann and Storch, 2007 from
Huch Teeg (RHN-A/9), Valley of Lakes, Mongolia. Late Oligocene, letter zone $\mathrm{C} 1$. All figured specimens are the holotype $(\mathrm{H})$ or paratypes. Ziegler et al. (2007). g Left mand. p4-m1 labial view (NHMW 2006/0037/0003). h Left mand. p4-m1 lingual view (NHMW 2006/0037/0003). i Left mand. p4-m1 occlusal view (NHMW 2006/0037/0003). j Left M1 (NHMW 2006/0037/0001), H. k Right M2 (NHMW 2006/0037/0002). 1 Left $\mathrm{m} 2$ of mand. (NHMW 2006/0037/0004). m Left mand. m2, labial view (NHMW 2006/0037/0004). n Left mand. m2, lingual view (NHMW 2006/0037/0004) 


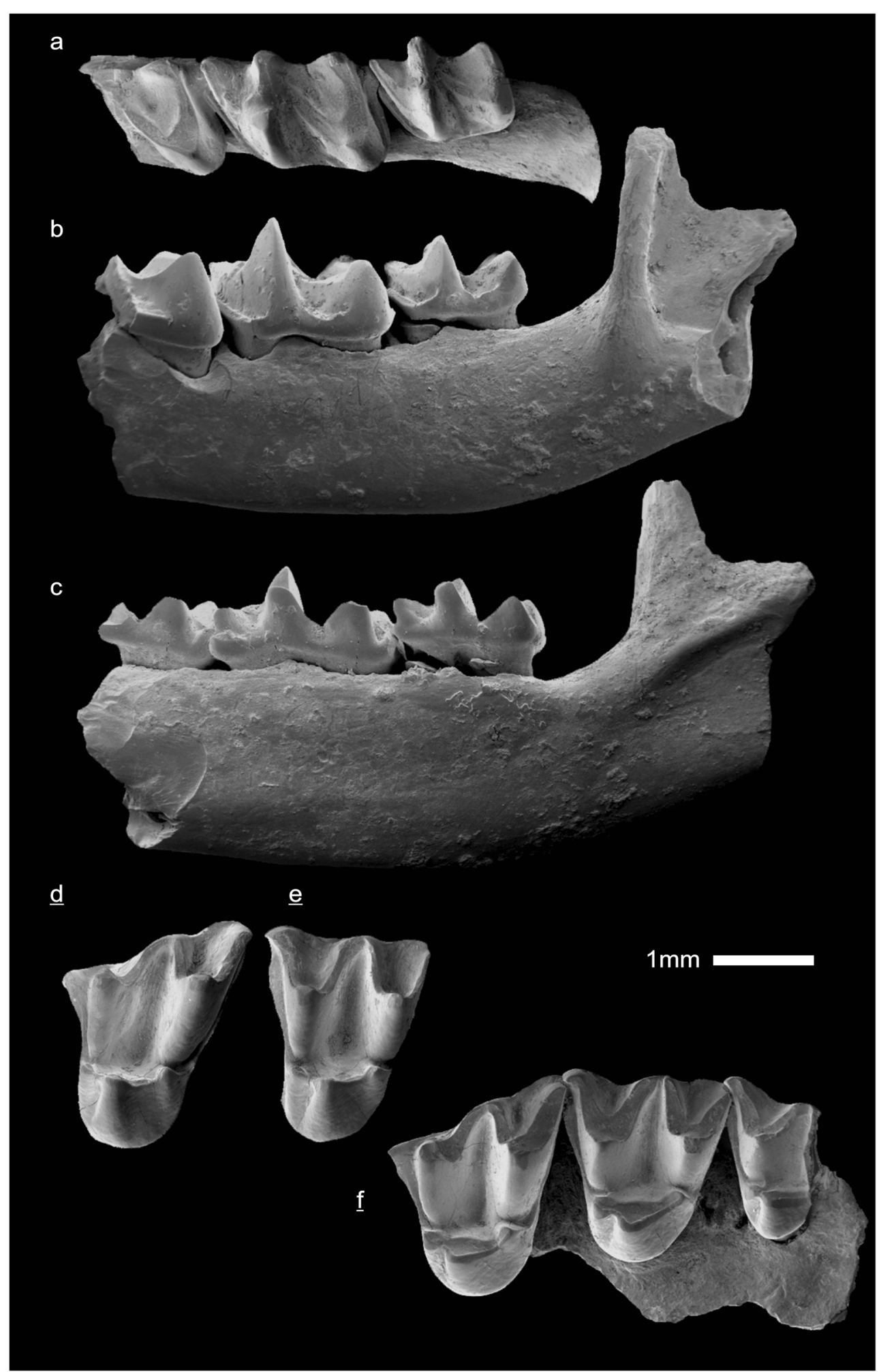

Fig. 40 Family Talpidae. Mongolopala tathue Ziegler, Dahlmann and Storch, 2007 from Tatal Gol (TAT-D/1) and Hsanda Gol (SHG-C/1), Valley of Lakes, Mongolia. Early Oligocene, letter zone A. Holotype (H), paratypes (P). Ziegler et al. (2007). a-c Left mand. m1-3 (NHMW
2006/0055/0002), TAT-D/1. a Occlusal view, b labial view, c lingual view d Right M1 (NHMW 2006/0056/0001), SHG-C/1 e Right M2 (NHMW 2006/0056/0002), SHG-C/1 f Right Max Mī-3 (NHMW 2006/ 0055/0001), TAT-D/1, H 
Fig. 41 Family Aplodontidae. Ninamys kazimierzi Vianey-

Liaud, Gomes Rodrigues and Marivaux, 2013 from Taatsiin Gol (TGR-B/1) and Ikh Argalatyn Nuruu (IKH-A/1+2), Valley of Lakes, Mongolia. Early

Oligocene, letter zone B. Maridet et al. (2017, this issue). a Left maxilla P4-P3-M3 (NHMW 2009/0137/0001), TGR-B/1 b-e Right mand. p4-m3 (NHMW 2015/0358/0001), IKH-A/1+2. b Right $\mathrm{p} 4, \underline{\mathbf{c}}$ right $\mathrm{m} 1$, d right $\mathrm{m} 2, \underline{\mathbf{e}}$ right m3. Ninamys arboraptus (Shevyreva, 1966) from Taatsiin Gol (TGR-B/1), Valley of Lakes, Mongolia. Early Oligocene, letter zone B. Maridet et al. (2017, this issue).f-h Right m1-3 (NHMW 2009/01ㅜㅇ/0001), TGR-B/1. f Right $\mathrm{m} 1, \underline{\mathbf{g}}$ right $\mathrm{m} 2, \underline{\mathbf{h}}$ right $\mathrm{m} 3$. Prosciurus? mongoliensis

\section{Wang and Dashzeveg, 2005}

from Tatal Gol (TAT-D/1), Valley of Lakes, Mongolia. Early

Oligocene, letter zone A. Maridet et al. (2017, this issue). $\mathbf{i}-\mathbf{k}$ Left mand. m1-3 (NHMW 2015/0350/ 0001). i Left $\mathrm{m} 1$, j left $\mathrm{m} 2$, $\mathbf{k}$ left m3. Promeniscomys cf. sinensis (Wang, 1987) from Taatsiin Gol (TGR-AB/21, letter zone B) and Tatal Gol (TAT-D/1, letter zone A), Valley of Lakes, Mongolia. Early Oligocene. Maridet et al. (2017, this issue). 1-o Left mand. p4-m3 (NHMW 2015/0366/ 0001), TGR-AB/21, letter zone B. 1 Left p4, m left m1, n left m2, o left m3. p-r Left max. P4-M2 (NHMW 2015/0351/0001), TAT$\mathrm{D} / 1$, letter zone A. $\mathbf{p}$ Left P4, q left M1, $\mathbf{r}$ left M2

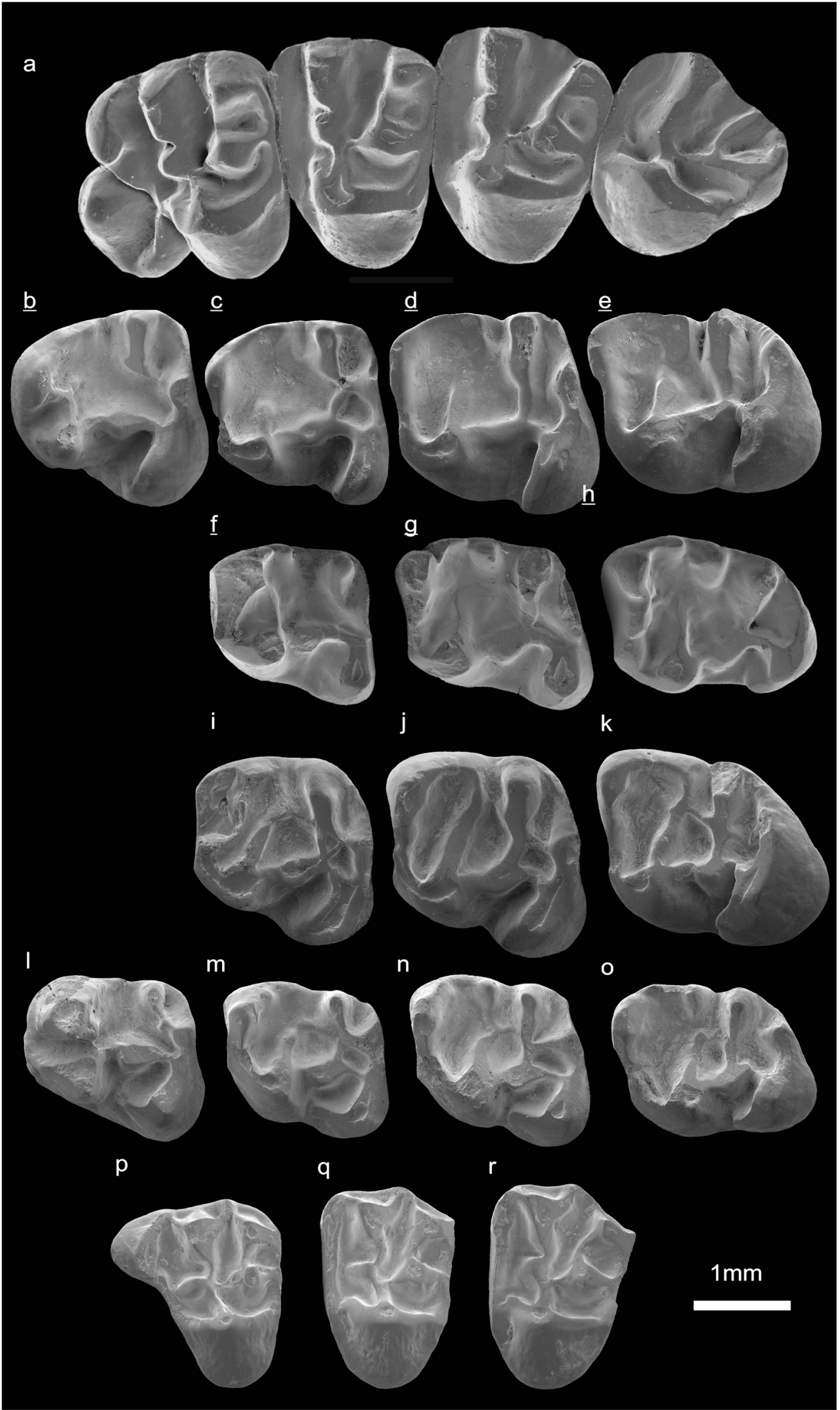


Fig. 42 Family Aplodontidae. Proansomys badamae sp. nov. Maridet, Daxner-Höck, LópezGuerrero and Göhlich, 2017 from Taatsiin Gol (TGR-C/1, TGR-C/7), Valley of Lakes, Mongolia. Late Oligocene, letter zone C. Maridet et al. (2017, this issue). a Right P4 (NHMW 2015/03̄81/0001), TGR-C/7. b Left M1/2 (NHMW 2015/0381/ 0002), TGR-C/7. c Left M1/2 (NHMW 2015/0381/0003), TGRC/7. d Left M3 (NHMW 2015/0381/0006), TGR-C/7. e- $-\underline{\mathbf{h}}$ Right mand. p4-m3 (NHMW 2015/0374/0002), TGR-C/1. e

Right $\mathrm{p} 4, \underline{\mathbf{f}}$ right $\mathrm{m} 1, \underline{\mathbf{g}}$ right $\overline{\mathrm{m}} 2, \underline{\mathbf{h}}$ right m3. Family Sciuridae.

Kherem shandgoliensis Minjin, 2004 from Hotuliin Teeg (HTE*), Valley of Lakes, Mongolia. Early Miocene, letter zone D. Maridet et al. (2014a). i Left max. P4-M1 (NHMW 2013/0407/0001). j Right max. M1-3 (NHMW 2013/0407/0002). Pteromyini indet. from Unkheltseg (UNCHA/4), Valley of Lakes, Mongolia. Early Miocene, letter zone D. Maridet et al. (2014a). k Left m1/2 (NHMW 2013/0412/0003). I Left p4 (NHMW 2013/0412/0002). m Left d4 (NHMW 2013/0412/ 0001). Plesiosciurus aff. sinensis Qiu and Liu, 1986 from Ulan Tolgoi (UTO-A/5), Valley of Lakes, Mongolia. ?Middle Miocene, letter zone D1/2. Further occurrences are Toglorhoi (TGWA/2a, Late Oligocene), Hotuliin Teeg (HTE*), and Unkheltseg (UNCH-A/4), early Miocene. Maridet et al. (2014a). n Right M1 2 (NHMW 2013/0400/0001), UTO-A/5. o Right m1/2 (NHMW 2013/0400/0004), UTO-A/5. p Left m3 (NHMW 2013/0400/ 0005), UTO-A/5

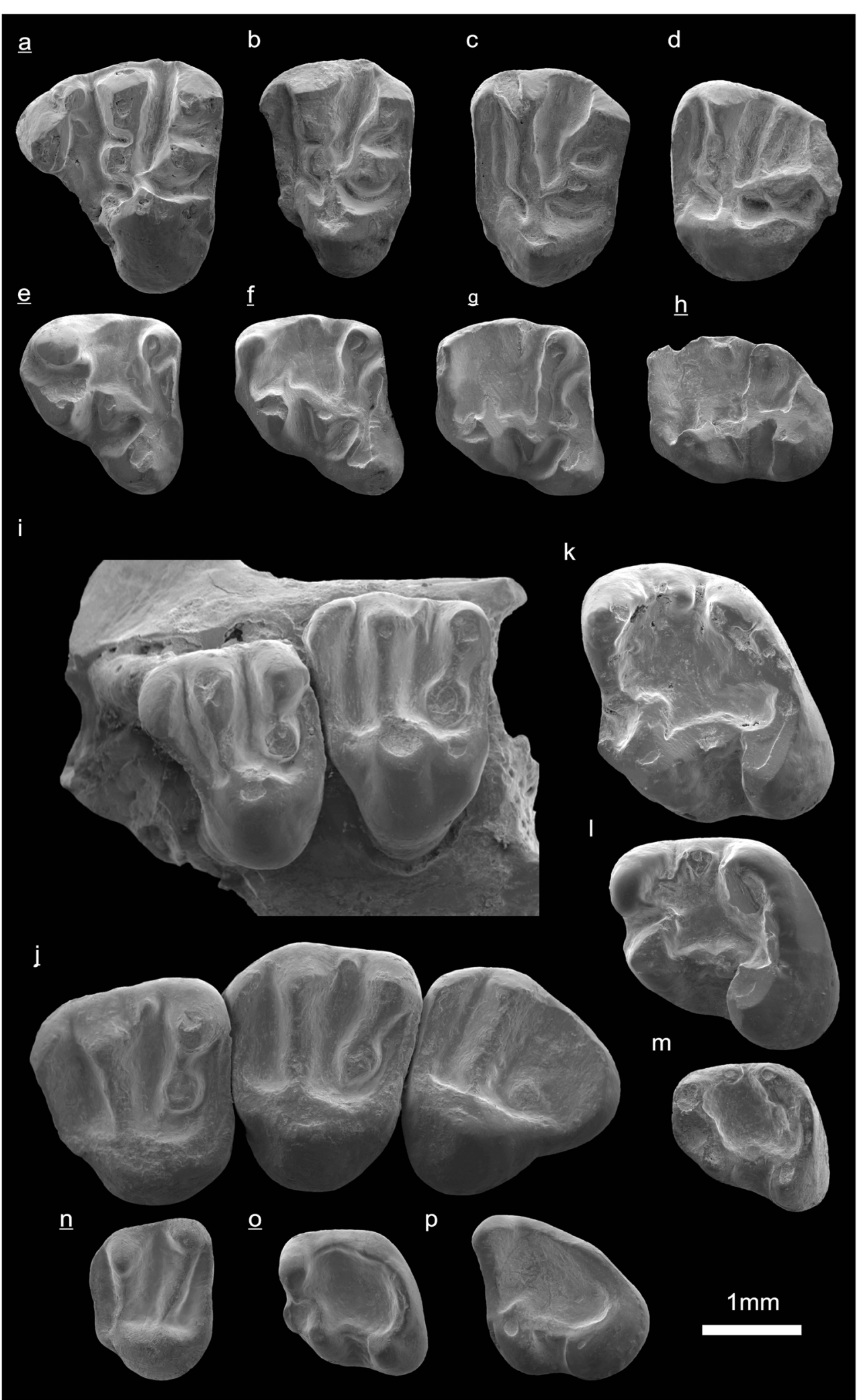




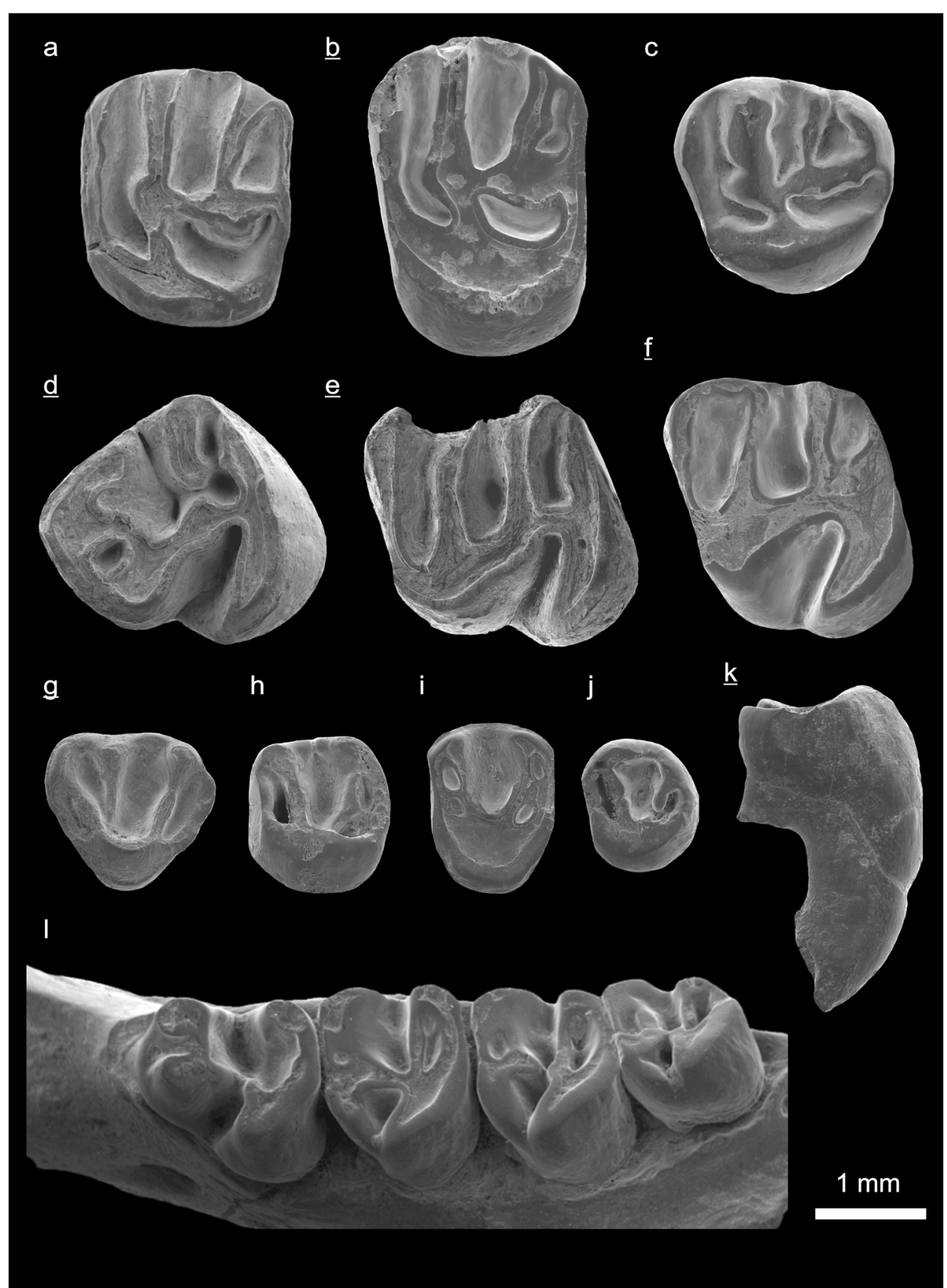

Fig. 43 Fam. Cylindrodontidae. Anomoemys lohiculus (Matthew and Granger, 1923) from Del (DEL-B/7, letter zone B) and Taatsiin Gol (TGR-A/ 13, letter zone A and TGL-A/11, letter zone B), Valley of Lakes, Mongolia. Early Oligocene. Daxner-Höck et al. (2010). a Left M1 (NHMW 2009/0140/0002), Del-B/7. b Right M2 (NHMW 2016/0015/0001), TGL-A/11. c Left M3 (NHMW 2016/0014/0001), TGR-A/13. d Right p4 (NHMW 2016/0015/0003), TGL-A/11. e Right m1/2 (NHMW 2016/0015/0004), TGL-A/11. f Right m2 (NHMW
2009/0140/0003), DEL-B/7. Ardynomys sp. from Tatal Gol (TAT-037 and TAT-D/1), Valley of Lakes, Mongolia. Early Oligocene, letter zone A. Daxner-Höck et al. (2010). g Right D4 (NHMW 2016/0017/0002), TAT-037. h Left M1/2 (NHMW 2016/0130/0003), TAT-D/1. i Left M1/2 (NHMW 2016/0130/0006), TAT-D/1. j Left M3 (NHMW 2016/0130/ 0004), TAT-D/1. k Right M1/2, distal view (NHMW 2016/0130/0007), TAT-D/1. 1 Left mand. p4-m3 (NHMW 2016/0017/0001), TAT-037 
Fig. 44 Family Ctenodactylidae. Tataromys minor longidens

Schmidt-Kittler, Vianey-Liaud and Marivaux, 2007 from

Taatsiin Gol (TGW-A/2b). Late

Oligocene, letter zone $\mathrm{C}$.

Schmidt-Kittler et al. (2007). a Left P4 (NHMW 2006/0100/ 0013). b Left P4 (NHMW 2006/0100/0011). c Left M1 (NHMW 2006/0100/0015). d Left M2 (NHMW 2006/0100/ 0020). e Right M3 (NHMW 2006/0100/0009). f Left d4 (NHMW 2006/0100/0030). g Left p4 (NHMW 2006/0100/ 0031). h Right m1 (NHMW 2006/0 $\overline{1} 00 / 0033)$. i Left m2 (NHMW 2006/0100/0037). j Left m3 (NHMW 2006/0100/0038). Tataromys sigmodon Matthew and Granger, 1923 from

Toglorhoi (TGW-A/2a, TGW-A/ 2b), Valley of Lakes, Mongolia. Late Oligocene, letter zone C. Schmidt-Kittler et al. (2007). k Left D4 (NHMW 2006/0105/ 0003)TGW-A/2a. I Left P4 (NHMW 2006/0106/0009)TGWA/2b. m Left M1 (NHMW 2006/0105/0005)TGW-A/2a. n Right M2 (NHMW 2006/0106/ 0004)TGW-A/2b. o Right M3 (NHMW 2006/0106/0001)TGWA/2b. p Left p4 (NHMW 2006/0105/0011)TGW-A/2a. q Left m1 (NHMW 2006/0105/ 0017)TGW-A/2a. r Left m2/3 (NHMW 2006/0105/0018)TGWA/2a. s Left m3 (NHMW 2006/0105/0020)TGW-A/2aw. $\boldsymbol{d}$. t-w Left mand. p4-m3 (NHMW 2012/0037/0001), TAT-055. t Left $\mathrm{p} 4$, u left $\mathrm{m} 1, \mathbf{v}$ left $\mathrm{m} 2$, w left m3. $\mathbf{x}-\mathbf{z z}$ Maxilla left P4-M2 and right M1-M3 (NHMW

2012/0024/0001), SHG-AB/top. x Left P4, y left M1, z left M2, zz right $\mathrm{M} 3$

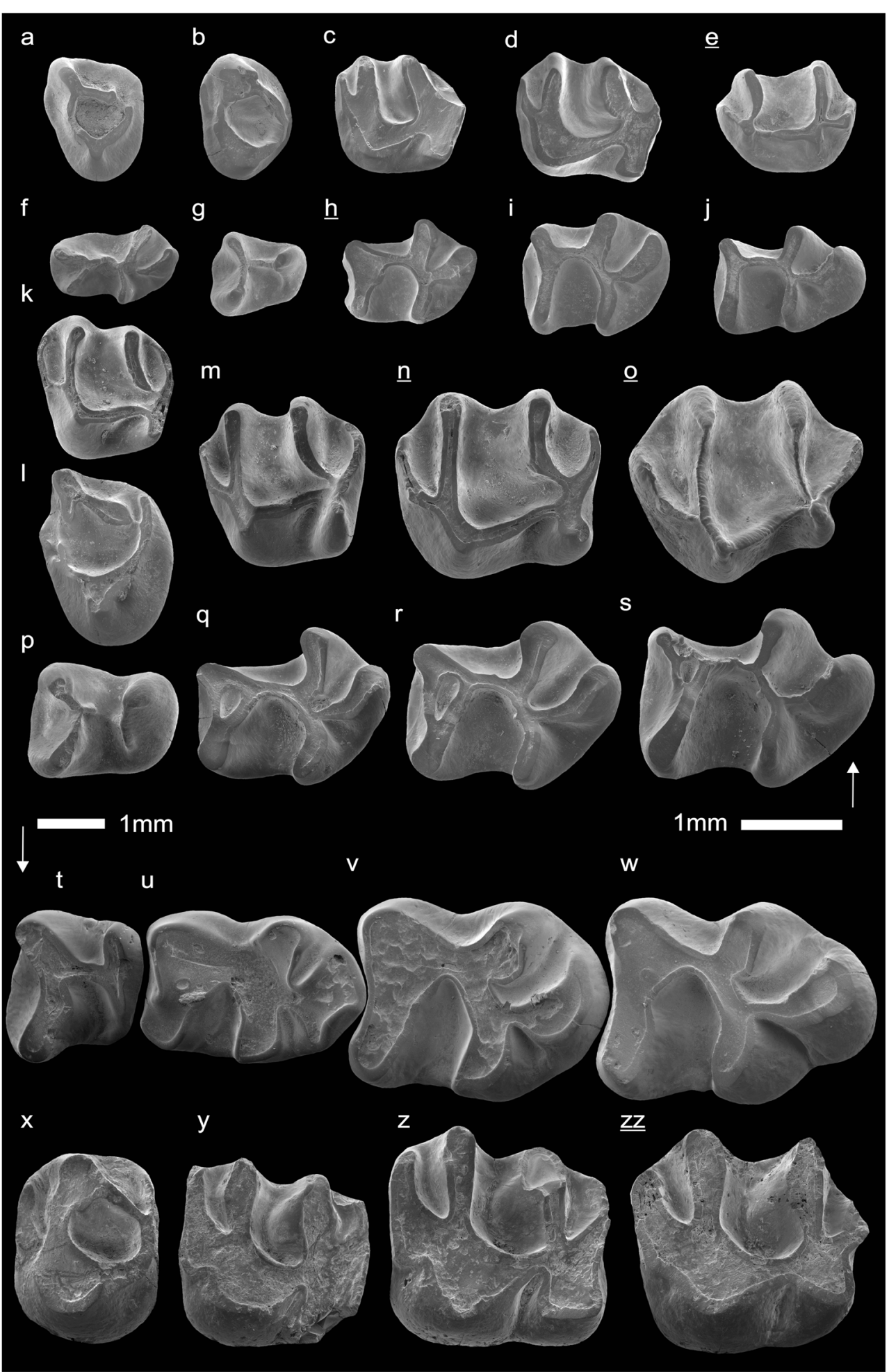




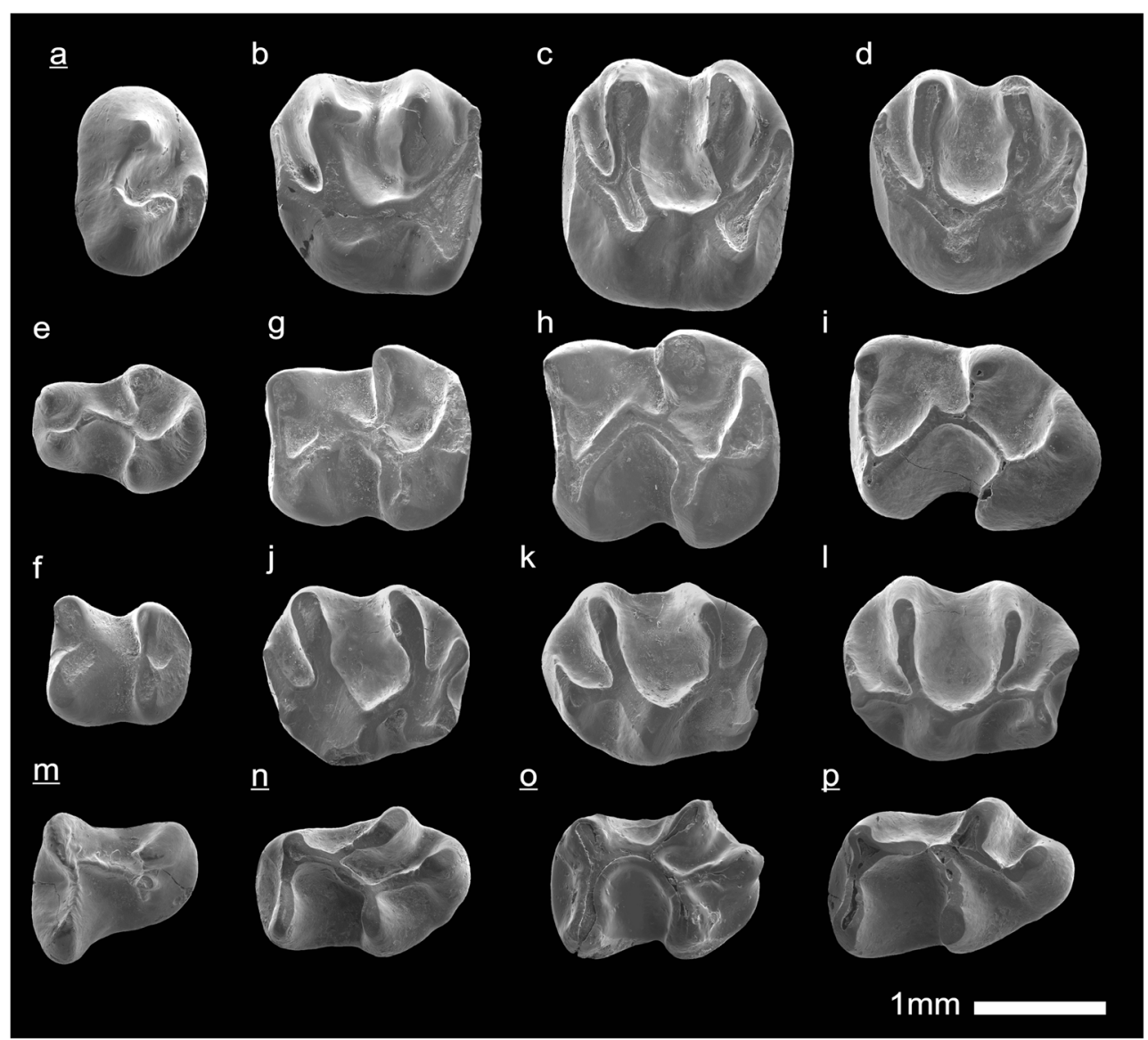

Fig. 45 Fam. Ctenodactylidae. Karakoromys decessus Matthew and Granger, 1923 from Hsanda Gol (SHG-A/9, SHG-A*), letter zone B and Khongil (HL-A/1), letter zone A, Valley of Lakes, Mongolia. Early Oligocene. Schmidt-Kittler et al. (2007), Oliver et al. (2017, this issue) a Right P4 (NHMW 2012/0021/0002), SHG-A/9. b Left M1 (NHMW 2012/0021/0005), SHG-A/9. c Left M2 (NHMW 2012/0021/0004), SHG-A/9. d Left M3 (NHMW 2012/0059/0012), HL-A/1. e Left d4 (NHMW 2012/0059/0013), HL-A/1. f Left p4 (NHMW 2012/0022/ 0003), SHG*. g Left m1 (NHMW 2012/0022/0004), SHG*. h Left m2
(NHMW 2012/0022/0006), SHG*. i Left m3 (NHMW 2012/0059/0014), HL-A/1. Huangomys frequens Schmidt-Kittler, Vianey-Liaud and Marivaux, 2007 from Taatsiin Gol (TGR-AB/22), Valley of Lakes, Mongolia. Early Oligocene, letter zone B. Schmidt-Kittler et al. (2007). j Left M1 (NHMW 2006/0075/0016). k Left M2 (NHMW 2006/0075/ 0018). I Left M3 (NHMW 2006/0075/0023). m Right p4 (NHMW 2006/0075/0029). n Right m1 (NHMW 2006/0075/0033). o Right m2 (NHMW 2006/0075/0050), TGR-AB/21. p Right m2/3 (NHMW 2006/0075/0034)

Fig. 46 Fam. Ctenodactylidae. Yindirtemys birgeri Bendukidze, 1993 from Tatal Gol (TAT-051/2), Valley of Lakes, Mongolia. Late Oligocene, letter zone C1. Oliver and Daxner-Höck (2017). a-d Left maxilla right and left P4-M3 (NHMW 2012/0060/0001). a Left P4, b left M2, c left M2, d left M3. Yindirtemys deflexus (Teilhard de Chardin, 1926) from Huch Teeg (RHN-A/7) and Del (DEL-B/12), Valley of Lakes, Mongolia. Late Oligocene, letter zone C1. Schmidt-Kittler et al. (2007), Oliver and Daxner-Höck (2017). e Right D4 (NHMW 2006/0090/0015), RHN-A/7. f Left P4 (NHMW 2006/0090/0039), RHN-A/7. g Right M1 (NHMW 2009/0086/0005), TGW-A*. h Right M2 (NHMW 2006/0090/0053), RHN-A/7. i Left M3 (NHMW 2006/0090/0010), RHN-A/7. j Left mand. p4-m3 (NHMW 2006/0090/0001), RHN-A/7. k Right d4 (NHMW 2006/0090/0021), RHN-A/7 Yindirtemys suni (Li and Qiu, 1980) from Hotuliin Teeg (HTS-056/3, letter zone C1-D; HTE-014-018, HTE-008, and HTE-009, letter zone D) and Unkheltseg (UNCH-A/4, letter zone D), Valley of Lakes, Mongolia. Late Oligocene and early Miocene. Oliver and Daxner-Höck (2017). I Right P4 (NHMW 2012/0031/0012), HTE014-018. m Right M2 (NḦMW 2012/0047/0001), HTS-056/3. n Right

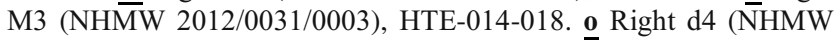
2006/0088/0001), UNCH-A/4. p Right m2 (NHMW 2012/0032/0005), HTE-008. q Left m3 (NHMW 2012/0033/0009), HTE-009 


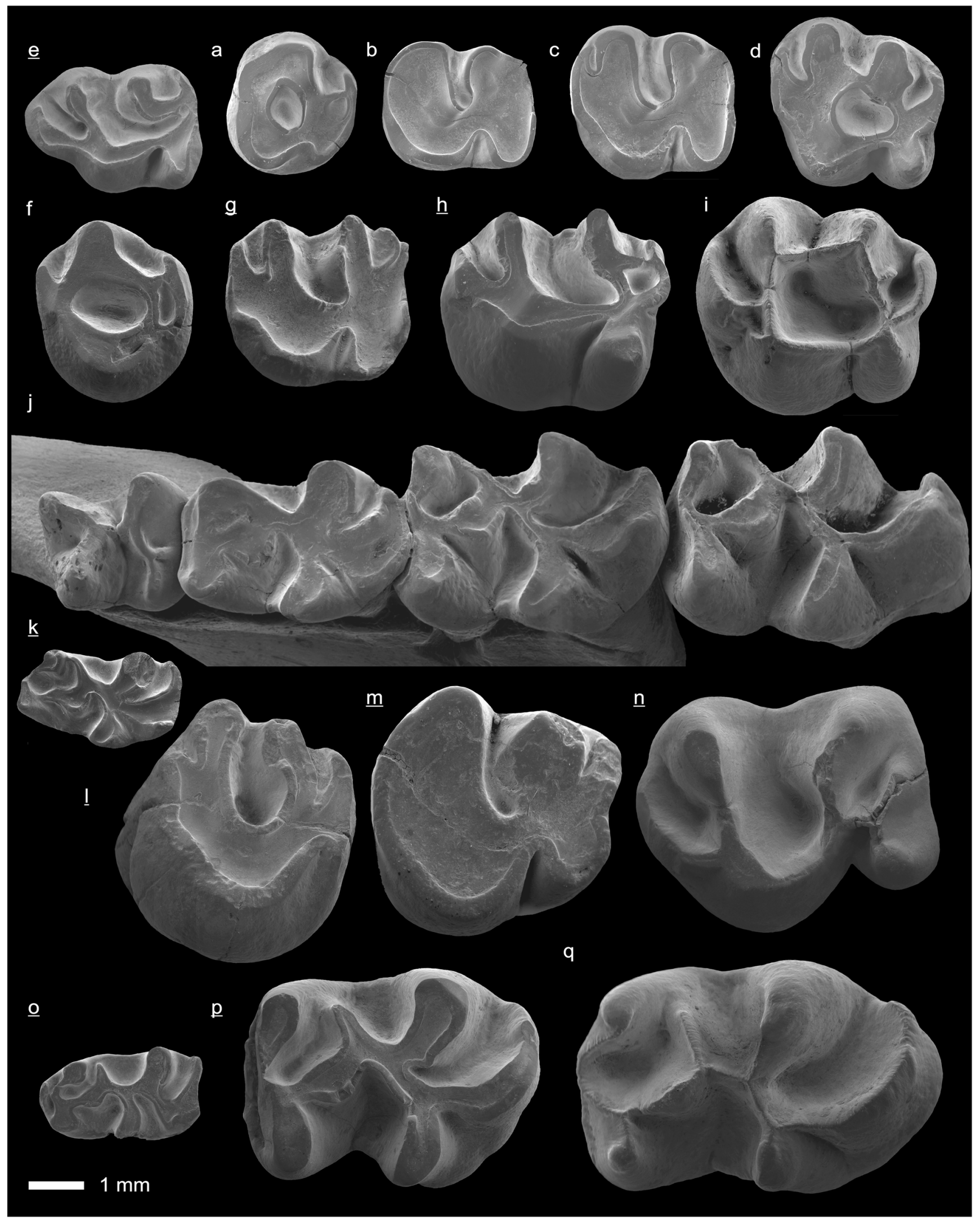




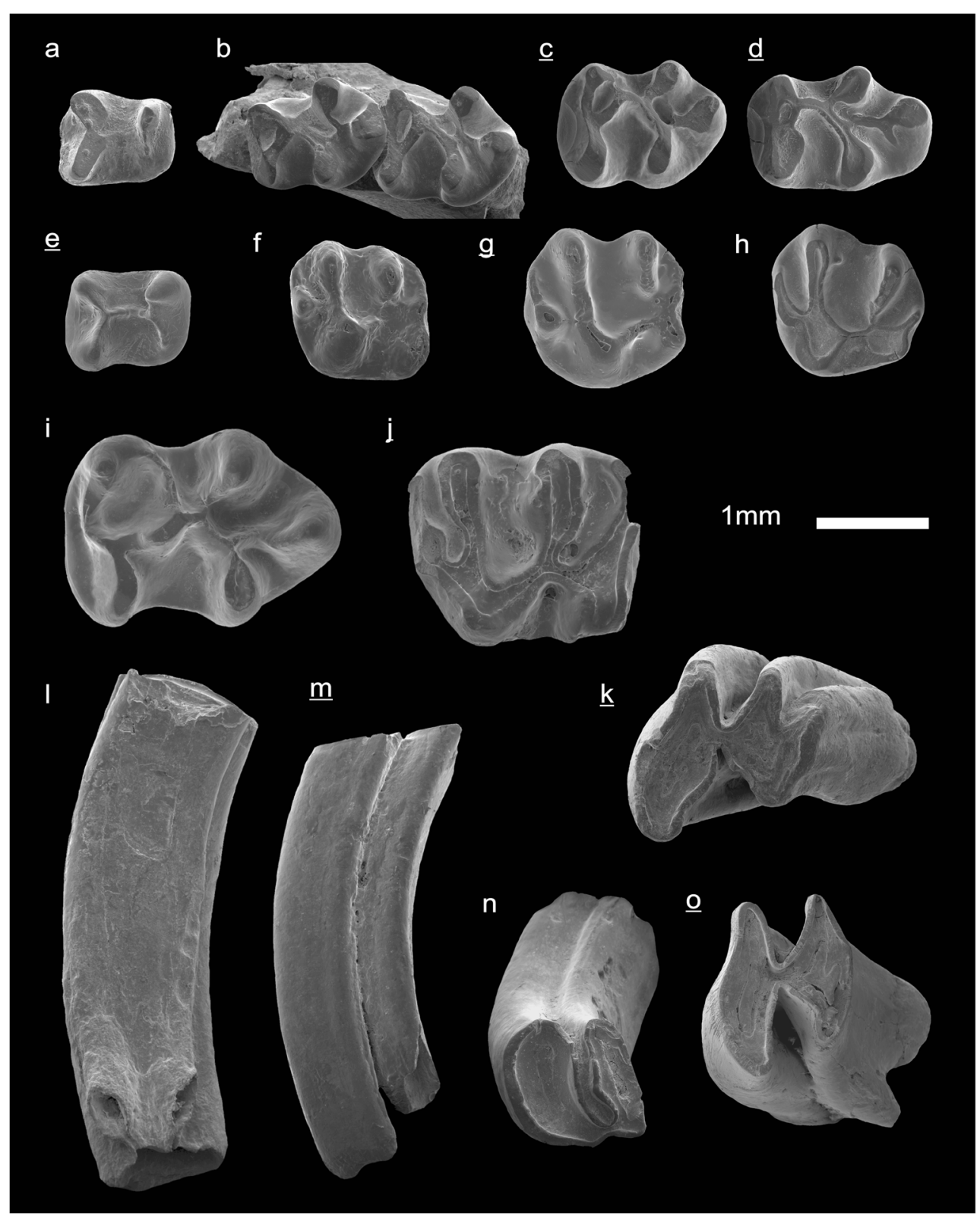

Fig. 47 Fam. Ctenodactylidae. Yindirtemys shevyrevae Vianey-Liaud, Schmidt-Kittler and Marivaux, 2006 from Hsanda Gol (SHG-AB/1718, SHG-AB/17-20) and Taatsiin Gol (TGR-AB/22, TGR-AB/21), Valley of Lakes, Mongolia. Early Oligocene, letter zone B. SchmidtKittler et al. (2007). a Left p4 (NHMW 2006/0094/0002), SHG-AB/1720. b Left m1-2 (NHMW 2006/0094/0001), SHG-AB/17-20. c Right m2 (NHMW 2006/0095/0001), SHG-AB/17-18. d Right m3 (NHMW 2006/0097/0001), TGR-AB/22. e Right p4 (NHM̄M 2006/0096/0007), TGR-AB/21. f Left M1 (NHMW 2006/0096/0001), TGR-AB/21. g Right M2 (NHMW 2006/0096/0012), TGR-AB/21. h Left M3 (NHMW 2006/0096/0003), TGR-AB/21. Yindirtemys aff. ulantatalensis (Huang, 1985) from Unzing Khurem (TAR-A/2), Valley of Lakes,
Mongolia. Late Oligocene, letter zone C. Schmidt-Kittler et al. (2007). i Left m3 (NHMW 2006/0091/0001), TAR-A/2. j Right M2 (NHMW 2006/0091/0002), TAR-A/2. Prodistylomys nov. spec. 1 from Hotuliin Teeg (HTE-012), Valley of Lakes, Mongolia. Early Miocene, letter zone D. Oliver et al. (in prep.). k Right m2, occlusal view (NHMW 2012/0051/ 0001), HTE-012 Prodistylomys nov. spec. 2 from Huch Teeg (RHN-A/ 12), Luugar Khudag (LOG-A/1) and Unkheltseg (UNCH-A/3), Valley of Lakes, Mongolia. Early Miocene, letter zone D. Oliver et al. (in prep.). 1 Left M1/2, distal view (NHMW 2012/0050/0004), RHN-A/12. m Right M1/2, lingual view (NHMW 2012/0048/0024), LOG-A/1. n Left M1/2, occlusal-labial view (NHMW 2012/0049/0005), UNCH-A/3. o Right m2, occlusal view (NHMW 2012/0048/0001), LOG-A/1 


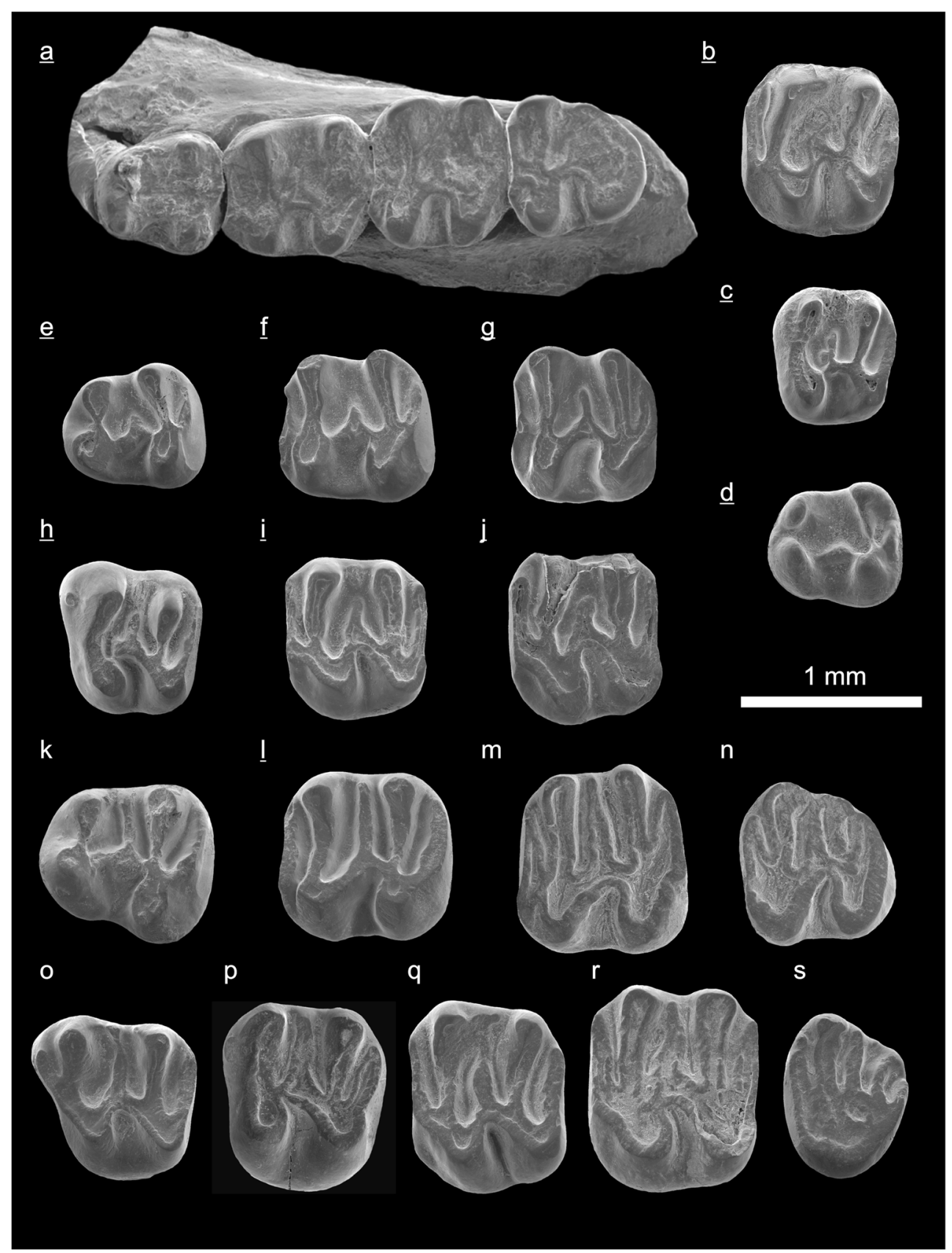

Fig. 48 Fam. Eomyidae. Eomys aff. orientalis Wang and Emry, 1991 from Taatsiin Gol (TGR-AB/21) and Hsanda Gol (SHG-A/17-18), Valley of Lakes, Mongolia. Early Oligocene, letter zone B. Maridet et al. (2015). a Right mand. p4-m3 (NHMW 2013/0059/0001), TGR-AB/21. b Right M1/2 (NHMW 2013/0055/0004), SHG-A/17-18. c Right P4 (N̄HMW 2013/0055/0002), SHG-A/17-18 E. cf. orientalis Wang and Emry, 1991 from Tatal Gol (TAT-C/1), Valley of Lakes, Mongolia. Early Oligocene, letter zone A. Maridet et al. (2015). d Right p4 (NHMW 2013/0054/0001) ef. Asianeomys bolligeri (Lopatin, 2000) from Toglorhoi (TGW-A/2b), Valley of Lakes, Mongolia. Late Oligocene, letter zone C. Maridet et al. (2015). e Right p4 (NHMW 2013/0064/0005). f Right m1/2(NHMW 2013/0064/0006). g Right m1/2(NHMW
2013/0064/0007). h Right P4 (NHMW 2013/0064/0001). i Right M1/2 (NHMW 2013/0064/0003). j Right M1/2 (NHMW 2013/0064/0004) Asianeomys dangheensis (Wang, 2002) from Unkheltseg (UNCH-A/3) and Hotuliin Teeg (HTE-12/5), Valley of Lakes, Mongolia. Early Miocene, letter zone D. Maridet et al. (2015). k Left p4 (NHMW 2013/0073/0007), UNCH-A/3. I Right m1/2 (NHMW 2013/0073/ 0008), UNCH-A/3. m Left m1/2 (NHMW 2013/0073/0009), UNCH-A/ 3. n Left m3 (NHMW 2013/0073/0010), UNCH-A/3 o Left D4 (NHMW 2013/0073/0001), UNCH-A/3. p Left P4 (NHMW 2013/0073/0003), UNCH-A/3. q Left M1/2 (NHMW 2013/0073/0004), UNCH-A/3. r Left M1/2 (NHMW 2013/0073/0005), UNCH-A/3. s Left M3 (NHMW 2013/0070/0017), HTE-12/5 (= HTE-005) 


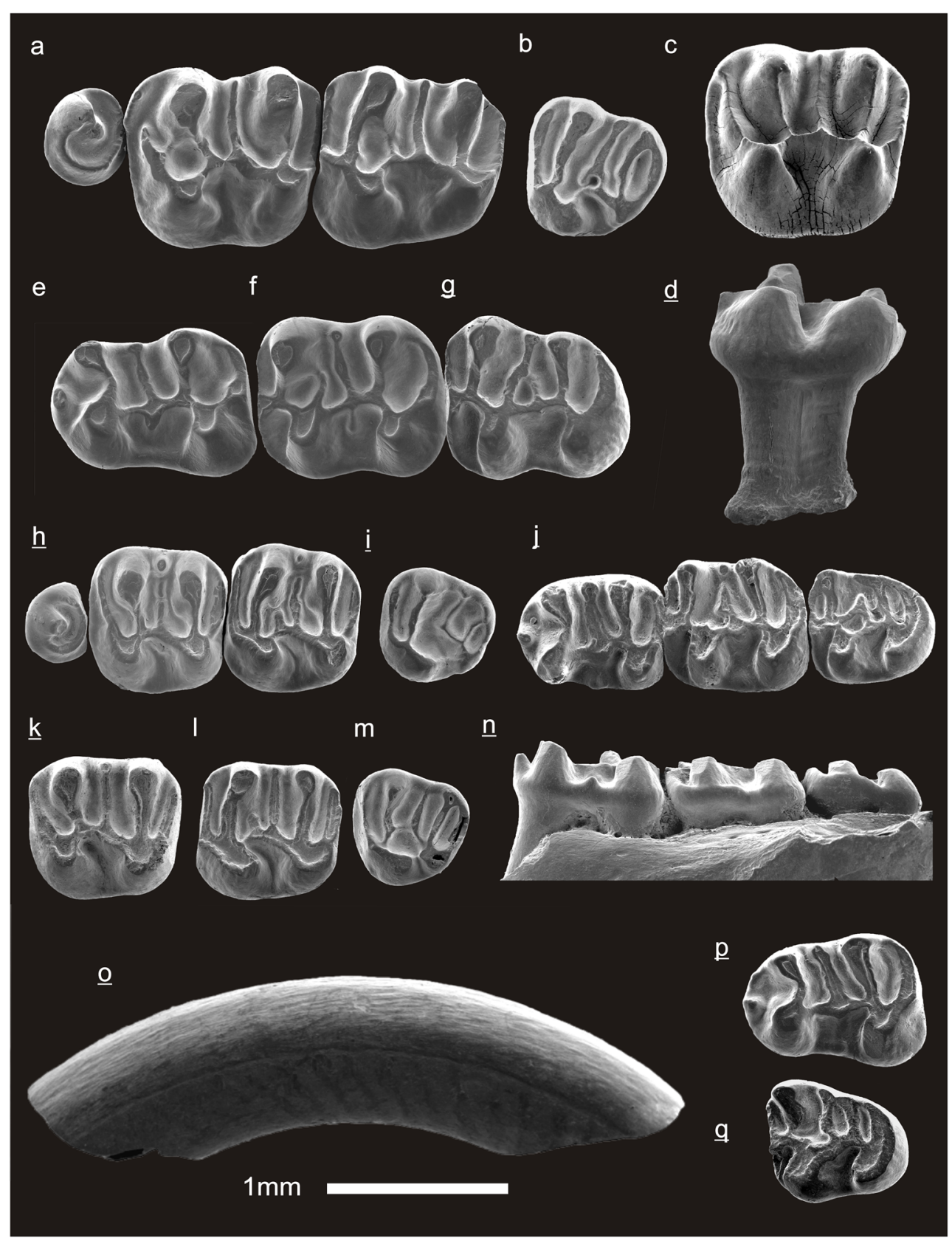

Fig. 49 Fam. Dipodidae. Heosminthus chimidae Daxner-Höck, Badamgarav and Maridet, 2014 from Taatsiin Gol (TGR-B/1), Valley of Lakes, Mongolia. Early Oligocene, letter zone B. All figured specimens are the holotype $(\mathrm{H})$ and paratypes. Daxner-Höck et al. (2014). a Left P4-M2 (NHMW 2013/0128/0001), H. b Left M3 (NHMW 2013/0128/0006). c Left M1 (NHMW 2013/0128/0007). d Right M2, lingual (NHMW 2013/0128/0003). e Left m1 (NHMW 2013/0128/0010). f Left m2 (NHMW 2013/0128/0014). g Right m3 (NHMW 2013/0128/ 0015) Heosminthus borrae Daxner-Höck, Badamgarav and Maridet, 2014 from Unkheltseg (UNCH-A/3B; letter zone B) and Huch Teeg
(RHN-A/12; letter zone D), Valley of Lakes, Mongolia. Early Oligocene (UNCH-A/3B) and early Miocene (RHN-A/12). Holotype (H). DaxnerHöck et al. (2014). h Right P4-M2 (NHMW 2013/0117/0001), UNCH-A/ 3B, H. i Right M3 (N̄HMW 2013/0117/0005), UNCH-A/3B. j Right m1-3 (NHMW̄ 2013/0127/0004), RHN-A/12. k Right M1 (NHMW 2013/0127/

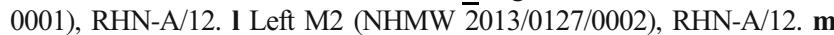
Left M3 (NHMW 2013/0117/0006), UNCH-A/3B. n Right m1-3 (NHMW 2013/0117/0007), UNCH-A/3B. o Right Inc. sup. (NHMW 2013/0127/ 0005), RHN-A/12. p Right m1 (NHMW 2013/0117/0008), UNCH-A/3B. q Right m3 (NHMW 2013/0117/0013), UNCH-A/3B 


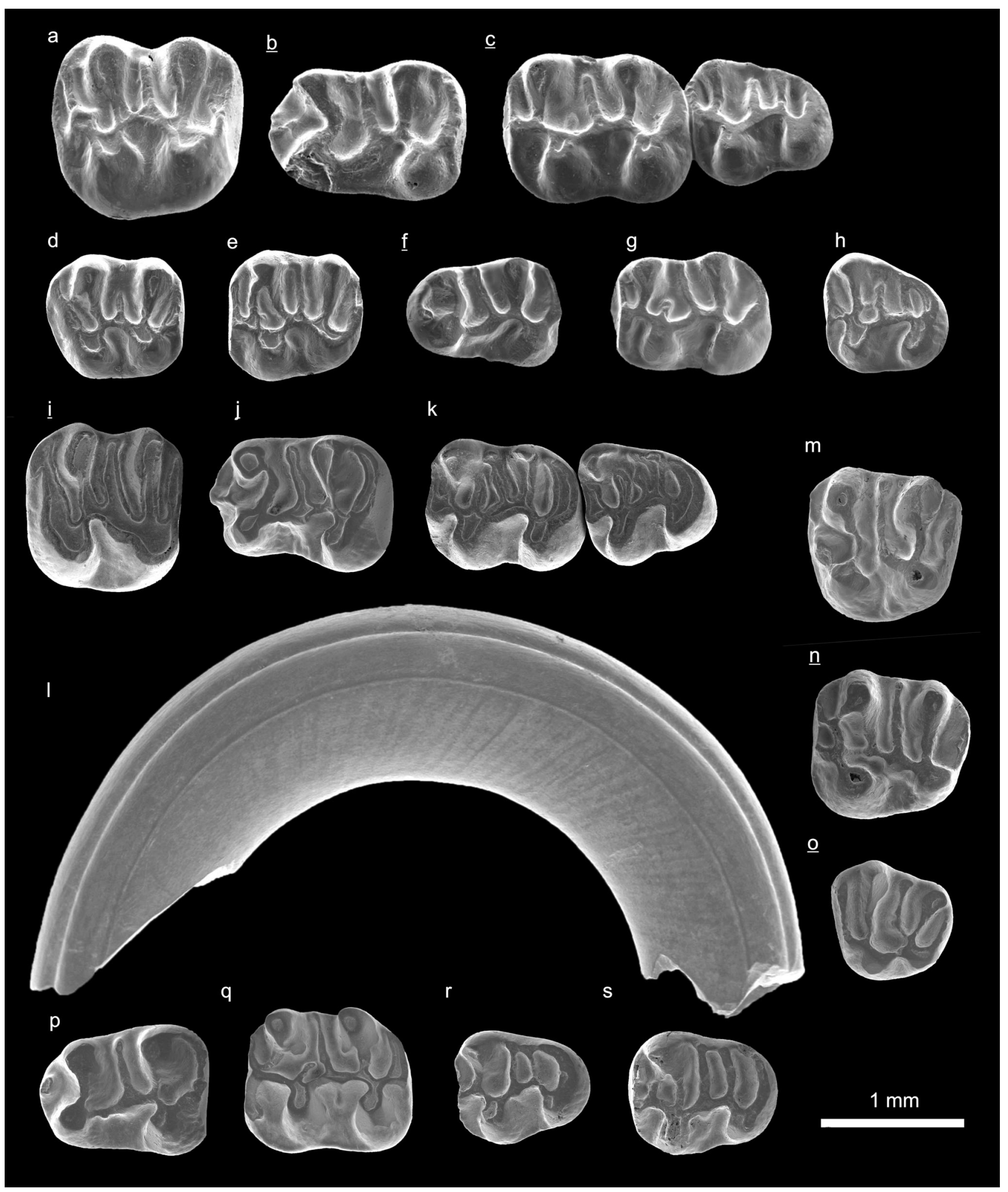


Fig. 50 Fam. Dipodidae. Plesiosminthus asiaticus Daxner-Höck and Wu, 2003 from Huch Teeg (RHN-A/7), Valley of Lakes, Mongolia. Late Oligocene, letter zone C1. Daxner-Höck and Wu (2003), Daxner-Höck et al. (2014). a Left M1 (NHMW 2001/0064/0001/2). b Right m1 (NHMW 2001/0064/0001/7). c Right m2-3 (NHMW 2001/0064/0001/ 9) Plesiosminthus promyarion Schaub, 1930 from Huch Teeg (RHN-A/ 9) and Hotuliin Teeg (HTS-056/2), Valley of Lakes, Mongolia. Late Oligocene letter zone C1-D. Daxner-Höck and Wu (2003), DaxnerHöck et al. (2014). d Left M1 (NHMW 2013/0175/0001), HTS-056/2. e Left M2 (NHMW 2013/0175/0002), HTS-056/2. f Left m1 (NHMW 2001/0065/0001/5), RHN-A/9. g Left m2 (NHMW 2001/0065/0001/8), RHN-A/9. h Left m3 (NHMW 2013/0175/0004), HTS-056/2. Plesiosminthus barsboldi Daxner-Höck and Wu, 2003 from Unkheltseg (UNCH-A/3), Valley of Lakes, Mongolia. Early Miocene, letter zone D. All figured specimens are paratypes. Daxner-Höck and Wu (2003), Daxner-Höck et al. (2014). i Right M1 (NHMW 2001/0066/0002/7). j Right m1 (NHMW 2001//0066/0002/13). k Left m2-3 (NHMW 2001/0066/0002/19). Plesiosminthus olzi DaxnerHöck, Badamgarav and Maridet, 2014 from Hotuliin Teeg (HTE-005 and HTE-008), Valley of Lakes, Mongolia. Early Miocene, letter zone D. Holotype (H). Daxner-Höck et al. (2014). I Left Inc. sup. (NHMW 2013/0176/0009), HTE-008. m Left M1 (NHMW 2013/0176/0001), HTE-008, H. n Right M2 (NHMW 2013/0176/0005), HTE-008. o Right M3 (NHMW 2013/0176/0003), HTE-008. p Left m1 (NHMW 2013/0176/0006), HTE-008. q Left m2 (NHMW 2013/0177/0001), HTE-005. r Left m3 (NHMW 2013/0176/0008), HTE-008. s Left m3 (NHMW 2013/0176/0007), HTE-008 


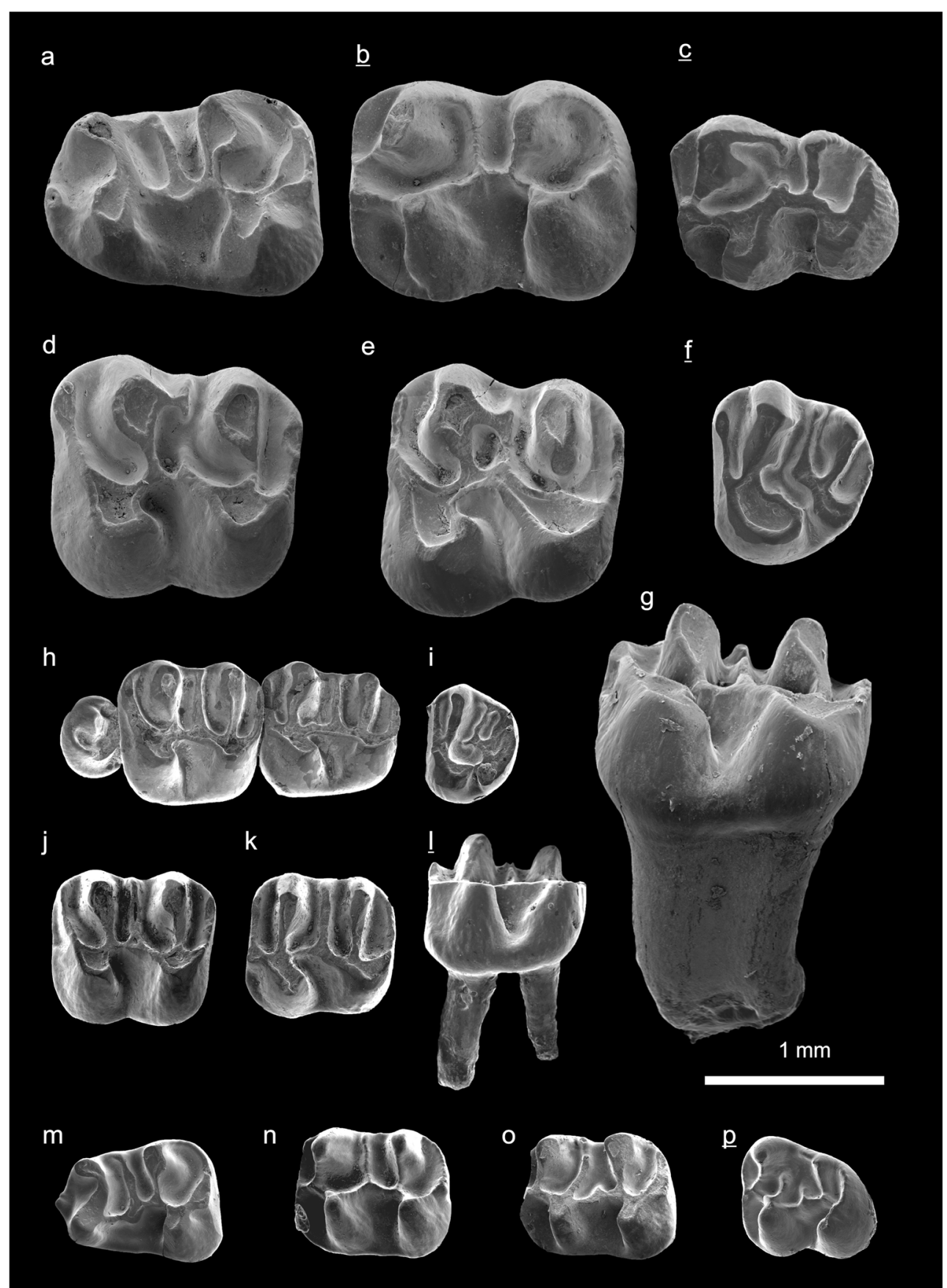

Fig. 51 Fam. Dipodidae. Onjosminthus baindi Daxner-Höck, Badamgarav and Maridet, 2014 from Taatsiin Gol (TGR-A/13+14, TGL-A/2), Tatal Gol (TAT-D/1), and Hsanda Gol (SHG-C/1), Valley of Lakes. Early Oligocene, letter zone A. Paratype (P). Daxner-Höck et al. (2014). a Left m1 (NHMW 2013/0180/0003), TGR-A/13. b Right m2 (NHMW 2013/0181/0004), TGL-A/2. c Right m3 (NHMW 2013/0179/ 0005), P, TAT-D/1. d Left M1 (NHMW 2013/0180/0002), TGR-A/14. e Left M2 (NHMW 2013/0181/0001), TGL-A/2. f Right M3 (NHMW 2013/0179/0002), P, TAT-D/1, P. g Left M1, lingual view (NHMW 2013/0183/0001), SHG-C/1. Bohlinosminthus parvulus Lopatin, 1999 from Toglorhoi (TGW-A/2a+b; letter zone C), Hsanda Gol (SHG-AB/17-
20; letter zone B), Taatsiin Gol (TGR-C/1; letter zone C), and Tatal Gol (TAT-C/1; letter zone A), Valley of Lakes. Early to late Oligocene. Daxner-Höck et al. (2014). h Left P4-M2 (NHMW 2013/0211/0001), TGW-A/2b. i Left M3 (NHMW 2013/0205/0002), SHG-AB/17-20. j Left M1 (NHMW 2013/0210/0001), TGW-A/2a. k Left M2 (NHMW 2013/0210/0002), TGW-A/2a. I Right M2, lingual view (NHMW 2013/0203/0002), TAT-C/1. m Left m1 (NHMW 2013/0210/0005), TGW-A/2a. n Left m2 (NHMW 2013/0205/0005), SHG-AB/17-20. o Left m2 (NHMW 2013/0206/0003), TGR-C/1. p Right m3 (NHMW 2013/0211/0004), TGW-A/2b 


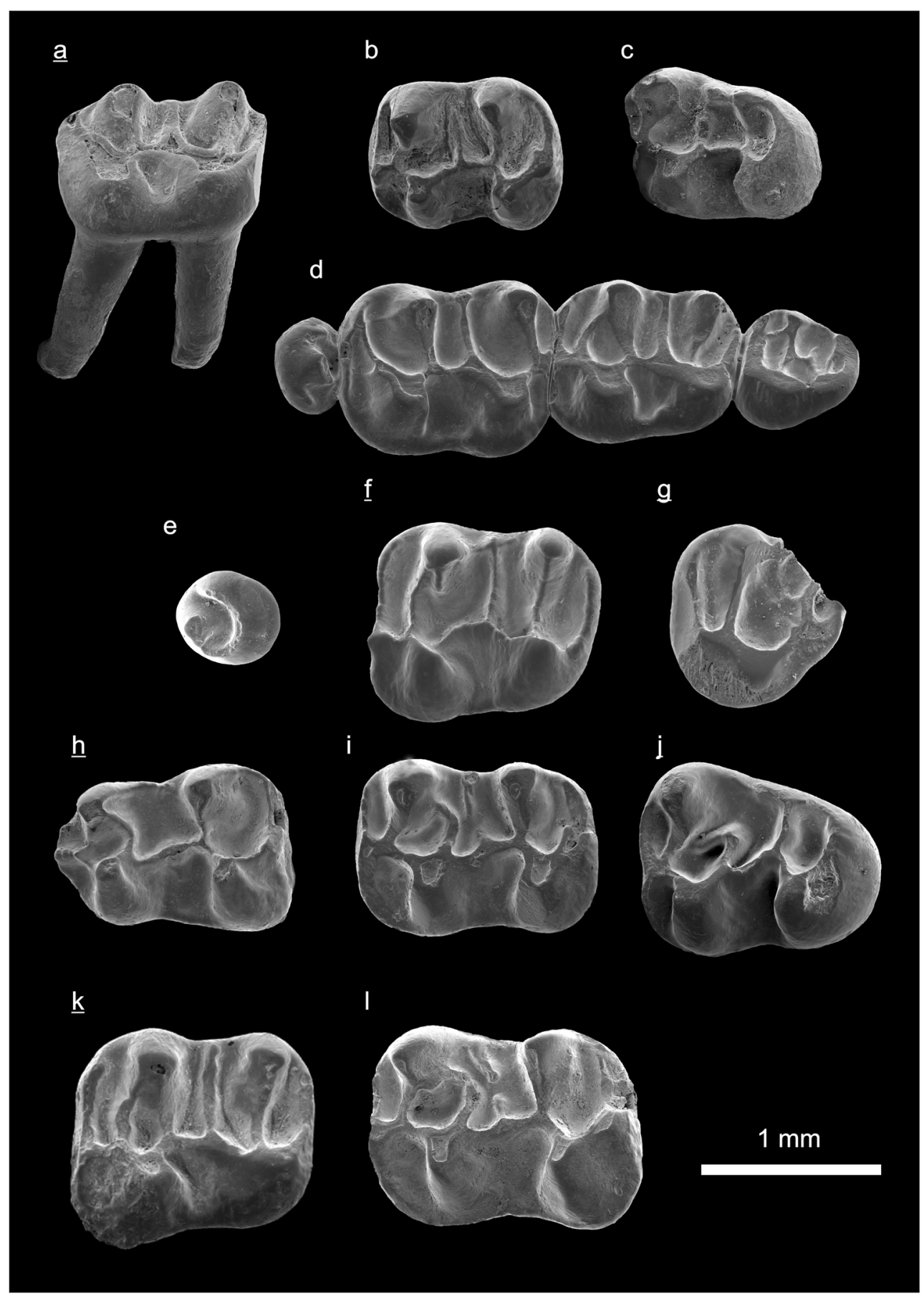

Fig. 52 Fam. Dipodidae. Parasminthus debruijni Lopatin, 1999 from Taatsiin Gol (TGR-C/1; letter zone C), Del (DEL-B/12; letter zone C1), and Tatal Gol (TAT-E/27; letter zone C1), Valley of Lakes. Late Oligocene. Daxner-Höck et al. (2014). a Right M1, lingual view (NHMW 2013/0199/0001),TGR-C/1. b Left m2 (NHMW 2013/0200/ 0003),DEL-B/12. c Left m3 (NHMW 2013/0199/0002),TGR-C/1. d Left max. P4-M3 (NHMW 2013/0198/0001),TAT-E/27. Parasminthus cf. tangingoli Bohlin, 1946 from Taatsiin Gol (TGR-C/1; letter zone C) and Del (DEL-B/12; letter zone C1), Valley of Lakes. Late Oligocene.
Daxner-Höck et al. (2014). e Left P4 (NHMW 2013/0192/0001),TGR-C/ 1. f Right M2 (NHMW 2013/0192/0002),TGR-C/1. g Right M3 (NḦMW 2013/0196/0002), DEL-B/12. h Right m1 (NHMW 2013/0192/0003),TGR-C/1. i Left m2 (NHMW 2013/0192/0005),TGRC/1. j Right m3 (NHMW 2013/0192/0006),TGR-C/6. Parasminthus cf. asiaecentralis Bohlin, 1946 from Unzing Khurem (TAR-A/2; letter zone C) and Del (DEL-B/12; letter zone C1), Valley of Lakes. Late Oligocene. Daxner-Höck et al. (2014). k Right M2 (NHMW 2013/0263/0001),TARA/2. 1 Left m2 (NHMW 2013/0191/0002), DEL-B/12 

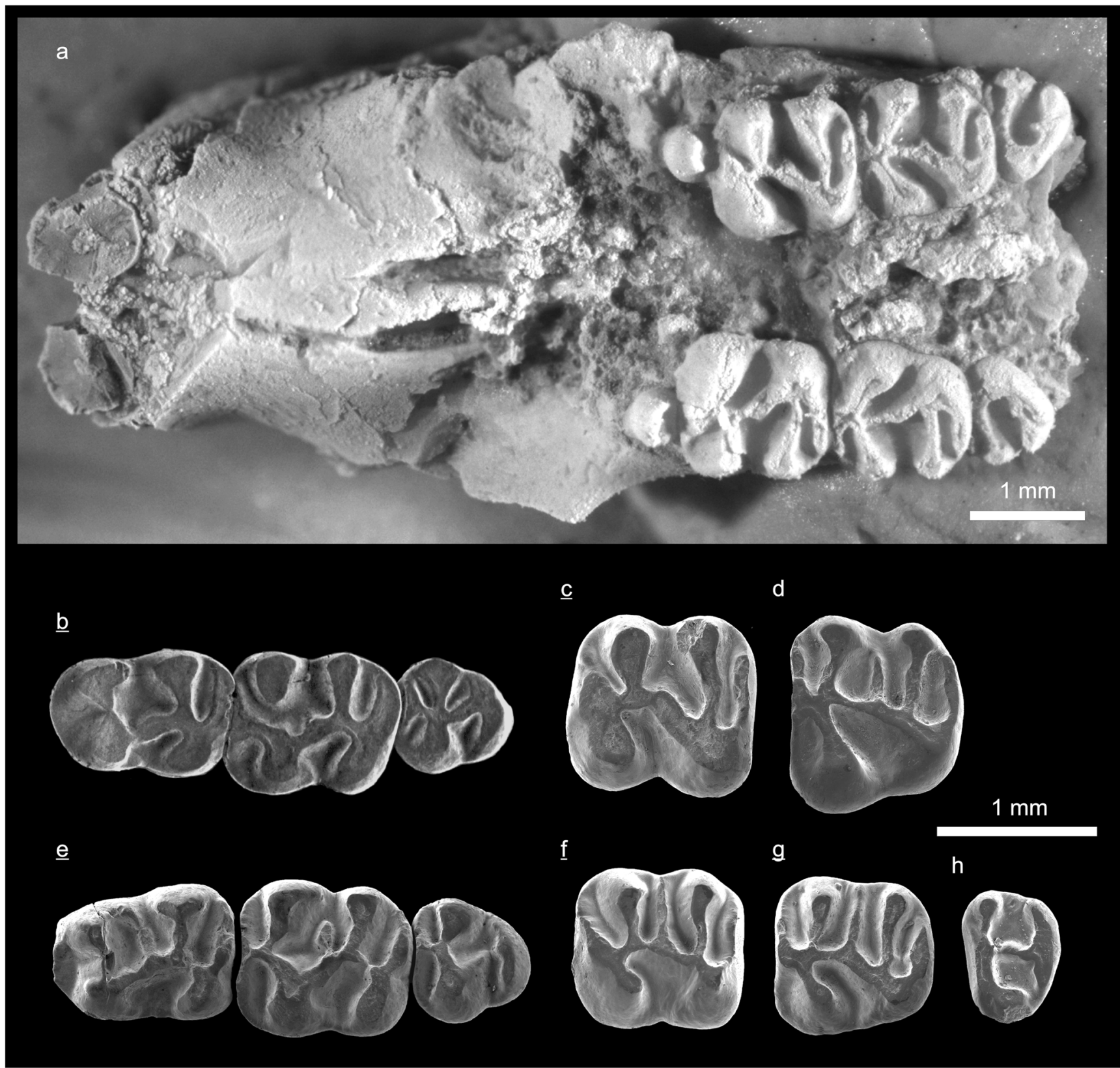

Fig. 53 Fam. Dipodidae. Litodonomys huangheensis Wang and Qiu, 2000 from Unkheltseg (UNCH-A/3), Valley of Lakes. Early Miocene, letter zone D. Daxner-Höck et al.( 2014). a Skull with right and left P4M3 (NHMW 2013/0232/0001). b Right mand. m1-3 (NHMW 2013/0232/0005). c Right M1 (NHM̄W 2013/0232/0007). d Left M2 (NHMW 2013/023리잉. Litodonomys jajeensis (Li and Qiu, 1980) from Hotuliin Teeg (HTE-007, HTE-012) and Unkheltseg (UNCH-A/3), Valley of Lakes. Early Miocene, letter Biozone D. Daxner-Höck et al. (2014). e Right mand. m1-3 (NHMW 2013/0246/0001), HTE-007. f. Left M1 (NḦMW 2013/0248/0001), HTE-012. g Right M2 (NHMW 2013/0242/0015), UNCH-A/3. h Left M3 (NHMW 2013/0242/0017), $\mathrm{UNCH}-\mathrm{A} / 3$ 


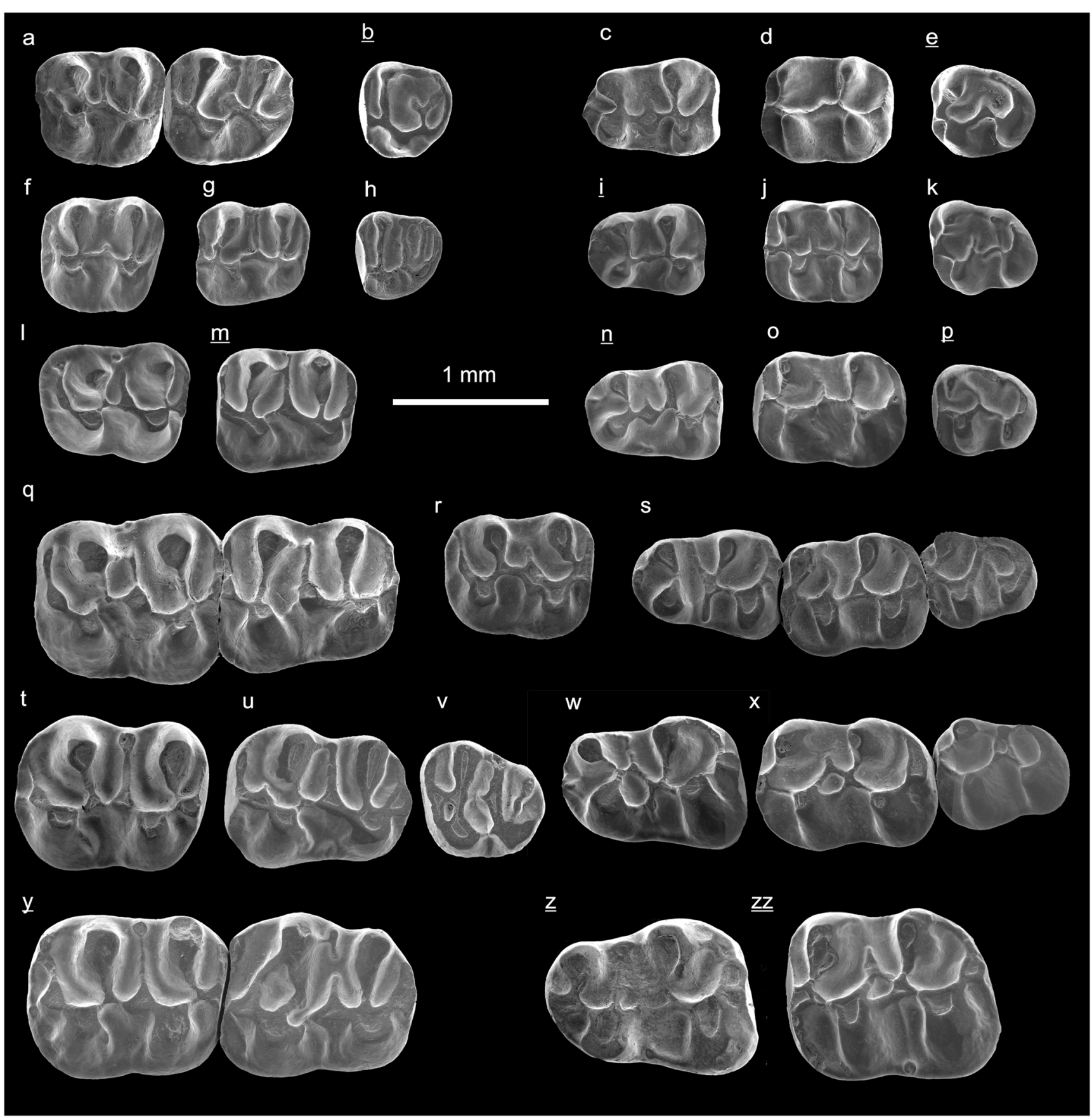


Fig. 54 Fam. Dipodidae. Allosmintus khandae (Daxner-Höck, 2001) from Talyn Churum (GRAB-II), Tatal Gol (TAT-D/1), and Taatsiin Gol (TGR-A/13), Valley of Lakes, Mongolia. Early Oligocene, letter zone A. Paratype (P). Daxner-Höck (2001), Daxner-Höck et al. (2014). a Left M1-2 (NHMW 2001/0032/0005/1), GRAB-II. b Right M3 (NHMW 2001/0032/0001/21), TAT-D/1. c Left m1 (NHMW 2001/0032/0002/3), TGR-A/13. d Left m2 (NHMW 2001/0032/0002/4), TGR-A/13. e Right m3 (NHMW 2001/0032/0001/9), TAT-D/1, P. Allosminthus minutus (Daxner-Höck, 2001) from Hsanda Gol (SHG-A/9, SHG-AB/17-20), Tatal Gol (TAT-C/6+7), Taatsiin Gol (TGR-B/1), and Ikh Argalatyn Nuruu (IKH-A/3-4), Valley of Lakes, Mongolia. Early Oligocene, letter zone B. Paratypes (P). Daxner-Höck (2001), Daxner-Höck et al. (2014). f Left M1 (NHMW 2001/0033/0005/9), SHG-AB/17-20. g Left M2 (NHMW 2001/0033/0003/2), SHG-A/9, P. h Left M3 (NHMW 2001/0033/0008/3), TGR-B/1. i Right m1 (NHMW 2001/0033/0003/5), SHG-A/9, P. j Left m2 (NHMW̄ 2001/0033/0006/3), IKH-A/3-4. k Left m3 (NHMW 2001/0033/0011/4), TAT-C/6+7. Shamosminthus sodovis Daxner-Höck, 2001 from Taatsiin Gol (TGR-B/1 and TGL-A/11), Valley of Lakes, Mongolia. Early Oligocene, letter zone B. DaxnerHöck (2001), Daxner-Höck et al. (2014). I Left M1 (NHMW 2001/0034/0003/3), TGR-B-/1. m Right M2 (NHMW 2001/0034/0003/ 1), TGR-B-/1. n Right m1 (NHM̄W 2001/0034/0003/13), TGR-B-/1. o Left m2 (NHMW 2001/0034/0006/2), TGL-A/11. p Right m3 (NHMW 2001/0034/0003/16), TGR-B-/1. Shamosminthus tongi Huang, 1992 from Tatal Gol (TAT-055), Valley of Lakes, Mongolia. Late Oligocene, letter zone C. Daxner-Höck et al. (2014). q Left M1-2 (NHMW 2013/0251/0001), TAT-055. Heterosminthus aff. nanaus Zazhigin and Lopatin, 2000 from Hotuliin Teeg (HTE-005 and HTE-014-018), Valley of Lakes, Mongolia. Early Miocene, letter zone D. Daxner-Höck et al. (2014). r Left M1 (NHMW 2013/0262/0001), HTE-005. s Right m1-3 (NHMW 2013/0261/0001), HTE-014-018. Heterosminthus firmus Zazhigin and Lopatin, 2000 from Unkheltseg (UNCH-A/3), Valley of Lakes, Mongolia. Early Miocene, letter zone D. Daxner-Höck (2001), Daxner-Höck et al. (2014). t Left M1 (NHMW 2001/0036/0001/ 2). u Left M2 (NHMW 2001/0036/0001/22). v Left M3 (NHMW 2001/0036/0001/36). w Left m1 (NHMW 2001/0036/0001/53). x Left m2-3 (NHMW 2001/0036/0001/84). Heterosminthus cf. lanzhouensis Wang and Qiu, 2000 from Huch Teeg (RHN-021) and Hotuliin Teeg (HTS-056/1+2), Valley of Lakes, Mongolia. Late Oligocene, letter zone C1-D. Daxner-Höck et al. (2014). y Right M1-2 (NHMW 2013/0259/ 0001), RHN-021. z Right m1 (NHMW 2013/0260/0002), HTS-056/1+2. zz Right $m 2$ (NHM̄̄ 2013/0260/0003), HTS-056/1+2 


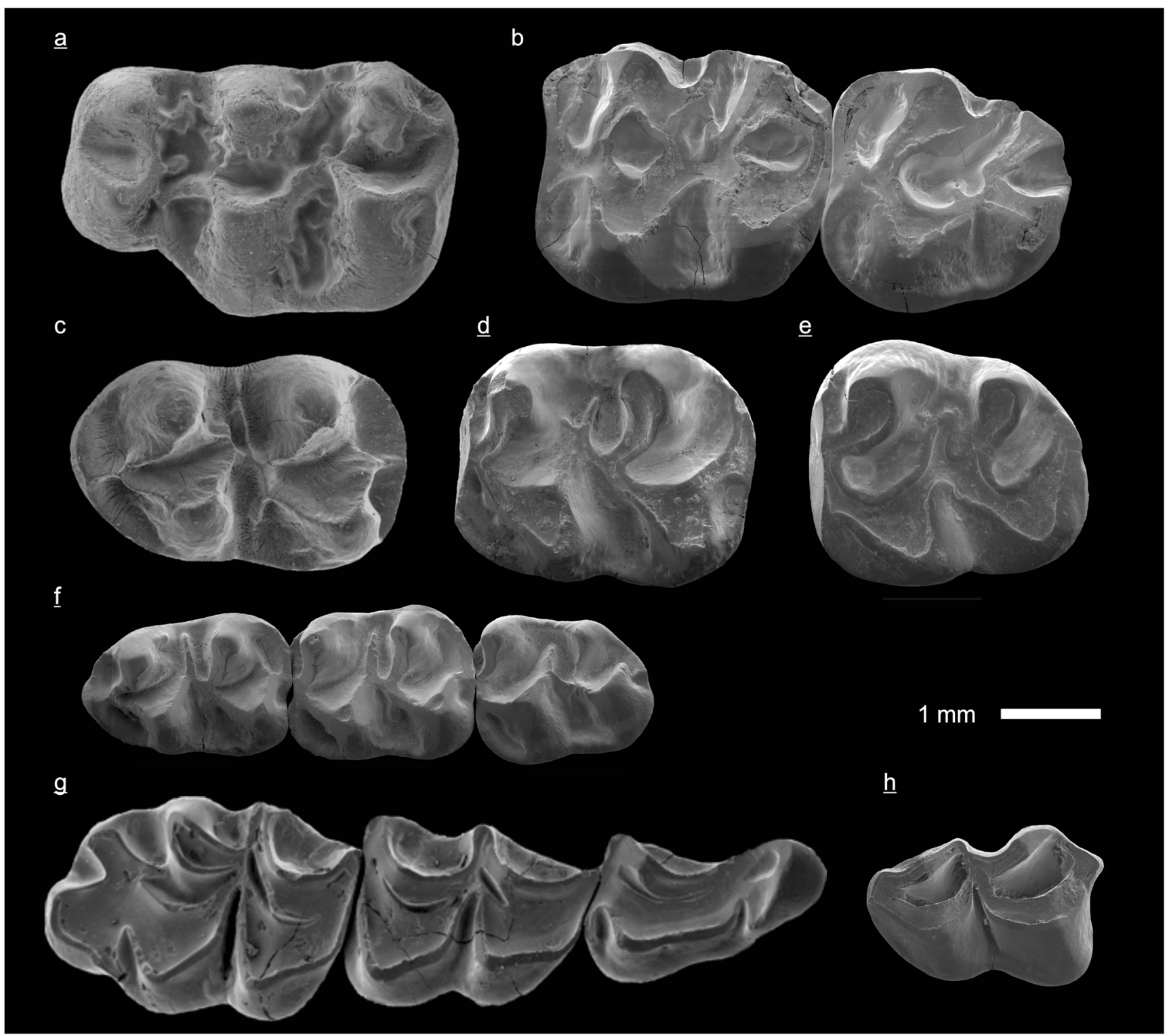

Fig. 55 Fam. Cricetidae s.1. Cricetops dormitor Matthew and Granger, 1923 from Taatsiin Gol (TGR-AB/22) and Hsanda Gol (SHG* and SHG-AB/12), Valley of Lakes, Mongolia. Early Oligocene, letter zone B. Daxner-Höck et al. (2010), Maridet et al. (2014b). a Right M1(NHMW 2009/0139/0001), TGR-AB/ 22. b Left M2-3 (NHMW 2014/0218/0055), SHG*. c Left m1 (NHMW 2009/0139/0002), TGR-AB/22. d Right m2 (NHMW 2016/0020/0002), SHG-AB/12. e Right m3 (NHMW 2016/0020/ 0001), SHG-AB/12. Cricetops minor Wang, 1987b from Tatal
Gol (TAT-D/1), Valley of Lakes, Mongolia. Early Oligocene, letter zone A. f Right mand m1-3 (NHMW 2014/0225/0002). Selenomys mimicus Matthew and Granger, 1923 from Tatal Gol (TAT-C/2) and Taatsiin Gol (TGL-A/2), Valley of Lakes, Mongolia. Early Oligocene, letter zone B. Daxner-Höck et al. (2010), Maridet et al. (2014b). g Right max M1-3 (NHMW 2009/0133/0001), TGL-A/2. h Right m2 (NHMW 2016/0021/ 0002), TAT-C/2 


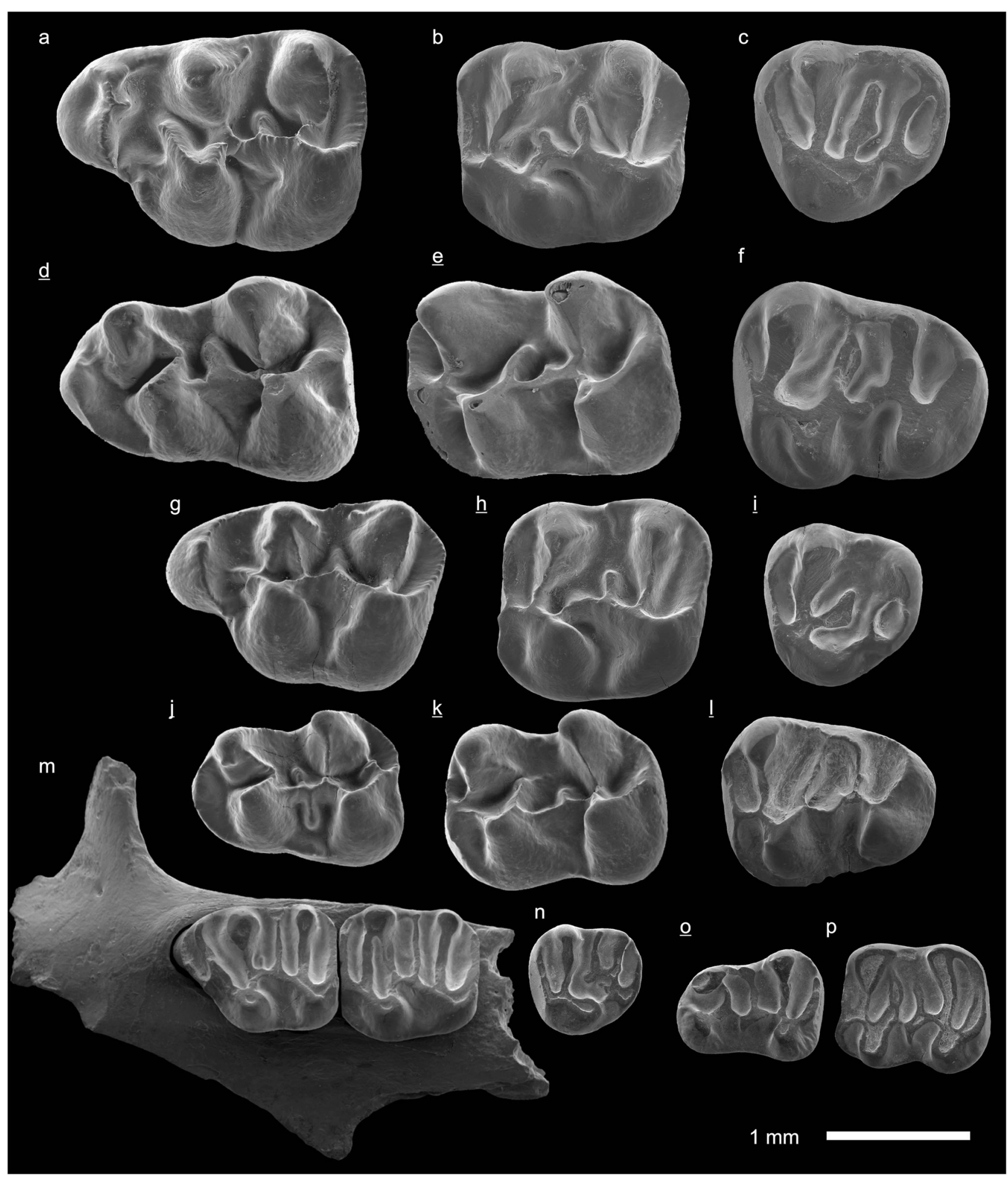


Fig. 56 Fam. Cricetidae s.l. Eucricetodon asiaticus (Matthew and Granger, 1923) from Tatal Gol (TAT-C/3 and TAT-D/1; letter zone A), Hsanda Gol (SHG-A/20; letter zone B), Taatsiin Gol (TGR-B/1; letter zone B), and Ikh Argalatyn Nuruu (IKH-A/2; Biozone B), Valley of Lakes, Mongolia. Early Oligocene. Daxner-Höck et al. (2010), Maridet et al. (2014b), López-Guerrero et al. (2017a, this issue). a Left M1 (NHMW 2015/0249/0001), TAT-C/3. b Left M2 (NHMW 2015/0252/ 0001), TAT-D/1. c Left M3 (NHMW 2015/0243/0003), SHG-A/20. d Right m1 (NHMW 2009/0135/0002), TGR-B/1. e Right m2 (NHMW 2009/0135/0004), TGR-B/1. f Left m3 (NHMW̄ 2015/0240/0010), IKH-A/2. Eucricetodon caducus (Shevyreva, 1967) from Tatal Gol (TAT-D/1; letter zone A), Hsanda Gol (SHG-C/1; letter zone A), Taatsiin Gol (TGR-AB/22; letter zone B), and Ikh Argalatyn Nuruu (IKH-A/1; letter zone B), Valley of Lakes, Mongolia. Early Oligocene. Daxner-Höck et al. (2010), Maridet et al. (2014b), López-Guerrero et al. (2017a, this issue). g Left M1 (NHMW 2009/0132/0001), SHG-C/1. h Right M2 (NHMW 2009/0276/0001), IKH-A/1. i Right M3 (NHMW 2009/0287/0013), TAT-D/1. j Right m1 (NHMW 2009/0132/0002), SHG-C/1. k Right m2 (NHMW 2009/0132/0004), SHG-C/1. I Right m3 (NHMW̄ 2009/0294/0003), TGR-AB/22. Ulaancricetodon bädamae Daxner-Höck, 2000 from Taatsiin Gol (TGL-A/11) and Del (DEL-B/7), Valley of Lakes, Mongolia. Early Oligocene, letter zone B. Daxner-Höck (2000). m Left max. M1-2 (NHMW 1999/0083/0033/1), TGL-A/11. n Left M3 (NHMW 2016/0018/0001), DEL-B/7. o Right m1 (NHMW 2016/0018/0006), DEL-B/7. p Left m2 (NHMW̄ 2016/0018/0005), DEL-B/7 
Fig. 57 Fam. Cricetidae s.l. Eucricetodon bagus Gomes Rodrigues, Marivaux and Vianey-Liaud, 2012 from Toglorhoi (TGW-A/2a and TGW$\mathrm{A} / 2 \mathrm{~b}$ ) and Taatsiin Gol (TGR-C/2), Valley of Lakes, Mongolia. Late Oligocene, letter zone C. DaxnerHöck et al. (2010), Maridet et al. (2014b), López-Guerrero et al. (2017a, 2017b, this issue). a Left M1 (NHMW 2015/0272/0005), TGW-A/2a. b Right M2 (NHMW 2015/0271/0008), TGR-C/2. c Right M3 (NHMW 2015/0273/ 0021), TGW-A/2b. d Right m1 (NHMW 2015/0272/0038), TGWA/2a. e Right m2 (NHMW 2015/0272/0043), TGW-A/2a. f Right m3 (NHMW 2015/0273/ 0035), TGW-A/2b. Eucricetodon jilantaiensis Gomes Rodrigues, Marivaux and Vianey-Liaud, 2012 from Toglorhoi (TGW-A/2a and TGW-A/2b), Valley of Lakes, Mongolia. Late Oligocene, letter zone C. Maridet et al. (2014b), López-Guerrero et al. (2017a, this issue). $\mathbf{g}$ Left $\mathrm{ml}$ (NHMW 2015/0340/0011) TGW-A/2a. h Right m2 (NHMW 2015/0340/ 0017) TGW-A/2a. i Left m3 (NHMW 2015/0336/0018) TGWA/2b. j Left M1 (NHMW 2015/0336/0001) TGW-A/2b.

Eucricetodon cf. occasionalis

Lopatin, 1996 from Taatsiin Gol (TGR-AB/22) and Ikh Argalatyn Nuruu (IKH-A/2), Valley of Lakes, Mongolia. Early Oligocene, letter zone B. López-Guerrero et al. (2017a, this issue). $\mathbf{k}$ Right M1(NHMW 2015/0335/0001), TGR-AB/22. I Right M2 (NHMW 2015/0334/0002), IKH-A/2. m Left m2 (NHMW 2015/0334/0005), IKH-A/2. n Left m3 (NHMW 2015/0335/0002), TGR-AB/22.

Paracricetodon sp. from Taatsiin Gol (TGR-A/14), Valley of Lakes, Mongolia. Early Oligocene, letter zone A. Maridet et al. (2014b), López-Guerrero et al. (2017b, this issue). o Right M2 (NHMW 2015/0533/0001). Witenia sp. from Unkheltseg (UNCH-A/3B), Valley of Lakes, Mongolia. Early Oligocene, letter zone B. LópezGuerrero et al. (2017b, this issue). p Left M2 (NHMW 2015/0537/0001)
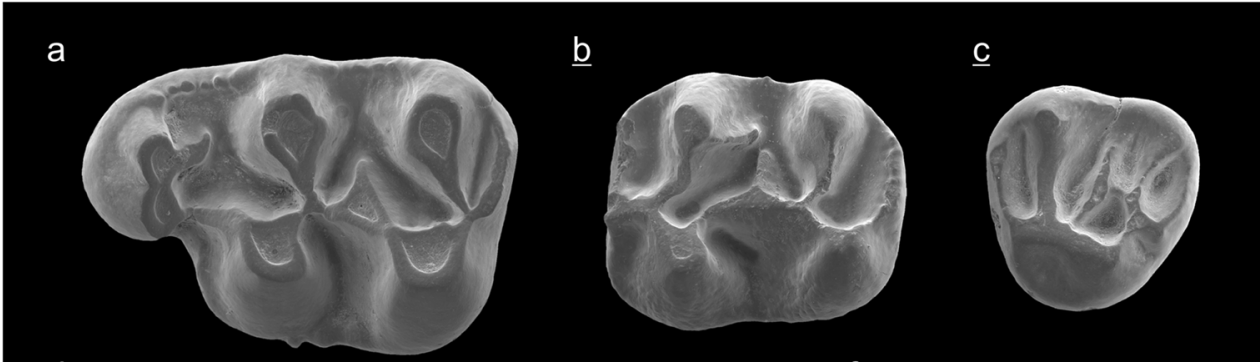

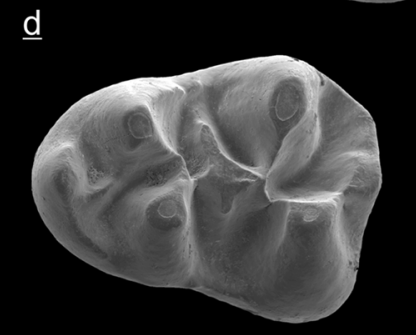

e

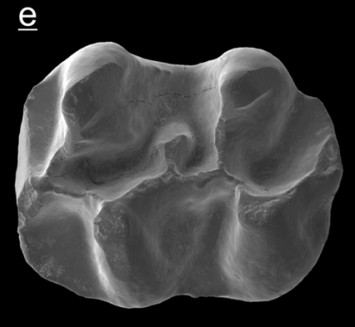

f

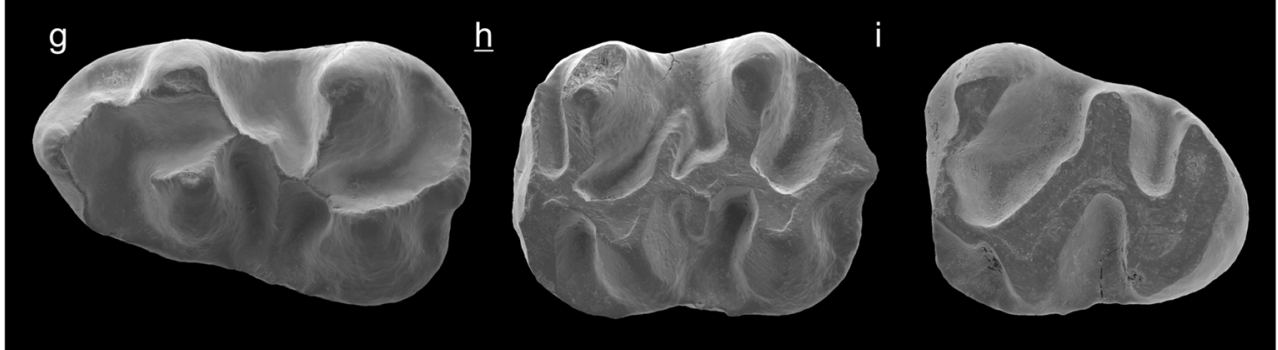

으
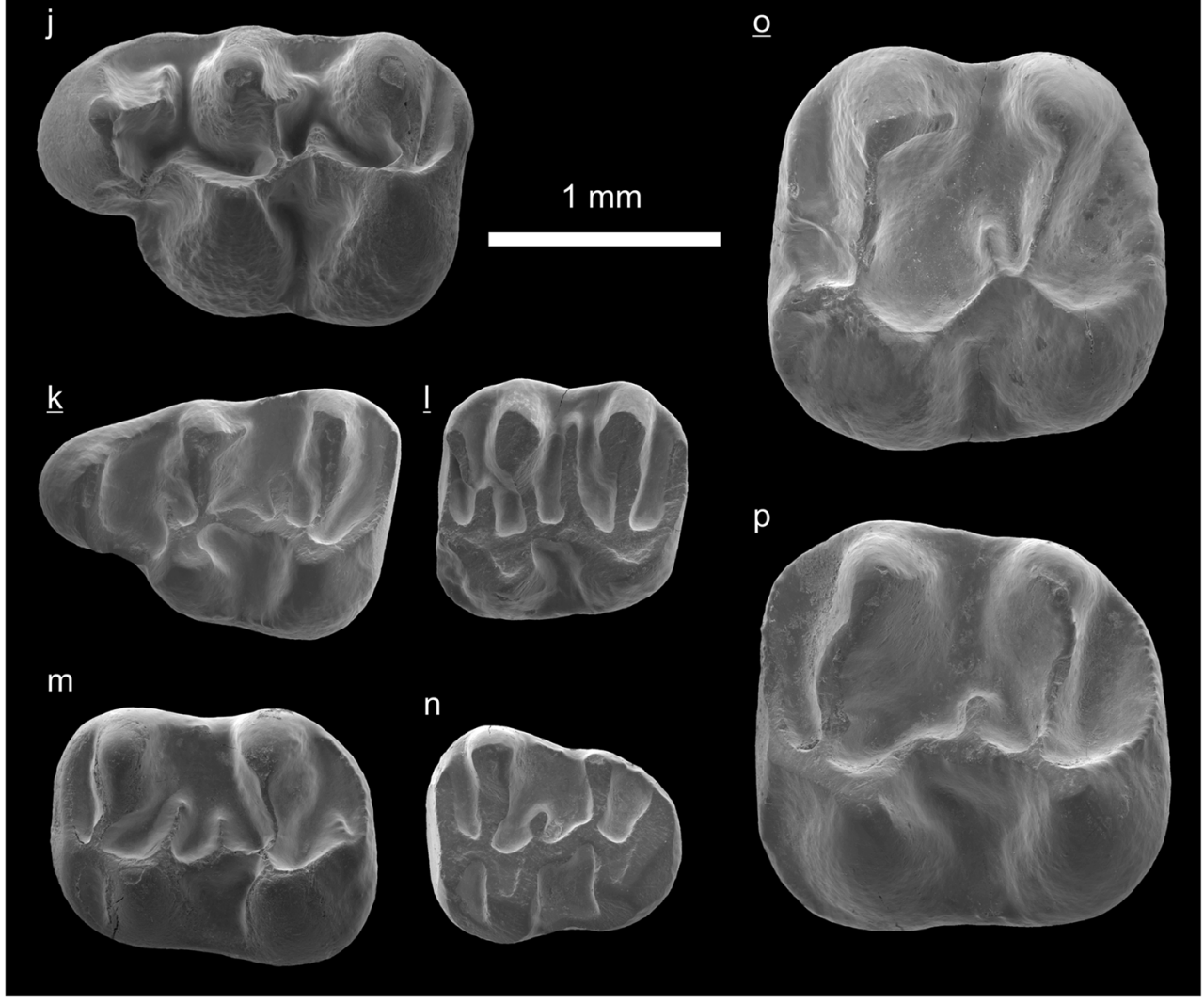
Fig. 58 Fam. Cricetidae s.1 Eocricetodon meridionalis

(Wang and Meng, 1986) from Unkheltseg (UNCH-A/3B; letter zone B), Del (DEL-B/7; letter zone B), Taatsiin Gol (TGR-B/1; letter zone B) (a-c), and $\boldsymbol{E}$. $\boldsymbol{c f}$. meridionalis/E. meridionalis (Wang and Meng, 1986) from Toglorhoi (TGW-A/2a; letter zone C) (c), Valley of Lakes, Mongolia. Oligocene, letter zones B and C. Maridet et al. (2014b), López-Guerrero et al. (2017b, this issue). a Left M1 (NHMW 2015/0311/0001), UNCH-A/3B. b Left max. M2-3 (NHMW 2015/0300/0001), DEL-B/7. c Right m1 ( NHMW 2015/0307/ 0001),TGR-B/1. d Left mand. m2-3 (NHMW 2015/0310/0002), TGW-A/2a. Bagacricetodon tongi Gomes Rodrigues,

Marivaux and Vianey-Liaud, 2012 from Toglorhoi (TGW-A/ 2b), Valley of Lakes, Mongolia. Late Oligocene, letter zone C. Maridet et al. (2014b), LópezGuerrero et al. (2017b, this issue). e Left max. M1-3 (NHMW 2015/0318/0004). f Left m1 (NHMW 2015/0318/0009). g Left m2 (NHMW 2015/0318/ 0017). h Right $\mathrm{m} 3$ (NHMW 2015/03 $18 / 0024$ ).

Democricetodon sui Maridet, $\mathrm{Wu}, \mathrm{Je}, \mathrm{Bi}$, Ni and Meng, 2011 from Unkheltseg (UNCH-A/3), Valley of Lakes, Mongolia. Early Miocene, letter zone D. Höck et al. (1999), Maridet et al. (2014b). i Right M1 (NHMW 2013/0432/0006). j Right M2 (NHMW 2013/0432/0003). k Left m1 (NHMW 2013/0432/ 0004). I Right m2 (NHMW 2013/0432/0005)
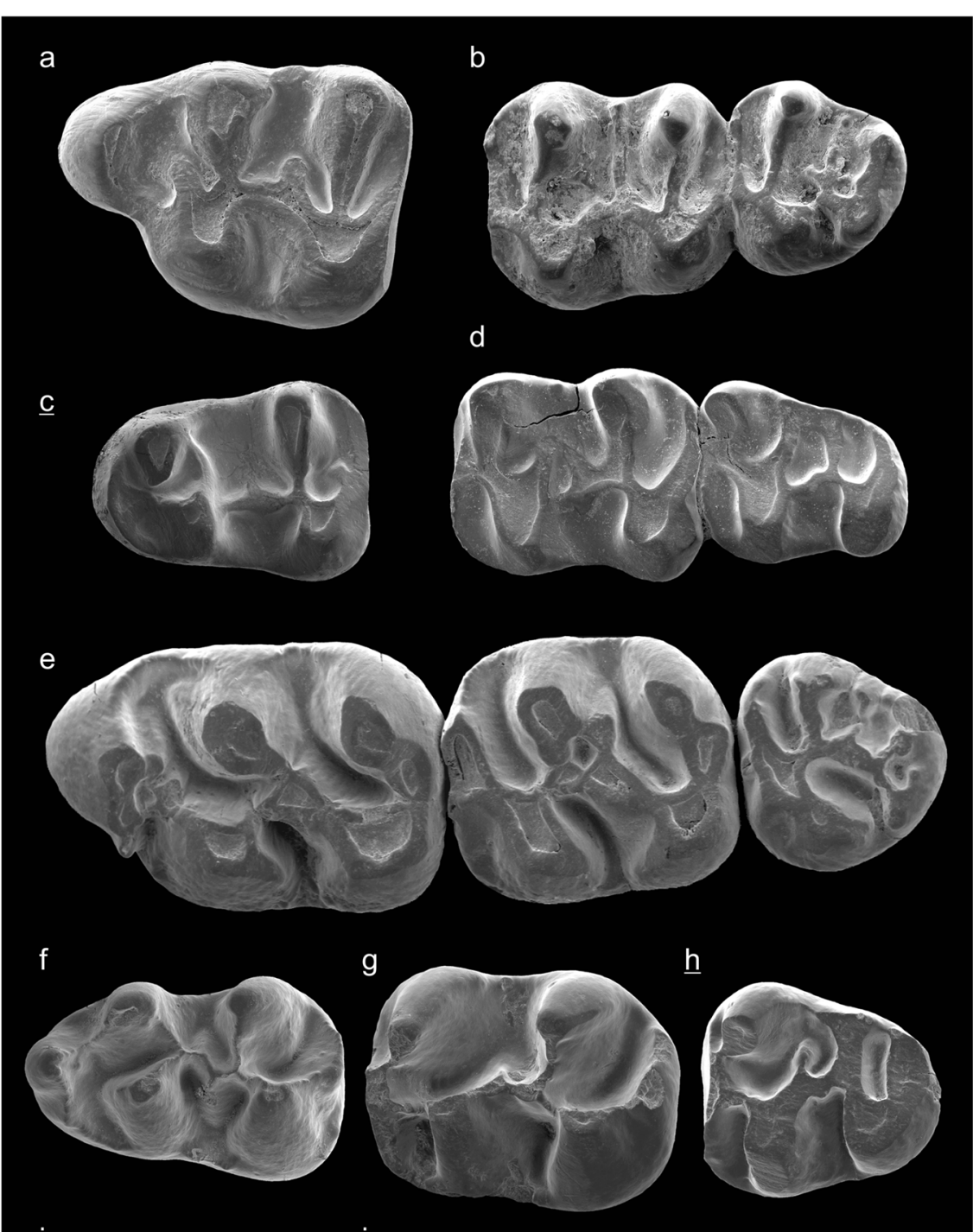

$\underline{\text { h }}$
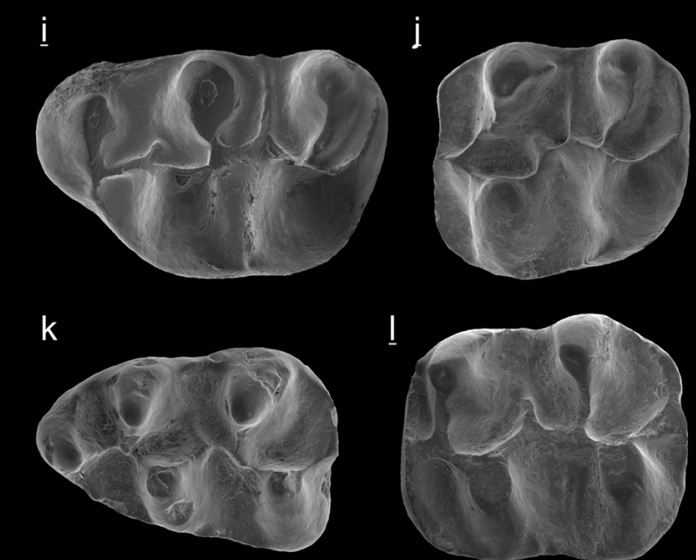

$1 \mathrm{~mm}$ 


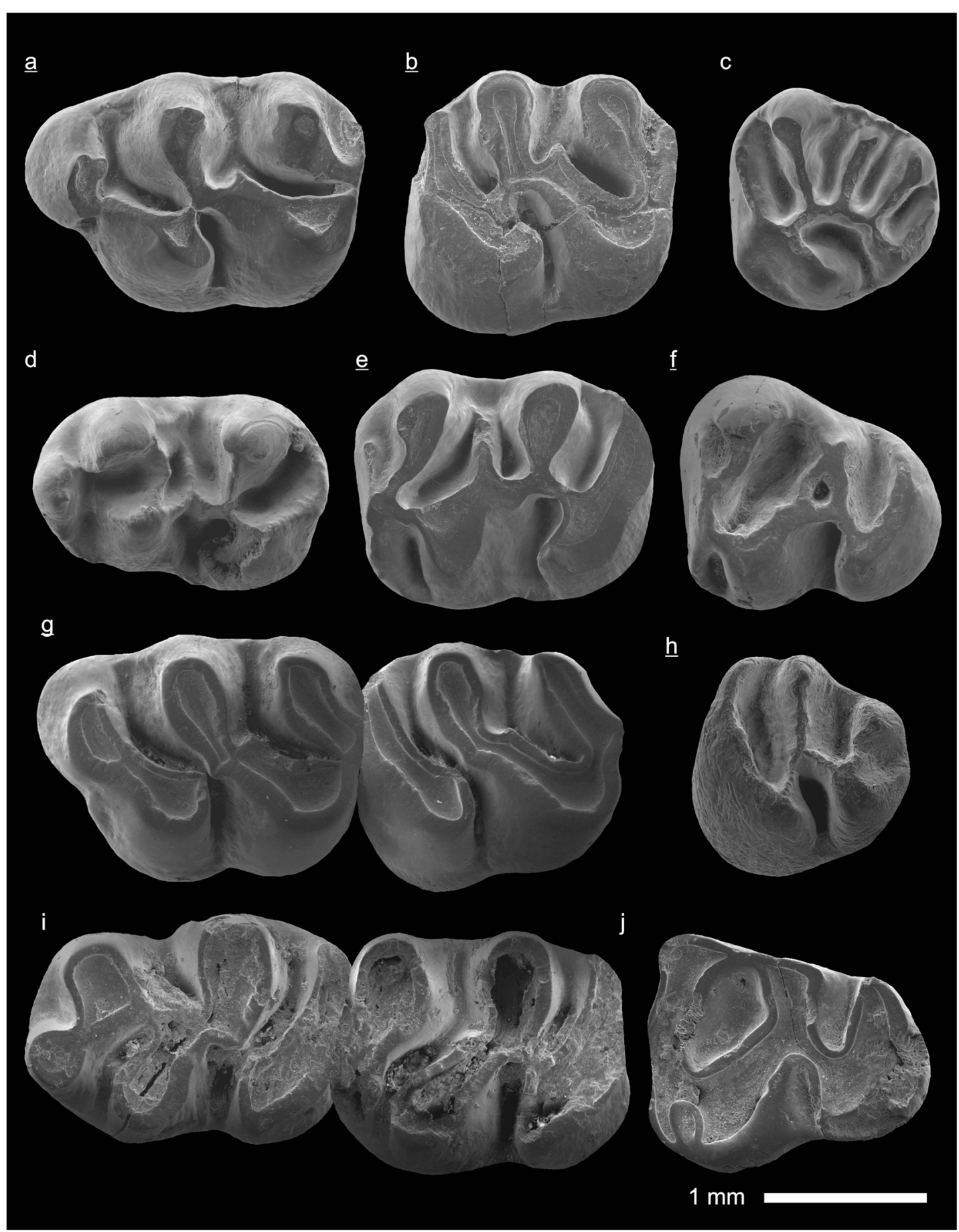

Fig. 59 Fam. Cricetidae s.l. Aralocricetodon shokensis Bendukidze, 1993 from Taatsiin Gol (TGR-C/1, TGR-C/2; letter zone C), Toglorhoi (TGW-A/2a; letter zone C), Unzing Churum (TAR-A/2; letter zone C), and Del (DEL-B/12; letter zone C1), Valley of Lakes, Mongolia. Late Oligocene. Daxner-Höck et al. (2010), Maridet et al. (2014b), LópezGuerrero et al. (2017b, this issue). a Right M1 (NHMW 2009/0142/ 0005), TGR-C/1. b Right M2 (NHMW 2015/0321/0004), TAR-A/2. c Left M3 (NHMW 2015/0323/0001), TGW-A/2a. d Left m1 (NHMW
2015/0323/0002), TGW-A/2a. e Right m2 (NHMW 2015/0322/0009), TGR-C/2. f Right m3 (NHMW 2015/0325/0002), DEL-B/12. Argyromys nov. spec. from Toglorhoi (TGW-A/2a), Valley of Lakes, Mongolia. Late Oligocene, letter zone C. López-Guerrero et al. (in prep.) g Right max. M1-2 (NHMW 2015/0312/0001). h Right M3 (NHMW 2015/0312/0006). i Left mand m1-2 (NHMW 2015/0312/0007). j Left m3 (NHMW 2015/0312/0012) 


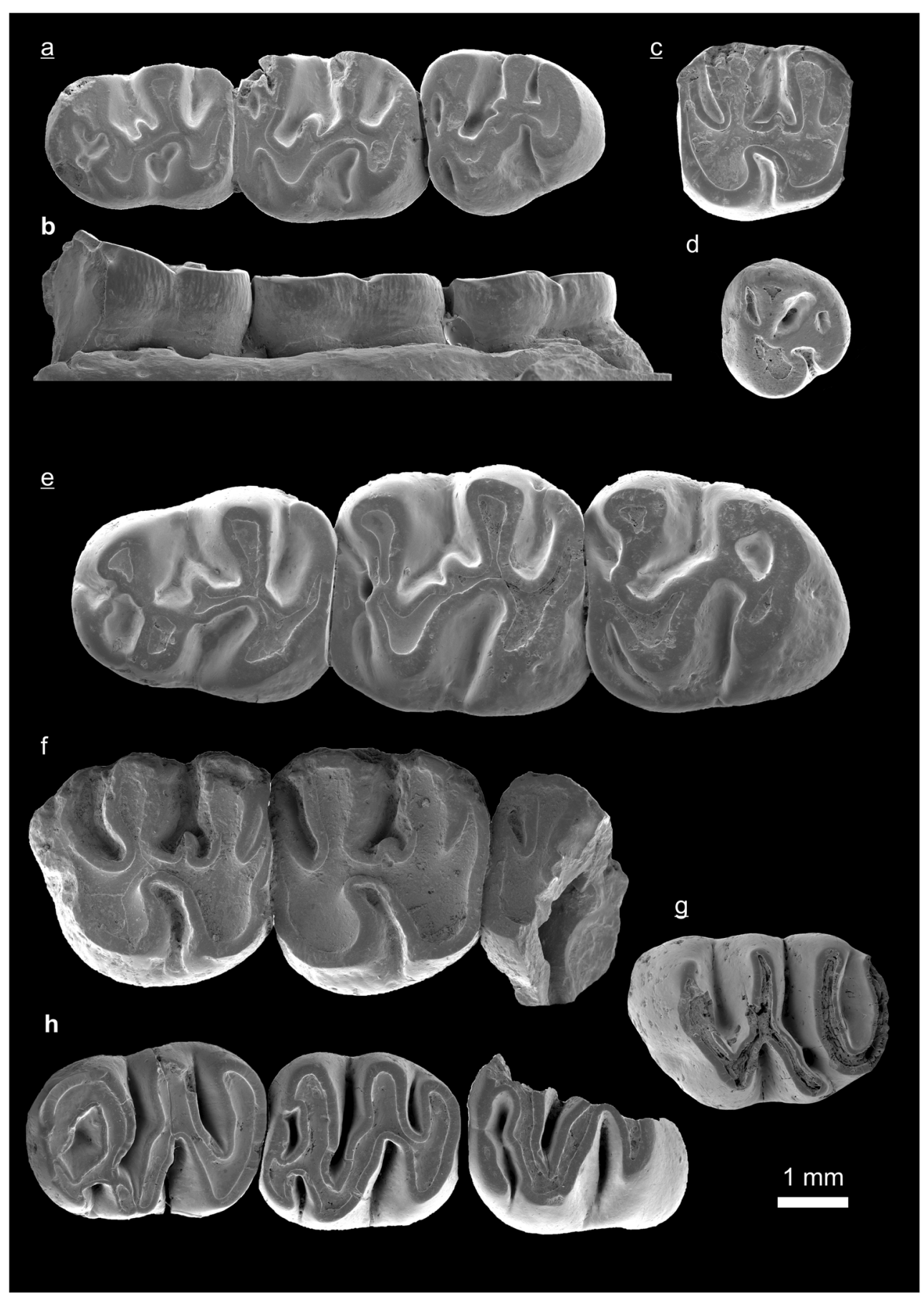

Fig. 60 Fam. Tachyoryctoididae. Tachyoryctoides bayarmae DaxnerHöck, Badamgarav and Maridet, 2015 from Taatsiin Gol (TGR-C/1+2; letter zone C) and Toglorhoi (TGW-A/3+4; letter zone C1), Valley of Lakes, Mongolia. Late Oligocene. Daxner-Höck et al. (2015). a Right mand. m1-3 (NHMW 2012/0063/0002), TGW-A/3+4, P. b Left mand. m1-3, labial view (NHMW 2012/0062/0001), TGR-C/1. c Right M2 (NHMW 2012/0063/0004), TGW-A/3+4, P. d Left M3 (NHMW 2012/0063/0006), TGW-A/3+4, P. Tachyoryctoides radnai Daxner-
Höck, Badamgarav and Maridet, 2015 Taatsiin Gol (TGR-C/1-2), Valley of Lakes, Mongolia. Late Oligocene, letter zone C. Daxner-Höck et al. (2015). e Right m1-3 (NHMW 2014/0445/0001), H. f Left max. M1-3 (NHMW 2014/0445/0008), P. Ayakozomys sp. from Luugar Khudag (LOG-A/1) and Hotuliin Teeg (HTE*), Valley of Lakes, Mongolia. Early Miocene, letter zone D. Daxner-Höck et al. (2015). $\underline{\mathbf{g}}$ Right M1 (NHMW 2012/0066/0001), LOG-A/1. h Left mand. m1-3 (NHMW 2012/0065/0001), HTE* 


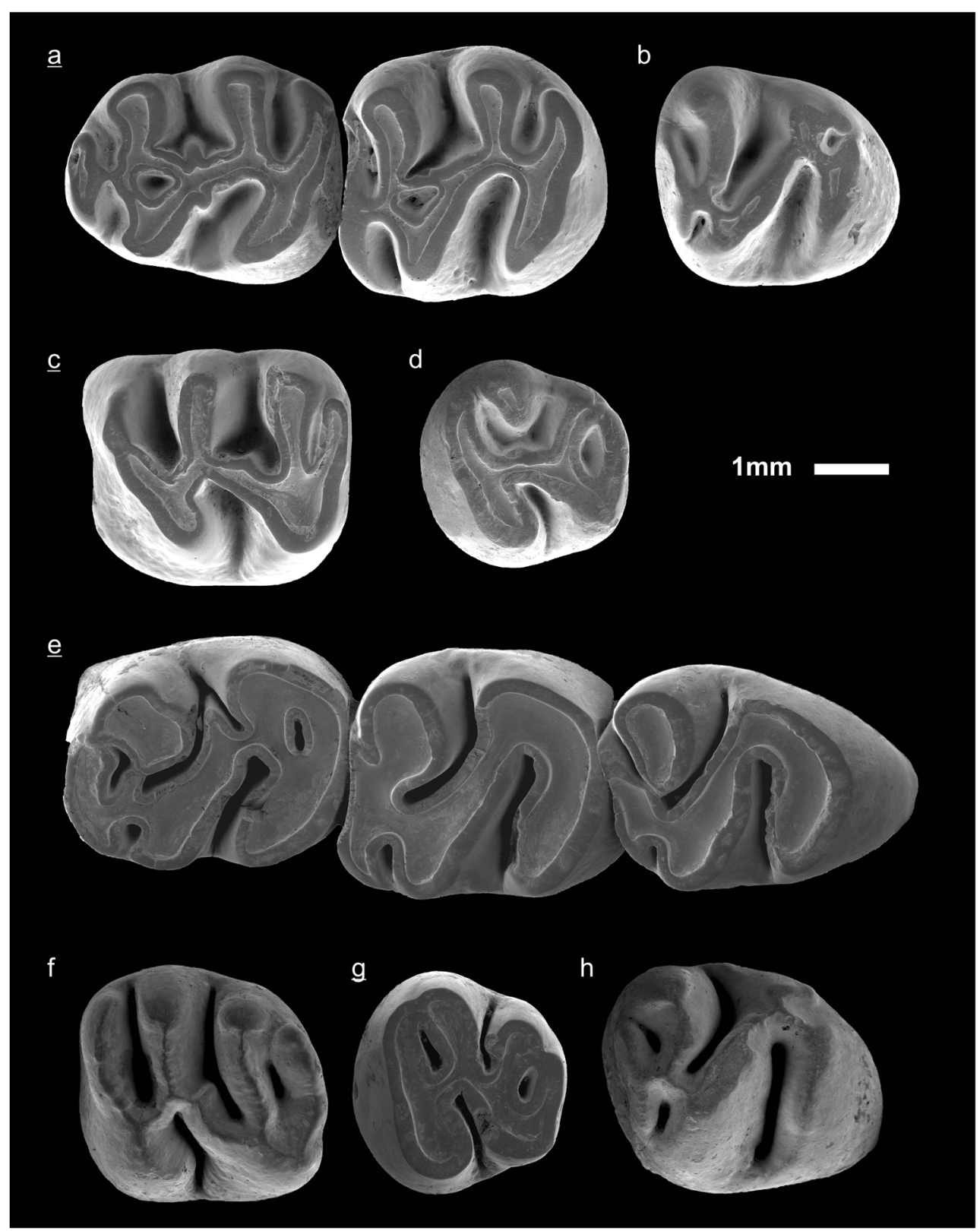

Fig. 61 Fam. Tachyoryctoididae. Tachyoryctoides obrutschewi Bohlin, 1937 from Tatal Gol (TAT-051/2), Ikh Argalatyn Nuruu (IKH-B/5), and Hotuliin Teeg (HTE-057), Valley of Lakes, Mongolia. Late Oligocene, letter zone C1. Daxner-Höck et al. (2015). a Right m1-2 (NHMW 2013/0450/0001), TAT-051/2. b Left $\mathrm{m} 3$ from jaw with m2-3 (NHMW 2013/0449/0001), HTE057. c Right M1 (NHMW 2013/0451/0001), IKH-B/5. d Left
M3 (NHMW 2013/0449/0003), HTE-057. Tachyoryctoides tatalgolicus Dashzeveg, 1971 from Tatal Gol (TAT-043 and TAT-E/22), Valley of Lakes, Mongolia. Late Oligocene, letter zone C1. Daxner-Höck et al. (2015). e Right m1-3 (NHMW 2013/0453/0001), TAT-043. f Left M- (NHMW 2013/0453/ 0004), TAT-043. g Right M3 (NHMW 2013/0454/0001), TAT-E/ 22. h Left m3 (NHMW 2013/0453/0003), TAT-043 


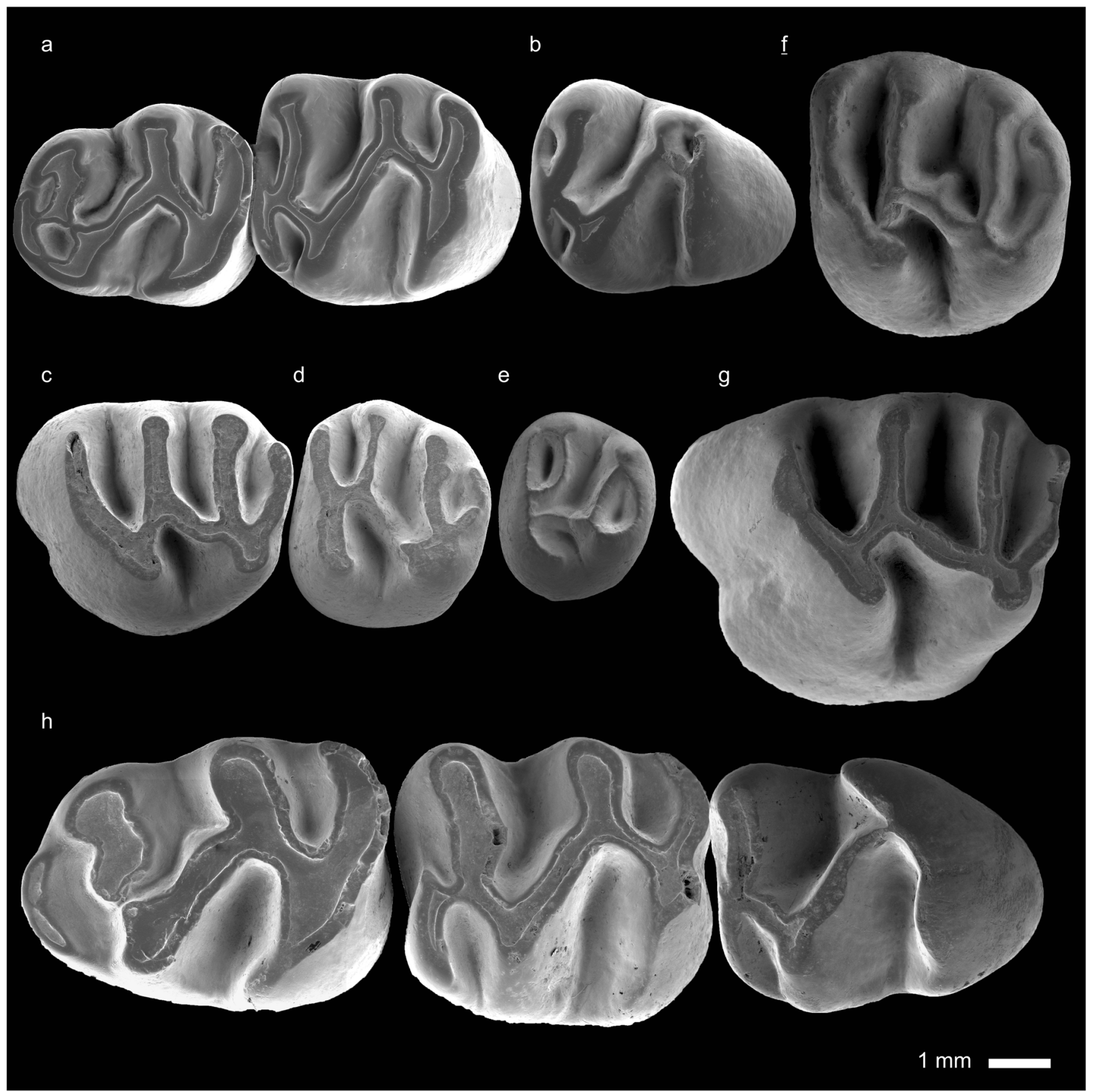

Fig. 62 Fam. Tachyoryctoididae. Tachyoryctoides kokonorensis Li and Qiu, 1980 from Hotuliin Teeg (HTE* and HTE-012), Valley of Lakes, Mongolia. Early Miocene, letter zone D. Daxner-Höck et al. (2015). a Left m1-2 (NHMW 2013/0456/0001), HTE*. b Left m3 (NHMW 2013/0456/0002), HTE*. c Left M1 (NHMW 2013/0457/0002), HTE-012. d Left M2 (NHMW 2013/0457/ 0003), HTE-012. e Left M3 (NHMW 2013/0457/0004), HTE-
012. Tachyoryctoides engesseri Wang and Qiu, 2012 from Hotuliin Teeg (HTE* and HTE-008), Valley of Lakes, Mongolia. Early Miocene, letter zone D. Daxner-Höck et al. (2015). f Right M2 (NHMW 2012/0068/0003), HTE*. g Left M1 (NHMW 2012/0068/0002), HTE*. h Left m1-3 (NHMW 2013/0463/0001), HTE-008 
Table 19 The fossil list comprises all identified fossils from the Taatsiin Gol and Taatsiin Tsagaan Nuur region and their stratigraphic ranges (letter zones A-D)

Vertebrata and Gastropoda of the Valley of Lakes/Oligocene early Miocene

Mongolian letter zones

A B

B $\quad$ C

C1

C1-D D

\section{Marsupialia}

(Ziegler et al. 2007)

Asiadelphis tjutkovae Emry, Lucas, Szalay and Tleuberdina, 1995

Asiadelphis zaissanensis Gabunia, Shevyreva and Gabunia, 1990

$\mathrm{x}$

$\mathrm{x} \quad \mathrm{x}$

Lagomorpha

(Erbajeva 2007, 2013, 2017, this issue; Erbajeva and Daxner-Höck 2014)

\section{Leporidae}

Ordolagus cf. teilhardi (Burke, 1941)

\section{Palaeolagidae}

Desmatolagus cf. vetustus Burke, 1941

Desmatolagus youngi (Gureev, 1960)

Desmatolagus gobiensis Matthew and Granger, 1923

Desmatolagus robustus Matthew and Granger, 1923

Desmatolagus cf. simplex (Argyropulo, 1940)

Desmatolagus cf. shargaltensis Bohlin, 1937

Desmatolagus cf. chinensis Erbajeva and Sen, 1998

Desmatolagus cf. orlovi (Gureev, 1960)

Desmatolagus sp.

Bohlinotona pusilla (Teilhard de Chardin, 1926)

Amphilagus magnus Erbajeva, 2013

Amphilagus orientalis Erbajeva, 2013

Amphilagus plicadentis Erbajeva, 2013

Amphilagus complicidens nov. spec. (identified by Erbajeva)

\section{Ochotonidae}

Bohlinotona cf. pusilla (Teilhard de Chardin, 1926)

Sinolagomys kansuensis Bohlin, 1937

Sinolagomys major Bohlin, 1937

Sinolagomys ulungurensis Tong, 1989

Sinolagomys sp.

Sinolagomys badamae nov. spec. Erbajeva, Bayarmaa, Daxner-Höck and Flynn (2017, this issue)

Sinolagomys gracilis Bohlin, 1942

Bellatona kazakhstanica Erbajeva, 1988

Bellatona yanghuensis Zhou, 1988

Alloptox cf. minor Li, 1978

\section{Eulipotyphla}

(Ziegler et al. 2007)

\section{Erinaceidae}

Zaraalestes minutus (Matthew and Granger, 1924a)

Zaraalestes sp.

Palaeoscaptor acridens Matthew and Granger, 1924a

Palaeoscaptor cf. rectus Matthew and Granger, 1924a

Palaeoscaptor aff. rectus Matthew and Granger, 1924a

Palaeoscaptor gigas (Lopatin, 2002)

Palaeoscaptor tenuis Ziegler, Dahlmann and Storch, 2007

Erinaceidae indet.

Amphechinus taatsiingolensis Ziegler, Dahlmann and Storch, 2007

Amphechinus aff. taatsiingolensis Ziegler, Dahlmann and Storch, 2007

Amphechinus minutissimus Ziegler, Dahlmann and Storch, 2007

Amphechinus major Ziegler, Dahlmann and Storch, 2007

Exallerix pustulatus Ziegler, Dahlmann and Storch, 2007

Exallerix sp.

\section{Soricidae}

\section{(1)}

\section{.}


Table 19 (continued)

Vertebrata and Gastropoda of the Valley of Lakes/Oligocene early Miocene

Mongolian letter zones

A $\quad$ B

$\begin{array}{llll}\mathrm{C} & \mathrm{C} 1 & \mathrm{C} 1-\mathrm{D} & \mathrm{D}\end{array}$

Gobisorex kingae Sulimski, 1970

Heterosoricinae indet. sp. 1-3

Taatsiinia hoeckorum Ziegler, Dahlmann and Storch, 2007

Tavoonyia altaica Ziegler, Dahlmann and Storch, 2007

Crocidosoricinae indet. sp. 1-11

\section{Talpidae}

cf. Asiapternodus mackennai Lopatin, 2003

Mongolopala tathue Ziegler, Dahlmann and Storch, 2007

Talpidae indet. sp. 1-9

\section{Rodentia}

\section{Aplodontidae}

(Maridet et al. 2017, this issue)

Promeniscomys cf. sinensis Wang, 1987a

Prosciurus? mongoliensis Wang and Dashzeveg, 2005

Prosciurus ? nov. spec.

Ninamys kazimierzi Vianey-Liaud, Gomes Rodrigues and Marivaux, 2013

Ninamys arboraptus (Shevyreva, 1966)

Proansomys badamae sp. nov. Maridet, Daxner-Höck,

$\begin{array}{ccccc}\mathrm{x} & \mathrm{x} & \mathrm{x} & & \\ \mathrm{x} & & \mathrm{x} & & \mathrm{x} \\ \mathrm{x} & & & \mathrm{x} & \\ & & \mathrm{x} & & \\ \mathrm{x} & \mathrm{x} & \mathrm{x} & & \mathrm{x}\end{array}$

López-Guerrero, Oliver (2017, this issue)

Ansomyinae indet.

Ansomys sp. 1

$\mathrm{X}$

$\mathrm{X}$

$\mathrm{X}$

x

$\mathrm{X}$

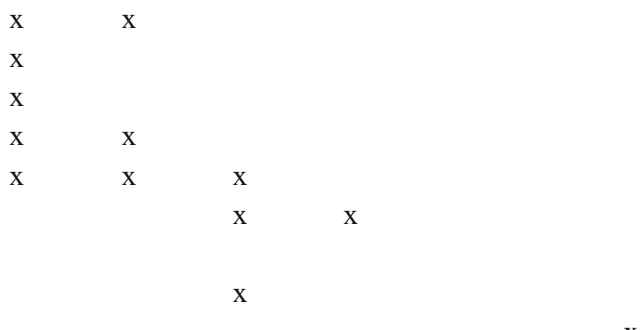

Sciuridae

(Maridet et al. 2014)

Plesiosciurus aff. sinensis Qiu and Liu, 1986

Kherem shandgoliensis Minjin, 2004

Pteromyini indet.

Eutamias sp.

Eomyidae

(Maridet et al. 2015)

Eomys cf. orientalis Wang and Emry, 1991

Eomys aff. orientalis Wang and Emry, 1991

Eomys sp.

Asianeomys cf. bolligeri (Lopatin, 2000)

Asianeomys dangheensis (Wang, 2002)

\section{Ctenodactylidae}

(Schmidt-Kittler et al. 2007, Oliver et al. 2017, and Oliver \& Daxner-Höck 2016, this issue) Karakoromys decessus Matthew and Granger, 1923

Huangomys frequens Schmidt-Kittler, Vianey-Liaud and Marivaux, 2007

Yindirtemys shevyrevae Vianey-Liaud, Schmidt-Kittler and Marivaux, 2006

Tataromys sigmodon Matthew and Granger, 1923

Tatataromys minor longidens Schmidt-Kittler, Vianey-Liaud and Marivaux, 2007

Tataromys plicidens Matthew and Granger, 1923

Yindirtemys aff. ulantatalensis (Huang, 1985)

Yindirtemys deflexus (Teilhard de Chardin, 1926)

Yindirtemys birgeri Bendukidze, 1993

Yindirtemys suni Li \& Qiu, 1980

Prodistylomys nov. sp. 2 (in prep.) Oliver, López-Guerrero

\& Daxner-Höck (in prep)

Prodistylomys nov. sp. 1 (in prep.) Oliver, López-Guerrero

\& Daxner-Höck (in prep)

Prodistylomys sp.

$\mathrm{X}$

Cylindrodontidae

(Daxner-Höck et al. 2010)

Ardynomys sp.

$\begin{array}{ll}\mathrm{x} & \mathrm{x} \\ \mathrm{x} & \mathrm{x} \\ \mathrm{x} & \mathrm{x} \\ & \mathrm{x}\end{array}$


Table 19 (continued)

Vertebrata and Gastropoda of the Valley of Lakes/Oligocene early Miocene Mongolian letter zones

A $\quad$ B $\quad$ C $\quad$ C1 $\quad$ C1-D $\quad$ D

Anomoemys lohiculus (Matthew and Granger, 1923)

$\mathrm{x} \quad \mathrm{x}$

Tsaganomyidae

(Wessels et al. 2014)

Cyclomylus lohensis Matthew and Granger, 1923

Cyclomylus biforatus Wang, 2001

Cyclomylus intermedius Wang, 2001

Tsaganomyidae indet.

Coelodontomys asiaticus Wang, 2001

Tsaganomys altaicus Matthew and Granger, 1923

\section{Dipodidae}

(Daxner-Höck 2001, Daxner-Höck and Wu 2003, Daxner-Höck et al. 2014)

Allosminthus khandae (Daxner-Höck, 2001)

Allosminthus minutus (Daxner-Höck, 2001)

Heosminthus chimidae Daxner-Höck, Badamgarav and Maridet, 2014

Heosminthus sp.

Heosminthus borrae Daxner-Höck, Badamgarav and Maridet, 2014

Onjosminthus baindi Daxner-Höck, Badamgarav and Maridet, 2014

Shamosminthus sodovis Daxner-Höck, 2001

Shamosminthus sp.

Shamosminthus tongi Huang, 1992

Bohlinosminthus parvulus (Bohlin, 1946)

Parasminthus cf. tangingoli Bohlin, 1946

Parasminthus debruijni Lopatin, 1999

Parasminthus cf. asiaecentralis Bohlin, 1946

Plesiosminthus sp.

Plesiosminthus asiaticus Daxner-Höck and Wu, 2003

Plesiosminthus promyarion Schaub, 1930

Plesiosminthus olzi Daxner-Höck, Badamgarav and Maridet, 2014

Plesiosminthus barsboldi Daxner-Höck and Wu, 2003

Litodonomys huangheensis Wang and Qiu, 2000

Litodonomys lajeensis (Li and Qiu, 1980)

Heterosminthus firmus Zazhigin and Lopatin, 2000

Heterosminthus cf. lanzhouensis Wang and Qiu, 2000

Heterosminthus aff. nanus Zazhigin and Lopatin, 2000

Muridae (Cricetidae s. I.) and Tachyoryctoididae

(Daxner-Höck 2000, 2015; Maridet et al. 2014; López-Guerrero

et al. (2017a, 2017b, this issue)

Tachyoryctoides radnai Daxner-Höck, Badamgarav and

Maridet, 2015

Tachyoryctoides bayarmae Daxner-Höck, Badamgarav

and Maridet, 2015

Tachyoryctoides obrutschewi Bohlin, 1937

Tachyoryctoides tatalgolicus Dashzeveg, 1971

Tachyoryctoides sp.

Tachyoryctoides kokonorensis Li and Qiu, 1980

Tachyoryctoides engesseri Wang and Qiu, 2012

Ayakozomys sp.

Ulaancricetodon badamae Daxner-Höck, 2000

Selenomys mimicus Matthew and Granger, 1923

Cricetops dormitor Matthew and Granger, 1923

Cricetops minor Wang, 1987b

Paracricetodon sp.

Witenia sp.

Eocricetodon meridionalis (Wang and Meng, 1986)

$\begin{array}{lllll}\mathrm{X} & \mathrm{X} & & & \\ \mathrm{X} & & \mathrm{X} & & \\ \mathrm{X} & \mathrm{X} & \mathrm{X} & & \\ \mathrm{X} & \mathrm{X} & \mathrm{X} & & \\ \mathrm{X} & \mathrm{X} & \mathrm{X} & & \\ \mathrm{X} & \mathrm{X} & \mathrm{X} & \mathrm{X} & \mathrm{X}\end{array}$


Table 19 (continued)

Vertebrata and Gastropoda of the Valley of Lakes/Oligocene early Miocene Mongolian letter zones

A

Eucricetodon caducus (Shevyreva, 1967)

Eucricetodon asiaticus Matthew and Granger, 1923

Eucricetodon ※f.'occasionalis Lopatin, 1996

Eucricetodon bagus Gomes Rodrigues et al., 2012

Eucricetodon jilantaiensis Gomes Rodrigues at al., 2012

Eucricetodon sp.

Cricetidae indet.

Bagacricetodon tongi Gomes Rodrigues at al., 2012

Aralocricetodon schokensis Bendukidze, 1993

Argyromys nov. spec. López-Guerrero, Zhang and

Daxner-Höck (in prep)

Primus sp.

Democricetodon sui Maridet et al., 2011

\section{Creodonta}

(Morlo \& Nagel 2007, Nagel and Morlo 2003)

Hyaenodon cf. mongoliensis (Dashzeveg, 1964)

Hyaenodon cf. incertus Dashzeveg, 1985

Hyaenodon pervagus Matthew and Granger 1924b

Hyaenodon eminus Matthew and Granger, 1925a

cf. Hyaenodon gigas Dashzeveg, 1985

Hyaenodontidae indet.

\section{Carnivora}

(Morlo \& Nagel 2007, Nagel and Morlo 2003)

Amphicynodon teilhardi (Matthew and Granger, 1924b)

aff. Amphicynodon sp.

Amphicynodon sp.

Amphicticeps shackelfordi Matthew and Granger, 1924b

Shandgolictis elegans Hunt, 1998

Asiavorator altidens Spassov and Lange-Badré, 1995

cf. Asiavorator sp.

Nimravus mongoliensis (Gromova, 1959)

Palaeogale sp.

Carnivora indet.

\section{Leptictida}

(Morlo \& Nagel 2002)

cf. Ergilictis sp. Lopatin, 1997

Didymoconus colgatei Matthew and Granger, 1924b

Didymoconus berkey Matthew and Granger, 1924b

Didymoconidae indet.

\section{Perissodactyla}

(Heissig 2007)

Paraceratherium sp.

cf. Benaratherium sp.

Aceratherium (Alicornops) cf. pauliacense (Richard, 1937)

Elasmotheriini indet.

cf. Hoploaceratherium gobiense (Beliajeva, 1960)

cf. Caementodon sp.

\section{Ruminantia}

(Vislobokova \& Daxner-Höck 2002)

Lophiomeryx angarae Matthew and Granger, 1925b

Lophiomeryx sp.

Praetragulus gobiae (Matthew and Granger, 1925b)

Miomeryx sp.

Gobimeryx dubius Trofimov, 1957

\begin{tabular}{|c|c|c|c|}
\hline X & $\mathrm{x}$ & & \\
\hline \multirow[t]{5}{*}{$\mathrm{x}$} & $\mathrm{x}$ & & \\
\hline & $\mathrm{x}$ & & \\
\hline & $\mathrm{x}$ & $\mathrm{x}$ & $\mathrm{x}$ \\
\hline & $\mathrm{x}$ & $\mathrm{x}$ & \\
\hline & & $\mathrm{x}$ & \\
\hline \multirow[t]{4}{*}{$\mathrm{X}$} & $\mathrm{x}$ & $\mathrm{x}$ & $\mathrm{x}$ \\
\hline & & $\mathrm{x}$ & $\mathrm{X}$ \\
\hline & & $\mathrm{x}$ & $x$ \\
\hline & & $\mathrm{x}$ & \\
\hline
\end{tabular}


Table 19 (continued)

Vertebrata and Gastropoda of the Valley of Lakes/Oligocene early Miocene Mongolian letter zones

Gobimeryx sp.

Pseudomeryx gobiensis Trofimov, 1957

Pseudogelocus mongolicus Vislobokova and Daxner-Höck, 2002

Pseudomeryx sp.

Prodremotherium sp.

Paragelocus aff. scotti Schlosser, 1902

Eumeryx culminis Matthew and Granger, 1924a

Eumeryx sp.

Dremotherium cf. guthi Jehenne, 1987

Amphitragulus sp.

Bovidae gen. 1

Bovidae gen. 2

Palaeohypsodontus sp.

Gobiocerus sp.

Ruminantia indet.

\section{Amphibia and Reptilia}

(Böhme 2007)

\section{Anura}

Pelobatidae (aff. Uldzinia)

Anura indet.

\section{Squamata}

Squamata indet.

Tinosaurus sp.

Acrodonta indet.

Lacerta sp. 1

Lacerta sp. 2

Lacerta sp. 3

Lacertidae indet.

Scincomorpha indet.

Melanosaurini indet.

Calamagras sp.

\section{Gastropoda}

(Stworzewicz 2007; Neubauer et al. 2013)

Pupoides steklovi Prysjazhnjuk, Devjatkin, Badamgarav and Liskun, 1975

\section{?Strobilops sp.}

Vallonia cf. lepida (Reuss, 1849)

Vallonia stworzewiczae Neubauer, Harzhauser, Daxner-Höck and Piller, 2013

Vallonia sp.

Vertigo cf. bicolumellata Steklov and Tsytovich, 1967

Gastrocopta devjatkini Prysjazhnjuk, Devjatkin, Badamgarav and Liskun, 1975

Gastrocopta cf. mongolica Prysjazhnjuk, Devjatkin, Badamgarav and Liskun, 1975

Gastrocopta shandgolica Prysjazhnjuk, Devjatkin, Badamgarav and Liskun, 1975

Gastrocopta tuvaense Steklov, 1967

Gastrocopta valentini Stworzewicz, 2007
A

\section{B}

C

C1

C1-D

D

X $\mathrm{x}$

$\mathrm{x} \quad \mathrm{x}$

$\mathrm{x} \quad \mathrm{x}$

$\mathrm{x} \quad \mathrm{X}$

$\mathrm{x}$

$\mathrm{X}$

$\mathrm{x}$

X

$\mathrm{X}$

$\mathrm{X}$

X

$\mathrm{x}$

X

X

X

X

X $\mathrm{X}$

X

$\mathrm{x}$

x $x$

X $\mathrm{x}$

$\mathrm{X}$

X

$\mathrm{x}$

X
X

$\mathrm{x}$ $\mathrm{x}$

$\mathrm{X}$ 


\section{Conclusions}

The Taatsiin Gol and Taatsiin Tsagaan Nuur region, part of the Valley of Lakes, yields Oligocene and Miocene sediment deposits. They are very important in several respects. First, the sequences of the Hsanda Gol and Loh Fms. contain a rich mammalian fauna and provide unique evidence of mammal evolution and climatic changes (Harzhauser et al. 2016). Second, the Cenozoic strata are intercalated with basalt flows, and the ${ }^{40} \mathrm{Ar} /{ }^{39} \mathrm{Ar}$ data of these basalts constrain the time of sediment deposition. Thus, basalt ages and Mongolian letter zones enable a composite age chronology for the studied area (Höck et al. 1999; Daxner-Höck et al. 2010).

From Luuny Yas in the northwest to Ihk Argalatyn Nuur in the east ( $101-102^{\circ}$ longitude), 20 sections and 6 fossil localities were investigated in detail (Table 3, Fig. 3). The description of sections are original, comprising lithology, sediment structures and thicknesses of sediment layers, illustrations of the localities/sections, the GPS positions, faunal lists of the fossil horizons, biozonation, radiometric ages of imbedded basalts, and magnetostratigraphic data (Figs. 4, 5, 6, 7, 8, 9, $10,11,12,13,14,15,16,17,18,19,20,21,22,23,24,25,26$, 27, 28, and 29).

The composite sequence includes four formations from bottom to top: The lowermost fluvio-lacustrine sequence is named Tsagan Ovo Fm. It is overlain by red clay and silt of the Hsanda Gol Fm., which itself is divided by basalt I (31.5 Ma) into the lower and upper Hsanda Gol beds. Upsection, fluvial deposits of the Loh Fm. follow, which are locally covered by pebbles of the Tuyn Gol Fm. Basalt II flows, dated at $\sim 27 \mathrm{Ma}$, contact sediments of the Hsanda Gol and Loh Fms, as evidenced in sections ABO-A and TAR-A, respectively. Most basalt II occurrences with ages between $\sim 25$ and $\sim 28$ Ma do not have contact with fossil beds (Tables 1and 2). The upper parts of several sections, which are built up by the Loh and Tuyn Gol Fms. and comprise fossils younger than lowermost Miocene, are not considered in this study.

Magnetostratigraphic measurements of the TGR sections show that the Tsagan Ovo Fm. corresponds with Chrons $\mathrm{C} 15 \mathrm{r}-\mathrm{C} 13 \mathrm{r}$, an age range of $>35-34 \mathrm{Ma}$, which is late Eocene. The lower Hsanda Gol strata and basalt I correspond with the palaeomagnetic polarity chrons $\mathrm{C} 13 \mathrm{r}-\mathrm{C} 12 \mathrm{r}$, an age range of $24-31.2$ Ma (Kraatz and Geisler 2010; Sun and Windley 2015), which is early Oligocene. Thus, the boundary between the Tsagan Ovo and Hsanda Gol Fms. corresponds with the Eocene-Oligocene boundary (EOB). The boundary between the Hsanda Gol and Loh Fms. is heterochronous. Locally, Hsanda Gol sediments range to the latest Oligocene (e.g. section TAT-E; Fig. 21); in other regions, sedimentation of the Loh Fm. started in the early late Oligocene (e.g. section TAR-A; Fig. 18).
We sampled more than 19,000 mammal fossils from 70 individual fossil layers, yielding a total of 176 mammal species, mostly small mammals. The representation of large mammals, lower vertebrates, and gastropods is comparably poor.

This unique dataset enables evaluation and formalization of the Mongolian letter zones A, B, C, C1, C1-D, and D (Harzhauser et al. 2017, this issue). The biostratigraphic data from Oligocene and early Miocene sequences, the ${ }^{40} \mathrm{Ar} /{ }^{39} \mathrm{Ar}$ ages of basalts I and II (Tables 1 and 2 and Höck et al. 1999), and magnetostratigraphic measurements (Kraatz and Geisler 2010; Sun and Windley 2015) help correlate sections and fossil sites with the Geomagnetic Polarity Time Scale GPTS (Gradstein et al. 2012) and assess the precise ages of mammal faunas and time ranges of Mongolian letter zones (Figs. 30 and 31).

Importantly, the $\delta^{13} \mathrm{C}$ and $\delta^{18} \mathrm{O}$ isotope values of authigenic carbonate in calcrete horizons and analyses of mammal community structures reflect changes of the palaeoclimate during the Oligocene and early Miocene (Richoz et al. 2017, this issue; Harzhauser et al. 2016, accepted).

The manifold dental morphology is illustrated by SEM images of teeth from marsupials, insectivores, and rodents (Figs. 32, 33, 34, 35, 36, 37, 38, 39, 40, 41, 42, 43, 44, 45, 46, 47, 48, 49, 50, 51, 52, 53, 54, 55, 56, 57, 58, 59, 60, 61, and 62), and Table 19 lists all investigated fossil taxa and the respective stratigraphic ranges.

Acknowledgements Open access funding provided by Austrian Science Fund (FWF). This research was supported by four projects of the Austrian Science Fund (FWF): P-10505-GEO, P-15724-N06, P23061-N19 to G.D.-H. and a Lise Meitner grant M-1357-B17 to O.M. Travel expenses of G.D.-H. to China and Mogolia were partly covered by the Austrian Academy of Sciences. We thank our Mongolian and European team members for manifold support during several seasons of field campaigns and subsequent laboratory work in Ulaan Baatar, Vienna, and Graz. Special thanks to H.P. Schmid, T. Bolliger, E. Luginger-Öttl, G. Furtmüller, and O. Montag for unpublished field data; to Li Ping for identifying Cricetops minor from Tatal Gol; and to R. Quezada-Hinojosa for geochemical analyses and for drawing some geological sections. W. Frank provided so far unpublished ${ }^{40} \mathrm{Ar} /{ }^{39} \mathrm{Ar}$ data of basalts, and $\mathrm{K}$. Constenius from Petro Matad LLC, Ulaan Baatar, made an unpublished geological cross-section available to us. M. Stachowitsch helped improve the English. We specifically thank the reviewers W. Wessels and an anonymous reviewer for careful comments and critical remarks, and the Editors P. Königshof and S. Weber for manifold information and help. All these persons and institutions are gratefully acknowledged for their support.

\section{Compliance with ethical standards}

Conflict of interests The authors declare that they have no competing interests.

Open Access This article is distributed under the terms of the Creative Commons Attribution 4.0 International License (http:// creativecommons.org/licenses/by/4.0/), which permits unrestricted use, distribution, and reproduction in any medium, provided you give appropriate credit to the original author(s) and the source, provide a link to the Creative Commons license, and indicate if changes were made. 


\section{References}

Argyropulo, A. I. (1940). A review of finds of Tertiary rodents in the USSR and adjacent regions of Asia. Priroda, 12, 74-82 (in Russian).

Baljinyam, I., Bayasgalan, A., Borisov, B. A.,Cisternas, A., Demyanovich, M. G., Ganbaatar, L., Kochetkov, V.M., Kurushin, R.A., Molnar, P., Philip, H., Vashchilov, Y. Y. (1993): Ruptures of major earthquakes and active deformation in Mongolia and its surroundings. Geological Society of America. Memoir, 1-62.

Beliajeva, E. I. (1960). Ob Azeraterijach Mongolii (über die Aceratherien der Mongolei). Trudy PIN Akademi Nauk SSSR, 77(4), 108-127.

Bendukidze, O. G. (1993). Miocene micromammals from Kazakhstan and Turgai. Tiblisi (Metsniereba), 1-139. (In Russian).

Berkey, C. B. \& Morris, F. K. (1927). Geology of Mongolia. Natural History of Central Asia. The American Museum of Natural History, 1-475.

Bohlin, B. (1937). Oberoligozäne Säugetiere aus dem Shargaltein-Tal (Western Kansu). Palaeontologia Sinica, C, 3, 1-66.

Bohlin, B. (1942). The fossil mammals from the tertiary deposit of Tabenbuluk, Western Kansu. Part I: Insectivora and Lagomorpha. VI. Vertebrate Palaeontology, 3, 1-113.

Bohlin, B. (1946). The fossil mammals from the tertiary deposit of Tabenbuluk, Western Kansu. Part II: Simplicidentata, Carnivora, Artiodactyla, Perissodactyla and Primates. VI. Vertebrate Palaeontology, 4, 1-259.

Böhme, M. (2007). 3. Herpetofauna (Anura, Squamata) and paleoclimatic implications: preliminary results. In G. DaxnerHöck (Ed), Oligocene-Miocene Vertebrates from the Valley of Lakes (Central Mongolia): Morphology, Phylogenetic and Stratigraphic Implications. Annalen des Naturhistorischen Museums in Wien, 108A, 43-52.

Burke, J. J. (1941). New fossil Leporidae from Mongolia. American Museum Novitates, 1117, 1-23.

Dashzeveg, D. (1964). Two new Oligocene Hyaenodontidae from ErghilyinDzo (Mongolian People's Republic). Acta Palaeontologica Polonica, 9, 263-274.

Dashzeveg, D. (1971). A new Tachyoryctoides (Mammalia, Rodentia, Cricetidae) from the Oligocene of Mongolia. Proceedings of the Joint Soviet- Mongolian Geological Research Expedition, 3, 6870. in Russian.

Dashzeveg, D. (1985). Nouveau Hyaenodontinae (Creodonta, Mammalia) du Paléogène de Mongolie. Annales de Paleontologie, 71(4), 223-256.

Dashzeveg, D. (1996). Some carnivorous mammals from the Paleogene of the Eastern Gobi Desert, Mongolia, and the application of Oligocene carnivores to stratigraphic correlation. American Museum Novitates, 3179, 1-14.

Daxner-Höck, G. (2000). Ulaancricetodon badamae n. gen. n. sp. (Mammalia, Rodentia, Cricetidae) from the Valley of Lakes in Central Mongolia. Paläontologische Zeitschrift, 74(1/2), 215-225.

Daxner-Höck, G. (2001). New zapodids (Rodentia) from Oligocene-Miocene deposits in Mongolia. Part 1. Senckenbergiana lethaea, 81(2), 359-389.

Daxner-Höck, G., \& Badamgarav, D. (2007). 1. Geological and stratigraphical setting. In G. Daxner-Höck (Ed), OligoceneMiocene vertebrates from the Valley of Lakes (Central Mongolia): morphology, phylogenetic and stratigraphic implications. Annalen des Naturhistorischen Museums in Wien, 108A, 1-24.

Daxner-Höck, G., \& Wu, W. Y. (2003). Plesiosminthus (Zapodidae, Mammalia) from China and Mongolia: migrations to Europe. In J. W. Reumer, W. Wessels (Eds), Distribution and Migration of Tertiary Mammals in Europe. Deinsea,10,127-151.
Daxner-Höck, G., Höck, V., Badamgarav, D., Furtmüller, G., Frank, W., Montag, O. \& Schmid, H. P. (1997): Cenozoic stratigraphy based on a sediment-basalt association in Central Mongolia as requirement for correlation across Central Asia. In J. P. Aguilar, S. Legendre, S. \& J. Michaux, (Eds), Biochronologie mammalienne du Cénozoique en Europe et domaines reliés. Mémoires et Travaux de l'Institut de Montpellier, E.P.H.E., 21, 163-176.

Daxner-Höck, G., Badamgarav, D., \& Erbajeva, M. (2010). Oligocene stratigraphy based on a sediment-basalt association in Central Mongolia (Taatsiin Gol and Taatsiin Tsagaan Nuur Area, Valley of Lakes): review of a Mongolian-Austrian project. Vertebrata PalAsiatica, 48(4), 348-366.

Daxner-Höck, G., Badamgarav, D., Erbajeva, M., \& Göhlich, U. B. (2013). Miocene mammal biostratigraphy of Central Mongolia (Valley of Lakes). New results. In X. Wang, L. J. Flynn, \& M. Fortelius (Eds.), Fossil mammals of Asia. Neogene biostratigraphy and chronology (pp. 477-494). New York: University Press.

Daxner-Höck, G., Badamgarav, D., \& Maridet, O. (2014). Dipodidae (Rodentia, Mammalia) from the Oligocene and Early Miocene of Mongolia. Annalen des Naturhistorischen Museums in Wien, 116, 131-214.

Daxner-Höck, G., Badamgarav, D., \& Maridet, O. (2015). Evolution of Tachyoryctoidinae (Rodentia, Mammalia): evidences of the Oligocene and Early Miocene of Mongolia. Annalen des Naturhistorischen Museums in Wien, 117, 161-195.

Devjatkin, E. V., Balogh, K., \& Duduch, A. (2002). Geochronology of basalts from the Valley of Lakes, Mongolia, and their correlation with the Cenozoic Sedimentary sequence. Russian Journal of Earth Sciences, 4(5), 389-397.

Emry, R. J., Lucas, S. G., Szalay, F. S., \& Tleuberdina, P. A. (1995). A new herpetotheriine didelphid (Marsupialia) from the Oligocene of central Asia. Journal of Vertebrate Paleontology, 15, 850-854.

Erbajeva, M. A. (1988). Cenozoic pikas (taxonomy, systematics and phylogeny). Nauka, 1-224.

Erbajeva, M. A. (2007). 5. Lagomorpha (Mammalia): preliminary results. In G. Daxner-Höck (Ed), Oligocene-Miocene vertebrates from the Valley of Lakes (Central Mongolia): morphology, phylogenetic and stratigraphic implications. Annalen des Naturhistorischen Museums in Wien, 108A, 165-171.

Erbajeva, M. A. (2013). New species of Amphilagus (Lagomorpha, Mammalia) from the Miocene of the Valley of Lakes, Central Mongolia. Paleontological Journal, 47(3), 311-320.

Erbajeva, M. A., \& Daxner-Höck, G. (2014). The most prominent Lagomorpha from the Oligocene and Early Miocene of Mongolia. Annalen des Naturhistorischen Museums in Wien, $116,215-245$.

Erbajeva, M. A., \& Sen, S. (1998). Systematic of some Oligocene Lagomorpha (Mammalia) from China. Neues Jahrbuch für Geologie und Paläontologie, Monatshefte, 1998(2), 95-105.

Erbajeva, M.A., Bayarmaa, B., Daxner-Höck, G., L.J. Flynn (2017): The occurrence of Sinolagomys (Lagomorpha) from the Valley of Lakes (Mongolia). In G. Daxner-Höck and U. Göhlich (Eds.) The Valley of Lakes in Mongolia, a key area of Cenozoic mammal evolution and stratigraphy. Palaeobiodiversity and Palaeoenvironments, 97(1) Doi: $10.1007 / \mathrm{s} 12549-016-0262-\mathrm{z}$ (this issue).

Gabunia, L. K., Shevyreva, N. S. \& Gabunia, V. C. (1990). A new opossum (Didelphidae, Marsupialia, Metatheria, Mammalia) from the base of the Oligocene of the Zaysan Depression (East Kazakhstan). Paleontologicheskiy Zhurnal, 101-109.

Gomes Rodrigues, H., Marivaux, L., \& Vianey-Liaud, M. (2012). The Cricetidae (Rodentia, Mammalia) from Ulantatal area (Inner Mongolia, China): new data concerning the evolution of Asian cricetids during the Oligocene. Journal of Asian Earth Sciences, 56, 160-179. doi:10.1016/j.jseaes.2012.05.007. 
Gradstein, F. M., Ogg, J. G., Schmitz, M. D., \& Ogg, G. M. (2012). The geologic time scale 2012 (Vol. 2 vols, pp. 11144). Oxford: Elsevier.

Gromova, K. (1959). Première découverte d'un chat primitif au Paléogèned' Asie central. Vertebrata PalAsiatica, 3, 59-71.

Gureev, A. A. (1960). Oligocene lagomorphs (Lagomorpha) from Mongolia and Kazakhstan. In Flerov, K. K. (ed), Tertiary Mammals. Paleontological Institute, Transactions, 77/4, 5-34.

Harzhauser, M., Daxner-Höck, G., López-Guerrero, P., Maridet, O., Oliver, A., Piller, W. E., Richoz, S., Erbajeva, M. A., \& Göhlich, U. B. (2016). The stepwise onset of the Icehouse world and its impact on Oligo-Miocene Central Asian mammals. Nature Scientific Reports, 6, 36169. doi:10.1038/srep36169.

Harzhauser, M., Daxner-Höck, G., López-Guerrero, P., Maridet, O., Oliver, A., Piller, W.E, Richoz, S., Erbajeva, M.A., \& Göhlich U.B. (2017). Oligocene and early Miocene biostratigraphy of the Valley of Lakes in Mongolia. In G. Daxner-Höck and U. Göhlich (Eds.) The Valley of Lakes in Mongolia, a key area of Cenozoic mammal evolution and stratigraphy. Palaeobiodiversity and Palaeoenvironments, 97(1) Doi: 10.1007/s12549-016-0264-x (this issue).

Heissig, K. (2007). 8. Rhinocerotidae (Perissodactyla, Mammalia). In G. Daxner-Höck (Ed), Oligocene-Miocene vertebrates from the Valley of Lakes (Central Mongolia): morphology, phylogenetic and stratigraphic implications. Annalen des Naturhistorischen Museums in Wien, 108A, 233-269.

Höck, V., Daxner-Höck, G., Schmid, H. P., Badamgarav, D., Frank, W., Furtmüller, G., Montag, O., Barsbold, R., Khand, Y., \& Sodov, J. (1999). Oligocene-Miocene sediments, fossils and basalts from the Valley of Lakes (Central Mongolia) - an integrated study. Mitteilungen der Geologischen Gesellschaft, 90, 83-125.

Huang, X. S. (1985). Middle Oligocene ctenodactylids (Rodentia, Mammalia) of Ulantatal, Nei Mongol. Vertebrata PalAsiatica, 23(1), 27-38 (in Chinese with English abstract).

Huang, X. S. (1992). Zapodidae (Rodentia, Mammalia) from the Middle Oligocene of Ulantatal, Nei Mongol. Vertebrata PalAsiatica, 30, 249-286.

Hunt, R. M. (1998). Evolution of the aelurid Carnivora: diversity of the earliest aeluroids from Eurasia (Quercy, Hsanda Gol) and the origin of felids. American Museum Novitates, 3252, 1-65.

Jehenne, Y. (1987). Les ruminants primitifs du Paléogene et du Néogene inférieur de 1'Ancien Monde: Systematique, Phylogénie, Biostratigraphie. Université de Poitier (These), 1-288.

Kraatz, P., \& Geisler, J. H. (2010). Eocene-Oligocene transition in Central Asia and its effects on mammalian evolution. Geology, 38(2), 111114. doi:10.1130/G30619.1.

Kurushin, R. A., Bayasgalan, A., Ölzibat, M., Enhtuvishin, B., Molnar, P., Bayarsayhan, C., Hudnuth, K. W., \& Lin, J. (1997). The Surface Rupture of the 1957 Gobi-Altay, Mongolia, Earthquake. Geological Society of America Special Paper, 320, 1-143.

Li, C. K. (1978). Two new Lagomorphs from the Miocene of Lantian, Shensi. Professional Papers of Stratigraphy and Palaeontology, 7, 143-146 (in Chinese).

Li, C. K., \& Qiu, Z. D. (1980). Early Miocene mammalian fossils of Xining Basin, Quinghai. Vertebrata PalAsiatica, 18(3), 198-214.

Lopatin, A. V. (1996). The stratigraphy and small mammals from the Aral Formation, the Altynshokysu Locality (Northern Aral Region). Stratigraphy and Geological Correlation, 4(2), 65-79.

Lopatin, A. V. (1999). New Early Miocene Zapodidae (Rodentia, Mammalia) from the Aral Formation of the Altynshokysu Locality (North Aral Region). Paleontological Journal, 33(4), 429-438.

Lopatin, A. V. (2000). New Early Miocene Aplodontidae and Eomyidae (Rodentia, Mammalia) from the Aral Formation of the Altynshokysu Locality (North Aral Region). Paleontological Journal, 34, 81-85.
Lopatin, A. V. (2002). The largest Asiatic Amphechinus (Erinaceidae, Insectivora, Mammalia) from the Oligocene of Mongolia. Paleontological Journal, 36(3), 302-306.

Lopatin, A. V. (2003). A zalambdodont insectivore of the family Apternodontidae (Insectivora, Mammalia) from the Middle Eocene of Mongolia. Paleontological Journal, 37(2), 187195.

López-Guerrero, P., Maridet, O., \& Daxner-Höck, G. (2017a). Evolution of the genus Eucricetodon (Rodentia, Mammalia) from the Valley of Lakes (Mongolia): a taxonomical description and update on the stratigraphical distribution. In G. Daxner-Höck and U. Göhlich (Eds.) The Valley of Lakes in Mongolia, a key area of Cenozoic mammal evolution and stratigraphy. Palaeobiodiversity and Palaeoenvironments, 97(1) Doi:10.1007/s12549-016-0251-2 (this issue).

López-Guerrero, P., Maridet, O., \& Daxner-Höck, G. (2017b). The Cricetidae (Rodentia, Mammalia) from the Oligocene of the Valley of Lakes (Mongolia): the genera Aralocricetodon and Eocricetodon, Bagacricetodon, Witenia and Paracricetodon. In B. Mottequin, L. Slavik and P. Königshof (Eds.) Climate change and biodiversity patterns in the mid-Palaeozoic. Palaeobiodiversity and Palaeoenvironments, 97(1) Doi:10.1007/s12549-016-0266-8 (this issue).

Maridet, O., Wu, W. Y., Ye, J., Bi, S. D., Ni, X. J., \& Meng, J. (2011). Earliest occurrence of Democricetodon in China, in the Early Miocene of the Junggar Basin (Xinjiang) and comparison with the genus Spanocricetodon. Vertebrata PalAsiatica, 49(4), 393-405.

Maridet, O., Daxner-Höck, G., Badamgarav, D., \& Göhlich, U. B. (2014a). New discoveries of Sciurids (Rodentia, Mammalia) from the Valley of Lakes (Central Mongolia). Annalen des Naturhistorischen Museums in Wien, 116, 271-291.

Maridet, O., Daxner-Höck, G., Badamgarav, D., \& Göhlich, U. B. (2014b). Cricetidae (Rodentia, Mammalia) from the Valley of Lakes (Central Mongolia): focus on the Miocene record. Annalen des Naturhistorischen Museums in Wien, 116, 247269.

Maridet, O., Daxner-Höck, G., Badamgarav, D., \& Göhlich, U. B. (2015). The eomyid rodents (Mammalia) from the Oligocene and Miocene of the Valley of Lakes (Central Mongolia). Paläontologische Zeitschrift, 89(2), 207-228.

Maridet, O., Daxner-Höck, G.,López-Guerrero, P., \& Göhlich, U.B. (2017). The record of Aplodontidae (Rodentia, Mammalia) from the Oligocene and Miocene of the Valley of Lakes (Central Mongolia) with some comments on the morphologic variability. In G. Daxner-Höck and U. Göhlich (Eds.) The Valley of Lakes in Mongolia, a key area of Cenozoic mammal evolution and stratigraphy. Palaeobiodiversity and Palaeoenvironments, 97(1) doi:10.1007/s12549-016-0255-y (this issue).

Matthew, W. D., \& Granger, W. (1923). Nine new rodents from the Oligocene of Mongolia. American Museum Novitates, 102, 1-10.

Matthew, W. D., \& Granger, W. (1924a). New insectivores and ruminants from the Tertiary of Mongolia, with remarks on the correlation. American Museum Novitates, 105, 1-7.

Matthew, W. D., \& Granger, W. (1924b). New Carnivora from the Tertiary of Mongolia. American Museum Novitates, 104, 1-9.

Matthew, W. D., \& Granger, W. (1925a). New creodonts and rodents from the Ardyn Obo Formation of Mongolia. American Museum Novitates, 193, 1-7.

Matthew, W. D., \& Granger, W. (1925b). New ungulates from the Ardyn Obo Formation of Mongolia, with faunal list and remarks on correlation. American Museum Novitates, 195, 1-12.

Meng, J., \& McKenna, M. C. (1998). Faunal turnovers of Paleogene mammals from the Mongolian Plateau. Nature, 394, 364-367.

Meng, J., Ye, J., Wu, W.-Y., et al. (2006). A recommended boundary stratotype section for Xiejian stage from northern Junggar Basin: 
implications to related bio-chronostratigraphy and environmental changes. Vertebrata PalAsiatica, 44(3), 205-236 (In Chinese with English summary).

Meng, J., Ye, J., Wu, W.-Y., Ni, X.-J., \& Bi, S.-D. (2008). The Neogene Dingshanyanchi Formation in Northern Junggar Basin of Xinjiang and its stratigraphic implications. Vertebrata PalAsiatica, 46(4), 90110 (In Chinese with English summary).

Meng, J., Ye, J., Wu, W. Y., Ni, X. J., \& Bi, S. D. (2013). A single-point base definition of the Xiejian Age as an exemplar for refining Chinese land mammal ages. In X. M. Wang, L. J. Flynn, \& M. Fortelius (Eds.), Fossil mammals of Asia: Neogene biostratigraphy and chronology (pp. 124-141). New York: Columbia University Press.

Minjin, B. (2004). An Oligocene sciurid from the Hsanda Gol Formation, Mongolia. Journal of Vertebrate Paleontology, 24(3), 753-756.

Morlo, M., \& Nagel, D. (2002). New Didymoconidae (Mammalia) from the Oligocene of Central Mongolia and first information on toot eruption sequence of the family. Neues Jahrbuch für Geologie und Paläontologie, Abhandlungen, 223(1), 123-144.

Morlo, M., \& Nagel, D. (2006). New remains of Hyaenodontidae (Creodonta, Mammalia) from the Oligocene of Central Mongolia. Annales de Paleontologie, 92(3), 305-321.

Morlo, M., \& Nagel, D. (2007). 7. The carnivore guild of the Taatsiin Gol area: Hyaenodontidae (Creodonta, Carnivora and Didymoconidae). In G. Daxner-Höck (Ed), Oligocene-Miocene vertebrates from the Valley of Lakes (Central Mongolia): morphology, phylogenetic and stratigraphic implications. Annalen des Naturhistorischen Museums in Wien, 108A, 217-231.

Nagel, D. \& Morlo, M. (2003). Guild structure of the carnivorous mammals (Creodonta, Carnivora) from the Taatsiin Gol area, Lower Oligocene of Central Mongolia. In J. W. Reumer \& W. Wessels (Eds), Distribution and Migration of Tertiary Mammals in Europe. Deinsea, 10, 419-429.

Neubauer, T. A., Harzhauser, M., Daxner-Höck, G., \& Piller, W. E. (2013). New data on the terrestrial gastropods from the OligoceneMiocene Transition in the Valley of Lakes, Central Mongolia. Paleontological Journal, 47, 374-385.

Ogg, J. G. \& Lugowski, A. (2004). TSCreator visualization of enhanced Geologic Time scale 2004 database (version 6.0): http://www. tscreator.org, 2012.

Oliver, A. \& Daxner-Höck, G. (2017). Large-sized species of Ctenodactylidae from the Valley of Lakes (Mongolia): an update of dental morphology, biostratigraphy and paleobiogeography. Paleontologia Electronica 20.1.1A: 1-22palaeo-electronica.org/ content/2017/1729-ctenodactylidae-from-mongolia.

Oliver, A., Sanisidro, O., Bayarmaa, B., Ichinnorov, N. \& Daxner-Höck, G. (2017). Turnover and diversification rates in Ctenodactylidae (Rodentia, Mammalia) from Mongolia. In G. Daxner-Höck and U. Göhlich (Eds.) The Valley of Lakes in Mongolia, a key area of Cenozoic mammal evolution and stratigraphy. Palaeobiodiversity and Palaeoenvironments, 97(1) Doi :10.1007/s12549-016-0265-9

Prysjazhnjuk, V. A., Devjatkin, E. V., Badamgarav, D., \& Liskun, I. G. (1975). The first find of terrestrial mollusks in the Oligocene of Mongolia. The Joint Soviet-Mongolian Paleontological Expedition, Transactions, 2(167-177), 360-361.

Qiu, Z. D., \& Liu, Y. P. (1986). The Aragonian vertebrate fauna of Xiacaowan, Jiangsu. 5. Sciuridae (Rodentia, Mammalia). Vertebrata PalAsiatica, 24(3), 195-212.

Reuss, A. E. (1849). Beschreibung der fossilen Ostracoden und Mollusken der tertiären Süsswasserschichten des nördlichen Böhmens. Palaeontographica, 2, 16-42.

Richard, M. (1937). Une nouvelle espèce de Rhinocéridé aquitanien: Diaceratherium pauliacensis. Bulletin de la Société d'histoire naturelle de Toulouse, 71, 165-170.
Richoz, S., Baldermann, A., Frauenwallner, A., Harzhauser, M., DaxnerHöck, G., Klammer, D., Piller, W.E. \& Quezada-Hinoyosa, R. (2017). Geochemistry and mineralogy of Oligocene and early Miocene sediments from the Valley of Lakes (Mongolia). In G. Daxner-Höck and U. Göhlich (Eds.) The Valley of Lakes in Mongolia, a key area of Cenozoic mammal evolution and stratigraphy. Palaeobiodiversity and Palaeoenvironments, 97(1) Doi:10.1007/s12549-016-0268-6 (this issue)

Schaub, S. (1930). Fossile Sicistinae. Eclogae Geologicea Helvetiae, 23(2), 616-636.

Schlosser, M. (1902). Beiträge zur Kenntnis der Säugetierreste aus den süddeutschen Bohnerzen. Beiträge zur Paläontologie, Abhandlungen, N.F., $5 / 3,1-258$.

Schlupp, A. (1996). Neotectonique de la Mongolie Occidentale Analysee a partir de Donnees de Terrain, Sismologiques et Satellitaires. These L'Université Louis Pasteur de Strasbourg, 1-172.

Schmid, H.P. (1999). Environmentanalytische Untersuchungen an tertiären kontinentalen Sedimenten im Valley of Lakes, Zentrale Mongolei. Diplomarbeit, Universität Wien, pp. 1-102.

Schmidt-Kittler, N., Vianey-Liaud, M., \& Marivaux, L. (2007). 6. Ctenodactylidae (Rodentia, Mammalia). In G. Daxner-Höck (Ed), Oligocene-Miocene vertebrates from the Valley of Lakes (Central Mongolia): morphology, phylogenetic and stratigraphic implications. Annalen des Naturhistorischen Museums in Wien, 108A, 173-215.

Shevyreva, N. S. (1966). On the evolution of rodents from the Middle Oligocene of Kazakhstan. Bulletin Mosk,Ohshch. Ispyt. Prirody, Otded Geologitche, 41, 143.

Shevyreva, N. S. (1967). Cricetodon from Middle Oligocene of Central Kazakhstan. Palaeontological Journal, 2, 90-98 (in Russian).

Spassov, N., \& Lange-Badré, B. (1995). Asiavorator altidens gen. et $\mathrm{sp}$. nov., un mammifére carnivore nouveau de l'Oligocène supérieur de Mongolie. Annales de Paleontologie, 81(3), 109-123.

Steklov, A. A. (1967). Terrestrial mollusks from the Neogene of Tuva. In B. E. Bykhovsky (Ed.), Mollusks and their role in ecosystems and formation of faunas (pp. 269-279). Trudy Zoologicheskogo Instituta Akademii Nauk SSSR.

Stetklov, A. A., \& Tsytovich, M. V. (1967). On a find of Neogene terrestrial mollusks in the Kostankol valley in Central Kazakhstan. Byulleten Moskovoskogo Ob-va Ispytatelei Prirody Otdel Geologicheskii, 42(3), 108-119.

Stworzewicz, E. (2007). 2. Molluscan fauna (Gastropoda: Pulmonata: Pupilloidea): a systematic review. In G. DaxnerHöck (Ed), Oligocene-Miocene vertebrates from the Valley of Lakes (Central Mongolia): morphology, phylogenetic and stratigraphic implications. Annalen des Naturhistorischen Museums in Wien, 108A, 25-41.

Sulimsky, A. (1970). On some Oligocene insectivore remains from Mongolia. Acta Palaeontologica Polonica, 21, 53-70.

Sun, J., \& Windley, B. F. (2015). Onset of aridification by 34 Ma across the Eocene-Oligocene transition in Central Asia. Geology, 11, 10151018. doi:10.1130/G37165.1.

Teilhard de Chardin, P. (1926). Mammiféres Tertiaires de Chine et de Mongolia. Annales de Paleontologie, 15, 1-51.

Tong, Y. S. (1989). A new species of Sinolagomys (Lagomorpha, Ochotonidae) from Xinjiang. Vertebrata PalAsiatica, 27(2), 103116 (in Chinese with English summary).

Trofimov, B. A. (1957). Nouvelles données sur les Ruminantia les plus ancien d'Asie. Curs. Conf. Inst. "Lucas Mallada", 4, 137-141.

Vianey-Liaud, M., Schmidt-Kittler, N., \& Marivaux, L. (2006). The Ctenodactylidae (Rodentia, Mammalia) from the Oligocene of Ulantatal (Inner Mongolia, China). Palaeovertebrata, 34(3-4), 111-206.

Vianey-Liaud, M., Gomes Rodriges, H. \& Marivaux, L. (2013). Early adaptive radiations of Aplodontoidea (Rodentia, Mammalia) on the Holarctic region: systematics, and 
phylogenetic and paleobiogeographic implications. doi:10.1007 /s12542-012-0143-3.

Vislobokova, I. A., \& Daxner-Höck, G. (2002). Oligocene-Early Miocene ruminants from the Valley of Lakes (Central Mongolia). Annalen des Naturhistorischen Museums in Wien, 103A, 213-235.

Wang, B. Y. (1987a). Discovery of Aplodontidae (Rodentia, Mammalia) from Middle Oligocene of Nei Mongol, China. Vertebrata PalAsiatica, 25, 32-45.

Wang, B. Y. (1987b). Discovery of Cricetids (Rodentia, Mammalia) from Middle Oligocene of Nei Mongol, China. Vertebrata PalAsiatica, 25(3), 187-198.

Wang, B. Y. (2001). On Tsaganomyidae (Rodentia, Mammalia) of Asia. American Museum Novitates, 3317, 1-50.

Wang, B. Y. (2002). Discovery of Late Oligocene Eomyodon (Rodentia, Mammalia) from the Danghe Area, Gansu, China. Vertebrata PalAsiatica, 40, 205-236.

Wang, B. Y., \& Dashzeveg, D. (2005). New Oligocene sciurids and aplodontids (Rodentia, Mammalia) from Mongolia. Vertebrata PalAsiatica, 43(2), 85-99.

Wang, B. Y., \& Emry, R. J. (1991). Eomyids (Rodentia: Mammalia) from the Oligocene of Nei Mongol, China. Journal of Vertebrate Paleontology, 11, 370-377.

Wang, B. Y., \& Meng, J. (1986). Eucricetodon (Rodentia, Mammalia) from the Lower Oligocene of Qujing, Yunnan, China. Vertebrata PalAsiatica, 24(2), 110-120.
Wang, B. Y., \& Qiu, Z. X. (2000). Dipodidae (Rodentia, Mammalia) from the Lower Member of Xianshuihe Formation in Lanzhou Basin, Gansu, China. Vertebrata PalAsiatica, 38(1), 10-35 (in Chinese with English summary).

Wang, B. Y., \& Qiu, Z. X. (2012). Tachyoryctoides (Muroidea, Rodentia) fossils from Early Miocene of Lanzhou Basin, Gansu Province, China. Swiss Journal of Palaeontology, 131, 107-126.

Wessels, W., Badamgarav, D., van Olselen, V., \& Daxner-Höck, G. (2014). Tsaganomyidae (Rodentia, Mammalia) from the Oligocene of Mongolia (Valley of Lakes). Annalen des Naturhistorischen Museums in Wien, 116, 293-325.

Zazhigin, V. S., \& Lopatin, A. V. (2000). The history of the Dipodoidea (Rodentia, Mammalia) in the Miocene of Asia: 1. Heterosminthus (Lophocricetinae). Paleontological Journal, 34(3), 319-332.

Zhou, X. (1988). Miocene ochotonid (Mammalia, Lagomorpha) from Xinzhou, Shanxi. Vertebrata PalAsiatica, 26/4,139-148. (Chinese with English summary).

Ziegler, R., Dahlmann, T. \& Storch, G. (2007). 4. Marsupialia, Erinaceomorpha and Soricomorpha. In G. Daxner-Höck (Ed.), Oligocene-Miocene vertebrates from the Valley of Lakes (Central Mongolia): morphology, phylogenetic and stratigraphic implications. Annalen des Naturhistorischen Museums in Wien, 108 A, 53-164. 